\title{
GLOBAL SUSTAINABILITY AND THE NEW ZEALAND HOUSE
}

\author{
By \\ J. Andrew Alcorn
}

\begin{abstract}
A thesis
submitted to the Victoria University of Wellington

in fulfilment of the requirements for the degree of

Doctor of Philosophy

in Architecture
\end{abstract}

Victoria University of Wellington

2010 


\section{Abstract}

"How do you build a sustainable house in New Zealand - is it even possible?" This thesis is structured in three parts to answer this question. The first part asks, then answers, "What is sustainability?", "How do you measure sustainability?" and "How do you know when you have reached sustainability - what is its limit?" The second part describes the methodologies for conducting embodied energy and $\mathrm{CO}_{2}$ analysis. The third part applies the results of the sustainability definition, and the energy and $\mathrm{CO}_{2}$ methodologies to a series of house designs.

Part 1 defines, measures, and establishes a limit for sustainability. It reviews the history of sustainability and sustainable development. A distillation of what is being sought by the various parties to the sustainability debate then contributes to a checklist of essential requirements for a functional definition of sustainability. Addressing climate change is shown to be the major requirement. The checklist enables answers to the questions about measuring sustainability, and knowing when its limit has been reached, and leads to a functional definition: Sustainability meets the needs of the present without annual $\mathrm{CO}_{2}$ emissions exceeding what the planet can absorb.

The requirements for sustainability indicator methods are examined. A robust way of comparing environment impacts is introduced. Several common sustainability indicators are examined against the requirements, but are found wanting, while two are found to be effective: energy and $\mathrm{CO}_{2}$ analysis.

Human population and annual global carbon absorption are used to identify global and per-capita sustainability limits, which can be applied at many scales to many activities. They are applied to New Zealand's housing sector to identify a sustainable annual per-house emissions target, including construction, maintenance, and operation.

Part 2 reviews the methodologies to measure and delimit sustainability using embodied energy and embodied $\mathrm{CO}_{2}$ analysis. A new, fast, accurate, and reliable process-based hybrid analysis method developed for this research is used to derive embodied energy and $\mathrm{CO}_{2}$ coefficients for building materials. 
Part 3 applies the results of the sustainability definition and limit, and the energy and $\mathrm{CO}_{2}$ methodologies and coefficients from analysing building materials, to a series of house designs within New Zealand and global contexts. A spreadsheet-based calculator developed for this analysis that has potential beyond this thesis is described. A method is presented for annualising emissions to fairly account for differing building components' lifetimes.

Finally, a sustainable house is shown to be possible by combining several strategies to meet the challenging sustainable emissions target. Technologies that reduce grid electricity use - solar hot water, PV, and wind-generators - are crucial, cutting emissions the most. Bio-based materials sequestering carbon are the second most important strategy: strawbale insulation to $\sim \mathrm{R} 10$, and timber for framing, cladding, windows, linings, and roofing. Efficient appliances, lighting, and other low-emission materials were also helpful.

Other key outcomes were: hot water heating emits the most $\mathrm{CO}_{2}$, double any other category; heating energy emissions are smaller than any other category; $\mathrm{CO}_{2}$-optimal conventional insulation levels are $\sim \mathrm{R} 5 ; \mathrm{CO}_{2}$ flux of materials is double operating energy $\mathrm{CO}_{2}$ for sustainable houses. 


\section{Preface}

This thesis looks at certain aspects of humanity, the planet, and their future, all the way from the near to the distant. It attempts a partial reconciliation of what humanity might do in the immediate and long-term future, with its previous actions. The beginnings of the thesis were in architecture, and it has an architectural question at its core. It also arrives at an architectural conclusion. Along the way, though, it covers territory that has traditionally belonged to other disciplines: sustainable development, embodied energy (EE) analysis, and embodied carbon dioxide $\left(\mathrm{ECO}_{2}\right)$ analysis. For architecture to become sustainable, disciplines such as life cycle analysis, which encompass all three fields just mentioned, and others, will need to be integrated into architectural research and practice.

I would like to thank the many people who have given me their support over the course of this project, because without them it would not have got done, and any insights it now contains would have remained out of sight. I would especially like to thank my supervisors, Dr George Baird and Dr Mike Donn, for their patience, perspective, and perspicacity - from the initial idea, through the broad sweep of the project, to the output of the final product. It is a much better product for their persistent inputs. It was Dr Baird's research on energy in buildings that initially led to my interest in, and laid the foundations for, my research in embodied energy of buildings. It was Dr Donn's enthusiasm for environmental issues and how buildings related to them that sparked my search for ways to make buildings sustainable. His deep understanding of a very broad range of environmental research demanded a wide perspective and sharp focus.

My family also deserve special thanks for having put up with the fallout from my attention being otherwise engaged. Several friends have given valuable advice, reflections, and input. I have also had invaluable help from colleagues in the architecture, building, and environmental professions, and I thank them all.

Many of the numbers used in the thesis, especially in Chapter 9, were derived from Excel spreadsheet analyses, which offer figures to several decimal places. Where they 
have been used in the text, some of these significant figures remain if they are potentially valuable in further calculations or subsequent analyses. They should not be taken as necessarily indicating the precision of the collected data.

Petagrams (Pg) and tonnes ( $\mathrm{t}$ ) are both used as units for quantifying carbon and $\mathrm{CO}_{2}$, to be consistent with commonly used figures. The Intergovernmental Panel on Climate Change (IPCC) uses Pg for global carbon emissions and absorptions. Tonnes per-capita is a commonly used unit for comparing countries.

$\mathrm{CO}_{2}$ is referred to frequently. The analyses done on materials primarily deal with $\mathrm{CO}_{2}$ emissions, but also cover $\mathrm{CO}_{2}$ equivalents where these are part of emissions from analysed processes. For instance, in the analyses of the house designs in Chapter 9 the predominant influence on emissions is from grid electricity; thus, the analysis to derive emission factors for New Zealand electricity explicitly includes $\mathrm{CO}_{2}$ and $\mathrm{CO}_{2}$ equivalents. For the sake of simplicity, however, rather than using the abbreviation ' $\mathrm{CO}_{2}$-e', the abbreviation $\mathrm{CO}_{2}$ is used. $\mathrm{CO}_{2}$ should be understood as meaning $\mathrm{CO}_{2}$ and $\mathrm{CO}_{2}$ equivalents, unless it is clearly indicated otherwise.

J Andrew Alcorn asserts his moral right to be identified as the author of this work. 


\section{Contents}

$\begin{array}{ll}\text { Abstract } & 2\end{array}$

$\begin{array}{lr}\text { Preface } & 4\end{array}$

$\begin{array}{ll}\text { Abbreviations } & 16\end{array}$

$1 \quad$ Aims and Objectives $\quad 17$

$\begin{array}{lll}1.1 & \text { Introduction } & 17\end{array}$

$\begin{array}{lll}1.2 & \text { Research Background } & 18\end{array}$

$\begin{array}{ll}\text { 1.3 Attempts at Sustainability: Earth and Strawbale } & 18\end{array}$

1.4 Research Question 20

$\begin{array}{lll}1.5 & \text { Aims } & 20\end{array}$

$\begin{array}{lll}1.6 & \text { Objectives } & 21\end{array}$

1.6.1 Understanding and Defining Sustainability 21

1.6.2 Measuring Sustainability $\quad 22$

1.6.3 Emission Limit and Target 22

1.6.4 Embodied Energy and Embodied $\mathrm{CO}_{2}$ Analysis 22

1.6.5 Materials Analysis Methodology 23

1.6.6 Selected Technologies Analysis $\quad 23$

1.6.7 Rating Houses 23

1.6.8 Meeting the Target 23

1.7 Hypothesis 23

2 Sustainability - What Is It? 25

2.1 Introduction 25

2.2 Confusion in Sustainability 26

2.3 A Brief History of Sustainability 28

2.3.1 The Momentum of Growth 28

2.3.2 Up to Brundtland $\quad 32$

2.3.3 Brundtland and Other Guides 40

2.3.3.1 The Brundtland Report $\quad 40$

2.3.3.2 After Brundtland 47

2.3.4 Summary of the Brief History 50

2.4 Requirements for a Functional Definition of Sustainability 52

2.5 Definition of Sustainability: A Climate Change Focus 54

2.6 Sustainability Limits: Making the Definition Functional 56

2.7 Conclusion 56 
3 Measuring Sustainability: Assessing Indicators and Their Requirements

$\begin{array}{lll}3.1 & \text { Introduction } & 57\end{array}$

3.2 Requirements of Sustainability Indicators 58

3.3 Some Commonly Used Sustainability Indicators 64

3.3.1 Material Flow Accounting $\quad 64$

$\begin{array}{ll}\text { 3.3.2 Sustainability Index } & 65\end{array}$

3.3.3 Triple Bottom Line $\quad 65$

3.3.4 Index of Sustainable Economic Welfare and Genuine Progress Indicator $\quad 67$

$\begin{array}{lll}3.3 .5 & \text { The Natural Step } & 68\end{array}$

3.4 Methods that Attempt Sustainability Measurement 68

$\begin{array}{lll}3.4 .1 & \text { Ecological Footprint } & 69\end{array}$

$\begin{array}{ll}3.4 .2 & \text { Life Cycle Assessment }\end{array}$

3.4.2.1 LCA History 74

3.4.2.2 Complexity 77

$\begin{array}{ll}3.4 .2 .3 \text { Weighting } & 80\end{array}$

3.4.2.4 LCA: Suitability as a Sustainability Indicator 83

$\begin{array}{ll}3.4 .3 & \text { Emergy } \\ & 84\end{array}$

$\begin{array}{lll}3.5 & \text { Summary } & 87\end{array}$

4 Measuring Sustainability: Effective Methods 88

$\begin{array}{lll}4.1 & \text { Introduction } & 88\end{array}$

$\begin{array}{ll}4.2 & \text { Jevons' Paradox } \\ \end{array}$

4.2.1 Primary Form of the Paradox 90

$\begin{array}{ll}\text { 4.2.2 Secondary Form of the Paradox } & 91\end{array}$

4.2.3 Jevons' Paradox and Economics 93

4.2.4 Jevons' Paradox at the Global Scale - Boulding's Dismal Theorems 95

4.2.5 Theoretical and Global Solutions 96

$\begin{array}{lll}4.3 & \text { Energy Analysis } & 99\end{array}$

$\begin{array}{ll}\text { 4.3.1 Centrality of Energy } & 99\end{array}$

$\begin{array}{ll}\text { 4.3.2 Energy and Jevons' Paradox } & 101\end{array}$

4.3.3 The Maximisation of Energy Imperative 102

4.3.4 Energy Impacts and the Economy 105

4.3.5 Limits to Growth 107

4.3.6 Energy as Sustainability Indicator 108

$\begin{array}{lll}4.4 \mathrm{CO}_{2} \text { Analysis } & 110\end{array}$

4.4.1 Non- $\mathrm{CO}_{2}$ Greenhouse Gases 111

$\begin{array}{lll}\text { 4.4.2 Key Environmental Problems } & 113\end{array}$ 
4.4.3 A Means to Compare Environmental Impacts 114

4.4.3.1 Non-Climate Change Impacts 114

4.4.3.2 Climate Change Impacts 116

$\begin{array}{lll}4.4 .4 \mathrm{CO}_{2} \text { Limit } & 119\end{array}$

4.4.5 $\mathrm{CO}_{2}$ as Sustainability Indicator $\quad 119$

$\begin{array}{lll}4.5 & \text { Conclusion } & 126\end{array}$

$5 \mathrm{CO}_{2}$ Limits $\quad 127$

$\begin{array}{lll}5.1 & \text { Introduction } & 127\end{array}$

$\begin{array}{ll}5.2 & \text { Population } \\ & 127\end{array}$

5.2.1 Uncertainty in Population and $\mathrm{CO}_{2}$ Emission Projections 128

$\begin{array}{lll}\text { 5.2.2 Population Projections } & 129\end{array}$

5.2.3 Equity of Per-capita $\mathrm{CO}_{2}$ Emissions 133

$\begin{array}{ll}\text { 5.3 Global } \mathrm{CO}_{2} \text { Emissions and Absorptions } & 135\end{array}$

$\begin{array}{lll}5.4 & \text { Per-capita } \mathrm{CO}_{2} \text { Emission Limits } & 140\end{array}$

5.4.1 Sustainable Populations versus Emission Levels 142

$\begin{array}{ll}5.5 & \text { Housing } \mathrm{CO}_{2} \text { Emissions } \\ & 145\end{array}$

5.5.1 House and Household Size 145

5.5.2 Proportion of New Zealand $\mathrm{CO}_{2}$ Emissions for Houses 146

5.5.3 $\mathrm{CO}_{2}$ Emissions from New Zealand Houses 148

5.5.4 Sustainable $\mathrm{CO}_{2}$ for House Operation 150

$\begin{array}{lll}5.6 & \text { Conclusion } & 154\end{array}$

6 Embodied Energy Analysis $\quad 155$

$\begin{array}{lll}6.1 & \text { Introduction } & 155\end{array}$

6.2 Terms, Definitions, Meanings, and Usage 156

6.2.1 Statistical Analysis 157

6.2.2 Input-Output Analysis 157

6.2.3 Process Analysis 157

6.2.4 Hybrid Analysis 157

6.2.5 System Boundary 158

6.2.6 Direct and Indirect Energy 160

6.2.7 Gross and Process Energy Requirement 160

6.2.8 Primary and Secondary Fuels 161

6.2.9 Energy Requirement of Energy 162

6.2.10 Average and Marginal Energy 162

6.3 Historical Context of Embodied Energy Analysis 163

6.3.1 Early Analyses 163

6.3.2 Recent Hybrid Analyses 166 
$\begin{array}{lll}6.4 & \text { Statistical Analysis } & 168\end{array}$

$\begin{array}{lll}6.5 & \text { Input-Output Analysis } & 168\end{array}$

6.5.1 Problems with Input-Output Analysis 170

6.5.1.1 Price Level Variation 170

6.5.1.2 Producer Price versus Purchase Price 171

6.5.1.3 Physical Flow versus Dollar Values 171

6.5.1.4 Technology Changes 172

6.5.1.5 Aggregation 172

6.5.1.6 Age of Data 173

6.5.1.7 Energy Allocation for Secondary Products 173

$\begin{array}{ll}\text { 6.6 Process Analysis } & 174\end{array}$

$\begin{array}{lll}\text { 6.6.1 Problems with Process Analysis } & 174\end{array}$

6.6.1.1 Large Research Effort $\quad 175$

6.6.1.2 Undercounting from Ignored Ancillary Inputs 175

6.6.1.3 Data Acquisition 175

6.6.1.4 Aggregation 176

6.6.1.5 Process Variability 176

6.6.1.6 Energy Allocation for Secondary Products $\quad 177$

$\begin{array}{lll}6.7 & \text { Hybrid Analysis } & 177\end{array}$

6.7.1 Comparison of Hybrid and Input-Output Results 179

6.7.1.1 Cement and Concrete 181

$\begin{array}{ll}\text { 6.7.1.2 Sand and Aggregate } & 182\end{array}$

6.7.1.3 Steel 182

6.7.1.4 Other Metals 182

6.8 Embodied Energy Analysis in Practice 183

$\begin{array}{lll}\text { 6.8.1 Conventions } & 183\end{array}$

6.8.1.1 Energy of Human Labour 184

6.8.1.2 Energy of Profit and Taxes 186

6.8.1.3 Methodology for Energy of Profits and Taxes 188

6.8.1.4 Energy of Feedstock 188

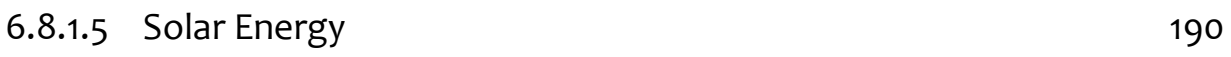

6.8.1.6 Energy Allocation for Secondary Products 190

6.8.1.7 Second-Use Materials 191

6.8.1.8 Gross and Net Calorific Values 192

6.8.2 Data acquisition 192

6.8.3 Energy Requirement of Energy 196

$\begin{array}{ll}\text { 6.8.4 Transport Energy } & 196\end{array}$

6.8.5 Capital Equipment Energy 198

$\begin{array}{ll}\text { 6.8.6 Weighting of Data } & 198\end{array}$ 
$\begin{array}{ll}\text { 6.8.7 Data Limit } & 200\end{array}$

$\begin{array}{lll}6.9 & \text { Summary } & 200\end{array}$

7 Embodied $\mathrm{CO}_{2}$ Analysis $\quad 202$

$\begin{array}{lll}7.1 & \text { Introduction } & 202\end{array}$

7.2 Choosing Average or Marginal $\mathrm{CO}_{2}$ Emissions Analysis 203

7.3 $\mathrm{CO}_{2}$ Emission Factors for Energy 206

7.3.1 Coal 206

$\begin{array}{ll}7.3 .2 \text { Gas } & 207\end{array}$

$\begin{array}{ll}7.3 .3 & \text { Geothermal } \\ & 208\end{array}$

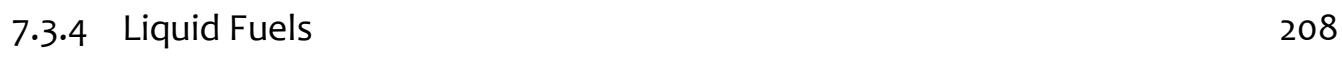

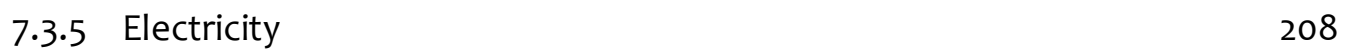

7.3.5.1 Marginal Electricity Emissions 209

7.3.5.2 Electricity $\mathrm{CO}_{2}$ Emission Factor Methodology 211

7.3.5.3 An Electricity $\mathrm{CO}_{2}$ Emission Factor 213

7.3.5.4 Average Electricity Emissions 215

7.4 Industry Emission Factors 216

$\begin{array}{lll}7.5 \mathrm{CO}_{2} \text { Absorption } & 217\end{array}$

7.6 Long Term Carbon Sequestration 218

$\begin{array}{lll}7.7 & \text { Conclusion } & 219\end{array}$

$\begin{array}{llr}8 & \text { Selected Material Analyses } & 220\end{array}$

$\begin{array}{lll}8.1 & \text { Introduction } & 220\end{array}$

$\begin{array}{lll}8.2 & \text { Methodology } 220\end{array}$

8.2.1 Annual Output 222

8.2.2 Ingredient Inputs 222

8.2.3 Energy Inputs 223

8.2.4 Transport 224

8.2.5 Capital Equipment 226

8.2.6 Other Data 228

$\begin{array}{ll}\text { 8.2.7 Data Confidentiality } & 229\end{array}$

8.2.8 Data Gathering 229

8.2.9 Data Checking 230

8.2.10 Specific Materials Methodology 230

8.3 Example Analysis - Recycled Steel 231

8.3.1 Ingredient Inputs - Recycled Steel 234

8.3.1.1 Allocation 237

8.3.2 Energy Inputs - Recycled Steel 238

8.3.3 Transport-Recycled Steel 240 
8.3.4 Capital Equipment - Recycled Steel 240

8.3.5 Other Data - Recycled Steel 241

$\begin{array}{ll}8.4 & \text { Timber } \\ & 241\end{array}$

8.4.1 Ingredient Inputs - Timber 242

8.4.2 Energy Inputs - Timber 243

8.4.3 Transport - Timber 244

8.4.4 Capital Equipment - Timber 244

8.4.5 $\mathrm{CO}_{2}$ Absorption - Timber 244

8.5 Concrete 245

8.5.1 Ingredient Inputs - Concrete 245

8.5.2 Energy Inputs - Concrete 246

8.5.3 Transport-Concrete 246

8.5.4 Capital Equipment - Concrete 247

$\begin{array}{ll}8.6 \text { Wind Generator } & 247\end{array}$

8.6.1 Ingredient Inputs - Wind Generator 248

8.6.2 Transport and Capital Equipment - Wind Generator 249

8.6.3 Other Data - Wind Generator 249

8.6.4 Discussion - Wind Generator 250

8.7 Other Materials 251

$\begin{array}{lll}8.8 \text { Conclusion } & 251\end{array}$

9 Calculating House Sustainability 252

9.1 Introduction 252

9.2 House Model 253

9.2.1 Selected House: ZALEH 253

9.2.2 The ZALEH Model 254

9.3 Modelling the Houses 255

9.3.1 1970s House 256

9.3.2 2000s Houses 256

9.3.3 2010s House 257

9.3.4 2020s Houses 257

9.3.5 Modelling Strategies $\quad 257$

9.4 The Calculator $\quad 258$

9.4.1 House Calculation Spreadsheets 259

9.4.2 Data Spreadsheet 264

9.4.3 Parameters and Results Spreadsheet: Front Page 264

9.4.4 Assessing Strategy Gains 266

9.4.4.1 Strategy Gains: Examples $\quad 267$

9.4.5 Checking Robustness: Validity of the Calculator 269 
9.4.5.1 Sensitivity Analysis

9.4.5.2Average versus Marginal Electricity 270

9.5 General Input Parameters 271

$\begin{array}{ll}9.5 .1 & \text { Sustainability Limit } \\ 9.5 .2 & 271\end{array}$

9.5.2 Global Population $\quad 272$

9.5.3 Household Size $\quad 273$

9.5.4 House Size 273

9.5.5 Lifetime of Houses 274

9.6 Input Parameters: Construction Methods, Materials, and Components 276

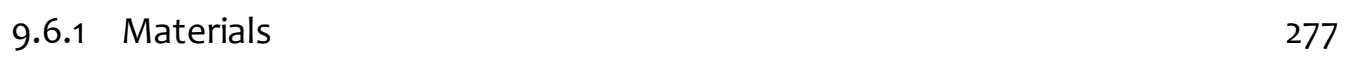

9.6.2 Lifetime of Components and Materials 278

$\begin{array}{ll}\text { 9.6.2.1 Aluminium } & 278\end{array}$

9.6.2.2 Concrete, Earth and Associated Materials $\quad 279$

$\begin{array}{ll}\text { 9.6.2.3 Insulation } & 279\end{array}$

9.6.2.4 Framing Timber $\quad 279$

9.6.2.5 Other Timber $\quad 280$

9.6.2.6 Strawbale 280

9.6.3 End-of-Life Carbon Loss in Landfills $\quad 281$

$\begin{array}{ll}\text { 9.6.4 Paint Rates } & 281\end{array}$

9.6.5 Insulation and R Values $\quad 282$

$\begin{array}{ll}\text { 9.6.6 Floors } & 284\end{array}$

9.6.6.1 Concrete Slab Floors $\quad 284$

9.6.6.2 Suspended Timber Floors $\quad 285$

$\begin{array}{ll}\text { 9.6.7 Walls } & 285\end{array}$

9.6.7.1 Lightweight Exterior Walls $\quad 285$

9.6.7.2 Heavyweight Exterior Walls $\quad 287$

$\begin{array}{ll}9.6 .8 \text { Roofing } & 288\end{array}$

$\begin{array}{ll}\text { 9.6.9 Framing Calculations } & 289\end{array}$

9.6.10 Windows and Doors $\quad 291$

9.7 Input Parameters: Energy 292

9.7.1 Operating Energy 292

9.7.2 Photovoltaics 293

9.7.3 Solar Hot Water 293

$\begin{array}{ll}9.7 .4 \text { Wind } & 294\end{array}$

9.8 Significance and Implications 294

9.8.1 Hot Water, Heating and Insulation 294

9.8.2 Emissions from Materials 299

9.8.3 Lighting and Efficient Appliances 300

$\begin{array}{ll}\text { 9.8.4 Energy Generation } & 302\end{array}$ 
9.8.4.1 Zero Emissions without Photovoltaics or Wind 303

9.8.5 Embodied Energy Importance 303

9.8.6 Embodied $\mathrm{CO}_{2}$ Importance $\quad 304$

9.8.7 Sustainability Strategy Gains: $\mathrm{CO}_{2}$ Reduction 306

$\begin{array}{ll}9.9 \text { Conclusion } & 307\end{array}$

10 Conclusions 310

10.1 A Sustainability Definition and the Steps To It 310

10.2 Discarding Unsuitable Sustainability Indicators 312

10.3 Effectively Comparing and Measuring Environmental Impacts 312

$\begin{array}{lll}10.4 \mathrm{CO}_{2} \text { Limits } & 312\end{array}$

10.5 Detailed Analysis Methods 313

10.6 Testing the Hypothesis: Sustainability Analysis of New Zealand Houses 314

10.7 Conclusion: Proving the Hypothesis 315

10.8 Specific Results 316

10.8.1 Heating Emissions Insignificance $\quad 316$

$\begin{array}{ll}\text { 10.8.2 Hot Water Emissions } & 317\end{array}$

$\begin{array}{ll}\text { 10.8.3 Construction Emissions } & 317\end{array}$

$\begin{array}{ll}\text { 10.8.4 Other Emissions } & 318\end{array}$

$\begin{array}{ll}\text { 10.8.5 Grid Electricity Emissions } & 318\end{array}$

$\begin{array}{ll}\text { 10.8.6 Policy Directions } & 319\end{array}$

$\begin{array}{ll}10.9 \text { Key Outcomes } & 319\end{array}$

$\begin{array}{ll}10.10 & \text { Further Research } \\ & 320\end{array}$

10.10.1 Comparing Environmental Impacts: Recovery Times 321

$\begin{array}{ll}\text { 10.10.2 Life Expectancy } & 321\end{array}$

$\begin{array}{ll}\text { 10.10.3 End of Life } & 321\end{array}$

10.10.4 Extending the Calculator Model 322

10.10.5 Other Sustainability Strategies 323

10.10.6 Global Actions towards Sustainability 323

10.10.7 Average versus Marginal Energy: Implications 324

10.10.8 Labour, Profits, Taxes, and Money in Sustainability Measures 324

10.10.9 Comparison with Other Methods 325

Appendix A: Lifetimes of Building Materials, Components, Houses 326

Appendix B: Embodied Energy and Embodied CO2 Coefficients 327

Embodied Energy and Embodied $\mathrm{CO}_{2}$ Coefficients $\quad 328$

$\begin{array}{ll}\text { References } & 330\end{array}$ 


\section{List of Figures}

Figure 2.1 US Energy Production, Use and Debt; Economic Debt 39

$\begin{array}{lll}\text { Figure 3.1 Per-capita Ecological Footprint versus Bio-capacity } & 73\end{array}$

Figure 4.1 Gross World Product, Fossil-Fuel $\mathrm{CO}_{2}$ Emissions, Global Temperature 95

$\begin{array}{lll}\text { Figure 4.2 Biodiversity Loss from Mass Extinctions } & 117\end{array}$

$\begin{array}{lll}\text { Figure 5.1 Global Carbon Flux } & 137\end{array}$

Figure 5.2 Sustainable Population at Per-capita Carbon Absorption/Emission Levels 143

Figure 5.3 Average Household Size 1971-2006, Selected Countries 145

$\begin{array}{lll}\text { Figure 5.4 Residential Percentage of National Emissions } & 149\end{array}$

Figure 5.5 Derivation of Sustainable Per-house $\mathrm{CO}_{2}$ Emissions 152

Figure 6.1 Levels in the Definition of the System Boundary 159

Figure 7.1 New Zealand Fossil Fuel Electricity CO2 versus Hydro Generation 210

Figure 7.2 Ratio of Electricity Generation from Coal and Gas 210

Figure 8.1 Spreadsheet for Recycled Steel Reinforcing 233

Figure 8.1a EE coefficient of ingredient 234

Figure 8.1b Silico-manganese, ferro-silicon, lime and oxygen 235

$\begin{array}{lll}\text { Figure 8.1C Carbon and Water } & 235\end{array}$

$\begin{array}{lll}\text { Figure 8.1d } \quad \mathrm{CO}_{2} \text { emissions } & 236\end{array}$

$\begin{array}{lll}\text { Figure 8.1e } \quad \mathrm{CO}_{2} \text { emissions } & 239\end{array}$

$\begin{array}{lll}\text { Figure 8.1f Capital equipment } & 241\end{array}$

$\begin{array}{lll}\text { Figure } 8.2 & \text { Timber } & 242\end{array}$

Figure 9.1 House Model 255

Figure 9.2a Typical Calculator Worksheet Layout: Detail 261

Figure 9.2b Calculator Worksheet Layout: Overall View 262

Figure 9.3a Precedent and Dependent Cell Traces in a Typical Worksheet: Detail 263

Figure 9.3b Precedent and Dependent Cell Traces in a Typical Worksheet 263

Figure 9.4a Calculator Front Page: Overall View 265

Figure 9.4b Calculator Front Page: 2020s Houses Detail 266

$\begin{array}{lll}\text { Figure 9.5 Front Page Detail: Results } & 267\end{array}$

Figure 9.6 2010s House: Heating Energy Increase to 2000s Level 269

$\begin{array}{lll}\text { Figure } 9.7 \text { Average Floor Areas of New Dwellings } & 274\end{array}$

Figure $9.8 \mathrm{CO}_{2}$ Flux: Percentage by House Lifetime 276

Figure 9.9 $\mathrm{CO}_{2}$ Emissions for Slab Floor, Timber Wall, Steel Roof Houses (kg/yr) 295

Figure 9.10 CO2 Emissions \& Absorptions: Slab Floor, Timber Walls, Steel Roof (kg/yr) 297

Figure 9.11 Annualised $\mathrm{CO}_{2}$ Flux: Slab Floor, Timber Wall, Steel Roof Houses (\%) 298

Figure 9.12 Houses 11, 12, 13, and 14: $\mathrm{CO}_{2}$ Emissions/Absorptions (kg/yr) 301

Figure 9.13 Annualised Energy: Slab Floor, Timber Wall, Steel Roof Houses (\%) 305 


\section{List of Tables}

Table 4.1 New Zealand $\mathrm{CO}_{2}$ and Non- $\mathrm{CO}_{2}$ Greenhouse Gas Emissions 112

Table 5.1 UN Projections for Population In 2050, Medium Variant (billions) 130

Table 5.2 Energy Intensity per Household Member in USA, 2001

Table 5.3 Selected Country and Region Carbon Emissions Per-capita 134

Table 5.4 Global Per-capita Carbon Limit for Absorption Capacities \& Populations 142

Table 5.5 Absorbable Per-capita and Per-house CO2 Emissions 153

$\begin{array}{lll}\text { Table 6.1 } & \text { EE Coefficient Changes 1983-1996 } & 180\end{array}$

Table 6.2 Residential Building Construction: Wages, Salaries, Profits, and Taxes 188

Table 7.1 $\mathrm{CO}_{2}$ Emission Factors for Coal 207

Table 7.2 CO2 Emission Factors for Gas 208

Table 7.3 CO2 Emission Factors for Geothermal 208

Table 7.4 NZSIC Industry CO2 Emission Factors $\quad 217$

Table 8.1 Energy Percentage of Transport for Selected Materials 226

Table 8.2 Energy of Capital Equipment for Selected Materials 228

Table 8.3 $\mathrm{CO}_{2}$ Emissions, Average Electricity 245

Table 9.1 Net Annual $\mathrm{CO}_{2} \%$ Change with +/- 20\% Parameter Variation 270

$\begin{array}{lll}\text { Table } 9.2 & \text { Life Expectancy of Selected Materials (years) } & 278\end{array}$

Table 9.3 ZALEH Insulation R Values: 200m² House 282

Table 9.4 Concrete Slab Floor Materials 284

Table 9.5 Suspended Timber Floor Materials 285

Table 9.6 Lightweight Exterior Wall Materials 286

Table 9.7 Energy and Emissions: Concrete Floor, Timber Walls, Steel Roof 299

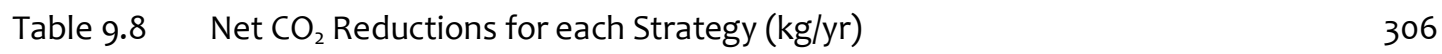




\section{Abbreviations}

\begin{tabular}{|c|c|}
\hline AGW & Anthropogenic Global Warming \\
\hline ANZSIC & Australian and New Zealand Standard industrial Classification \\
\hline $\mathrm{C}$ & Carbon \\
\hline $\mathrm{CO}_{2}$ & Carbon Dioxide \\
\hline $\mathrm{CO}_{2}-\mathrm{e}$ & $\mathrm{CO}_{2}$ equivalent \\
\hline EA & Energy Analysis \\
\hline $\mathrm{ECO}_{2}$ & Embodied $\mathrm{CO}_{2}$ \\
\hline EE & Embodied Energy \\
\hline EEA & Embodied Energy Analysis \\
\hline $\mathrm{EF}$ & Ecological Footprint \\
\hline ERE & Energy Requirement of Energy \\
\hline EROEI & Energy Return On Energy Invested \\
\hline GDP & Gross Domestic Product \\
\hline GER & Gross Energy Requirement \\
\hline GFCF & Gross Fixed Capital Formation \\
\hline GHG & Greenhouse Gas \\
\hline GHGs & Greenhouse Gases \\
\hline GPI & Genuine Progress Indicator \\
\hline GWP & Global Warming Potential \\
\hline IFIAS & International Federation of Institutes for Advanced Study \\
\hline $\mathrm{I}-\mathrm{O}$ & Input-Output \\
\hline IPCC & Intergovernmental Panel on Climate Change \\
\hline ISEW & Index of Sustainable Economic Welfare \\
\hline ISO & International Organization for Standardization \\
\hline $\mathrm{kg}$ & kilogram \\
\hline LCA & Life Cycle Assessment \\
\hline LCM & Life Cycle Management \\
\hline MDF & Medium Density Fibreboard \\
\hline MFA & Material Flow Accounting \\
\hline MJ & megajoule \\
\hline $\mathrm{NPP} / \mathrm{C}$ & Net Primary Production relative to Consumption \\
\hline NZSIC & New Zealand Standard Industry Classification \\
\hline OECD & Organisation for Economic Co-operation and Development \\
\hline OED & Oxford English Dictionary \\
\hline PER & Process Energy Requirement \\
\hline PV & Photovoltaic \\
\hline SETAC & Society of Environmental Toxicology and Chemistry \\
\hline SHW & Solar Hot Water \\
\hline SI & Sustainability Index \\
\hline TBL & Triple Bottom Line \\
\hline TNS & The Natural Step \\
\hline
\end{tabular}




\section{$1 \quad$ Aims and Objectives}

See first, think later, then test. But always see first. Otherwise you will only see what you were expecting. Most scientists forget that.

- Douglas Adams, 1984

\subsection{Introduction}

"How can you build a sustainable house in New Zealand?" This research question is answered in the last part of the thesis. In order to be able to answer that question however, it was necessary to determine what sustainability is, how to measure it, and within what sustainability envelope the house has to stay. Logically, sustainability had to be the starting point to answer the research question.

The thesis is in three parts. The first part, in Chapters 2-5, deals with what sustainability is and how to measure it. After defining sustainability in a functional way, and what its limits are, methods of measuring it are assessed. Two effective methods are identified: embodied energy (EE) and embodied carbon dioxide $\left(\mathrm{ECO}_{2}\right)$ analysis.

The second part, in Chapters 6-8, address EE and $\mathrm{ECO}_{2}$ analysis in detail - how to do it and how it has been done in this case (EE research was one of the original sparks behind the thesis).

The third part, Chapter 9, applies the arguments and knowledge from the earlier chapters, and determines the sustainability of houses in the New Zealand context, by means of $\mathrm{EE}$ and $\mathrm{ECO}_{2}$ analysis, comparing the result against a sustainability limit.

Each of the three parts could easily have formed a $\mathrm{PhD}$ thesis by itself. However, since the end goal was to answer a particular question, and since the answer to that question could only be found by integrating all three parts, they were all included. This means their treatment is not as detailed as it could have been had each one occupied the whole space available in a $\mathrm{PhD}$ thesis. Nonetheless, their treatment is sufficiently detailed to show the methods and rationales within them. 


\subsection{Research Background}

In 1983 Baird and Chan published Energy Cost of Houses and Light Construction Buildings, a report widely used as a reference for those wanting data on the EE of building materials.

Baird and Chan acknowledged their report was a preliminary investigation. Since it was published changes in technology, improvements in energy use, and changes in environmental impact research methodology meant updating was required. Alcorn $(1995 ; 1998)$ undertook a series of $\mathrm{EE}$ analyses, and subsequently $\mathrm{ECO}_{2}$ analyses (2001; 2003), initially to update the Baird and Chan coefficients for New Zealand building materials. The framework developed in these earlier analyses formed the basis for the $\mathrm{EE}$ and $\mathrm{ECO}_{2}$ analyses undertaken in this thesis.

Alcorn's analyses from 1995 to 2003 did not, however, apply the resulting coefficients of building materials to whole houses, or address the wider questions of sustainability. Nebel and Szalay (2007) used data from Alcorn (2003) and heatingonly operating energy data in the life cycle analysis of a New Zealand house. Irrespective of assumptions within the Nebel and Szalay study, such as lifetimes of materials, its LCA methodology was unable to comment on the actual sustainability of the house. LCA and measuring sustainability are addressed in Chapters 2-5.

This thesis is thus a further step in a nearly 30 year research effort investigating the environmental impact of New Zealand houses. It is the first time a full range of detailed data on environmental impacts of house construction and operation has been undertaken. It is the first study able to confidently predict how close to sustainability individual house designs are.

\subsection{Attempts at Sustainability: Earth and Strawbale}

During research for a Bachelor of Architecture final-year dissertation on Earth Building in New Zealand (Alcorn, 1994), people with a strong interest in building sustainable houses were interviewed. Further similar interviews were later 
undertaken when the author was the secretary of the Earth Building Association of New Zealand, during the establishment of the Strawbale Practitioners Group, and during consultancy with prospective and current strawbale homeowners.

Interviewees included owners of earth houses, who had built them with a belief that they were 'sustainable'. They had chosen to use earth as the primary building material because of its perceived sustainable attributes: low EE; low transport energy from (normally) locally sourced material; low toxicity; low maintenance requirement; high thermal mass; high acoustic attenuation; abundance; recyclability; lack of finishing needed; ability to moderate internal humidity; ability to absorb smells and toxins, as well as other attractions, such as its aesthetic qualities, cheapness, and ability to be built by the homeowner on site. The perceived attributes for strawbale houses were similar, but also included high insulation value, carbon dioxide $\left(\mathrm{CO}_{2}\right)$ sequestration, use of a 'waste' material, good seismic performance, and rapid construction.

The owners of earth and strawbale houses, and others with an active interest in sustainability were also interested in technologies and strategies that could enhance what was believed to be a sustainable house. Solar water heating, low toxicity insulation such as wool, wood-fired heating, water heating and cooking, good natural lighting, efficient appliances, on-site electricity generation, on-site grey water treatment, composting toilets, and home gardening were all features commonly discussed and adopted by the earth and strawbale homeowners and those interested in the houses. In short, they were following ideas proposed back in the mid-1970s, in works such as "The Autonomous House" (Vale and Vale, 1975).

There was acknowledgment, however, that although many apparently sustainable ('green') features might be incorporated, whether a particular mix, or even all of them together, might achieve a sustainable house, remained an open question. Did the addition of 'green' design and technologies, or even a fully autonomous house, equate to a sustainable house? There were two frequently asked questions amongst the sustainability-aware homeowners, and even more amongst those contemplating 
such a house but still with limited knowledge or experience: "How do you build a sustainable house?" and "What is a sustainable house?"

\subsection{Research Question}

After many years of being asked what a sustainable house was, the research question that initiated this thesis was well formed, although simple:

\section{How do you build a sustainable house in New Zealand?}

\subsection{Aims}

The identified problem was that buildings, including houses, account for a significant proportion of resource use, including energy, and account for a significant proportion of harmful environmental impacts, including greenhouse gases. Overall, the energy and resource use and the emissions are beyond what is sustainable, as will be seen in later chapters. A general aim, then, is:

\section{to reduce the environmental impact of housing to a sustainable level.}

This general aim is shared by a large and growing number of individuals and organisations worldwide. Various methods have been proffered to improve the environmental performance of buildings. For a variety of reasons, including uncertainty about the scale and importance of different environmental impacts, many of these methods have tended to make simple comparative assessments between buildings, or building practices, as the basis for sustainable performance measurement. A scale that is referential to other buildings has been used, rather than one that linked to a clear sustainability scale independent of the buildings. Because of the absence of a functional sustainability guideline extrinsic to the building process, ratings and weightings have been proposed for these methods that are based on a variety of measures, including mere estimates of what good sustainable building practice is. A shortcoming of this approach is that surprises may await analysts when particular aspects are assessed or reassessed in the light of future understanding. 
The long-term goal this research seeks is sustainability in the New Zealand housing stock. Another general goal, then, is to assist policy direction in New Zealand housing. Such guidance is also sought outside policy circles.

Therefore the specific aim for this piece of research is:

to provide a reliable, accurate, and specific guide to building a sustainable house in the New Zealand context.

\subsection{Objectives}

To meet the research aim a number of prior objectives needed to be met. In order to understand houses, detailed analysis of the inputs to a bouse was necessary. This included the physical components, plus the energy needed to operate the house. First, a careful breakdown of the physical components of the house, and a careful analysis of the operating energy inputs and modes was needed. The operating energy analysis has been done primarily by Isaacs et al. (2006).

\subsubsection{Understanding and Defining Sustainability}

The first of the prerequisite objectives was to understand and define unequivocally what sustainability is so that houses can be measured against this definition, and be identified as sustainable - or some distance from it.

Sustainability is a contested concept (Davidson, 2001). Deciding on which definition of sustainability to use requires more than plucking the most likely, most palatable, or most common definition available. The chosen definition needs to be readily translatable to the problem of assessing houses for sustainability. It needs to have widespread acceptance to be useful in policy guidance. It needs to be robust over a long timeframe. To choose or make such a definition requires an understanding of sustainability. Understanding and defining what sustainability is forms the substance of Chapter 2. 


\subsubsection{Measuring Sustainability}

Once a definition was established, the next objective was to derive a way of measuring sustainability. This is a central objective of the research. Hitherto, sustainability, as it applies to buildings, has been conceived in a somewhat vague way. Such a sustainability measure needs to be applicable to a wide range of endeavours. It also needs to be easy to apply, objective, reliable, specific, and pertinent to current and foreseeable major environmental issues. The methods that already exist for estimating sustainability need to be assessed for reliability, applicability, and any potential contribution they may have for a specific measure of sustainability. Most importantly, they need to be assessed in the light of the adopted definition of sustainability. These issues are dealt with in Chapters 3 and 4.

\subsubsection{Emission Limit and Target}

This thesis will argue that the most appropriate measure of sustainability is $\mathrm{CO}_{2}$ emissions, because of the importance of climate change and $\mathrm{CO}_{2}$ 's link to it. To apply such a measure it is necessary to determine a sustainable emission limit, on a percapita basis. From a per-capita $\mathrm{CO}_{2}$ emission limit an associated objective is to derive a per-house limit for $\mathrm{CO}_{2}$ emissions, to prevent variable numbers of inhabitants one house might accommodate over its lifespan from distorting the figures. $\mathrm{A} \mathrm{CO}_{2}$ emission target for houses can then be established as the basis for rating their sustainability. The case for a $\mathrm{CO}_{2}$ limit is made in Chapter 5 .

\subsubsection{Embodied Energy and Embodied $\mathrm{CO}_{2}$ Analysis}

With a $\mathrm{CO}_{2}$ emission target, different houses and house types can be assessed against it. To do this the $\mathrm{CO}_{2}$ emissions of houses need to be established. This requires attaining a prior objective: analysis of the energy and $\mathrm{CO}_{2}$ associated with producing the materials the house is constructed of, the $\mathrm{EE}$ and $\mathrm{ECO}_{2} . \mathrm{ECO}_{2}$ data is derived from EE data. In practice the two can be analysed simultaneously, but they are presented separately, forming Chapters 6 and 7. 


\subsubsection{Materials Analysis Methodology}

While Chapters 6 and 7 deal with the overall aspects of $\mathrm{EE}$ and $\mathrm{ECO}_{2}$ analysis, Chapter 8 presents a detailed and transparent methodology. This is necessary to meet the objectives of acceptance of a sustainability definition, and its easy applicability, objectivity and specificity. The methodology that this thesis follows for materials analysis differs from other methodologies. It is illustrated with analysis case studies of three materials, in Chapter 8.

\subsubsection{Selected Technologies Analysis}

When rating houses against the $\mathrm{CO}_{2}$ target, different materials choices yield different results. In addition, specific 'sustainable' systems or technologies, such as solar water heating or electricity generating systems can be expected to significantly affect the $\mathrm{CO}_{2}$ profile. This requires the assessment of 'sustainable' technologies for their $\mathrm{CO}_{2}$ contribution. A case study analysis is described in Chapter 8.

\subsubsection{Rating Houses}

With the underlying methodologies and data established, the next objective is to rate existing whole houses for their $\mathrm{CO}_{2}$ contribution. This serves as a benchmark to compare the performance of other houses, using a range of designs, materials, and 'sustainable' technologies. This forms the early part of Chapter 9.

\subsubsection{Meeting the Target}

With results for a range of houses, materials and technologies, it is possible to discover which strategies either approach, meet, or exceed the sustainable $\mathrm{CO}_{2}$ limit. Using these observations, a further objective is to predict what strategies might further improve the sustainability of New Zealand houses. This forms the basis of Chapter 9.

\subsection{Hypothesis}

Many different design strategies and technologies have been applied to houses to improve their environmental performance. These include passive solar design, high insulation levels, high thermal mass, double glazing, efficient appliances, solar hot water, solar and wind electricity, grey and black water treatment, and low impact 
materials such as earth, straw and wool. Houses may frequently incorporate one or more of these features described as "sustainable" or "green". What has not been known until now is whether these features do actually make a house sustainable.

To be able to judge if a house really is sustainable, it is first necessary to know what sustainability is and is not. It may seem, from the common application of the word, and indeed from some of the proffered definitions, that sustainability means that one thing is less bad than another. But less bad is still bad.

There are uncertainties and difficulties in knowing if a house is sustainable: firstly, at what point of being 'less bad' does something stop being bad and cross the boundary to being good? Secondly, it is not clear from cursory analysis that something which seems less bad is, in fact, less bad. As Boulding (1986) observes,

The World is a very complex system. It is easy to have too simple a view of it, and it is easy to do harm and to make things worse under the impulse to do good and make things better.

In gauging the sustainability of a house, a whole-world view needs to be maintained, within which is placed the definition, measurement, and limits of sustainability. When assessing the sustainability of houses, the manifold uncertainties require that careful analysis is done, and related to a clear definition, and limit, of sustainability.

The above methodological hurdles notwithstanding, by applying enough passive and active strategies to a house, can it be made sustainable? The hypothesis of this research, then, is that:

\section{By making strategic design and construction decisions, materials choices, and technology selections, the $\mathrm{CO}_{2}$ profile of houses can be brought within a target limit that can be considered sustainable.}

The test of this hypothesis occurs in Chapter 9. The above objectives are used to analyse various house types, design and construction strategies, to determine how well they approach the derived measure of sustainability. 


\section{Sustainability - What Is It?}

There are many definitions of sustainable development, and therein lies the first set of problems.

- Mark Mawhinney, 2002

'Sustainable development' is a meeting point for environmentalists and developers.

- Simon Dresner, 2002

\subsection{Introduction}

If sustainable development were a clear and agreed goal, there would not be so many meanings and definitions; we would be in agreement about the goal, the way towards it, and the term itself. Nonetheless, to enable this thesis, a clear notion and a functional and supportable definition of sustainability needs to be adopted This is a necessary step to assessing methods of house construction as sustainable or unsustainable and therefore achieving the aim of providing a reliable, accurate and specific guide to building a sustainable house in New Zealand (see Section 1.5).

Nitin Desai (2002), contributing architect to the fabric of the familiar Brundtland (1987) definition, comments that "the issue is not defining sustainable development, but understanding it". To help understand sustainable development, and to elucidate its politics, definitions, terms, and application, this chapter gives a brief account of the early and recent history of the debate around it. Without such an historical résumé the confusion around sustainability resists clarification. This happens with Mawhinney (2002), who attempts to grapple directly with the issues, without looking carefully at how the various political and environmental factions arrived at their present positions.

After the brief history, a list of requirements for a functional definition of sustainability is distilled from the history and debate. Initial arguments are made to focus on one central environmental issue for a functional definition and the means 
to measure specific activities for sustainability. A resultant functional definition, and indicator, of sustainability is presented.

Assessment of this chapter's listed requirements for a functional definition of sustainability, against available literature, is left to Chapter 3, as is a comparative assessment of some common sustainability indicators against the listed requirements. Chapters 4 and 5 assess two effective sustainability indicators against the listed requirements.

\subsection{Confusion in Sustainability}

The fact that we need to ask the question, 'What is sustainability?' points to the lack of consensus around what the main problems and priorities of sustainability are and how to respond to them. The confusion around these issues is the precursor to the confusion around the term and definitions. Davison (2001) notes this confusion in the use and meaning of the various associated terms:

[T] he language of sustainable development is conceptually incoherent and politically compromised...The incoherence of this language is wonderfully displayed in George Myerson and Yvonne Rydin's earnest discourse analysis of sustainable development. The authors jumble together terms like sustain, sustainability, and sustainable development and then analyse a jumble of texts from Our Common Future and Blueprint for a Green Economy to the work of Naess and Henderson. In the midst of the resultant shambles, they claim that "sustainable development represents new ethics, new politics, and new economics" (Myerson and Rydin, 1996)... There is danger, clearly, in any form of discourse analysis that is not undergirded by an analysis of the relationship between texts, practice, and politics.

Because of the "conceptual incoherence" in much of the language, and thinking, around sustainable development, useful texts where the authors have a clear view of the territory and grasp of the issues, are uncommon. Stand-out exceptions, exhibiting clarity and incisiveness, are Davison (2001) in Technology and the Contested 
Meanings of Sustainability, and particularly Dresner (2002), from the Policy Studies Institute at the University of Westminster, in The Principles of Sustainability. Their work is therefore frequently cited in this chapter.

In 1983 the United Nations established the Brundtland Commission, to investigate deterioration of natural and human resources and propose 'strategies for achieving sustainable development'. The resulting Brundtland (1987) Report, Our Common Future, included the now familiar definition of sustainable development: "development that meets the needs of the present without compromising the ability of future generations to meet their own needs". This "Brundtland Definition" is often cited as a definition of 'sustainability', but it, too, contains confusion. It is discussed further in Section 2.2.3 "Brundtland and Other Guides".

Mawhinney (2002) reaches the end of his book Sustainable Development: Understanding the green debates, saying, "The link between starting point [of the debate about sustainable development], the process and the end-goal has been an unsolvable simplistic query throughout the text." His title notwithstanding, he is conceding that he, and we, have not reached understanding, but remain mired in debate. Mawhinney begins by wondering if it is "possible to have [a] defining explanation, or does it depend on your political viewpoint?" but concludes merely, having failed to iron out the issue, that "It is encouraging to note that where there is debate there can be progress." The debate has been ongoing, under various headings, for over a century now, but (if there has been any progress) it does not seem to have brought us close to any agreement.

The debate about meanings and definitions will continue for some time yet. Understanding may exist about what sustainability requires, but there are various different understandings, each with its proponents and detractors, in conflict with each other. Through examination of the history and debate, however, the aims of the various factions can be distilled, and a working definition extracted. This allows the assessment of particular ways of constructing houses and whether they are sustainable, or at least how distant they are from a sustainable target. 
Davison (2001) observes, "sustainability is an essentially contested domain". There are, however, some clear physical realities and limits that are no longer contested. Mawhinney (2002) comments: "What is clear is that change is necessary. What is not clear is how much change is necessary, leaving the way open for the debate on how much is needed or desirable." There is now more clarity on a range of issues than when Mawhinney was commenting. Limits have emerged that can point precisely to just how much change is necessary in certain areas, including aspects of house construction.

\subsection{A Brief History of Sustainability}

\subsubsection{The Momentum of Growth}

Rachel Carson published Silent Spring in 1962. Prior to that, in spite of a few sporadic warning voices, humanity was still fully on the course of growth, fuelled by science and development emanating from the enlightenment, and by religious belief, particularly in the Christian dominated and high-consuming United States (Dresner, 2002).

A 1968 lecture by physicist William Pollard indicates the momentum and exceptional nature of humanity's growth. Pollard (1969) recognised the huge changes the growing population was bringing to the earth:

Our century, the twentieth, is unique in the whole history of our species on the planet, and indeed in the whole incredibly longer history of the earth itself. There is nothing in these previous histories to which it can be compared. We find ourselves in the midst of revolutionary changes of a magnitude and scope far beyond that of any other cataclysm which the earth has experienced throughout its billions of years.

When making comparison between current climatic events and extinction rates, and past cataclysms, recent developments in paleontological understanding underline the scale of the change that Pollard refers to. The benchmark in the earth's geological history is the fourth great extinction event, the Permian/Triassic boundary, when up to $95 \%$ of all species died out (Ward, 2008; Benton, 2003). Pollard would not have 
had the benefit of recent research, but, at least, would have compared modern developments with the fifth great extinction event at the Cretaceous/Tertiary (KT) boundary, 65 million years ago, which saw around $50-65 \%$ of species die out.

Pollard, also a deacon in the Protestant Episcopal Church, saw the changes in a religious context - as part of man's [sic] right and obligation. With a small typographical error and possible Freudian slip, he quotes Genesis 26-28:

So, Cod [sic] created man in his own image and blessed them and said to them; 'Be fruitful and multiply and fill the earth and subdue it; and have dominion over the fish of the sea, and over the birds of the air, and over the cattle, and over all the earth'.

Pollard's typographical error prompts an alternative view, as was held by the new breed of environmentalists, to the path laid down by God, as per Genesis. By applying the image of the cod fish, and the recent decimation of the cod fishery (Myers, 1997), as symbolic of species exploited and overexploited by man to reach the present position of filling the earth; or the sense of cod (OED, 2006) as representative of (male) human reproductive organs and thereby the path to current population levels, the passage takes on a secular and rather different meaning.

While recognising the magnitude of the changes ensuing, Pollard, embracing the injunction of Genesis 26-28, was enthusiastic, typifying prevalent religious attitudes:

Clearly our century...is the one in which the biblical injunction to be "fruitful and multiply and fill the earth" is at last being fulfilled... To us and to our generation the lot has fallen to experience the fulfilment of the purpose asserted for man when he began to inhabit this planet thirty-five thousand years ago; namely, that he should in the fullness of time multiply and fill the whole earth.

Pollard exemplifies the view of nature as something to be conquered. If, in the process of that conquering, some local problem was created (such as the collapse of the cod fishery), there had always been somewhere else to move on to. Overall, 
nature was viewed as so large that anything people did to it could not fundamentally affect it (Boulding, 1966). The contradiction between the view of nature as large and incorruptible and the notion of humanity growing and "filling the whole earth" was not appreciated. Pollard could refer to recent human presence as both "cataclysm" and "fulfilment". In spite of the "cataclysmic" consequences, growth was still progress, towards the "fulfilment of the purpose asserted for man".

This view of human 'progress', as Davison (2001) characterises it, leading to a better world, and eventually to utopia, is still the philosophical foundation for most of western society. It has, predictably, been adopted by developing countries who want a slice of the progress. Naming his Massey Lectures A Short History of Progress after this idea, Wright (2006) views progress as having become a religion of its own:

Our practical faith in progress has ramified and hardened into an ideology - a secular religion which, like the religions that progress has challenged, is blind to certain flaws in its credentials. Progress, therefore, has become "myth"... "Myth" is an arrangement of the past, whether real or imagined, in patterns that reinforce a culture's deepest values and aspirations... Myths are so fraught with meaning that we live and die by them.

Diamond (2005) also focuses on the risk inherent in living by unexamined myths rather than by rational observation and action. He identifies that a key determinant of whether societies survive or fail is their ability to examine and adjust their core beliefs in the face of altered conditions.

Adherence to this unquestioned view of progress as synonymous with growth underlies modern economics too. The fundamental requirement of healthy economies, and hence healthy societies, in the view of mainstream economists, politicians, and citizens, is steady growth. Boulding (1958) identified the prevailing attitude of economists early, in a wry couplet:

The wise economist is loath

To give up anything for growth 
Boulding (1971) later explicitly connected this with environmental effects:

Economics has been incurably growth-oriented and addicted to everybody growing richer, even at the cost of exhaustion of resources and pollution of the environment.

A healthy monetary economy (by definition a growing one) is viewed as a prerequisite for having the ability to deal with environmental problems. Brundtland (1987) claimed “poverty reduces people's capacity to use resources in a sustainable manner; it intensifies pressure on the environment". New Zealand's own Minister for the Environment stated: "We cannot look after the environment without a strong economy" (Hobbs, 2005).

An economic growth orientation exists not just in capitalist economies, but also in centrally planned countries, striving to improve the living standard of their people (Bonner, 2006). China's one child policy, a rare example of restraint, has been no match for the growth goal of their (new) capitalist economic orientation, showing $\sim 9 \%$ annual GDP expansion.

The goal of environmentalists to safeguard the natural world was always going to be difficult in the face of such a unity of human purpose to grow, expand, and 'improve', in endless development, until "dominion over all the earth" is reached. The universality and entrenchment of the mythical regard for progress as growth-inwealth in human society makes it difficult to change. Dawkins (1976) identifies it as part of the genetic makeup. Our selfish genes are programmed to bear offspring to continue themselves, and the species, and to improve our lot in order to improve our chances in reproduction, without due regard for the greater environmental consequences. Our enmeshment in the myth of progress via growth makes it difficult for us to see it objectively and thus adopt a change of course. Wright concludes that our civilisation is like a repeat offender who, when let out of jail, commits the same crime as did past civilisations - of over-exploitation of the environment (Wright 2006; Diamond, 2005). 
The maximisation of personal lifestyle and comfort is common to developing and developed countries alike. Wealthy countries may espouse reduced environmental impact, while simultaneously increasing theirs. Developing countries, emulating developed ones, attempt to catch up with their personal consumption levels, irrespective of the environmental consequences. Even when increased standards of living exceed what is necessary to improve reproductive chances and fecundity, the human instinct to maximise personal resources has continued to drive rising living standards and consumption. Few voluntarily reduce their personal comfort noticeably. A solar hot water system or a Prius rather than a Landcruiser may be chosen, but such changes can be made without compromise to comfort.

The task of attempting to slow the momentum of growth, then, has several hurdles. There is not only history, genetics, and religion to overcome, but most importantly, a liking for personal comfort. The challenge was taken up, however, in many different initiatives over many years, which aimed to highlight emerging environmental damage, and point the way to sustainability.

\subsubsection{Up to Brundtland}

In the decades before the 1987 World Commission on Environment and Development that produced the Brundtland Report a number of individuals and groups sought to reduce or prevent the environmental impacts they were observing. They are too numerous to refer to all of them here, but some of the main ones are mentioned or discussed. Individual publications in this environmental effort are italicised, and groups, schools of thought, principles, or movements are in bold.

By 1962, with 17 years of consumer society since the end of the Second World War, the powerful forces of genetics, history, religion, progress, and comfort that acted to maintain the growth status quo were a juggernaut that was not going to stop with the publication of just one book by Rachel Carson. It was, however, the acceleration of technology and consumption after WWII which fully ignited the environmental movement. The application of some technologies was having serious impacts on the environment. 
Carson's was not the first move in the environmental cause. Osborn (1948) with Our Plundered Planet, Vogt (1948) with Road to Survival, and Leopold (1949) with A Sand County Almanac had all taken up the ecological argument (Davison, 2001). John Muir's Sierra Club, conservationism, and the precautionary principle dated from the late 19th century. Earlier, Malthus (1798), witnessing the growth in population since the beginning of the industrial revolution, published an essay warning of the consequences of exponential growth in population, but only linear growth in food supply. Malthus was criticised for being a prophet of doom. Malthusianism is still derided today, as food supply has largely kept pace with population growth.

What Rachel Carson did, however, was to observe the effects and changes of technology and project forward to a time when there would be no birds to wake us next season. The future, rather than just present desires, began to loom large and to look dystopian rather than utopian. When DDT showed up in Antarctic penguins, the world, and thus nature, began to look smaller (Dresner, 2002). The sense that there was always somewhere else to move on to began to be challenged.

In 1966 the view of the world as a finite and shrinking entity was encouraged by Barbara Ward's (1966) Spaceship Earth and Kenneth Boulding's (1966) The Economics of the Coming Spaceship Earth. Photographs from the Apollo lunar missions of the Earth in space in the late 60s made the view widely shared (Dresner, 2002). Other environmental events, such as the 1967 sinking of the Torrey Canyon off the British coast began to have widespread effects. They commanded global attention and prompted the sense of a whole planet under attack, rather than merely a local area. This sense contributed to the public nature of the demonstrations associated with the first Earth Day in 1970.

In 1968, as spaceship earth consciousness and the back-to-the-earth hippy movement were spreading a new awareness of caring for the planet, the Ehrlichs (1968) published The Population Bomb, giving impetus to a new Malthusianism (Dresner, 2002). The predicted starvation of hundreds of millions of people in India, Asia, and Africa did not eventuate, however, because of the so-called green revolution. High yield, disease resistant varieties of wheat were bred in the 1960s just 
as it was looking to the Ehrlichs, who had witnessed the plight of the poor in India, that starvation was inevitable. Food supply as a limiting factor to population was thereby moved out another half century. On the other side of the ledger, increasingly available contraception, among other reasons, was about to bring the annual global population growth rate down, to about $1.2 \%$ by the end of the century, from a peak at $2.1 \%$ around the time of publication of the Ehrlichs' book (Cohen, 2003).

With population increase slowing, food supply increasing, and the Ehrlichs' predictions beginning to look off the mark, the Malthusian/Development debate was re-fuelled on the development side. This developing catastrophist versus cornucopian schism was, particularly, between environmentalists and economists. Famously, economist Julian Simon made, and won, a bet with Paul Ehrlich that a selection of metal prices would fall throughout the 1980s (Abernethy, 1991).

While the Ehrlichs scared some into action (Dresner, 2002), to others they were merely crying wolf, and their influence gradually waned. One enduring legacy of the Ehrlichs', however, developed after the 1968 publication, was the formulation of an equation, $I=P A T$, that included the factors of consumption or affluence $(A)$ and population $(P)$ contributing to overall impact $(I)$, taking account of the specific impact of the technology or method of producing the consumed goods or services $(T)$. The basic equation is still in use as population, together with consumption, is again being seen as the central problem (Mawhinney, 2002; Miller, 1992).

Neo-Malthusianism was given further impetus when the Club of Rome sponsored Meadows et al. (1972) to produce The Limits to Growth, in which various resources and human population growth were factored into a computer program to estimate the likely time to exhaustion of those resources. The interest in this work saw it translated into more than 30 languages.

Even more than the Ehrlichs' book, Limits to Growth generated much debate, and, later, criticism. Among other accusations was the suggestion that the computer program was designed to produce the answers the Meadows already 'knew', or was at least influenced by their assumptions. It was also seen as undervaluing the role of 
technological innovation, resource substitution, and dematerialisation which were, and are, key aspects of the cornucopian position that resources will not run out. A criticism of Meadows et al., that is still active today in the sustainable development debate, was that it promoted despair, and hence distraction from the more urgent tasks at hand (Dresner, 2002). As witnessed during the Simon-Ehrlich bet, commodity prices steadily fell to the end of the century, supporting the cornucopian position and undermining that of Meadows et al. and the catastrophists. Limits to Growth contained useful warnings, but these were ignored and discredited because of minor errors of timing. The result was that it served more to strengthen the hand of the development lobby.

Later, Meadows referred to Daly to make a definition of sustainability.

Sustainability is my word for the moment to talk about what I do. Not sustainable development, and Lord knows, not sustainable growth. I mean Herman Daly's very clear, very strict definition. ...[S]table population...stable throughput...for each source and sink below its limits...Sustainability means meeting those physical requirements; and beyond that, meeting those social requirements that have to be met so that the system doesn't blow itself apart socially (Dresner, 2002).

Later still, Meadows et al. (2004) defined sustainability: "a sustainable society is one that can persist over generations; one that is far-seeing enough, and wise enough not to undermine either its physical or its social systems of support".

With Limits to Growth, and Barbara Ward's (1972) Only One Earth released, a 1972 Stockholm Conference on Human Environment was organised. The chair of the conference, Maurice Strong, “coined the term 'ecodevelopment' as a way of verbally reconciling the desire for development plus environmental protection" (Dresner, 2002). As the (added) italics highlight, the verbal exercise and the desire to bring together development and ecologically benign action were, and remain, easier than the practice of doing so. 
Schumacher (1973) in Small is Beautiful, introduced 'appropriate technology' as a way that ecodevelopment might be made to work and achieve sustainability in practice. It did not show a way to the sort of wealth enjoyed by developed countries, however; poor countries felt as though they were being told by the rich countries to be happy with their lot. The effect was for 'ecodevelopment' and 'appropriate technology', to be discredited (Dresner, 2002). A new term was needed to escape the Schumacherian baggage and make another attempt at uniting environmental concerns and development concerns. The 'ecodevelopment' word was thus a forerunner to the 'sustainable development' term.

At the Stockholm conference, poverty as an issue for the developing world was a highlight of concern, as was the idea that poor countries could not afford to worry about, and certainly could not spend large amounts of money on, environmental issues (Dresner, 2002). From this stance emerged the idea that environmental protection depended on strong economies.

Poor countries were then, and are still, indignant at being warned about pollution by developed countries. This attitude produced something of an impasse between countries such as the United States and China: the United States unwilling to sign the Kyoto Protocol without the requirement for developing countries to commit to equivalent emission reductions, and China, which signed the Protocol, unwilling to shoulder the burden of bringing down emissions levels beyond its modest 'developing country' targets without the US, the major emitter historically, being part of the Protocol (Liu, 2005; Norberg-Hodge, 2010, ENS, 2010).

Two factors helped the inclusion of the word 'development' alongside 'sustainable' in the Brundtland report: guilt on the part of many developed countries, and support for the right of poor countries to develop and catch up with developed countries by the same industrialisation route, even if it meant environmental damage (see below).

Dresner (2002) suggests the earliest appearance of the term sustainability appears to be in 1974, when it was used by the World Council of Churches in a Bucharest conference on Science and Technology for Human Development, a response to the 
Limits to Growth publication (Hallman, 2002). Key aspects of their description of a sustainable society were (in their order):

- An equitable distribution of commodities in short supply

- The ability for people to participate in social decisions

- Global food supply well above demand

- $\quad$ Pollution well below the absorptive capacity of ecosystems

- Non-renewable resource use below the equivalent resource creation from technological innovation

- A level of human activity small enough not to be adversely influenced by severe weather events.

Many of these requirements found their way into subsequent sustainability proposals, notably Brundtland, which also starts from a position where the equity issue is central. Unlike the last three bullet points of this list, however, Brundtland did not specify substantial safety margins for the various human/environmental parameters.

Another spin-off of the Limits to Growth publication was Herman Daly's (1977) Steady-State Economics. Daly's prescriptions too, bear similarities to the World Council of Churches prescriptions, notably the connection between the human scale and global carrying capacity, and the rate of non-renewable resource use. Daly (1992) states four principles of sustainable development:

- Limit the human scale to that which is within the earth's carrying capacity.

- Ensure that technological progress is efficiency-increasing, rather than throughput increasing.

- $\quad$ For renewable resources, harvesting rates should not exceed regeneration rates; and waste emissions should not exceed the assimilative capacities of the receiving environment.

- Non-renewable resources should be exploited no faster than the rate of creation of renewable substitutes (e.g. fossil-fuel use should not exceed the rate at which wind/solar/wave energy replacements are introduced). 
The link between economic activity and material and energy use, and the resultant waste and pollution, was made, especially, by Daly. Goldsmith $(1975,1999)$ made a similar point: that reduction of environmental damage will not meaningfully occur until economic activity reduces: "The only thing which may save us is the complete collapse of the global economy". Arguing limits again, Daly claimed that entropy restricts the physical size the economy can reach.

In 1980 The Global 2000 Report to President Carter outlined trends in population, natural resources and the environment, and painted a picture of a world in the year 2000 "more crowded, more polluted, less stable ecologically and more vulnerable to disruption" (Barney, 1980). Carter had already warned the American people in 1977, soon after he came to power, about "an unpleasant...problem unprecedented in [American] history". This was the energy crisis he saw threatening to overwhelm the country. With the Global 2000 report, and with the effect of the 1973 OPEC oil shock in the recent memories of Americans, the influence of the 1970s' warnings from the Ehrlichs, Meadows et al. and others had made it all the way to the top of the most influential country. The influence even extended to the top of the White House, where Carter installed solar panels. While the 1973 OPEC oil embargo against America was a response to the political process unfolding in the Middle East, the energy and economic effects on America seem likely to have underlain Carter's "sacrifice" strategies. The lingering effects of the second oil shock of 1979 underscored the 1980 report.

Carter's dose of realism, however, contributed to Americans being, as Bonner (2006) puts it, "discouraged...they had lost confidence in themselves". The effect of the 1970s' warnings, on America's environmental leanings, proved, however, to be a short-lived effect: in 1981 Reagan came to power, declared it was "morning in America", and set about opposing and dismantling efficiency initiatives, starting with the solar panels on the White House roof (Darley, 2004). As Darley notes, "ever since then "sacrifice" has become a taboo word". As Bonner (2006) has it, Reagan came along "with a message of hope, optimism, and something-for-nothing". 
Bonner focuses on the financial debt the US has amassed since the mid eighties under (initially) Reagan. The energy debt that Carter was warning about and trying to tackle has grown with it, impelled by the free spending attitude initiated by Reagan. The two are connected: Reagan's "morning in America" attitude to economics necessitated a commensurate rise in energy consumption, albeit at a somewhat lower rate as efficiency measures made some headway. Figure 2.1 shows the relationship between US total energy production, total energy use, and debt. The expanding gap between energy use and production amounts to energy debt, which is made up primarily by rising oil imports.

\section{Figure 2.1 US Energy Production, Use and Debt; Economic Debt}

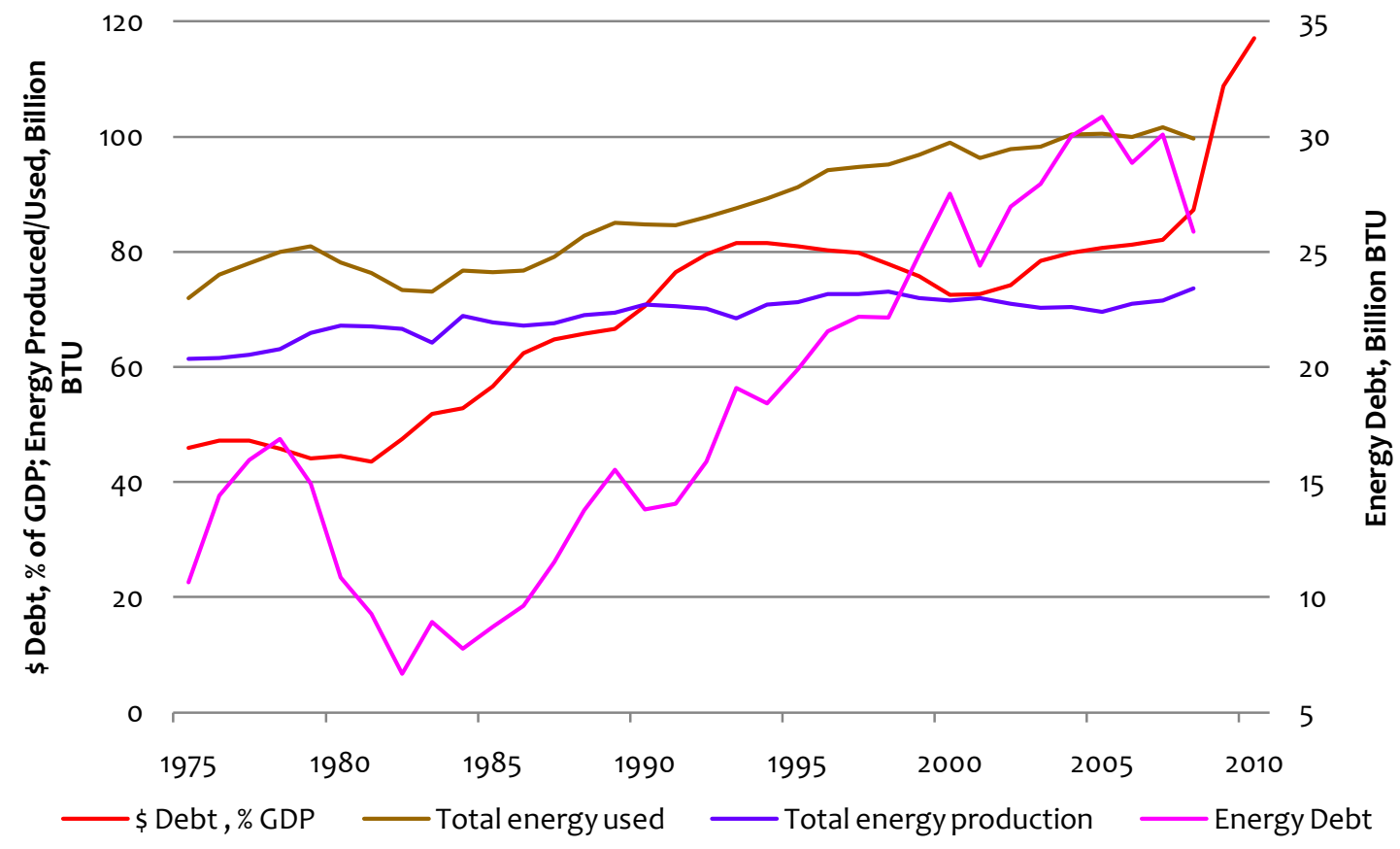

Source: US EIA, 2008; Chantrill, 2009

1980 saw the first use of the term 'sustainable development', in the IUCN (1980) World Conservation Strategy: Living Resources Conservation for Sustainable Development. The definition contained in the Strategy was remarkably similar to what appeared seven years later in the Brundtland definition: "the management of human use of the biosphere so that it may yield the greatest sustainable benefit to present and future generations" (Dresner, 2002). The report aimed for the "greatest good to the greatest number for the longest time", as Pinchot (1998) put it, and appeared to sanction development so long as the environment was respected. It was, 
however, written by environmentalists from developed countries with a strong bottom line of conservation, and thus lost favour with the development lobby and agencies seeking to eliminate third world poverty through development. Since the Strategy did not specify how 'sustainable development' was to be achieved it failed to be economically and politically persuasive, leaving this to the World Commission on Environment and Development and the Brundtland Report of 1987 (Dresner, 2002).

Up to the Brundtland Report, the sustainability debate consisted of two major opposing factions. Environmentalism grew from small beginnings with voices such as Malthus, Muir, Pinchot and Leopold. Its influence gradually spread with more voices added and increasing environmental impacts for them to decry. The development faction supported growth, progress and improved lifestyles. Its main strength lay in wealthy western countries, but was bolstered by the poor countries wanting to catch up with comfortable western lifestyles. The debate ebbed and flowed. The growth and progress faction had the weight of history, genetics, and religion to support it. Conversely, the environmental cause was on a rising trajectory and had increasingly frequent and stark evidence to support it. Either one side or the other would have to give way as their interests crossed, or an answer that fitted the goals of both would need to be found. It was up to the Brundtland Report of 1987 to provide that apparent answer.

\subsubsection{Brundtland and Other Guides}

\subsubsection{The Brundtland Report}

The best-known definition, and the one that finally brought the concept of sustainable development into wide circulation, is the Brundtland (1987) definition:

\section{Development that meets the needs of the present without compromising the ability of future generations to meet their own needs.}

But how useful is it as the basis for a functional definition, which can be put into everyday use? 
Dresner (2002) notes that the simplicity and vagueness of the definition are its strength. By not being tightly worded it avoids alienating the major players in the sustainability debate: environmentalists, and growth proponents. As well as avoiding alienating the major lobbies, it promises something for everyone. It promises that development can continue. It promises that the needs of the poor can be met, which was a major obstacle in earlier negotiations, when the poor countries resisted being saddled with second-class status. It also promises environmental protection; a necessity if natural capital is to be maintained for the provision of needs into the future.

The simplicity and vagueness are, however, a weakness too. How could credibility be given to a definition that makes no mention of the way that its ideals might be reached? How was it to avoid having any or all agendas hung on its vague framework, which suited one interest group or another? What means did it contain of arbitrating between conflicting agendas?

O'Riordan (1988) criticises the vagueness of the Brundtland definition, and that the term sustainable development tends to give primacy to development over sustainability. This latter point certainly appears to be the case when one considers that providing for the needs of today's living occurs temporally ahead of future needs, and that future generations have no voice or vote. The Brundtland definition of sustainable development has predictably, then, been criticised not just for being vague, but for being linked with the growth agenda.

Despite the vagueness criticism, when the Brundtland report is examined beyond the well-known single sentence definition, it shows a concern for meeting basic human needs, and for recognising environmental limits. An important aspect of the report is its emphasis on the necessity of providing both intra-generational and intergenerational equality. It is the notion of equity that is used to unify the various strategies. 
The "strategic imperatives" listed in the report are:

- $\quad$ Reviving growth

- Changing the quality of growth ('decoupling' it from environmental impact)

- Meeting the essential needs for jobs, food, energy, water and sanitation

- $\quad$ Ensuring a sustainable level of population

- Conserving and enhancing the resource base

- $\quad$ Reorienting technology and managing risk; and

- Merging environment and economics in decision-making.

This list indeed shows a strong emphasis on growth. Desai, an architect of the Brundtland definition, who, when explaining the history of the inclusion of the 'development' aspect of 'sustainable development', pointed out that environmental controls were seen at the time as putting at risk the attainment of the basic needs of the world's poor (Dresner, 2002). The report itself states that the "key concepts" contained in the definition are "the concept of needs, in particular the essential needs of the world's poor, to which overriding priority [i.e. ahead of environmental concerns] must be given; and the idea of limitations...on the environment's ability to meet present and future needs".

The Brundtland report not only seeks to eliminate poverty, but has an aim to extend "to all the opportunity to fulfil their aspirations for a better life". This holds out the promise to poor countries of achieving first world living standards. It appears to be emphasising present needs ahead of future needs, as occurring in the well-known definition of sustainable development which opens chapter two of the report. Much is made of the elimination of poverty. Desai (2002), scrutinising the report says,

If you look carefully at that chapter of Brundtland which talks about sustainable development, and look also at the fine print in it, not just the famous definition which everybody comes up with...you will see that it is an attempt at talking in terms of redirecting development and growth, rather than stopping it. 
The Brundtland report can be distilled slightly differently than its own list of seven strategic imperatives indicates. Davison (2001) re-interprets the strategic imperatives, as they are contained in the report, into slightly different categories, with an emphasis on:

- The elimination of poverty and meeting basic needs

- Fulfilment of aspirations to a better life

- $\quad$ Renewed economic growth (to achieve the above aims)

- $\quad$ Equity within and between generations

- $\quad$ Effective democracy

- Adjustment of affluent lifestyles to the planet's means

- Population in harmony with the productivity of the ecosystem

- Human endeavour consistent with future and present needs.

In this interpretation, growth, equity and the elimination of poverty are again the apparent priorities of Brundtland. Adjusting lifestyles to immediate problems of ecosystems is well down the list, and having thought for the future comes last, reflecting the weight it is given in the text of the report.

However they are summarised, the Brundtland list of strategic imperatives do include an unequivocal environmental caveat, even if it is not prominent. Brundtland gives a warning that "living standards that go beyond the basic minimum are sustainable only if consumption standards everywhere have regard for long term sustainability". Another passage states, "sustainable global development requires that those who are more affluent adopt life-styles within the planet's ecological means in their use of energy, for example". This sense of limitation is then tied to the varying ability of the global ecosystem: "sustainable development can only be pursued if population size and growth are in harmony with the changing productive potential of the ecosystem". Even more direct language is used: "The concept of sustainable development does imply limits...imposed by...the ability of the biosphere to absorb the effects of human activities." Another passage is equally emphatic: "But ultimate limits there are, and sustainability requires that long before these are reached, the world must ensure equitable access to constrained resources 
and reorient technological efforts to relieve the pressure". Dealing explicitly with economic growth it says: "where economic growth has led to improvements in living standards, it has sometimes been achieved in ways which are globally damaging in the long term". The report is thus quite clear that it is not just a matter of raising the living standards of the poor, but that sacrifices will need to be made by the profligate first world. Presumably for political acceptability, it was drafted in understated ways that aimed not to alarm or inflame western readers.

In the above excerpts from Brundtland (1987), 'sustainable development' is used to indicate a means of reaching a state of "long term sustainability". The difference between the two terms is thus clear from the report. The difference between the two was not spelt out in the report, however, because at that time the prevailing term was 'sustainability' which had not yet become confused with 'sustainable development'.

O'Riordan (1988) noted that the Brundtland definition gained popularity because it can be used both by the development-and-growth lobby, and by the environmental lobby. Desai (2002), interviewed about his involvement in the Brundtland Commission, identified that:

The notion of sustainable development entered the Brundtland Commission basically as an attempt to find the meeting ground from a perception which saw environmental matters essentially as matters which controlled towards a perception which saw the issue more in terms of redirecting growth.

The Brundtland report certainly includes passages that speak for both the growth and environmental lobbies. By making a bridge between the interests of both lobbies, the report, and specifically its famous definition, became a unifying banner.

Brundtland's advantage has been that it has allowed both environmentalist and development concerns to work together. Its shortcoming is that it unifies the various factions under a banner that has allowed, if not encouraged, undue emphasis on continuing to provide for current needs, without reliable means of safeguarding 
future needs. Much is written in the Brundtland report about specific environmental damage, the urgency of tackling those problems, and the short amount of time available to do so. In the nearly two intervening decades, however, environmental degradation has continued to increase. Much has been written about environmental damage besides Brundtland: a small selection of readings could include Brown (2004); Burke (2006); Emanuel (2005); Giampietro and Mayumi (1998); Goldsmith (1975, 1999); Heinberg (2007); Le Quéré et al. (2007, 2009); Lovelock (2006, 2009); and Wilson (2002). Specifically climate change related readings include those listed in Section 2.5.

What has the Brundtland definition achieved? The strength of its vagueness and promises to all has allowed it to be taken up as the pre-eminent reference point for sustainable development. The two competing factions of growth and environmentalism, along with the interests of the world's poor, were united under the one banner of sustainable development. Because the Brundtland definition did not alienate major environmental, business, or political interests it succeeded as much as any single effort in bringing environmental concerns into general, and certainly policy, awareness. This was no small feat.

It is worth noting that the spirit and some of the language of the Brundtland report made it into the New Zealand Resource Management Act (MfE, 1991), the principal New Zealand law for environmental management:

\section{Purpose}

(1) The purpose of this Act is to promote the sustainable management of natural and physical resources.

(2) In this Act, sustainable management means managing the use, development, and protection of natural and physical resources in a way, or at a rate, which enables people and communities to provide for their social, economic, and cultural wellbeing and for their health and safety while- 
(a) sustaining the potential of natural and physical resources (excluding minerals) to meet the reasonably foreseeable needs of future generations; and

(b) safeguarding the life-supporting capacity of air, water, soil, and ecosystems; and

(c) avoiding, remedying, or mitigating any adverse effects of activities on the environment.

The inherent conflicts in the basic Brundtland definition have to some extent been illustrated by the tensions that have emerged around the application of the RMA in New Zealand. As Birdsong (1998) has observed, while it was "cutting edge" legislation in enshrining the idea of sustainable management, the act left interpretation to the New Zealand Environment Court. This engendered ongoing controversy, not least from within the court itself which has made direct or tangential criticism of parliament for the vagueness of the wording and lack of guidance it provided. In essence, the New Zealand government did not achieve the task of making a workably precise definition of sustainable development, but left this to the courts, who have in turn found it a difficult burden when making judgments between opposing development and conservation litigants.

The weakness of the Brundtland definition's vagueness meant growth continued without there being concern, or even recognition, that it was, and is, transgressing some of the Brundtland provisions. Developers can easily point to the aspects of the report that call for increased economic growth and claim to be operating by the Brundtland prescription. The vagueness meant the report failed to grasp an opportunity to give sufficiently clear guidance for containing environmental damage. No scientific limit for sustainable activity was set, nor any indication of how such a limit might be set. There was some guidance in the report for limiting environmental damage, but it was not heavily emphasised. The result is that, with over two decades of ongoing and accelerating environmental impacts, the task of reining them in is now that much harder and less palatable. Nonetheless, the cautionary and limiting provisions of Brundtland still need to be met. 
In essence, the Brundtland definition states an ideal: a satisfactory resolution to the needs and desires of all people, present and future. The claimants it aims to satisfy include not only the protagonists in the sustainable development debate: environmentalists and growth proponents, but also the current poor, and future generations. By being framed in this way Brundtland may have brought the factions together, but it also ensured continuing debate.

\subsubsection{After Brundtland}

Some useful sustainability guides appeared before Brundtland. The notable ones, covered in Section 2.3.2, were:

- $\quad$ Ehrlich and Holdren's $I=P A T$

- Meadows' meeting of physical limits, as per Daly, followed by meeting social needs sufficiently to keep the social fabric intact

- The World Council of Churches list of social and physical requirements

- Daly's Steady State attention to carrying capacity, non-increasing throughput, and indexing of resource and sink use to natural limits or creation of renewable substitutes

- $\quad$ Pinchot's greatest good for the greatest number over the longest time.

The Brundtland report, operating under the assumption of the three-pillars of sustainability, recognised the difficulty of finding a fixed definition: "No single blueprint of sustainability will be found, as economic...social and ecological conditions differ widely". Since its release, a number of initiatives emerged that sought a sustainability solution.

The first notable result from the Brundtland report was the 1992 Rio Earth Summit. This produced several initiatives, from the United Nations Framework Convention on Climate Change (UNFCCC), forerunner to the Kyoto Protocol, to Agenda 21, a blueprint with the enormous goal of achieving sustainable development which ran into severe funding problems from the rich countries (Dresner, 2002). Other initiatives included the Convention on Biological 


\section{Diversity, the Statement on Forest Principles, the Rio Declaration on Environment and Development, and the Business Council for Sustainable Development.}

The signed conventions from Rio tended to be watered down, especially in response to US refusals to be constrained in its policy options. Rio reporters observed:

While senior officials held briefings painting the Bush Administration as pro-environment, U.S. delegates backed the status quo on one topic after another, insisting over and over that "the American life-style is not up for negotiation.” (Elmer-DeWitt, 1992)

Poor countries resisted environmentally tight agreements that restricted their development scope. Both rich and poor countries generally refused to put environmental concerns ahead of development, allowing them only to be considered an adjunct to development.

The next significant step in the quest for sustainability after the Rio Earth Summit was the 1997 Kyoto Protocol, emerging from the UNFCCC, recognising climate change as a major sustainability challenge and seeking to limit it through internationally agreed greenhouse gas $(\mathrm{GHG})$ controls. The first Conference of the Parties (COP-1) took place in 1995 in Berlin. Six more meetings, through to COP-7 in Marrakech in 2001, were needed to finalise the Kyoto rules. After US refusal to join the Protocol a number of other countries also withdrew support. Eventually sufficient were persuaded to ratify the Protocol to achieve the required goal of representing 55\% of the 1990 emissions from Annex 1 (developed) countries.

The Kyoto Protocol as it currently exists is considerably below what was wanted by the more ambitious countries, especially the Europeans. It also falls considerably short of what is needed, according to the most recent scientific studies, to halt the rise in $\mathrm{CO}_{2}$ emissions, let alone begin to reduce them, (Najam, 2003). As Dresner (2002) observes, "the extreme difficulty in reaching agreement on the very modest reductions, and the current American refusal to accept even that shows that we 
have a very long way to go to reach agreement on measures that would truly limit climate change".

The above proposals to take practical steps towards sustainability were United Nations sponsored initiatives. The following guides are notable proposals that have come from outside this 'official' mechanism.

An alternative mechanism to the Kyoto protocol to reduce greenhouse gases (GHGs), proposed to the UNFCCC before its 1992 Rio signing by Aubrey Meyer of the Global Commons Institute, is Contraction and Convergence (GCI, 2009). This proposes that emissions be reduced by the amounts, and over the period of decades, set down by the Intergovernmental Panel on Climate Change (IPCC) as being necessary to ensure climate stability. This would be achieved by the apparently democratic or "egalitarian" mechanism of all countries being allocated a per-capita emission limit (Kitzes, 2007; Anderson, 2006). To reach a target some decades hence, say 2040, global and per-capita emissions would drop annually. High emitters would buy quotas from low emitters. Clearly, it is not a proposal likely to find favour with rich, high emitting countries such as the United States and other northern states. Nonetheless, it has, to date, achieved support from the European Parliament as well as developing countries, and is seen by many as the only defensible and acceptable mechanism that might bring global emissions into line with climatic realities (GCI, 2009; Anderson 2006).

Robert (2002) formulated The Natural Step in 1989. It evolved from a recursive consultation with scientists in Sweden - a kind of Delphi solution. It stated the key conditions of sustainability to be that nature is not subject to systematically increasing:

- $\quad$ concentrations of substances extracted from the Earth's crust

- $\quad$ concentrations of substances produced by society

- degradation by physical means and, in that society

- the ability for humans to meet their needs is not systematically undermined. 
The Natural Step aims to provide for human needs, as does Brundtland, but it has a focus more on limiting impacts on the environment.

Wackernagel and Rees (1996) formulated the Ecological Footprint method whereby the area of land and water needed to sustainably support a particular population was measured. Both its food and other resource needs were calculated in hectares, along with the area needed to absorb the wastes it emitted. While there are problems of data specificity the method is powerful in focusing local attention, down to the level of households, on comparative and ultimate performance. The identification that the global footprint exceeded the total area of the Earth in about the early 1980s helped to highlight the scale of environmental problems worldwide.

\subsubsection{Summary of the Brief History}

Tracing the evolution of the terms used summarises the progression of the debate. Prior to the 1970s, concern for the environment went under the headings 'conservation', 'environmentalism' and 'ecology'. In 1972 the appearance of the term 'ecodevelopment' introduced the idea that development and environmental concerns could co-exist. The continuing development of humanity, and relief of suffering of the poor, was placed alongside protection of the environment in policy debate. This was the basis for what can summarily be called the sustainability debate, although that word had yet to enter circulation. The 'ecodevelopment' term represented the beginning of the search for a way humanity could have its cake and eat it too. In 1973 'appropriate technology' suggested a way to do this, but fell foul of poor countries' sense of injustice.

In 1974 'sustainability' appeared, with the idea of a limit and safety margins, on how much of nature could be used to satisfy human demands. The interests of human development and those of nature were both included under the original meaning of 'sustainability'. By 1977 the definition of 'sustainability' gained a clearer emphasis on natural limits. By this time the concerns of long-term human survival were accepted by all, including environmentalists, ecologists, and conservationists. 
The question became, to what extent should emphasis be given to preserving nature, and to what extent to development to alleviate human poverty and inequality? In 1980 the term 'sustainable development' made its appearance, and seemed to place equal emphasis on the environmental and development sides of the question. In 1987 Brundtland also included both sides in its 'sustainable development' definition, but was more explicit and emphatic about the human development requirements. Environmentalists, ecologists and conservationists, who could live with the term and concept of 'sustainability' because of its strong emphasis on the protection of nature, continued to favour that term, but grew sceptical about 'sustainable development'.

Development proponents gathered support from Brundtland's strong weighting on development. They also gathered support from the mainstream who adopted the notion that with diligent effort they could have the cake of undiminished natural capital and also eat that cake through development.

Confusion and debate about 'sustainable development' evolves from the inherent conflict between the two words. The confusion is added to by the term being shortened to just 'sustainability', when this was earlier a term, accepted more by environmentalists, that emphasised the limits of natural capital, contrasting with the emphasis on development within the 'sustainable development' term. Sustainability meant a long term state of nature, and humanity's use of it, being able to be sustained into the distant future.

There is thus a double density fog surrounding the meaning, use, and real-world viability of the terms 'sustainability' and 'sustainable development': firstly, the conflict between 'sustainable' and 'development' as economic strategies; and secondly, the confusion between the terms 'sustainability' and 'sustainable development'.

International strategies are unfortunately not close to achieving sustainability. As the president of the UN General Assembly noted years ago, "we face...a recession of the very political will that is essential for catalyzing real change. The visionary ambition of Agenda 21 is tempered by some damning statistics which show that we are 
heading further away from, and not towards, sustainable development" (Ismail, 1997). In 2009, at the high-level G20, political agreement and action remain elusive, while local and global environmental consequences remain negative (Watson, 2009). The sustainable/development debate is still live; if international agreement is the only way to determine what sustainability is, however, a long wait could be in store.

\subsection{Requirements for a Functional Definition of Sustainability}

A number of requirements can be distilled from the history and debate surrounding sustainability.

Over the history of the sustainability debate the strength of the two factions sustainability and development - has remained essentially consistent. On the one hand is the concern for conservation, the biosphere, and natural environment. On the other is the concern for improving the health, happiness, and equity of people. As Dresner (2002) puts it, "the debate about sustainability could be defined as the ideas that emerge when concern for the global environment and concern for global social justice meet". Neither the environmental nor (social) development factions have succeeded in gaining universal support. The struggle between the two has ebbed and flowed over decades.

It would be an easy matter to settle on a definition for sustainability by choosing a position on one side of the fence or the other. However, the reality of the globally contested view demands cognisance of both sides of the debate. In a global debate, acknowledging each side of the contest, to avoid repeated argument and inaction, is essential for a functional definition.

If there is ongoing debate about where the emphasis should be on the sustainable versus development continuum, how, then, should a conclusion be drawn? While the Brundtland definition retains the internal conflicts that have characterised the debate over decades, it does, at face value, satisfy the requirements of both sides. By utilising this strength of the Brundtland definition, and by adding some robust 
scientific certainty to the environmental side of the argument, it is possible to use the Brundtland definition in a functional way.

What would be the essential characteristics of a functional definition? (see Section 3.2.) 'Functional' implies that a definition be readily translatable into daily decision-making, and that it could be used as the basis to assess polices or practices for their sustainability. This translation into use would need to be easily done, without the need for major new research or debate, to avoid further protracted discourse and the pursuant lack of effective action.

If a clear physical limit were tied to the part of the Brundtland definition which proscribes "compromising the ability of future generations to meet their own needs" then the definition would be easily operable. Development would be able to continue, so long as it adhered to the set parameter. Within that parameter, however, development could take whatever was the most effective course. Straightforward measurement or quantification would be needed, to know if the set parameter had been reached or exceeded.

Such a limit would need to be easily understood, or it would fail to be used widely. At a scientific level, it would need clarity, to allow easy understanding and to avoid debilitating debate. To be relevant the method would need to address central environmental concerns, but also be pertinent to a wide range of environmental concerns, both for the present and the long-term future - to match the Brundtland balance of present and future generations.

These requirements for a functional definition of sustainable development are summarised and reordered for further clarity. A functional definition of sustainable development:

1. Preserves the abilities of future and present generations to meet their needs

2. Establishes a clear physical limit (beyond which is unsustainability)

3. Facilitates measurement or quantification

4. Measures by a method appropriate to the present and the long-term future 
5. Addresses the biggest concerns

6. Addresses a wide range of concerns

7. Is scientifically well founded

8. Is scientifically clear and simple

9. Is easily understood

10. Is easily translatable to daily decisions

11. Does not require major new research or debate

12. Acknowledges and accommodates conflicting interests in the sustainability debate.

\subsection{Definition of Sustainability: A Climate Change Focus}

While there are many environmental problems, there is clear guidance towards a key sustainability measure. Scientists of many disciplines are almost unanimous about the biggest challenge for sustainability, and indeed for continued human civilisation now, and in the foreseeable future. The key issue for sustainability is climate change. Climate change as the key issue is discussed in more detail in Section 4.4

The list of publications attesting to the pre-eminence of climate change as the major environmental threat is too long to list here, but a small selection includes: Le Quéré et al, 2009; Hansen et al, 2008; Fischlin et al, 2007; Parry et al, 2007; Boston, 2006; Raupach and Fraser, 2006; Schellnhuber et al, 2006; Emanuel, 2005; Knutson and Tuleya, 2004; Alley et al, 2003; Benton, 2003; O'Neill and Oppenheimer, 2002; Houghton et al, 2001; White et al, 2001; Cox et al, 2000; and Wackernagel and Silverstein, 2000.

By recognising $\mathrm{CO}_{2}$, and other $\mathrm{GHG}$ equivalents, as the cause of climate change, and thus using $\mathrm{CO}_{2}$ as the basis for a measure, a functional definition of sustainability can thus be stated:

\section{Sustainability meets the needs of the present without annual $\mathrm{CO}_{2}$ emissions exceeding what the planet can absorb.}


This definition does not specifically mention future generations, as does the Brundtland definition, but safeguards the future automatically by stipulating that what the planet can annually sustain - on an indefinite basis - is not exceeded.

Two immediate rationales for assessment and action emerge when climate change is recognised as the major sustainability issue. The first is obvious: since climate change is the major issue, outweighing others on the sustainability horizon, it is the assessment of factors that contribute to, or reduce GHGs that are central to a functional definition. The measurement of $\mathrm{CO}_{2}$ and equivalent $\mathrm{GHG}$ s thus becomes a prime measure of sustainability (see Section 4.4.5).

When this method is chosen the second rationale for using $\mathrm{CO}_{2}$ as a yardstick of sustainability emerges. $\mathrm{CO}_{2}$ is a good proxy for the use of energy. Although there are some complicating factors, which will be dealt with in later chapters, $\mathrm{CO}_{2}$, as a proxy measure of energy, is thereby also a measure of activity generally, since energy is used for all human endeavours. It is the aggregate of human endeavours that puts strain on global ecosystems and natural resources generally. Broadly speaking, the more resources are consumed, the more energy is needed to do so. The more energy is obtained and utilised, the more is spent on securing and exploiting natural resources. Because of the interlinked nature of the global economy, even activities that are not $\mathrm{CO}_{2}$ emitters directly will have an impact, indirectly, on other activities that do emit $\mathrm{CO}_{2}$. There have been improvements in efficiency attempting to loosen the link between energy and environmental impact, but it is still a tight connection. There are clear links at the macro scale between energy, economy, consumption, and environmental impact (see Figure 4.2). Underlying these linkages is the tight link between energy and GHG emissions. The use of $\mathrm{CO}_{2}$ as a proxy for measuring sustainability is thus based on the largest threat - climate change, but also on another good proxy for other environmental impacts throughout the world: the procurement and use of energy. 


\subsection{Sustainability Limits: Making the Definition Functional}

Even when $\mathrm{CO}_{2}$ emissions are made central in defining sustainability, the definition remains merely aspirational and non-functional, unless a limit on $\mathrm{CO}_{2}$ emissions is defined. Without such a limit no activity can be determined as either sustainable or unsustainable, meaning the definition is not applicable to daily decision making. The definition available from Brundtland and other sustainability guides is useful here, as is climate science.

Climate science is increasingly clear about the extent of $\mathrm{CO}_{2}$ reductions needed to avoid serious climate change (Hansen, 2008). There are increasingly accurate measures of how much $\mathrm{CO}_{2}$ various global systems, such as oceans and forests, are capable of absorbing, now and into the future (Solomon, 2007). These can give clear measures of what the limits are (see Chapter 5). Current needs, as Brundtland describes them, must then fit within these limits to provide a habitable global climate for present and future generations. This is a third and crucial rationale for using $\mathrm{CO}_{2}$ as a yardstick. $\mathrm{CO}_{2}$ limits are discussed in more detail, and form the substance of Chapter 5.

\subsection{Conclusion}

This chapter has used the history of the sustainable development debate as a guide to what sustainability is, and to a functional definition. A preliminary case has been made for climate change in general, and $\mathrm{CO}_{2}$ emissions in particular, as the basis for both a definition of sustainability and for a way to measure the sustainability of any activity. Chapter 3 will examine the requirements of sustainability indicators in more detail, and how the above list withstands further scrutiny. It will then discuss some sustainability indicator methods that are in circulation, and their effectiveness for assessing sustainability. Chapter 4 will discuss some poorly understood impediments to the effective application of sustainability indicators, and make a detailed case for two effective and available means of measuring sustainability, which are then discussed in detail in Chapter 5. 


\section{$3 \quad$ Measuring Sustainability: Assessing Indicators and Their Requirements}

Sustainability is a systems level concept and not an organisational one.

- Markus Milne and Amanda Ball, 2005

\subsection{Introduction}

In Chapter 2, the debate around sustainable development was discussed to discover what sustainability was and to distil what might be needed in a functional definition and measurement method. The knowledge gap includes the particular requirements for a functional definition. To address that gap, this chapter extends analysis of the list of requirements from Chapter 2, by comparing them with requirements elaborated by some of the few authors in this field. After this examination, some of the more widely circulated sustainability indicators are reviewed to discover if they meet the identified requirements.

Paris and Kates (2003) observe that "proponents of sustainable development differ in their emphases on what is to be sustained, what is to be developed, how to link environment and development, and for how long a time". This lack of agreement is a result of the conceptual fog surrounding the understanding of sustainability and sustainable development discussed in Chapter 2. Paris and Kates further note that "despite the persistent definitional ambiguities associated with sustainable development, much work (over 500 efforts) has been devoted to developing quantitative indicators of sustainable development". Although there is a predictable confusion of intentions and outcomes of this sustainability indicator effort, some methods are gaining currency, while others languish.

Material Flow Accounting, the Sustainability Index, Triple Bottom Line, Index of Sustainable Economic Welfare and Genuine Progress Indicator, and The Natural Step are also briefly reviewed for their ability to meet the identified requirements, and for any potential contribution to a functional definition of, and guide to reaching, sustainability. An important characteristic sought when reviewing the sustainability indicators is an absolute versus comparative measure of sustainability. 
Finally, three indicators that offer at least some form of measurement of sustainability are assessed against the list of requirements. These are Ecological Footprint, Life Cycle Assessment, and Emergy.

Chapter 4 will continue the assessment of sustainability indicators. It includes an examination of two methods that, according to the list of requirements, are best able to indicate how far from sustainability any particular action, project, organisation, or country is. These two methods are discussed in detail in Chapter 5

\subsection{Requirements of Sustainability Indicators}

Ways of measuring sustainability have been proposed since its emergence as a concept in the 1970s. Even before the term sustainability came into general circulation, ways of determining environmental impact were being explored. Without a clear definition of sustainability, however, many of them fail some of the basic requirements listed in Section 2.4.

The fog of misunderstanding around the meaning and use of the terms sustainability and sustainable development has been transmitted to the selection and application of indicators or measures of sustainability. Several indicators in common use track the state of a number of environmental parameters. Unfortunately, these parameters are frequently given no weighting, even relative to each other. They are even less frequently related to specific or final measures of sustainability. Less common still is the attempt to specify on what basis the indicators are or should be selected, or what they are to be used for.

Analysis of the requirements for sustainability indicators is sparse in the literature. This may be as a result of the sudden realisation of the sustainability problem, and its scale. The sense of urgency that results from realisation of the scale and implications of environmental impacts appears to encourage both practitioners and the lay public to take action quickly, of whatever type seems initially appropriate. Perhaps in the minds of many the sense of urgency elevates the need for action above the need to identify what the actions should be; scrutiny of the worth of sustainability efforts or indicators becomes secondary. Such analysis is needed, however, in order to know if, 
or to what extent, efforts towards sustainability under different models are likely to be effective. The requirements for a functional definition of sustainability (Section 2.4) are relevant both to the measuring of sustainability and to the assessment of sustainability indicators.

Many indicators are essentially comparative. This point is made by van Kooten and Bulte (2000) who observes that:

Measurement is at best a relative exercise. The history of science indicates that the 'naturalness' of natural numbers depends as much on the cultural milieu as on 'science', which itself is affected by culture. What is true for the physical sciences is certainly truer for the biological and social sciences.

Cole (2006a) makes a similar observation when discussing sustainability measurement of buildings:

Almost all assessment methods evaluate the building's environmental performance by scoring improvements relative to typical practice...Assessments would logically be made of the extent of the progress that the building performance has made toward a declared, sustainable condition.

For Cole, the relative performance criteria fall within a 'green' perspective, whereas absolute assessment is part of 'sustainable' building.

In Section 2.4 the requirements for a functional definition and sustainability measurement method were discussed. The various points were assembled into a list of requirements of a functional definition of sustainability. Since the requirements are for a functional definition of sustainability, they are also applicable to sustainability indicators and measures - a means by which a definition is applied. Working from a functional definition of sustainability, a sustainability measurement method or indicator: 
1. Preserves the abilities of future and present generations to meet their needs

2. Establishes a clear physical limit (beyond which is unsustainability)

3. Facilitates measurement or quantification

4. Measures by a method appropriate to both the present and the long-term future

5. Addresses the biggest concerns

6. Addresses a wide range of concerns

7. Is scientifically well founded

8. Is scientifically clear and simple

9. Is easily understood

10. Is easily translatable to daily decisions

11. Does not require major new research

12. Acknowledges and accommodates conflicting interests in the sustainability debate.

Park (2005), Hecht (2005), an OECD (2004) paper, and van den Bergh and Verbruggen (1999) are among the few authors in this field. Their analyses are closely congruent with the list above.

Park (2005) lists the "three basic functions of indicators" as:

- $\quad$ Simplification

- Quantification

- Communication.

"Indicators generally simplify in order to make complex phenomena quantifiable so that information can be communicated." The functions of simplification and communication are addressed by requirements $2,8,9$, and 10 , to:

- $\quad$ set a clear physical limit

- $\quad$ be scientifically clear and simple

- $\quad$ be easily understood

- be easily translated into daily decision making. 
The quantification function is explicitly covered by requirements 2 and 3, to:

- $\quad$ set a clear physical limit

- measure or quantify.

The OECD (2004) discussion, on the selection criteria of environmental indicators, lists:

- $\quad$ policy relevance

- analytical soundness

- measurability.

Policy relevance is linked to:

- $\quad$ major challenges for the first decade of the 21 st century.

The importance of policy relevance is that without it the chance of any sustainability measurement method being translated into daily decisions is small. The policy relevance criterion is addressed by requirements 1, 2, 5, 6, 10 and 12, to:

- $\quad$ preserve the abilities of future generations to meet their needs (which is the overall policy aim)

- $\quad$ set a clear limit

- $\quad$ address the biggest concerns

- $\quad$ address a wide range of concerns

- $\quad$ be easily translatable to daily decision making

- acknowledge and account for conflicting interests (so ensuring policy acceptability and robustness).

The analytical soundness criterion is addressed by requirement 7 , to:

- $\quad$ be scientifically well founded.

The measurability criterion is addressed by requirements 2,3 and 8 , to:

- $\quad$ set down a clear limit

- $\quad$ measure or quantify

- $\quad$ be scientifically clear and simple. 
The relevance to major challenges of the first decade of the 21 st century criterion is addressed by requirements 5,6 and 11 , to:

- $\quad$ address the biggest concerns, and

- $\quad$ address a wide range of concerns

- not require major new research.

Van den Bergh and Verbruggen (1999) discuss specific criteria for guiding a choice of sustainability indicators. These include:

- $\quad$ objectivity and scientific soundness

- relation to clear policy objectives

- clarity of interpretation and understanding for non-scientists

- $\quad$ coverage of whole systems

- $\quad$ parameter values that are stable over a long period.

Objectivity and scientific soundness are addressed by requirement 7 , to:

- $\quad$ be scientifically well founded.

Relation to policy objectives is addressed by requirements 2, 5, 6 and 10, to:

- $\quad$ set a clear limit

- $\quad$ address the biggest concerns

- $\quad$ address a wide range of concerns

- be easily translatable into daily decisions.

Clarity is addressed by requirements 8 and 9, to:

- be scientifically clear and simple

- $\quad$ be easily understood.

Coverage of whole systems is addressed by requirement 6 , to:

- $\quad$ address a wide range of concerns.

Stable parameter values is addressed by requirement 4 , for $a$ :

- $\quad$ measurement method applicable to both the present and long-term future. 
Hecht (2005) addresses the social equality aspect that frequently attaches to the sustainability debate, and is prominent in the Brundtland discussion of sustainable development. She observes that:

Many sustainability advocates argue that to be sustainable, a society must be equitable, participatory, and democratic. But inequitable and dictatorial societies have been sustained very effectively for millennia; this concept of social sustainability fails the dictionary test.

While intergenerational equity may be a goal with the same aims as sustainability, intragenerational equity is not a pre-requisite, although it may be a good concurrent ideal and may aid the pursuit of sustainability globally. It is thus not a requirement for a sustainability indicator.

Hecht goes on to comment on the possibility of a definition of sustainability involving a decision on what we want to sustain. This attribute is not covered in the requirements emerging from Chapter 2 . The attributes of a sustainability definition could include the requirement to identify what it is that is to be sustained, but this is clearly a difficult judgement to make in the absence of specific widespread debate. By observing the general sustainability debate, a conclusion may be drawn that the, usually unspoken, condition that people want to sustain is the ability of humans to stay alive, now and into the future, at something like the current standard of living and something like the current population level. While overpopulation does occasionally makes its way into the debate, means of reducing the population or allowing it to fall are seldom proffered as serious arguments. Similarly, lower standards of living are occasionally mentioned but are not widely adopted. Most commonly, the debate revolves around ways to be more efficient or clever, so that less impact might result, while our sophisticated living standard is maintained. At the least, a definition of sustainability needs to account for the realities of the population level and standard of living as they are, and their still rising trajectories. 


\subsection{Some Commonly Used Sustainability Indicators}

\subsubsection{Material Flow Accounting}

Material Flow Accounting (MFA) grew from a number of sources interested in societal and industrial metabolism. Ayres used the metabolism description in 1989, but had performed an analysis of the material flows for the American economy in 1969, and the concept was established as far back as the 1950s (Bringezu, 2000). Its notion of human society and economy as part of the biosphere means it shares a number of features with other indicator systems.

MFA is concerned with measuring the flow of materials from the environment, through the economy, including their transformation through manufacturing, physical and chemical alteration, re-use and recycling, and final disposal. Materials are measured in their naturally occurring form or their chemical or elemental form by mass. In this way flows of toxic substances can be tracked and linked to different areas of environmental damage, such as climate change, ozone depletion, eutrophication, acidification, toxic emissions to air, water and soil, etc (Bringezu). This is an essential feature that is shared with Life Cycle Assessment (LCA). MFA is also allied to embodied energy (EE) and embodied carbon dioxide $\left(\mathrm{ECO}_{2}\right)$ analysis in that energy flows, via specific fuels, are tracked from source through to environmental emissions.

With an understanding of material flows, the concept of dematerialisation can be applied. Dematerialisation is effectively a form of improved efficiency, especially ecological efficiency, whereby not just improved energy efficiency is sought for particular activities, but the quantity of material needed to achieve a particular result is reduced.

The efficiency achieved by dematerialisation, in the MFA methodology, does not, however, deal with the paradox that efficiency may increase throughput by means of lowered costs, and therefore increased accessibility, of particular materials or activities. This risk results from the absence in the MFA methodology of a specified limit for material flows (see Section 4.2). MFA is able to measure flows to ascertain 
how much improvement has been achieved, but it does not determine at what level sustainability is reached. Another significant problem for the widespread application of MFA is the amount of data that needs to be collected and analysed. This applies both at the national or international level, as well as in the application of MFA to specific projects, such as construction of a house.

\subsubsection{Sustainability Index}

Brown and Ulgiati (1997) use emergy, as developed by Odum (see Section 3.7), as the basis for their Sustainability Index (SI). The method uses the ratio of two ratios: the emergy yield ratio divided by the environmental loading ratio. This shows the "incremental yield compared to the environmental load". This is useful as a relativistic measure, to "compare different economies in order to evaluate their relative long term global sustainability", or to "compare different processes yielding the same product" (Brown and Ulgiati, 1997). It is less useful for indicating whether a particular activity, process, or material can be considered acceptable from a sustainability viewpoint.

The relevance to pressing environmental concerns as opposed to general environmental performance is not emphasised. Soundness and quantification are evident, but not in a simplified form that facilitates understanding or ease of communication and use. The method is not easily applicable to small-scale investigation and does not provide a clear limit of sustainability. The SI remains relatively obscure, especially when considered alongside other indicators that emerged at about the same time.

\subsubsection{Triple Bottom Line}

Triple Bottom Line (TBL) reporting has become a commonly admired and utilised method of sustainability assessment, even though it is a relatively new concept, coined by Elkington (1997). Elkington's work has a business bias which is reflected in the application of TBL as a preferred methodology for financial organisations, although it may be applied by others. 
Milne and Ball (2005) identify the uncertainty and green-wash that can accompany the use of the concept, with "claims to be reporting on being sustainable...actually being sustainable...[and] to be moving towards sustainability" commonly following from "narrow and often incomplete reporting practices". The three-pillar model of sustainability: economic, environmental, and social, which shares the same three areas of assessment as the TBL method, suffers from the same emphasis on economic considerations and the subsuming of environmental concerns into what is only slightly altered from a business-as-usual practice. This pre-occupation with the economic, and the common relegation of the environmental components in TBL and the three-pillar model of sustainability, has received repeated criticism (Lowe 2005; Peet, 2004).

The TBL method, as Milne and Ball (2005) point out, frequently has the effect of focusing business attention on profitable survival, or financial sustainability, as business leaders are apt to describe it, at the expense of rising costs for the social or environmental aspects of the TBL. In the comfortable belief that they are "moving towards sustainability" businesses may thus be moving society further towards un-sustainability.

Milne and Ball (2005) conclude that sustainability is "essentially a systems level concept and not an organisational one", and that "most of the way business is currently organised is along unsustainable lines". Unless a business is assessed as part of a national or international network of business of a certain type, producing part of a prescribed and finite supply of a particular product within a sustainable parameter, it is difficult to imagine how it might be measured for sustainability.

McDonough and Braungart (1998) prescribe the "closed loop" system, where the waste or end-of-life product becomes the input for some other manufacturer, as representing sustainability. There remains no guarantee, however, that such a system would be sustainable at a global level, since the sheer volume of trade and manufacture, and the energy required to undertake it, may exceed the capacity of the planet. 
As with MFA, the sustainable limit to activity remains undefined in TBL, and hence unattained. This points to the need for a globally and nationally based measure of sustainability, through which specific limits can be applied to small scale endeavours, such as house construction, and the businesses that support such endeavours.

\subsubsection{Index of Sustainable Economic Welfare and Genuine Progress Indicator}

The Index of Sustainable Economic Welfare (ISEW) is an attempt, like the Net Primary Production relative to Consumption (NPP/C) method, to improve the wellestablished Gross Domestic Product (GDP) measure of national performance by including social and environmental considerations (Castaneda, 1999). The usual GDP measure is tempered by subtractions for environmental costs, while traditionally uncounted benefits, like childcare, are included. ISEW shares the GDP minus environmental costs aspect with the NPP/C method that has been used as a sustainability measure. ISEW has a strong emphasis on social and personal health, as well as remaining strongly economically oriented. The sustainability aspects can thus easily be swamped by these other considerations. The main benefit of the method appears to be that it retains most of the familiarity that comes from GDP.

The Genuine Progress Indicator (GPI) is essentially the same as the ISEW method (Lawn, 2003). Both use a range of measures, including the dollar value of personal consumption; (in)equality of income distribution; services; costs of urban physical and social infrastructure, benefits and disbenefits; capital flows; and the cost of resource use and loss (Lawn, 2003).

By the inclusion of resource use and loss, sustainability can be measured to a certain degree. Like the ISEW and the NPP/C methods, however, GPI has a notable value and contribution to sustainability understanding, but remains comparative and unable to determine whether an activity is sustainable or not. Its most valuable contribution is to identify a threshold beyond which the additional benefits of further economic growth are exceeded by the additional costs of that growth (Lawn, 2003). It is thus useful as a macro tool for assessing where an economy is in relation to that threshold - whether a country is moving in a 'better' direction, 
which may or may not be a sustainable one - but it does not offer a sustainability measure of specific activity.

\subsubsection{The Natural Step}

The Natural Step (TNS) uses four system conditions as its basis for assessment, as listed in Section 2.3.3.2; nature is not subject to systematically increasing:

- $\quad$ concentrations of substances extracted from the Earth's crust

- $\quad$ concentrations of substances produced by society

- $\quad$ degradation by physical means

and, in that society:

- $\quad$ the ability for humans to meet their needs is not systematically undermined.

As Upham (2000) notes, the application of these general principles is compromised by the lack of specificity about concentrations of substances within or degradation of nature. Nor is there a specific assessment of what humans require to meet their needs. Upham observes, "TNS systems conditions avoid specification of damage thresholds and use a criterion of systematic progression or worsening". He further notes that TNS is a powerful persuasive and educational tool, but "is not wholly science based". Again, measurements are relative, rather than against a specific limit.

The rationale of TNS for developing a set of minimum criteria is the lack of agreement around sustainability, as discussed in Chapter 2 (Holmberg and Karlsson, 1992). Unfortunately, the set of minimum criteria do not advance the understanding of sustainability much, or go very far in defining or measuring it. The general guiding principles of TNS are useful for avoiding some obviously environmentally detrimental actions, but other detrimental actions will not necessarily be identified from a TNS analysis.

\subsection{Methods that Attempt Sustainability Measurement}

The sustainability measurement methods discussed so far are all lacking one or more of the requirements listed in Section 3.2. A frequent problem is that they do not set a limit against which sustainability can be measured. They are thus not useful as the 
basis for a functional definition of sustainability, or as means of determining if something is sustainable or not.

The following group of methods investigated, in Sections 3.4.1 to 3.4.3, all make an attempt at measurement that can be used, at least to some extent, to indicate environmental impact, if not sustainability. For this reason they can be considered superior to the methods already discussed. They still, however, need to be assessed against the requirements of Section 3.2. Ecological Footprint, Life Cycle Analysis, and Emergy are related in that they measure the flow of one or more proxies for environmental impact. Material Flow Accounting could also be considered part of this category but is applicable to making comparative measures only.

\subsubsection{Ecological Footprint}

The Ecological Footprint (EF) method was developed by Wackernagel and Rees (1996) as a sustainability indicator based on land area used by countries, regions, cities, communities, households, or individuals. All activities, and therefore impacts, are converted into a single measure: global productive hectares. The underlying assumption of $\mathrm{EF}$ is that people and communities of various types have an environmental impact by means of consumption of resources and services from nature, and the generation of wastes. Impacts are calculated not only for the actual supply of products, but for the equivalent area needed to absorb waste as well. $\mathrm{CO}_{2}$ from the burning of fossil fuels is accounted for by calculating how much forest area would be needed to absorb an equivalent amount of $\mathrm{CO}_{2}$.

Activities are aggregated into six categories of land use:

- $\quad$ fields for gardens and crops

- $\quad$ pastureland for grazing animals

- $\quad$ forests for timber and fuel wood

- $\quad$ urban area for settlement and infrastructure

- forests for $\mathrm{CO}_{2}$ absorption

- $\quad$ coastal water for catching fish. 
By converting all impacts into a common unit, it is easy to sum the impact areas. This can be done at different scales, and the result divided by the population of that area to arrive at a per-capita footprint measurement. Comparing this value to the available land for that population indicates whether or not the sustainable limit has been exceeded. The actual areas available to that population are weighted according to the average global productivity of land of the various types. If a population has a footprint that exceeds the area available to it, the implication is that it is importing flows of goods or services from outside its area, or, conversely, that it is exporting its footprint beyond its own physical limits.

Costanza (2000) places EF in its context as an aggregate indicator along with other aggregate indicators, such as GNP, ISEW and EE. Costanza observes that the value of aggregate indicators is primarily the single number they produce which can be easily apprehended by policy and other decision makers. He notes this is an essential step for making any decision, whether the final reduction to a simple comparison is done explicitly or implicitly. The downside of aggregate indicators is that much of the process is done by the analyst rather than the decision maker using the result. It may be argued, however, that the analyst is often in a better position to do this. It is also usually true that the lay user or decision maker wants a simple result and does not want to undertake analysis (see Boustead, 1999, Section 3.4.2.2). What remains important, however, is that the decision maker remains aware of the background and process by which the single number is arrived at, and the compromises, assumptions, weightings, and uncertainties that are contained within it.

Moffat (2000) describes EF limitations as being: a static analysis; ignoring technological change; ignoring flows and underground resources; ignoring equity issues; and making no policy prescriptions. He also questions area as a suitable measure.

Costanza (2000), on the other hand notes the usefulness of EF as a learning and teaching tool which "communicates easily to almost everyone... everyone understands land area as a numeraire - even those who have trouble with money or 
energy as a numeraire". Moffat (2000) calls it "a clear, unambiguous message often in an easily digested form".

One strength of EF is also a weakness: it looks at discrete regions and can thereby indicate if a country, for example, is beyond its sustainable limits. The weakness is that regions are considered by themselves as units that achieve, or exceed, sustainability. This leaves out the contribution that trade makes, where one region can viably export the excess of what it is good at producing, while importing the products of another region that it is not good at producing. As Hecht (2006) observes, "at the extreme, each individual would have to be totally self-sufficient on a discrete plot of land".

Van den Bergh and Verbruggen (1999) are harsher in their criticism of the EF. They charge that the land use allocation assumptions are a de facto weighting system that introduces anomalies. For example, "land use by infrastructure has the same weight as land use by agriculture, although designating land for road infrastructure clearly is more environmentally destructive than designating it for [agricultural uses]". On an energy and $\mathrm{CO}_{2}$ basis this is apparent: the $\mathrm{CO}_{2}$ emissions from road construction, let alone use, are significantly higher than the emissions from grain growing. They do not mention, for example, the soil loss aspect of agriculture, however, which makes it less clear that land use for roading is more destructive than for agriculture.

Herendeen (2000) draws attention to the problem of "Confounding sustainable and conventional (unsustainable) agriculture in calculating 'food land". His assumption is that sustainable agriculture would require more land, again calling into question the aggregation based EF results.

Another criticism of van den Bergh and Verbruggen (1999) is that EF "does not distinguish between sustainable and unsustainable use of land, however defined". At a macro level this may not be a major problem. At the small scale it could make it difficult to apply EF to house construction. 
Van den Bergh and Verbruggen note that multiple uses for a given piece of land are common, undermining the accounting basis of EF. Moreover, the "hypothetical rather than actual land use" undermines the usefulness of the concrete nature of the measurement unit.

Ayres (2000) calls into doubt the ability of EF to provide policy evaluation capabilities. Van den Bergh and Verbruggen (1999) charge that the information EF provides can easily be misinterpreted and can support unsustainable policy, notably the impetus to expand, to average out the severe footprint of a relatively large population in a small area. They further point out that EF "provides no new insights: it is well known that the human species threatens the environment".

Wackernagel and Rees (1996) make some claims for EF that explain some of its current popularity. These include its simplicity, transparency, intuitiveness, concrete terms, and physical criterion for measurement. As they point out, this approach "stimulates public debate, builds common understanding and suggests a framework for action".

The EF scores well on many of the requirements from the list in Section 3.2 as a result of this orientation towards the needs of general users. User's ability to pursue their interests, so long as the footprint of the project or area in question does not exceed what is available, is maintained for both the development and sustainability sides of the sustainable development debate. EF is oriented to preservation of future generations. Although the scientific basis of the method has some detractors (and many supporters), and remains under development, it is scientifically clear. The method is reasonably straight forward, using reasonably easily accessed data, and thus avoids the need for major research. The issue of climate change is included. It is sometimes argued that a number of concerns are not directly addressed by EF, such as acidification or the depletion of ores. These may be fitted into the method with further development, but at the risk of added complexity, so less general usage. There is a clear method of measurement and limit to sustainable action. It is easily understood and communicated. 
At a global level the ecological footprint required by humanity to provide its needs is adequate for many of the EF categories: the biocapacity exceeds or matches the footprint areas. One category stands out, however, as having a footprint much bigger than the available biocapacity: forest for $\mathrm{CO}_{2}$ absorption. Ayres (2000) and van den Bergh and Verbruggen (1999) observe that over half of the global EF is accounted for by energy use, and the absorption of $\mathrm{CO}_{2}$. Wackernagel (2005) quotes the global per-capita EF as 2.2 ha. Figure 3.1 shows per-capita footprints and biocapacity in hectares. Without land used for $\mathrm{CO}_{2}$ absorption, the 1.8 ha would fairly easily accommodate the 1.08 ha needed for all other activity. It is $\mathrm{CO}_{2}$ that pushes the global footprint well beyond the bio-capacity of the planet. All other impacts, as important as they are, do not, even added together, match the impact of $\mathrm{CO}_{2}$.

Figure 3.1 Per-capita Ecological Footprint versus Bio-capacity

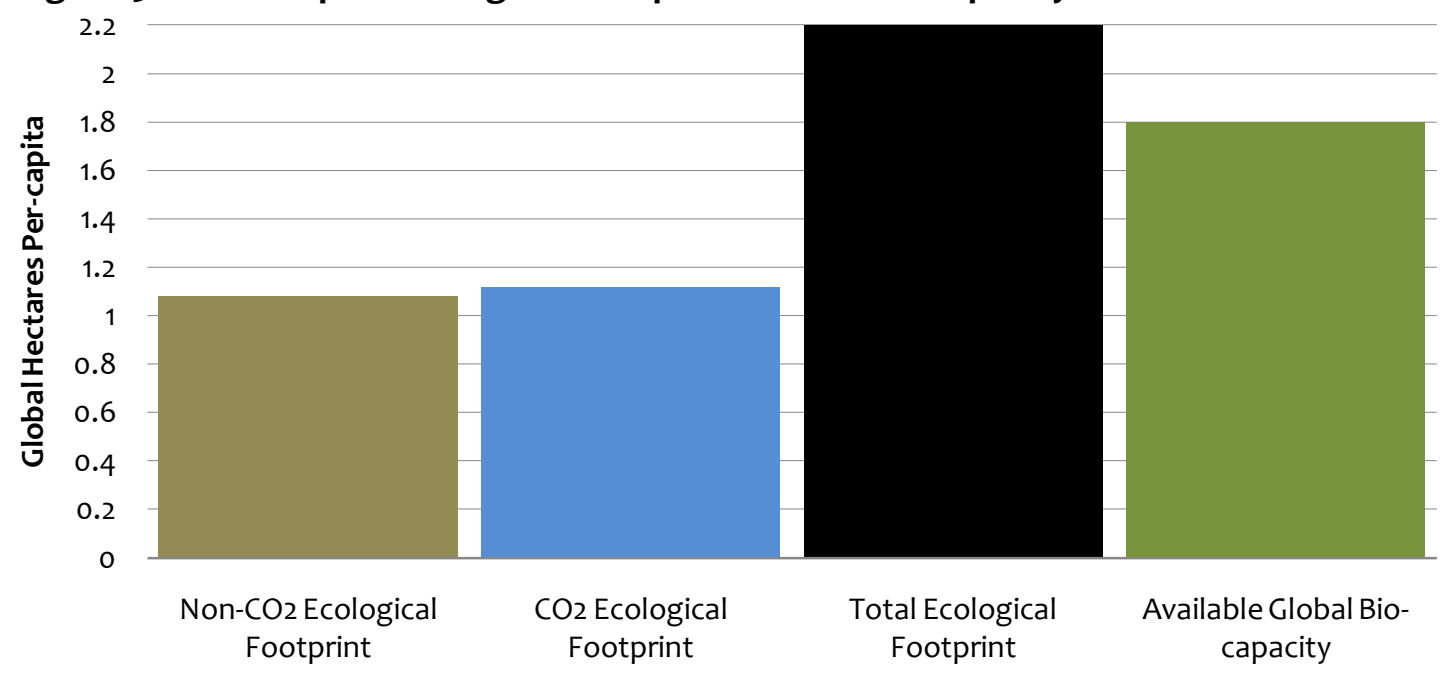

Source: Wackernagel (2005)

In being heavily weighted by $\mathrm{CO}_{2}, \mathrm{EF}$ is a de facto $\mathrm{CO}_{2}$-based indicator, but with added aggregation problems and data uncertainty. Further, Herendeen (2000) calls into question the concept of using forested land to soak up $\mathrm{CO}_{2}$, since once a forest is mature its $\mathrm{CO}_{2}$ absorption falls to almost zero. Thus, harvesting and storage of the forest timber, and replanting, is required, meaning the EF estimate for $\mathrm{CO}_{2}$ absorption area is probably too low. If $\mathrm{EF}$ were accordingly adjusted for $\mathrm{CO}_{2}$ absorption requirements, the method would be even more heavily weighted as a $\mathrm{CO}_{2}$ based indicator. The heavy weighting that $\mathrm{CO}_{2}$ has in the EF method points to the possibility of making $\mathrm{CO}_{2}$ a central aspect of a sustainability indicator and measure. 
Rees (2000) asserts that EF "resonates with the ideas of various other authors concerned with human carrying capacity". He cites Eugene Odum's lament about the heedless use by cities of their hinterlands. Natural capital accounting and the essential qualities of ecological economics are mentioned by Rees as a foundation for EF. Rees claims EF "corresponds closely to Ehrlich and Holdren's...I=PAT" (See Section 2.3.2.) Rees also asserts it is "conceptually related to the embodied energy (emergy) analysis of Howard Odum". The other connections to EF have been addressed already, or are not significant enough to require attention.

\subsubsection{Life Cycle Assessment}

Life Cycle Assessment (LCA) is the "compilation and evaluation of the inputs and outputs and the potential environmental impacts of a product system throughout its life cycle" (ISO 14040:1997). LCA is something of a hybrid environmental indicator, sharing features with MFA in its careful tracing of input ingredients and energy analysis, using energy as one measure of impact. Although the method has been evolving for some four decades, there are significant variations and evolutions still occurring in the methodology. The essential feature of LCA is that inputs, and the effects of acquiring those inputs, as well as outputs, and the ongoing effects of those outputs, are tracked far upstream and downstream, respectively. LCA attempts to genuinely be a 'cradle to grave' analysis.

\subsubsection{LCA History}

LCA emerged, along with other sustainability efforts, from the environmental awareness of the 60s, and energy shocks of the 70s. Early attempts to establish the environmental impact of manufacturing, that formed the first partial life cycle analyses, focused on energy analysis. General environmental awareness, however, also contributed, particularly around litter. Coca Cola undertook a study of beverage containers in 1966. In 1971 the Oregon Bottle Bill responded to the pollution effects of the advent of non-renewable beverage containers, especially cheap aluminium, plastic and steel items, instead of returnable glass bottles. The Bill, which required a small deposit on each beverage container, helped focus the attention of the public and industry on environmental concerns and the effects of the manufacturing process 
(Weidema, 1997; Boustead, 1999; Grant, 2002). German studies of biodegradable polymers and plastic packaging were conducted, in 1972 and 1974 (Grant, 2002).

The investigations of packaging went further than just the energy used for manufacture (Boustead, 1999). Industry began to study the life cycle of products. Packaging impacts remained a principal focus of LCA until the early 90s, however, as waste remained a very visible environmental effect.

Meanwhile, the energy crises from the 70s oil shocks faded, leaving local pollution as a principal concern. Energy use came to be seen not as a local problem, or even a problem at all per se, but only problematic in its effects. The rationale was that so long as the effects of energy use and procurement were tracked, energy itself was not needed as an impact category. This partial relegation of energy as an impact category occurred in some European applications of LCA, notably in methodology used by SimaPro software. European researchers tended to be more focused on local effects, such as acidification.

In the late 70 s and early 80 s a large Swiss Government study included investigation of acid rain, smog, soil and water nutrients, and energy (Grant, 2002; Weidema, 1997). By the 1990s attempts were being made to rate these impacts across categories. During the first conference of the Society of Environmental Toxicology and Chemistry (SETAC) in 1990, the term 'life cycle assessment' was used to reflect the attempt to put values on the disparate impacts. As SETAC was a society focused on air and water quality, it laid heavy emphasis on these categories in LCA (Boustead et al., 2000). There is, however, considerable agreement about which impact categories to use. Heijungs, (1996) lists:

- $\quad$ abiotic depletion

- $\quad$ energy depletion

- $\quad$ global warming

- $\quad \operatorname{smog}$ (summer and winter)

- $\quad$ acidification

- $\quad$ eutrophication (also referred to as nutrification) 
- $\quad$ ozone depletion

- human toxicity

- $\quad$ aquatic and terrestrial ecotoxicity.

One difficulty in gaining agreement on what to use for indicator measurements is that studies are done in unique situations for unique companies or organisations, each with their specific focus on parameters and outcomes. While the results may be of value to the organisations concerned, they are difficult to compare.

Beginning in 1997 various universities, research organisations, government departments, companies, and individuals contributed towards a common methodology, under the auspices of several SETAC conferences and working groups, to produce the ISO standards: ISO 14040 - 14049. These provide frameworks for conducting LCAs, and underlie computer software programs that facilitate analyses.

LCA is currently expanding rapidly in global use, with extensive literature including governmental and international regulation (JRC, 2009). It still retains a strong European influence, in its available data sets, and impact weightings. The European Reference Life Cycle Data System (ELCD) has evolved to the International Reference Life Cycle Data System (ILCD) initiative, seeking to harmonise life cycle data inventories and methodologies at a global level. This initiative extends and refines existing protocols through widespread international consultation, but still with a strong European input (Nebel, Alcorn and Wittstock, 2009). The global spread of LCA, as shown by the ILCD development, makes it the current leader in sustainability indicators, which is why it is given particular attention in this chapter.

In spite of its expanding application, LCA remains prey to some drawbacks that hinder other sustainability indicators, and possesses some unique to itself. 


\subsubsection{Complexity}

The complexity of LCA leads to a number of problems.

Complexity makes LCA labour intensive. Because LCA traces effects from cradle to grave, and because supply chains are routinely global, the data volume is large. Dove (2005) gives the example of a simple aluminium can of beer. The bauxite for the aluminium is mined in Australia, using globally and locally traded fossil fuels to do so, and having emissions to local air, soil, and water. The ore may be enriched in Europe, using a variety of possible energy mixes and having local emissions for the energy supply sites and regions and the enrichment site and region. Further local impacts arise from the European smelting operation, with a potentially different European energy mix. Filling of the can (and the production of the beer to go in it) happen at yet another European site, with a different set of energy and resource inputs. The beer may be marketed in North America, with another set of inputs to the marketing process. The disposal of the can will occur in America, although the recovered aluminium may be shipped to another country for re-smelting. Finally, there are the various transport types between each of the stages in the life cycle.

For even a simple can of beer a large data set results. For more complex processes, such as making and operating cars or buildings, the web of inputs and effects becomes vast. If inputs and effects are followed for long, LCA studies can effectively require modelling the whole world, at which point little simplification has been gained, as Park (2005) requires. Other indicator methods also use large quantities of data. In LCA, however, there are many different indicator categories, so the data gathering and analysis effort is multiplied.

Although LCA can be extremely precise, tracking inputs quantities in micrograms or smaller, the databases of these inputs may suffer the same aggregation problems as other data collection systems. While specific case studies may be made for different products or services, data for them often comes from aggregated process data or from databases of aggregated statistics or economic sources. Data providers, typically individual manufacturers, usually require confidentiality of supplied data, often maintained through the aggregation of data across several providers. 
Obfuscation of data sources to maintain confidentiality, along with the necessity to simplify what can be presented within dedicated software packages, results in analysis opacity, where methodology or data origins cannot be ascertained or verified. A high level of trust required for very detailed results is thus a feature of LCA.

The usual method of coping with the large data collection effort is truncation of the analysis. This is done at varying points by different analysts, however, and by different rationales, and depending on how much time, money and other resources are available. Truncation may be by different 'cut off rules, such as ignoring flows below a certain percentage of the final outcome, ignoring the flows for capital goods (the machines that make the product), or beyond a certain number of upstream steps (Grant, 2002). Without doing a complete analysis, decisions on truncation percentages can remain guesswork. Truncations of seemingly small omissions in the data can have significant effects on the final LCA result.

Because reliable and accurate data can be difficult or prohibitively expensive to obtain, or simply non-existent, poorer quality or proxy data may be used, with variable or unknown uncertainties. As well as truncation, gaps may be left in analyses to be filled with estimates based on untestable assumptions.

Because of the relatively small size of and close collaboration in the international LCA community, assumptions and methodological conventions can get widely circulated, applied, and accepted as sound, but remain without robust testing. An example is that attributional LCA (counting inputs and outputs for a process) is still the norm, with the assumption that the results provide a useful guide to sustainable action, even though a (more laborious) consequential analysis (counting the effects of a process) may show very different results (Ekvall, 2002). Conversely, relatively minor problems (in their overall sustainability significance) preoccupy analysts. A perennial debate, for example, surrounds allocation, a method to apportion specific impacts to different products or outputs, whether by physical, monetary, or other measures. 
The detail of LCA can be misleading, even for experienced users. Because of the very small amounts of traced ingredients, and the very large number of ingredients that can be traced, together with the ease-of-use and professional appearance of dedicated computer programs, it is easy to assume that the data involved in calculations is reliable, specific, and accurate. The precision of the amounts may suggest to LCA end-users that the accuracy is also high, even when a data quality grading system shows some data is lower quality.

The peer review step, within the ISO standards, adds some support to data veracity, but peer reviewers can be subject to the same potentially erroneous assumptions and errors as the original researchers and practitioners. Peer reviewers may not have the resources or time to thoroughly verify aspects of an analysis, so may look only for obvious errors.

Because of labour intensity, 'quick and dirty' LCAs are often produced, taking less specific but readily available data from other studies, or using proxy data where data specific to a process is unavailable. The net result is that LCAs may contain considerable variation in quality. Sufficient user attention is infrequently given to the reliability or accuracy of analyses. Completeness, accuracy and reliability remain problems in LCA even after many years of careful development of the method (Boustead, 1999).

Treloar (2001) finds that the ignored upstream inputs in an economic input-output table analysis can be very significant, when a typical process analysis is conducted, as with most LCAs. If the New Zealand economic input-output tables are analysed for building construction, the ignored inputs (and impacts) from wages and salaries, taxes, services (such as legal and engineering), and profits, represent approximately as much EE as the physical inputs to a building (see Section 4.3.5). Consistent with Treloar's findings, this suggests that in spite of the complexity of LCA, a large portion of upstream inputs and their associated impacts are routinely left unconsidered: real impacts are roughly double what is indicated in most LCAs. 
Because of the inherent complexity of LCA, for the results to be meaningful, a relatively high degree of detail needs to remain in the output result. This may be preferred by LCA practitioners, but it causes problems for lay people who are unable to grasp the implications of the multi-factored results. Boustead (1999) comments:

Increasingly, consumers, shareholders, customers, and designers amongst others are demanding information about the environmental implications of products and services. The problem, however, is that the volume of information needed to provide a comprehensive description of environmental performance is large. This is thought by many to be unacceptable as the results can only be interpreted by a small number of trained scientists and engineers. There is therefore a desire to simplify the results by compressing them into a single index, which essentially assigns a score to a product, or, in the extreme, an eco-label, which essentially says 'good' or 'bad'.

LCA practice has developed ways which do indeed simplify the results, down to a point where one 'score' can be compared to another 'score'. The process of simplification, however, leads to another major LCA problem: weighting.

\subsubsection{Weighting}

To achieve a single score the various impact categories need to be weighted. The impact categories considered vary with different methodologies adopted over the years. Categories have evolved slightly from those listed by Heijungs (1996). Categories in common current use are:

- Ozone layer depletion

- Heavy metals

- $\quad$ Carcinogens

- Summer smog

- Winter smog

- $\quad$ Pesticides

- $\quad$ Greenhouse gases 
- Acidification

- Eutrophication.

Other categories considered may include:

- Habitat destruction

- Desertification

- Depletion of water resources

- $\quad$ Land use

- $\quad$ Depletion of minerals.

The problems discussed in the previous section relate to the collection and management of data within each of these categories. These problems, however, remain comparatively minor next to the intractability of reaching agreement on how to weight each category.

For a process that deals with long time frames, such as buildings that last for centuries, it is impossible to know exactly what weighting to give, for example, to the effects of nuclear electricity generation. To date, the effects of radiation release for people and ecosystems can be partially assessed. It is not known, however, how much relative impact those effects will continue to have. Nor is it known how much more radiation will be released before the current, let alone future, nuclear power plants have ended their lives and been disposed of. It is thus impossible to be sure how much weighting to assign to nuclear generated electricity when considering different impact categories.

The range of options for weighting can result in quite different outcomes for the same material or process under consideration. Goedkoop and Oele (2002) observe, "A usually highly controversial issue is the weighting factor of impact categories, as this is to a large part a subjective issue". Boustead (1999) notes that:

by far the most serious problem arises with the final weighting factors. In converting a set of valuations into an index, it is necessary to assign multiplying factors, which indicate their relative importance. Assigning these weighting factors implies that it is possible to make sensible 
judgements about the relative importance of effects, such as global warming, acid rain and fossil-fuel use...It is critically important to recognise that there is no scientific way in which such value judgements can be made. These judgements are entirely subjective. [Emphasis added]

The intractable weighting problem means LCA is unable to arrive at an incontestable result. Analyses can thus be used to support almost any case, by adjusting weighting and other methodological details. As an LCA software program manual puts it, "as an LCA practitioner, you have a rather wide choice of alternative ways to perform your LCA" (Goedkoop and Oele, 2002). There is large scope for extensive argument over results.

Because of its complexity, LCA is open to manipulation and deliberate obfuscation. Boustead (1999) observes that "Eco-indices and eco-labels already exist and are in use. This does not however imply that they have any meaning nor does it mean that they cannot be misleading." Because of the subjective nature of the weighting step, it can be used to support unsustainable practices.

Boustead (1999) makes the case for treating separate environmental problems separately:

Keeping environmental objectives separate facilitates solutions on two fronts. First, each problem is addressed rigorously without modifying the original scientific data. This allows a designer to know the exact measure of the environmental problem. Secondly, it avoids making inaccurate decisions. Because there are numerous types of environmental issues associated with a production system, it is unlikely that any one design will simultaneously provide a solution to all environmental problems. More often than not, there are tradeoffs. As one factor is lowered (e.g. $\mathrm{CO}_{2}$ ), another may be increased (e.g. solid wastes).

The weightings used in the indicator methods within the LCA computer programs reflect a Eurocentric view. They also reflect the fact that LCA was developed before climate change emerged as the pre-eminent environmental problem. It could be that 
if $\mathrm{CO}_{2}$ was given a weighting that reflects its current position as by far the most pressing environmental threat, it would far outweigh the other categories in an LCA analysis. In that case, it would be simpler and more effective to use a $\mathrm{CO}_{2}$ based indicator directly.

\subsubsection{LCA: Suitability as a Sustainability Indicator}

For all its complexity and refinement, and its measurements in a number of 'sustainability' categories, LCA is ultimately unable to say if we are operating in a sustainable way or not. At best it allows comparisons between two alternative processes to indicate which might be preferable, given a certain choice around various important considerations. It can show if one process will cause more acidification, or if another will cause more smog. If a choice is made (and within current LCA methodology it must remain at a personal judgment level) to value acidification highly, then the result may indicate which process is better. The progress towards sustainability is not indicated, however, nor when the point of sustainability is reached.

While objections such as Boustead's have been made for many years, LCA is gaining in popularity. This rise appears to reflect increasing concern about environmental impacts, but even more, the (comparative) ease of application of this analysis method via dedicated computer software, Understanding and resolution of the problems associated with LCA is generally given a low priority. Understanding sustainability is likewise subservient to the enthusiastic uptake of a method that is gaining general recognition, and can make encouraging promises, even if they are illusory.

LCA is good at measuring, albeit with considerable effort and a complex result that requires skilled interpretation. It thus fails the 'clear and simple' requirement for sustainability indicators. If it is simplified to a single or a few indices to make it easily understood, it fails the good 'scientific foundation' requirement, as Boustead notes above. It is biased towards current needs, containing no method to apportion impacts between the present and future. The biggest concerns are not currently reflected by adequate weighting, awaiting a suitable scientific basis. A large and 
ongoing amount of research is needed to make LCA usable for daily decision making. If LCA problems could be resolved, it is potentially fair towards both sides of the sustainability debate. The principal stumbling block, however, is that LCA offers no sustainability limit and thus cannot say how close an action, product or service is to sustainability: it remains a comparative measure. LCA thus has inbuilt barriers to being a good sustainability indicator.

\subsubsection{Emergy}

Environmental analysis and ways of measuring environmental impact began in the 1960s and 1970s in response to growing environmental awareness and following the oil shocks of the 70s and the literature that appeared, increasingly frequently, about environmental damage and dangers. (Carson, 1962; Boulding, 1966; Ehrlich, 1968; Odum, 1971; Herendeen, 1972; Meadows, 1972; Odum and Odum, 1976; Boustead, 1979; Grant, 2002) The oil shocks of 1973 and 1979 focused attention on energy supply. Energy became the central issue to be grappled with. Mostly this was a concern about the lack of energy in relation to demand, both present and future. Efficiency of energy use became, and still is, a preoccupation in many fields, including buildings. However, energy also became a measure of human activity in the environment, and therefore a measure of damage. Howard Odum was the early leader in this field, with his publications in the 1970s (Odum, 1971; Odum and Odum, 1976). Indeed, as Cleveland et al. (2000) acknowledge, Odum established the foundations of several areas of research which "are key concepts of the analysis of sustainability in a variety of disciplines". These included "energy... [and] material flows, feedbacks, hierarchies, thresholds, [and] time lags".

Emergy was referred to by Scienceman, who coined the term, as energy memory (Brown and Herendeen, 1996). It is measured as accumulated or embodied solar energy, or solar emergy, to imply the memory of the solar inputs, with units of solar emjoules (sej). Like embodied energy, emergy is the sum of all upstream contributions, but counted all the way back to solar inputs. Brown (Brown and Herendeen, 1996) defines the "maximum emergy principle" thus: "Systems that will prevail in competition with others, develop the most useful work with inflowing emergy sources by reinforcing productive processes and overcoming limitations 
through system organization”. Brown also describes the maximum emergy principle as a "system of value that is donor based rather than receiver based. By this we mean that the value of something is derived from how much goes into it rather than how much one is willing to pay for it" (Brown and Herendeen). The word emergy is also used, without the solar aspect, to mean embodied energy. The potential for confusion is apparent.

Cleveland et al. (2000) make a number of criticisms of emergy methodology. These include that it is one dimensional, being based on units of solar or geothermal energy. The degree of change from the original solar energy is described by Odum as the transformity of the resultant energy source. Transformity is equivalent to energy intensity in EE analysis terms (Brown and Herendeen, 1996). Brown, an emergy analyst, concedes that the transformity of a material may vary, given different production processes. To avoid the time consuming aspect of calculating the transformity for each process under consideration, as well as the energy content, average transformities are used. This introduces a significant degree of aggregation, uncertainty, and inaccuracy.

Cleveland et al. (2000) contend that transformity is not an important measure, and that the usefulness of a particular form of energy is unrelated to its transformity. Oil, for example, is useful because of its high energy density, easy handling in a liquid form, and ready transportability.

Emergy analysis produces a result that is analytically interesting, but does not reflect the amount of damage that the provision and use of a particular energy source entails. Brown and Herendeen (1996) refer to the different 'transformities' of shrimp produced by different methods. The method with the lowest solar emjoules per Joule $(\mathrm{sej} / \mathrm{J})$ is by the "artisanal" fishing technique (4.0E6 sej/J), followed by the mechanised "Mexican fishing fleet" method (13.0E6 sej/J), while pond grown shrimp in Ecuador require $18.9 \mathrm{sej} / \mathrm{J}$. This would suggest that the first fishing method is preferable, but this emergy analysis says nothing about the environmental impact of a large fleet of shrimp boats on the ecology of the oceans, whereas the apparently most deleterious pond method leaves the oceanic food chain untouched. 
Brown and Herendeen (1996) criticise emergy as a labour intensive analytical technique, made more so by the inclusion of human labour inputs to the manufacturing process in the calculations.

To derive solar emergy of a resource or commodity, it is necessary to trace back through all the resources and energy that are used to produce it and express them in the amount of solar energy that went into their production.

Another criticism of emergy is that the methodology is internally inconsistent, where it claims energy quality to be directly correlated with emergy, whereas the same form of energy, coal for example, might have varying emergy. Cleveland et al's criticism that is most pertinent to assessing emergy as a viable sustainability measure is that it relies on a long series of calculations, with varying data quality. Within these calculations arbitrary conversion efficiencies are assumed for particular energy sources.

Emergy analysis, with its maximum emergy principle that promotes the maximisation of useful work for a given input of solar emergy, takes a long-term holistic view of the world, and humanity's place in it. It thus makes an overall larger attempt to model energy flows within the biosphere. This goal, however, is not necessarily useful to the attempt to understand and measure sustainability. In addition, emergy analysis remains prey to subjectivity, since, as Brown and Herendeen (1996) note, "useful work", a term with no agreed definition, is used to explain the principle.

Considering emergy as a sustainability measure, the impacts that affect different parts of the natural environment are not well correlated with the total solar insolation necessary to provide the inputs to the activities that cause the environmental impacts. Conversely, the energy that is utilised for various activities, and the work it does, is well correlated with adverse environmental impacts. 
Emergy analysis does provide a measure of sustainability. The emergy measure is relevant across wide time spans, and addresses a wide variety of environmental concerns, from a robust scientific foundation. It fails, however, to meet the majority of the listed requirements for a functional definition of sustainability.

\subsection{Summary}

Scrutiny shows the checklist of requirements for a functional definition and measurement method for sustainability is robust. Using the checklist, some sustainable indicators can be dismissed as failing at least one important criterion. The Ecological Footprint, Life Cycle Assessment, and Emergy methods all have potential as indicators, but also fall short of the full list of requirements. In particular they, like all the indicators discussed, fail to identify when one or a series of actions reaches, or exceeds, what can be considered sustainable.

One method that almost meets the full list of requirements, and another that does meet all requirements, have not been included in this chapter, because they deserve careful examination and therefore their own chapter. They are Embodied Energy Analysis and Embodied $\mathrm{CO}_{2}$ Analysis. They are discussed in Chapters 4 and 5 . 


\section{$4 \quad$ Measuring Sustainability: Effective Methods}

When we try to pick out anything by itself, we find it hitched to everything else in the Universe.

- John Muir

\subsection{Introduction}

Familiar methods of measuring sustainability, as discussed in Chapter 3, are deficient in at least one significant aspect. They have a common inability to simultaneously and adequately address the biggest and widest-ranging concerns. None of them are easily understood by lay people for application to daily decisions. None of them sets a clear limit that sustainable actions must not exceed. Assessed against the requirements of Chapter 2, they are deficient as sustainability measures. Sections 4.3 and 4.4 make the case for energy and $\mathrm{CO}_{2}$ analysis, respectively, as the best tools available for assessing sustainability. Before they are discussed, however, Section 4.2 explores a large and important caveat: without understanding Jevons' Paradox, both energy and $\mathrm{CO}_{2}$ analysis are subject to the same trap as all measurement methods that aim to reduce environmental impact through reduced resource use. Specific means of determining a clear sustainability limit are addressed in Chapter 5, while the detail of conducting $\mathrm{EE}$ and $\mathrm{ECO}_{2}$ analyses constitute Chapters 6 and 7, respectively.

\subsection{Jevons' Paradox}

A prime response to climate change and resource depletion, especially energy, has been the aim to use less energy. If energy is linked to environmental damage, and more energy use means more damage, surely using less energy will mean less damage? The term "eco-efficiency" and the slogan "reduce, re-use, recycle" tie together the notions of being ecologically 'friendly', and being efficient with energy or other resource use. Efficiency has become the cornerstone of attempts to reduce environmental damage. The logic is that if resource use is reduced at the micro level, it will also have a beneficial macro effect. The fact that efficiency may not promote ecological well-being or resource preservation, however, has been pointed out for at least 140 years, starting with Jevons, and has received recent re- 
examination (in restricted scientific circles) (Alcott, 2005; Dahmus and Gutowski, 2005; Grönkvist, 2005; Jollands, 2003; Binswanger, 2001; Greening and Greene, 2000; Herring, 2000, 1998; Saunders, 1992; Khazzoom, 1980; Jevons, 1865). After decades as a holy grail of the environmental movement, it is difficult, especially in policy circles, to challenge the pursuit of efficiency as an effective environmental strategy.

The economist William Stanley Jevons postulated what became known as The Jevons Paradox or Jevons' Paradox in 1865, after observing the effects of and debate surrounding the growing use of coal. Jevons' Paradox holds that as improving technology increases the efficiency of energy or other resource use, total demand for and hence consumption of the resource increases, rather than declines.

The effect on resource use of enhanced efficiency is that the system simply expands until it reaches some other limiting factor. In the process of expansion the system draws in more resources of all sorts. Similarly, by effectively increasing energy supply through greater efficiency, and hence effectively reducing the cost of energy, the system expands to a limiting factor. It simultaneously uses more of all the other resources it needs to expand, plus some others that become available only when energy is cheap. The overall result is a multiplier effect which converts the addition of more energy, or the improvement in energy efficiency which is equivalent, into greater consumption of all sorts, and in the process, greater environmental impact.

Jevons' Paradox has been variously known, throughout the debate around the concept, as the 'rebound', 'take back', 'boomerang', 'feedback', 'snap back', 'set back', 're-spending' or 'backfire' effect, and as the Khazzoom-Brookes postulate (Alcott, 2005, Grönkvist, 2005). Khazzoom, Brookes, and others, following Jevons, have argued the paradoxical rebound nature of efficiency, while purportedly ecologically oriented commentators, notably Lovins, Schipper, and Grubb, inter alia, maintain that efficiency reduces overall consumption (Alcott, 2005). Wackernagel and Rees, who might otherwise be thought of as proponents of efficiency in ecological footprint terms, have acknowledged the significance of Jevons' Paradox. They conclude that energy efficiency only works if efficiency gains are removed 
from circulation, perhaps by taxation which would be used for rehabilitation of natural capital (Herring, 1998).

\subsubsection{Primary Form of the Paradox}

The example used by Jevons to illustrate the paradox was specifically related to energy use. In The Coal Question Jevons (1865) noted there was a rise in coal use resulting from the improvement in energy efficiency provided by James Watt's steam engine over the inefficient Newcomen steam engine. Improving the efficiency of the technology effectively reduced the cost of the fuel, so that more people were encouraged or enabled to take up the technology, or to use more fuel. This example represents the primary or basic form of the paradox, where the improved efficiency increases fuel use, rather than the intuitively expected reduced use.

Another example of the basic form of Jevons' Paradox in action was the mandated improvement of fuel efficiency for cars in the US after the oil shocks of the 1970s and 1980s. Fuel efficiency rose, but leisure driving by Americans increased, negating the fuel efficiency gains (Giampietro and Mayumi, 1998).

Jevons' father was an iron merchant, giving Jevons first hand knowledge of the industry and the economic and energetic forces within it. Grönkvist (2005) quotes Jevons' historical example, with actual quantities for pig-iron production in Scotland. The example is still in the basic form, although a major economic effect was also produced by the efficiency improvement.

While the consumption of coal used in blast furnaces was reduced from seven to two tons of coal per ton of cast iron from 1820 to 1863, the production of pig-iron increased from 20,000 tons to $1,160,000$ tons. The consumption of coal used in Scottish blast furnaces increased by almost a factor of ten during this period when the fuel was much more efficiently used. 
Savinar (2004) uses a simple analogy to illustrate Jevons’ Paradox.

Think of our economy as a giant petroleum powered machine that turns raw materials into consumer goods which are later turned into garbage: If you remove the machine's internal inefficiencies, the extra [spare] energy is simply reinvested into the petroleum supply side of the machine. The machine then consumes petroleum [and other resources] and spits out garbage at an even faster rate.

\subsubsection{Secondary Form of the Paradox}

Savinar (2004) provides a micro-scale example of Jevons' Paradox. He posits a computer storeowner with a monthly electricity cost of $\$ 1,000$. By following several efficiency strategies, including improved insulation, lighting, and a reduced heating thermostat setting, the electricity bill is reduced to $\$ 500 /$ month. Two possible outcomes for the saved $\$ 500$ are offered by Savinar: 1) the $\$ 500$ is reinvested in the business by spending it on advertising, which increases sales, and thus the number of computers manufactured for sale, and thus the energy necessary for manufacture, transport, etc, of the computers. A resulting expansion of the overall economy, greater than the 'saved' and reinvested $\$ 500$, occurs. In outcome 2) the $\$ 500$ is banked, whereupon the bank lends it out at their usual ratio of 6 to 12 times deposits, meaning that between $\$ 3,000$ and $\$ 6,000$ is made available to other borrowers to purchase other goods and services from the general economy, thus increasing the consumption of energy and resources in the economy. Likewise, the general economy expands more than the value of the saved energy, with a resultant net increase in energy use, rather than a decrease. Other possibilities include the diverting of the $\$ 500$ to wages, shareholder dividends, lower prices, or the owner's pocket, all of which again serve to increase net consumption in the economy, and net energy consumption (Alcott, 2005).

In the example of the 'efficient' storeowner, the effects of Jevons' Paradox involve a more diffuse, but equally significant, secondary or wider-economy effect. Unlike the steam engine or internal combustion engine, the effects of the storeowners 'efficiency' measures are not repeated at all other stores throughout the economy, thereby encouraging a greater proliferation or use of computer stores. Rather, to 
produce the paradoxical increase in energy use, the 'efficient' storeowner example relies on the intermediation of money and its various uses to cause the effect.

In New Zealand the body most closely involved in energy efficiency, the Energy Efficiency and Conservation Authority (EECA), use the term "take back". A survey of their website reveals that the concept is dealt with in its basic form: when energy efficiency measures are instituted it is acknowledged that there may be some "take back" that reduces the effectiveness of the efficiency measure (EECA, 2006a; EECA, 2006b; Sheehan, 2006). The proportion of "take back" is either "deemed to be negligible", or is estimated to range from 10-30\%. The concept is not explicitly discussed in the documents that refer to it. In all cases, the effect is discussed only in its basic or primary form - within the system where efficiencies are instituted. The effects on the wider economy, such as where the saved money or energy may be spent and how these consequences may influence energy and other resource consumption, appear to be completely ignored. Such lack of analysis is by no means restricted to EECA.

An issue within the concern of EECA is household appliance efficiency. This is specifically addressed by Khazzoom (1980) who, as Alcott (2005) identifies, observed that, "changes in appliance efficiency have a price content... with increased productivity comes a decline in the effective price of commodities, and in the face of lower effective prices, demand does not remain stagnant...but tends to increase".

Alcott (2005) addresses the issue of the basic or primary effect, as used by EECA, and the secondary or economy-wide effect. The economy-wide effect compares the amount of resource that could be saved by instituting an efficiency measure, while demand remained constant, with what happens consequently, which is that consumption of the resource(s) falls, resulting in a lower or effectively lower price, thus spurring demand and more consumption.

If this demand rise is large enough more people consume more; no 'savings' really occur, and we have a paradox. The environmental efficiency strategy - lowering the ' $T$ ' factor in the $I=P A T$ equation in 
hopes of thereby lowering T' - must come to terms with this paradox, first identified as such by Jevons... Rebound analysis thus shows that holding demand constant is gratuitous. The 'savings' is theoretical only, because lower costs heighten demand (Alcott, 2005).

\subsubsection{Jevons' Paradox and Economics}

Alcott (2005) makes the observation that the reality of Jevons' model is "counter intuitive". He observes that improved energy efficiency or material efficiency (like financial or labour efficiency) may enable firms to "raise wages, increase dividends or lower prices, which leads to increased net consumption by workers, shareholders or consumers respectively". The use of more efficient technology lets the same, or more, be done for less input. This resource efficiency translates into an economic saving, which gets re-spent in the economy. The cost of the efficiency is essentially nil, apart from some altered machinery, or increased insulation, or whatever the specific efficiency may be. The resulting increased spending in the economy is thus a cost-free or debt-free injection of money to the economy (having subtracted the direct cost of the efficiency intervention). It is equivalent to the stimulus of a Keynesian multiplier (Machlup, 1939), which has its effect whether the extra money spent in the economy is from government spending (pump priming), reduced taxes, or efficiency savings.

Alcott (2005) addresses the objections of the efficiency proponents ('economy' adversaries as Jevons saw them). As well as the problem of viewing rebound merely at the micro scale, there are some historical facts that must be ignored by the efficiency proponents to maintain their case. Jevons asks what would have happened without the 'economy' of Watt's steam engine. As Alcott puts it:

The same question today is: If we assume a fuel technology frozen at Watt's thermal efficiency of about $4 \%$ - even imagining any number of institutional and factory-floor efficiency gains - is it plausible that 6 billion people would be living at today's affluence?... Both sides must explain the real rise in population-times-affluence. For this Jevons can invoke technological efficiency gains; his opponents cannot. Only if 
today's PxA is remotely possible at 'Watt' technology is the low rebound position plausible.

Arguing the price aspect, Alcott observes "no one would deny straightforward price increases lower consumption. Thus...to believe that economy [efficiency] "spares" fuel, they [Jevons opponents] must also believe that as inputs become more costly, we consume more of them."

Other objectors to Jevons' Paradox hold that the take back effect is dependent on the nature of the economy or region in which the efficiency takes place. The wealth of Britain was observed by Jevons, inter alia, to be dependent on coal (Alcott, 2005). The same wealth dependency on cheap fossil fuels is also true, however, of the entire developed world (Diamond, 2005; Heinberg, 2003; Bartlett, 2000; Price, 1995; Odum, 1976; Boulding, 1966; inter alia). Energy is wealth and money, as exemplified by the reference to oil as black gold.

In recent history, energy has meant associated $\mathrm{CO}_{2}$ emissions. Figure 4.1, charting year-on-year change, illustrates the close connection between economic and $\mathrm{CO}_{2}$ outputs and global temperature. The recessions from the 1970s and 1980s oil shocks are clearly evident, as are those in the early 1990s and around 2000. While global data for the current recession is still coming in, a similar pattern is emerging. As economic activity falls, so does fuel use. The connection between reduced fossil emissions and lowered global temperatures is less precise, because of variables such as the El NinoSouthern Oscillation (Houghton et al., 2001), but is still clearly visible. Temperature tends to lag behind emissions because of the inertia of ocean and atmosphere. 


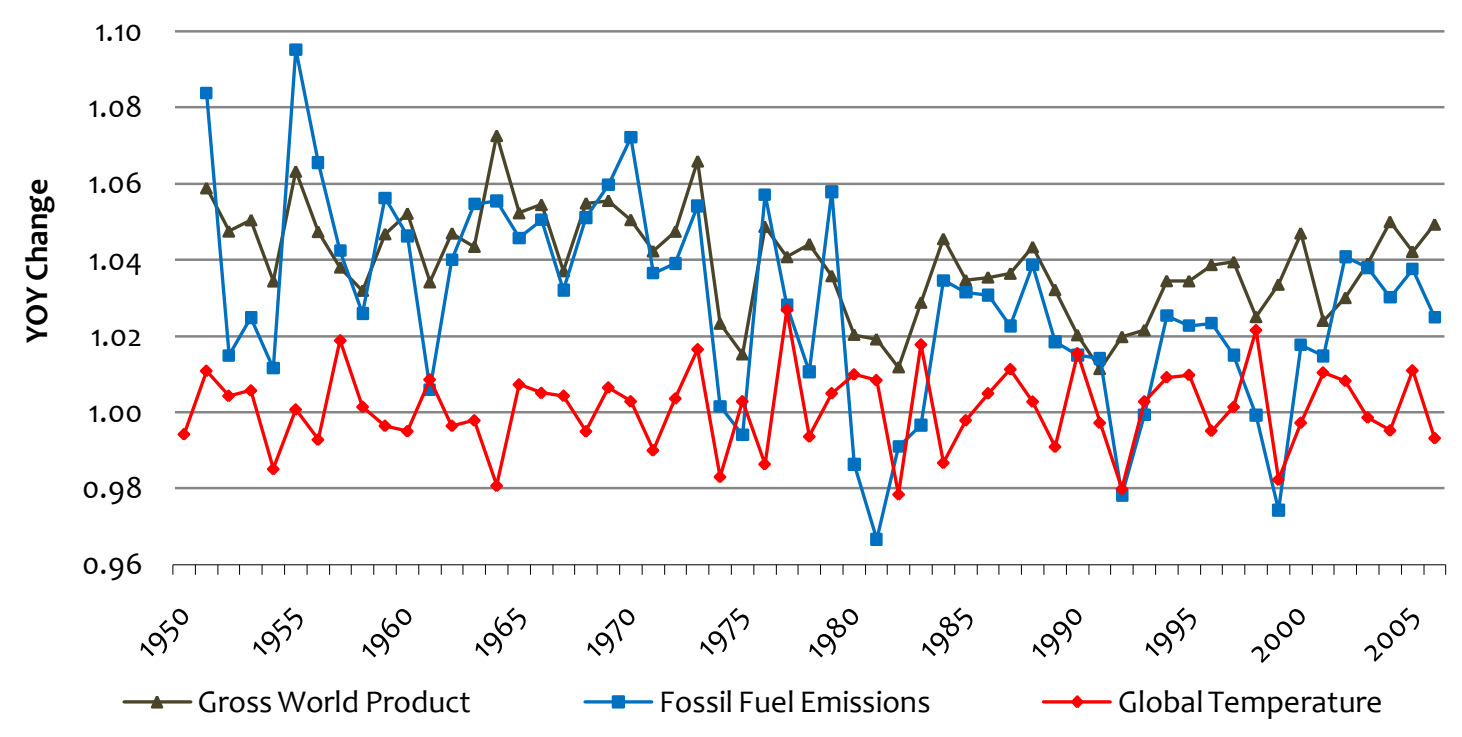

Sources: Maddison, 2003; EIA, 2006; IMF, 2006; GISS 2009

Herring (1998) quotes an economic historian uninvolved in the academic debate who agrees with Jevons:

...it is a regrettable fact that efficiency is never so complete as to lessen consumption. Economists from Jevons onwards have noted with perverse satisfaction that economy cheapens, that cheapness extends the market, and that measures of conservation or economy therefore increase, or at least do not diminish, the consumption of energy.

\subsubsection{Jevons' Paradox at the Global Scale - Boulding's Dismal Theorems}

In his foreword to a reprint of Malthus' Population: The First Essay, Boulding (1971) gives his Dismal Theorems:

\section{First Theorem: The Dismal Theorem}

If the only ultimate check on the growth of population is misery [including hunger], then the population will grow until it is miserable enough to stop its growth.

\section{Second Theorem: The Utterly Dismal Theorem}

This theorem states that any technical improvement can only relieve misery for a while, for so long as misery is the only check on 
population, the improvement will enable population to grow, and will soon enable more people to live in misery than before. The final result of improvements, therefore, is to increase the equilibrium population which is to increase the sum total of human misery.

\section{Third Theorem: The Moderately Cheerful Form of the Dismal Theorem}

Fortunately it is not too difficult to restate the Dismal Theorem in a moderately cheerful form, which states that if something else, other than misery and starvation, can be found which will keep a prosperous population in check, the population does not have to grow until it is miserable and starves, and it can be stably prosperous.

Boulding's theorems describe Jevons' Paradox in relation to population. Means of alleviating misery include increased food supply as achieved by the green revolution, or the provision of nuclear power as Lovelock (2006) supports; both are examples of efficient technologies, for producing food, or electricity, respectively. Both reduce misery "for a while", but both also facilitate population growth. The third theorem contains the idea of an external control on population, below the level of misery. Such a control has been attempted by China with their one child policy. Widely available contraception, abortion, and female education may be another effective control. (Boulding was writing at the time that cheap, safe, effective, readily available contraception was just beginning to emerge.) Boulding's theorems relate to population, but are not directly related to sustainability. A population kept in check by misery could be sustainable, or not. To address Jevons' Paradox, a limit on impact to the environment is necessary, irrespective of any interrelation with the level of population and its misery.

\subsubsection{Theoretical and Global Solutions}

Increased availability of energy could be expected to have a Keynesian multiplier effect on economic growth, resource use, and waste emissions generally. This could be expected whether the energy was from efficiency 'improvements' or new sources, such as an increase in nuclear fission or, even more so nuclear fusion (both championed by Lovelock (2006)). The resource use and emissions would be 
disproportionately larger than the scale of the new energy availability. From Ehrlich and Holdren's (1971) $I=P A T$ perspective, if the usual approach to addressing sustainability problems, reducing $T$ through efficiency 'improvements', is followed, $I$ is not reduced, as is generally assumed, but is increased because of the effectively greater available energy.

Rather than solving the current problem of energy shortage, Jevons' Paradox implies that even if the $\mathrm{CO}_{2}$ problem of energy provision were solved, any increase of energy supply would increase other resource use and waste streams. While professing to argue from a position of environmental concern, Lovelock's prescription, while potentially assisting the climate change problem, would, without any other externally imposed limits, move the world further away from, not closer to, general environmental sustainability. Climate change, currently the principal problem, if it were solved by nuclear energy, would then be replaced by some other proximate problem arising from increased consumption. The same is true for any other means by which the energy supply can be expanded, especially if cheaply so, be it by wind, solar, tidal, bio-fuel, or any combination of energy sources.

Jevons' is an apparent paradox only when local actions are conflated with effects on the wider environment. We have an expectation that what appears good at a micro level will, when expanded to the size of the economy, be good at the macro level. By acting locally, we believe we must be thinking globally. We believe any action must be better than no action, and thus that we need not analyse in detail the direction of the net effect. Such a projection from the micro to the macro is frequently erroneous, as Boulding (1986) observes. To aid our thinking, we are inclined to examine questions of efficiency in isolation, with a ceteris paribus assumption. In complex systems, such as monetary or resource economics, such simplification is inappropriate. If we bear in mind the complexities of the economy, although this is mentally demanding, the paradox disappears.

Alcott (2005) discusses some attempts, including Jevons' own ones, to resolve the paradox, but notes that it remains a theoretical riddle (sufficient to entail ongoing debate in several august journals (Saunders, 1992; Herring, 1998, 2000; Greening et 
al., 2000; Binswanger, 2001; Dahmus and Gutowski, 2005)). If, however, one is interested in sustainability and the solution of global environmental problems, rather than the theoretical debate, what is the solution to Jevons' Paradox? After comprehensively parsing the debate, Alcott concludes:

\section{Efficiency gains must be compensated for with physical caps like quotas or rationing.}

Other authors, from Khazzoom and Brookes in 1992 (Saunders, 1992), and including Herring, Greening et al. and Binswanger have made the same point (Grönkvist, 2005). Simultaneous and comprehensive global action towards efficiency across all sectors may also work, but seems even more unlikely.

Dahmus and Gutowski (2005) examine seven industrial sectors and reach a similar conclusion. They demonstrate that only in a case where there was policy intervention (a continually rising standard for refrigerator performance) was there a decrease in the sectoral energy use. This lends empirical weight to the theoretical arguments in favour of physical caps. If one is interested in sustainability, Jevons' Paradox, among other evidence, points towards a physical cap on energy use, and particularly on $\mathrm{CO}_{2}$. Energy and $\mathrm{CO}_{2}$ analysis are then critically important.

Jevons' Paradox is a crucial caveat on the use of any sustainability measurement method. It requires that measured reductions of harmful impacts be accompanied by "physical caps like quotas or rationing" if they are actually going to indicate a reduction in total global environmental impact. This caveat needs to be related to all attempts to reduce instances of energy consumption and $\mathrm{CO}_{2}$ emissions, including house construction and operation. Reducing house construction and operation energy and emissions only contributes to global sustainability if all other sectors similarly reduce emissions within a lower global emissions total or quota. Conversely, reduced energy-related emissions from housing without commensurate reductions in other sectors under a global cap would only increase net global emissions. 


\subsection{Energy Analysis}

\subsubsection{Centrality of Energy}

Whenever we do something we need and use energy to do it. In the process, our actions, however big or small, have an effect on the environment. This effect is at least local, but often global. The use of energy has an impact, but so does the process of obtaining that energy. Further, in utilising energy, we consume a wide range of resources other than energy, and these resources themselves require the provision and use of energy.

We use energy to do things. Jevons' Paradox indicates this equation works both ways: the more we do, the more energy is required; the more energy is available, the more we do. The more we do, the more damage results. By the time the end uses and effects of any particular energy source are aggregated, it is impossible to say the provision of that energy does not have negative environmental consequences. Renewable energy sources, such as hydro, wind or solar, cannot, therefore, be regarded as completely, or even nearly, environmentally benign. Because of the effects on the wider economy (see Section 4.3.4), no energy end-use can be regarded as a discrete activity, with only its own energy and environmental profile. Not only is there "little" we can do to feed the world's appetite for energy, as Mycio (2005) puts it "without doing some damage", we cannot do so at all. Everything is "hitched to everything else" (Muir, 1911), but some things are more hitched than others; energy is the central connection. It is this linkage between energy provision and use, on the one hand, and environmental damage, on the other, that makes energy analysis (EA), and closely related $\mathrm{CO}_{2}$ analysis, useful tools for gauging environmental impact.

A challenge for any sustainability indicator is the large and growing number of environmental concerns. This problem has been made more difficult by increases in knowledge over recent decades, and the consequent replacement of the apparently most significant concerns with new ones. Lowe (2000), for example, reviews the changes from 1990 to 2000 that took place in the understanding of climate change: "until recently it was not possible to state that anthropogenic climate change could be clearly detected against the background of natural variability. This situation 
appears now to have changed". Confidence in the causal link between human induced GHG emissions and climate change is now high, and widespread in the scientific community (Solomon et al., 2007). Currently, climate change appears to be by far the most significant threat (see Section 4.4.1), although other important threats, such as declining oil production, water shortage, or food scarcity, have (comparatively) recently reached common awareness; energy is linked to all of these.

Energy is not just central to human activity. Price (1995) puts energy in a global biological context: "Life on Earth is driven by energy. Autotrophs take it from solar radiation and heterotrophs take it from autotrophs." In a further comment: "exploiting a resource always requires energy", Price makes the link between energy and resource use. The converse is also true: using energy always involves resource exploitation, and not just the energy itself.

Energy is not only linked with using resources for beneficial outcomes. Whenever we produce waste of any sort it represents energy in the waste-producing process. Whenever harmful materials are emitted (gas, liquid, or solid), they represent the use of energy to derive them and are by-products of processes that also use energy: all emissions have an energy profile too. Price comments:

...the evolution of technology has meant the application of energy to a growing array of substances that can be "used to advantage". In the brief time since humans began living in cities, they have used more and more energy to exploit more and more resources.

Mycio (2005), weighing up the pros and cons of nuclear or other energy forms, notes the connection between energy provision and inevitable environmental damage:

...nuclear energy [gives] at least...a window of time for reducing our dependence on fossil fuels while pursuing research on alternative energy resources. But even those alternatives can have environmental costs. For example, to harness the energy of Ukraine's Dnieper River, Europe's third largest, over the years the Soviets transformed it into a series of 
shallow, eutrophic reservoirs where fish perish by the thousands during hot summers. Though there is probably less of a downside to wind or solar energy, it seems there is little we can do to feed the world's growing appetite for energy without doing some damage.

As Price and Mycio point out, energy is central to life's activity and to environmental damage. It is this inevitability and linkage that makes energy a good sustainability indicator. Sections 4.3.2 to 4.3.4 elaborate other aspects of the centrality of energy.

\subsubsection{Energy and Jevons' Paradox}

While the obtaining or use of energy may not in all cases cause much direct impact, energy allows a greater use of other resources and a greater application of technology, which causes more resource use and impact. Two examples from agriculture show Jevons' Paradox in action, and energy as central to global environmental impact.

The use of energy to operate efficient pumps instead of human or animal powered irrigation contributed significantly to the success of the green revolution from the middle of the 20th century. The energy used to operate the pumps was small. By comparison the increase in food output was large. More food was grown on each acre because of the technological improvement in irrigation. The increased food supply allowed a steadily growing population, using more energy in myriad ways, and more resources of all kinds. (Heinberg, 2003; Brown, 2004; Darley, 2004)

The green revolution shows another example of energy allowing the development and application of technology: synthetic fertiliser made from fossil fuels. The fuels used, as feedstock, did not directly contribute much energy, but merely contributed the chemicals to promote plant growth. This contributed to an expanded food supply, a rapid population rise in the later part of the 20th century, and a concomitant rise in energy use for the activities of that population (Diamond, 2005).

Turning the application of Jevons' Paradox upside down, a reduction of environmental impact, via a reduction in demand and throughput, is linked to an 
overall reduction in energy use, but is not necessarily linked to an improvement in energy efficiency. This is irrespective of the particular energy coefficient or energy efficiency of any individual process under consideration. Herring (2000) argues for this as a way of directly addressing $\mathrm{CO}_{2}$ emissions. If environmental impact was reduced, it would be reflected in lower total energy use; if total energy use was reduced, it would be reflected in lower environmental impact. This close correlation between energy and impact, as demonstrated in Figure 4.1, encompasses the effects of Jevons' Paradox, making energy a sustainability indicator with a wide and accurate coverage.

\subsubsection{The Maximisation of Energy Imperative}

Not only is energy central to human activity, it is central to evolutionary survival. In the natural world, any species that can effectively harness more energy than another tends to do better, other things, such as adequate food, water, soil, nutrients, and shelter, being equal. Lotka (1922) notes:

It has been pointed out by Boltzmann that the fundamental object of contention in the life-struggle, in the evolution of the organic world, is available energy. In accord with this observation is the principle that, in the struggle for existence, the advantage must go to those organisms whose energy-capturing devices are most efficient in directing available energy into channels favourable to the preservation of the species.

White (1959) made a similar argument:

- Technology is an attempt to solve the problems of survival.

- $\quad$ This attempt ultimately means capturing enough energy and diverting it for human needs.

- Societies that capture more energy and use it more efficiently have an advantage over other societies. 
Interpreting culture to mean the sum of human activity, this idea produced White's Law:

Culture evolves as the amount of energy harnessed per-c per year is increased, or as the efficiency of the instrumental means of putting the energy to work is increased.

Lotka and White both identify that it is the 'available' or 'harnessed' energy conferring the advantage. White specifically identifies efficiency having the same effect as increased energy.

The natural struggle of evolution is the story of individuals and species contriving to harness more energy, or, equivalently, minimise the cost of doing so. The individuals and species in a particular ecological area that do best are the ones that can make the best use of the conditions, including energy availability. To individual plants and animals, energy is available in the form of sunlight, or energy from geological origins, or from other plants or animals or their remains. Over time, an ecological balance occurs, given the prevailing conditions. This is the essence of Odum's maximum emergy [accumulated energy] principle:

Systems that will prevail in competition with others, develop the most useful work with inflowing emergy sources by reinforcing productive processes and overcoming limitations through system organization...If they do not maximise power, they will be selected against (Brown and Herendeen, 1996).

The same holds true for human societies in competition with each other. In contests, the successful societies, ceteris paribus, are ones that can maximise power physical, economic, or political - through the greatest amount and greatest use of energy, be it fossil, solar via fertile soil, or nuclear.

Humanity has managed to gain a large energetic advantage over other species, by utilising energy from sources other than the sun, plants, or things that eat plants. The energy sources used are principally fossil fuels. While these are derived from solar energy, they are not generally available to other species. In using this energy, 
however, humanity has disturbed the previous ecological balance. The extra energy confers competitive advantage. It enables humans to, for example, cut large areas of forest, exposing soil to depletion, or operate boats that deplete fish stocks, or operate pumps draining aquifers and waterways. The practical advantage energy confers simultaneously involves ecosystem damage.

Odum (1971) is quite clear about the link between energy and human industry, and by extension, the environmental impact that results from that industry:

Most people think that man has progressed in the modern industrial era because his knowledge and ingenuity have no limits - a dangerous partial truth. All progress is due to special power subsidies, and progress evaporates whenever and wherever they are removed. Knowledge and ingenuity are the means for applying power subsidies when they are available, and the development and retention of knowledge are also dependent on power delivery... All phenomena of the real world, and not just machines, operate according to...basic energetic principles. [Italics added]

Human history following the course of utilising newly available concentrated forms of fossil energy accords with Odum's energetic principle. The maximisation of power imperative applies generally, to machines, government regimes, and "all phenomena of the real world". The choice available to societies since the beginning of the industrial era has thus been to fall behind, or utilise more energy. Compared to the energy-use imperative, environmental damage has been a distant concern. The imperative to protect the environment is inevitably in direct competition with the imperative to maximise energy use.

Georgescu-Roegen (1977) observes that technological advances, (including efficiency) only raise living standards and thus material throughput. Energy use, and the escalating standard of living thus achieved, inevitably leads to conflict within and between social groups. According to Georgescu-Roegen, environmental damage, although unintentional, is inevitably related to energy use, and the social imperative to use it. 


\subsubsection{Energy Impacts and the Economy}

Impacts from energy use may be direct, secondary or indirect, and vary in their severity. Some detrimental effects of accessible cheap energy are related to resource depletion, such as fossil fuels or uranium. Some impacts are related to the direct effect of using energy, such as release of $\mathrm{CO}_{2}$. Some impacts are secondary, such as use of resources for equipment to burn fossil fuels, or use of resources for the activities enabled or promoted by energy, such as manufacture of construction materials. Beyond direct and secondary impacts, however, major impacts arise from the generally increased downstream activity enabled and promoted by the use of energy, which are irrespective of the particular sources or direct application of energy.

Direct energy-use effects include: energy resource depletion; acidification of soils; other emissions to soil, water and air, such as heavy metals or smog-forming chemicals; habitat loss; and climate changing greenhouse gas emissions. Secondary effects include: general resource depletion; soil, habitat and bio-diversity loss; water shortage, chemical pollution; spread of alien species; and overpopulation.

Energy end-use impacts vary in their effects. Operating an electric resistance heater, for example, has associated downstream impacts from production, installation and maintenance of the delivery infrastructure. Once electricity and the heater have been delivered, however, the use of the heater may have less environmental impact than the operation of a pump, say, to lift water from an aquifer, or using an electric lawnmower. Operating the heater merely raises the air temperature slightly; operating an electric water pump, however, lowers the water table. Many such pumps can have a long term adverse effect on ground water levels. Operating the electric lawnmower maintains the lawn, but it also encourages the use of water and herbicides to maintain the lawn.

Downstream effects, however, are significant; having readily available cheap energy in houses encourages heating in cool climates. The resulting expansion of manufacturing in turn generates more money to spend on other goods, services or 
investments. Each of these further involves the use of energy to obtain and provide the resources they use. In short, the growth of the economy is encouraged, even if the specific action, such as operating an electric heater, does not by itself cause direct environmental damage.

The easy and cheap provision of warmth fosters other downstream impacts. These include the construction of larger houses that can be readily heated, and activities that go on longer into the night because of comfortably warm conditions. Thus, more resources are used. The overall effect of one simple technology application is an expansion of the economy. The individual action cannot be considered in isolation.

Because of the intrinsic interrelatedness of the economy, it is impossible to disaggregate the myriad direct and indirect effects on the economy involved in the production and use of energy for any specific application. Because of the interrelatedness of activities, energy use, and economic activity, all energy use can be regarded as having nearly equal economic, and hence environmental, effect.

LCA was developed to keep a close track of the effects at each step of the energy provision and use chain so that they can be allocated to the relevant activity. It is not good, however, at tracing the consequences of activities. The wider economic effects of activities are almost always ignored in LCA.

Overall, a minor action at the individual level, once aggregated with other individual actions and their consequent economic and social effects, promotes a whole culture based on energy use. This creates an overall rise in energy consumption and environmental impacts. Factoring-in these economy-wide effects dilutes the specific energy intensity of a particular activity.

The interrelatedness of the economy and energy use is observable in economic input-output tables (Statistics, 2001). For the whole economy, industries pay, on average, $54 \%$ of total expenditure to other industries for goods or services needed for production activity. The other $46 \%$ of expenditure goes through wages, salaries, 
profits, taxes and capital consumption. These latter payments go directly back to the economy in a broad undifferentiated, and difficult-to-trace, way. Thus, approximately half of economic activity has a physical, and therefore energy, input that can fairly readily be traced. This energy can be counted, to show specific energy intensities for individual industries, and their products. The other half of activity cannot be readily traced. It can however, be regarded as part of general economic activity, and should be viewed as carrying the average energy intensity of the economy.

Because of interrelatedness, all activities that are part of the economy thus have a significant amount of energy associated with them irrespective of their specifically traceable energy profile. The variation of environmental impacts between different energy sources or different activities is therefore much less than indicated by the direct energy used by an activity. Energy is thus more representative of environmental impact than is apparent from initial examination.

\subsubsection{Limits to Growth}

From a political, economic or biological perspective, there is a clear imperative for the human species to maximise energy use, as discussed above. According to Brown and Herendeen (1996), this implies maximising efficiency, which equates to developing "the most useful work" with available energy. Given Jevons' Paradox, however, the maximisation of efficiency also implies an expansion of energy use, work done, resources utilised, and waste emitted. Expansion via this energy and consumption maximising principle only reaches an end, as with any species, when another limiting factor is reached.

Possible limiting factors appearing not far behind climate change, and likely to be associated with it, are limits to oil, coal, gas, water, and soil resources, plus the cycle of starvation, war and disease (Zhang et al., 2007).

Economic recession, as has recently commanded attention, is insignificant as a limiting factor, although it reduces climate impacts a little (see Figure 4.1). If complete collapse of the economy occurred, it could constitute a significant limit, as Goldsmith 
(1975, 1999) argues (see Section 2.3.2), but this is historically unprecedented. As Tainter (1988) argues, collapses of societies occur as a series of steps of reducing complexity and activity, not as sudden complete collapses. Complete economic collapse does not seem a likely candidate as an effective limiting factor.

Both principal population-limiting factors - climate change and oil depletion - are directly energy related. Addressing the climate change factor would require addressing oil (and other fossil-fuel) consumption, and thus more general environmental impacts of energy use. Thus, many other environmental problems would disappear if fossil-fuel-induced climate change problems were dealt with. The limits to growth are limits of the ability to use energy with impunity.

\subsubsection{Energy as Sustainability Indicator}

Sustainability indicators established before recent environmental concerns emerged often have difficulty accommodating these concerns while providing an accurate representation of sustainability. Many sustainability indicators are narrowly focused, so are not good at taking a general measure of sustainability. Conversely, the ubiquity of energy use connects it to both established and emerging environmental concerns. There is also a tight connection between the general and detailed uses of energy and the prime environmental impact, climate change, because nearly $90 \%$ of global energy supply is fossil-fuel based (BP, 2009).

Separating out individual instances of energy use, or any other action with environmental impacts, helps to conceptualise the problem, even if the direct and indirect impacts are traced far up and downstream. This is the approach used in LCA. It does not, however, encompass the systems-level reality of environmental impact. Simplification is a useful step for sustainability indicators when results are conveyed to lay users, but not at the conceptual level, when all influences need to be encompassed. Energy analysis (EA), as an aggregating indicator using a broad methodology such as economic input-output analysis, can be categorised with other aggregating indicators, as Costanza (2000) does, such as EF, GNP and ISEW, when its level of aggregation is at a high national or global level. When analysis is at a more detailed level, however, as with aggregation of factory data for one year, EA is also a 
finer-grained method, like LCA. Energy as a sustainability indicator accounts for the wide range of large and small inputs to activities, but provides a simple result that is easily understood by lay users.

The oil shocks of the 1970s focused attention on energy both as economically important and as an environmental indicator, as Brown and Herendeen (1996) observe:

Environmental analysts were satisfied to treat energy use as a first order indicator of overall environmental impact. In the 1980s the world oil price dropped and environmental analysts wanted a more detailed accounting of environmental impacts. In the 1990s the greenhouse implications of fossil-fuel burning have again promoted energy's use as an environmental indicator.

The interval of modest oil prices after the oil shocks allowed other environmental indicators to become established alongside, or ahead of energy but, as Boustead (2000) notes, energy is back at the forefront, especially because of its link to climate change:

Interestingly, by the late 1990s, things seem to have come full circle because there is a reawakening to the fact that energy use, the starting point for this work, is still a problem that has not gone away. Moreover, by far the greatest proportion of all air emissions arises from the production and use of fuels.

Energy is a useful measure because it reflects inputs to human activity. Easy energy has been the principal initiator of growth and environmental impact since the beginning of the industrial revolution. While at the micro level there are differences between the sources and uses of energy that cause significantly different outcomes, the scale of these differences is minimised in the wider economy because of the flow-on effects. Energy remains a key measure of environmental impact.

When measured against the sustainability indicators of Section 3.2, EA compares well. It can be used to specifically provide a measure that preserves the abilities of 
future generations to meet their needs. The scientific basis of the method is well established, clear, relatively simple, and easily understood. EA is relatively easily and cheaply undertaken. The results address a wide range of concerns, encompass the detail of specific processes, and at the same time emphasise the biggest concerns.

What is required for EA to become a fully functional sustainability indicator is a means by which it can determine when a level of sustainability has been reached, or exceeded; not merely when an action or product is 'better' than another. The debate for what such a limit might be has not taken place. It may be, for example, that the level of environmental damage that existed at a population of two billion at the end of the 1920s is demonstrated as a sustainable level, and the global energy use that existed then is taken as an allowable upper limit. Or, the level might be, say, at a population of around 2.5 billion - as existed around the middle of the 20th century.

Energy remains a useful comparative measure, even if it cannot show what an upper level of sustainable activity is, or be used alone to determine what a sustainable house is. The method which can show when a sustainability limit has been reached is the energy-related measure, $\mathrm{CO}_{2}$ analysis.

\section{4 $\quad \mathrm{CO}_{2}$ Analysis}

Section 4.3 shows why energy, because of its broad coverage, is a useful sustainability indicator. Its drawback, the inability to identify a limit for sustainable energy use, requires debate. This is effectively addressed by $\mathrm{CO}_{2}$ analysis.

Throughout this thesis, carbon $(\mathrm{C})$ and $\mathrm{CO}_{2}$ are both used in discussing the effects of burning fossil fuels. Fossil fuel combustion releases $\mathrm{CO}_{2}$ to the atmosphere, but the emissions, at a global scale, are often referred to just as carbon. Both units are used in this thesis. The conversion factor, based on molecular weight, is 3.666 units of $\mathrm{CO}_{2}$ to 1 unit of carbon. That is, there is $1 \mathrm{~kg}$ of carbon in $3.666 \mathrm{~kg}$ of $\mathrm{CO}_{2}$. The remaining mass is accounted for by the oxygen in $\mathrm{CO}_{2} \cdot \mathrm{CO}_{2}$ analysis is often referred to as carbon footprinting, and may include other GHGs. These are often included under the general heading ' $\mathrm{CO}_{2}$ equivalents' $\left(\mathrm{CO}_{2}-\mathrm{e}\right)$. This thesis uses the term " $\mathrm{CO}_{2}$ " as shorthand for " $\mathrm{CO}_{2}-\mathrm{e}$ ". When " $\mathrm{CO}_{2}$ " appears, it should be 
understood as " $\mathrm{CO}_{2}-\mathrm{e}$ ", unless it is clear that it is simply " $\mathrm{CO}_{2}$ ". In climate change calculations, $\mathrm{CO}_{2}$ equivalents are a preferable measure to carbon, since some GHGs such as nitrous oxide $\left(\mathrm{N}_{2} \mathrm{O}\right)$ do not contain any carbon. $\mathrm{N}_{2} \mathrm{O}$ and other GHGs are in some cases very important, and may have a global warming potential (GWP) much higher than $\mathrm{CO}_{2}$, which by convention has a GWP of 1. Methane, for example, has a GWP of 25 over a 100 year time horizon.

\subsubsection{Non- $\mathrm{CO}_{2}$ Greenhouse Gases}

Of the GHGs, $\mathrm{CO}_{2}$ is the easiest to calculate, given the availability of energy data and the known $\mathrm{CO}_{2}$ emissions for different energy types. While other GHGs are important, they form only a small part of the GHG total. New Zealand is similar to other countries in this regard.

Data for methane $\left(\mathrm{CH}_{4}\right)$ and $\mathrm{N}_{2} \mathrm{O}$ emissions from Statistics New Zealand (Statistics 2006b), shows only three industries emit more than $2 \%$ of GHGs that are not $\mathrm{CO}_{2}$. Of those three, only one industry emits more than $3 \%$ of its $\mathrm{GHG}$ as non-CO . It should be noted, however, as Statistics New Zealand acknowledges, that the data does not include $\mathrm{CH}_{4}$ emissions from agriculture, nor fugitive emissions from coal and gas use. Nonetheless, with the notable exception of agriculture and the implications for downstream building materials such as wool, $\mathrm{CO}_{2}$ is obviously the major GHG in New Zealand industry. Table 4.1 shows $\mathrm{CO}_{2}$-e totals for $\mathrm{New}$ Zealand industries and the percentages that non- $\mathrm{CO}_{2}$ gases are of the $\mathrm{CO}_{2}$-e total. 
Table 4.1 New Zealand $\mathrm{CO}_{2}$ and Non- $\mathrm{CO}_{2}$ Greenhouse Gas Emissions

\begin{tabular}{|c|c|c|c|c|}
\hline \multirow[b]{2}{*}{ Industry Category } & \multicolumn{4}{|c|}{ GHG Emissions (tonnes) } \\
\hline & $\mathrm{CO}_{2}$-e total & $\mathrm{CH}_{4} \%$ & $\mathrm{~N}_{2} \mathrm{O} \%$ & $\mathrm{CH}_{4}+\mathrm{N}_{2} \mathrm{O} \%$ \\
\hline Agriculture & $1,206,091$ & $0.39 \%$ & $1.44 \%$ & $1.83 \%$ \\
\hline Fishing & 488,394 & $0.34 \%$ & $1.41 \%$ & $1.75 \%$ \\
\hline Forestry and Logging & 182,825 & $0.34 \%$ & $3.58 \%$ & $3.92 \%$ \\
\hline Mining & 341,224 & $0.34 \%$ & $2.61 \%$ & $2.95 \%$ \\
\hline Petroleum Chemicals, Plastic and Rubber & $1,632,585$ & $2.66 \%$ & $0.21 \%$ & $2.87 \%$ \\
\hline Electricity and Water Supply & $6,729,571$ & $0.08 \%$ & $0.17 \%$ & $0.26 \%$ \\
\hline Food and Beverages & $1,691,544$ & $0.02 \%$ & $0.37 \%$ & $0.39 \%$ \\
\hline Textile, Apparel and Leather goods & 137,233 & $0.03 \%$ & $0.27 \%$ & $0.30 \%$ \\
\hline Wood Processing and Wood Products & 151,083 & $0.04 \%$ & $0.26 \%$ & $0.29 \%$ \\
\hline Paper and Printing and Publishing & 371,585 & $0.05 \%$ & $0.06 \%$ & $0.11 \%$ \\
\hline Non-metallic mineral production & 675,234 & $0.02 \%$ & $0.40 \%$ & $0.42 \%$ \\
\hline Basic Metal Industries & $1,696,930$ & $0.02 \%$ & $0.47 \%$ & $0.49 \%$ \\
\hline Machinery and Equipment Manufacturing & 296,685 & $0.04 \%$ & $0.18 \%$ & $0.21 \%$ \\
\hline Furniture and Other Manufacturing & 3,483 & $0.03 \%$ & $0.14 \%$ & $0.17 \%$ \\
\hline Construction & 340,562 & $0.03 \%$ & $0.19 \%$ & $0.22 \%$ \\
\hline Wholesale and Retail Trade & 844,675 & $0.34 \%$ & $0.88 \%$ & $1.22 \%$ \\
\hline Motels, Hotels, Guest Houses & 162,091 & $0.10 \%$ & $1.09 \%$ & $1.19 \%$ \\
\hline Communication & 61,328 & $0.42 \%$ & $1.38 \%$ & $1.80 \%$ \\
\hline Finance and Business Services & 118,348 & $0.05 \%$ & $1.10 \%$ & $1.16 \%$ \\
\hline Central Government Admin and Defense & 263,164 & $0.23 \%$ & $1.14 \%$ & $1.37 \%$ \\
\hline Local Government Administration & 78,275 & $0.29 \%$ & $1.08 \%$ & $1.38 \%$ \\
\hline Education & 219,574 & $0.18 \%$ & $0.86 \%$ & $1.04 \%$ \\
\hline Health and Welfare Services & 353,575 & $0.20 \%$ & $0.80 \%$ & $1.00 \%$ \\
\hline Other Community Services & 18,813 & $0.11 \%$ & $0.85 \%$ & $0.96 \%$ \\
\hline Transport and Storage & $8,023,486$ & $0.28 \%$ & $1.13 \%$ & $1.41 \%$ \\
\hline Household & $7,407,512$ & $0.56 \%$ & $0.74 \%$ & $1.30 \%$ \\
\hline New Zealand Total & $33,495,867$ & $0.38 \%$ & $0.71 \%$ & $1.10 \%$ \\
\hline Average & & $0.28 \%$ & $0.87 \%$ & $1.15 \%$ \\
\hline Percentage Category Colour Codes: & $<1 \%$ & $1-2 \%$ & $2-3 \%$ & $>3 \%$ \\
\hline
\end{tabular}

Source: Statistics New Zealand (2006b)

Obtaining non- $\mathrm{CO}_{2}$ GHG information for New Zealand manufacturing is difficult. Typically, manufacturers do not collect this data. The use of $\mathrm{CO}_{2}$ data as the measure of sustainability remains valid, however, even when non- $\mathrm{CO}_{2}$ data is unavailable. This is because the proportion of non- $\mathrm{CO}_{2}$ emissions, with the exception of agricultural products, averages just over 1\% of GHG emissions, which would often be below the margin of error. Where possible, non- $\mathrm{CO}_{2}$ GHGs have been included in calculations in this thesis. 


\subsubsection{Key Environmental Problems}

After thorough examination, Diamond (2005) identifies 12 serious environmental problems in his book Collapse: How Societies Choose to Fail or Survive:

1 Habitat destruction

2 Wild food loss

3 Biodiversity loss

4 Soil loss

5 Energy scarcity

6 Water shortage/depletion

7 Photosynthetic limit

8 Chemical pollution

$9 \quad$ Alien species spread

10 Atmospheric pollution

11 Overpopulation

12 Per-capita consumption/waste.

Climate change is a key theme, included within item 10, Atmospheric pollution, but also closely connected with all the other problems. Of the 12 , numbers 1-4 "consist of destruction or losses of natural resources". Numbers 5-7 "involve ceilings on natural resources". Numbers $8-10$ "consist of harmful things that we produce or move around". Numbers 11 and 12 are to do with overpopulation and its effects.

Each of the listed categories is a potential threat to human society, as Diamond elaborates. The different categories, however, also have implications for the rest of life on earth, except for energy scarcity which, in the context Diamond is using the term, is a human-only problem. Even then, the ways in which humans procure and use energy have impacts on other species. Climate change contributes to nine of the twelve categories: 1-4 and 6-10. It is also linked to category 5, and results from categories 11 and 12 . 


\subsubsection{A Means to Compare Environmental Impacts}

To compare the relative impacts of different environmental problems, the distribution and longevity of the effects can be examined. If the causes of environmental damage are removed, recovery occurs, but at different rates for different categories. These recovery times can be used as the basis for comparison of environmental impacts. By using this method an objective means is applied to different impact categories.

Coincidentally, using recovery times addresses a central stumbling block in LCA that of comparing the 'apples and oranges' of seemingly unrelated and conceptually disparate impact categories, and weighting them reliably. Boustead complains (see Section 3.4.2.3) about LCA, "that there is no scientific way in which such [weighting] judgments can be made". Using recovery times provides the scientific objectivity and robustness that is needed for weighting environmental impacts. More work is required to refine the recovery times relevant to each impact category, but sufficient evidence exists to determine the applicable orders of magnitude.

For most of Diamond's identified environmental problems, effects are relatively limited in duration or geographical extent.

\subsubsection{Non-Climate Change Impacts}

For habitats, recovery is a matter of leaving areas alone for some decades. This is illustrated, for example, in the exceptional abundance and diversity of species in the area surrounding Chernobyl after the effective exclusion of humans following the 1986 nuclear disaster (Lovelock, 2006; Mycio, 2005). While radiation has had some negative effects on the wildlife, Lovelock observes that it "is far less a hazard than is the presence of people and their pets".

In the same way, wild food loss, which is intimately connected with habitat loss, as well as over-hunting or harvesting, could be expected to self correct after a matter of decades or centuries if populations of affected species were left alone to recover. 
Soil accumulation happens over periods from decades to millennia. Lack of soil is one of the pressures on local species and ecosystems, although in those places where soil is most at risk, ecosystems have mostly been disrupted already. Soil loss is most frequently due to the removal of forest cover and the conversion of land to agricultural uses, especially cropping (Diamond, 2005), but is also an effect of climate change, through drought and flood. A lack of soil is felt first by the agricultural activities it was used for. Once agricultural use stops, soil recovery can begin, assuming there are not aggravating conditions such as drought.

Energy scarcity is a human concern, only representing an environmental danger from the process of procuring more.

Water scarcity is also important as a human concern. Rivers that no longer reach the sea would return to natural flows without the withdrawals for human activity. Many underground water reservoirs would replenish themselves over decades and centuries once withdrawals cease. Water inputs to rivers, lakes, and aquifers are also subject to climate change effects.

The photosynthetic limit is not an environmental impact. It represents the limit to human appropriation of photosynthetic output of the planet. Any photosynthetic production not used by people immediately returns to the local ecosystem.

Chemical pollution, while problematic for local species or ecosystems is relatively quickly remedied, in years or decades, or perhaps centuries for severe cases. Because chemical pollution happens in areas of human activity, its effects are felt by ecosystems that are close to human population centres, and hence is more problematic to those populations. Eutrophication of waterways, for example, is associated with agriculture and hence human habitation. While it causes significant damage, it is local in its effect and, on a geological time frame, is short lived.

Overpopulation and its effects, while included in Diamond's category of threats, only persist as long as humans do. Overpopulation is a threat to humanity and other 
species while it persists, but 'recovery' is by definition immediate once population falls. The same can be said about per-capita consumption and waste.

\subsubsection{Climate Change Impacts}

Throughout this chapter, and earlier chapters, climate change (Diamond's atmospheric pollution), has been mentioned repeatedly in connection with environmental impact; it is such an important concern that it is difficult not to consider it at every turn. While Diamond's list of non climate-related environmental problems are limited in duration or geographical extent, climate change, by contrast, is global, and has the potential to persist in its effects from millennia to hundreds of millions of years (Benton, 2003). The loss of the polar ice sheets, for example, would be associated with major global changes, affecting all life on earth. The time taken for formation of new ice sheets is uncertain, but is likely to be tens of thousands or hundreds of thousands of years (Coxall et al., 2005).

Biodiversity loss, associated with climate change, takes longer to correct, given rates of new species evolution (Benton, 2003). During recovery the effects of low biodiversity would be ones of absence more than negative impact on persisting species. The emergence of new species into a climatically and otherwise humanaltered world can be expected to differ from the range of species that existed immediately before human habitation began to have effects.

Recovery times after biodiversity loss associated with major climate change vary according to the degree of loss. Benton (2003) concludes that after the $90-95 \%$ species loss associated with climate change at the Permian-Triassic boundary, recovery took tens to hundreds of millions of years:

... with the appearance of large herbivores and new top predators in the Early Jurassic, perhaps one could say that pre-extinction levels of ecosystem complexity had at last been achieved, some 50 million years after the end-Permian crisis...At family and generic level, it took until the Early Cretaceous, at least 100 million years, for marine life to reach Late Permian levels again. The global pattern of recovery at species level...might have been as long as 150 million years. 
Figure 4.2 shows existing genera on its vertical axis, and mass extinction events from 540 million years ago (mya). There is an interval of $\sim 100+$ million years between the peaks of the Late Permian ( 250mya) and Late Jurassic ( 150 mya) as biodiversity recovered to similar levels from the Permian-Triassic extinction event. Other mass extinction events had less biodiversity loss and shorter recovery times, such as the dinosaur-killing KT event recovery at $\sim 65$ mya, latest of the "Big 5" extinctions. Its recovery lasted a mere 10 million years (Ward, 2007).

Figure 4.2 Biodiversity Loss from Mass Extinctions

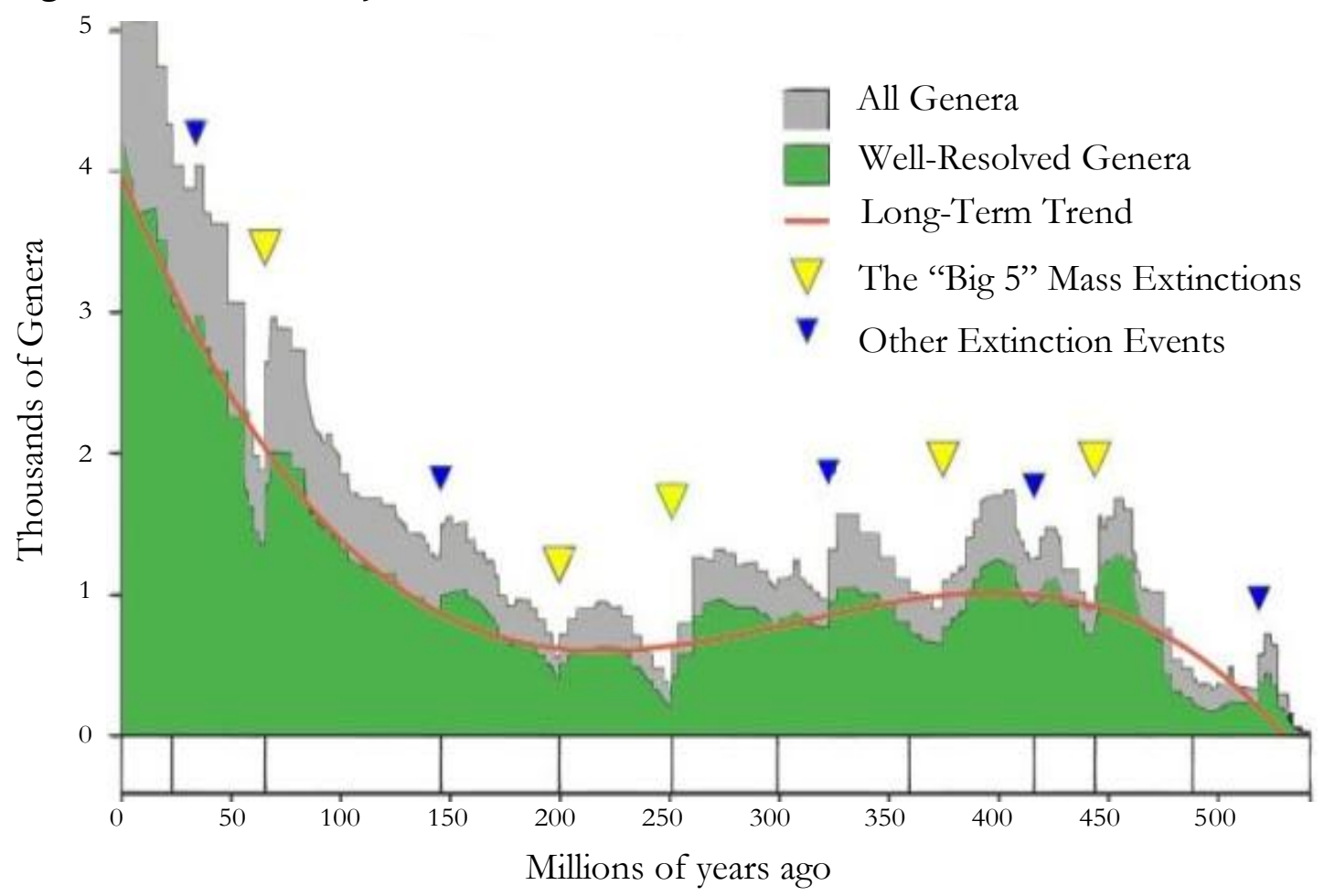

Source: Nielsen (2009)

The current high number of genera in Figure 4.2 may be comforting, but Benton calculates, within measurement uncertainties, that at present loss rates all life will be extinct in 800 to 20,000 years - an exceptionally fast rate in geological time. Each bar on the graph represents $\sim 5$ million years, so current losses do not appear.

As with the end-Permian, current biodiversity loss is intimately tied to climate change. It is the biodiversity-loss aspect of climate change, along with simple recovery of the climate after episodes of high $\mathrm{CO}_{2}-$ on the order of thousands to 
hundreds of thousands, or even millions of years (Benton, 2003) - that makes climate change of such significance.

Allied to the long-term effects of climate change and biodiversity loss, alien species spread is potentially a major disruption that could permanently change the character of ecosystems. Without human management, alien species are likely to cause locally altered paths of evolution as species best suited to conditions, especially conditions altered by climate change, thrive at the expense of traditional local species, or replace species that have gone extinct because of human activity. This new balance of biodiversity can, in a sense, imply that there will never be 'recovery' from current biodiversity loss and alien species spread. The ongoing 'threats' from a change in the distribution of species and the species themselves, however, are not threats to global life generally, although they are threats to human society and to the particular species at risk of competition or extinction.

On a shorter time scale, climate change is likely to be much more significant and widespread in its effects than other environmental impacts. Burke et al. (2006) show the spread of drought throughout the current century will double to affect $50 \%$ of the Earth's land surface with moderate drought, and 40\% with severe drought. Extreme drought is "predicted to increase from 1\% for the present day to $30 \%$ by the end of the twenty-first century".

The recovery times from non-climate impacts range from years to millennia, with most falling into the decades to centuries range. Recovery from climate-related impacts may take from millennia to hundreds of millions of years. Given paleontological and paleoclimatic evidence (Ward, 2007; Benton, 2003), climate change, and by implication $\mathrm{CO}_{2}$, is approximately 3-7 orders of magnitude more significant than any other environmental impact, with 5 orders of magnitude being a plausible central estimate. Even if analysis of different impacts is in error by an order of magnitude or two, climate change still outweighs other impacts to such an extent that they pale into insignificance. Environmental impacts of any sort are important and deserve examination and remedial action. As candidates for assessing 
environmental damage and sustainability, however, they are insignificant in relation to the magnitude of the threat posed by climate change.

\subsection{4 $\mathrm{CO}_{2}$ Limit}

$\mathrm{CO}_{2}$ is central to sustainability, but a method is required to define an acceptable level of $\mathrm{CO}_{2}$ emissions. As with Meyer's contraction and convergence mechanism, a percapita allowance can be deduced from global climate limits and applied to current activities to determine what reductions are necessary to fit within the bounds of the climate system. All aspects of current $\mathrm{CO}_{2}$ emitting activity need to be reduced to fit this limit if they are to provide a habitable global climate for present and future generations. This is a prerequisite for sustainability. Other activities may also need to be curtailed or modified, such as restricting land-use to the available global biocapacity as indicated by the Ecological Footprint method. If the absorption limit of the planet cannot be met, however, sustainability is not possible.

Net $\mathrm{CO}_{2}$ emissions to the atmosphere are currently much larger than terrestrial and oceanic absorptions (see Figure 5.1 Global Carbon Flux). Given this large discrepancy, all sectors need to contribute to reductions to reach a sustainable emissions level, and all are likely to show improvement with time. Changes in living patterns may alter the emissions from sectors somewhat differently. Higher energy costs, some form of climate change cost, and efficiency gains are likely across all sectors, however. Proportionality across different sectors is thus unlikely to change much. It is, furthermore, impossible to exactly determine the future shape of society and which sectors will show greater emissions reductions. It is reasonable, then, to use current activity patterns as the guide to future ones: a similar proportion of emissions can be assumed will come from housing construction and operation as currently, and equally for other sectors.

\subsection{5 $\mathrm{CO}_{2}$ as Sustainability Indicator}

By using a $\mathrm{CO}_{2}$ limit determined by current global absorptions, the definition, sustainability meets the needs of the present without annual $\mathrm{CO}_{2}$ emissions exceeding what the planet can absorb, becomes functional. By such a definition the aspiration for sustainable development can readily be put into practice. Any activity can be 
assessed against this limit to determine if it is sustainable. The limit can be used as the basis for indicators and measures of sustainability. At a conceptual level the definition leaves little room for misunderstanding. Additionally, it is consistent with a wide range of definitions of sustainability and sustainable development.

Most sustainability measures focus on one part of the right-hand or demand side of Ehrlich and Holdren's equation, typically seeking to lower $I$ by reducing $T$. This is often sought through improved technological efficiency, which often runs foul of Jevons' Paradox. Establishing a $\mathrm{CO}_{2}$ limit as the essential functional aspect of a sustainability measurement focuses on the left-hand or supply side of Ehrlich and Holdren's equation, by defining a maximum for $I$; the 'supply' of global $\mathrm{CO}_{2}$ absorptive capacity has a real limit. Using this method, individual activities can be tested for sustainability by applying values for $P, A$, and $T$, to check the product does not exceed $I$. To determine what the maximum allowable limit for an activity is, ahead of it being undertaken, a maximum for $T$ can be discovered.

Current values for population, $P$, are relatively easily applied. Affluence, $A$, is the number and scale of activities enjoyed by a society, or household, or individual. The current value for $A$ is obtained by using the percentage of demand for an activity relative to all activity in a particular country or region. New Zealand, for example, engages in housing, clothing, food, business, industrial, recreation, and many other activities (see Table 4.1, column 1). Each has a definable percentage of the total activity of our affluent economy, which can be obtained from the economic inputoutput tables.

With $I, P$, and $A$ defined, the remaining variable, $T$, is the $\mathrm{CO}_{2}$ emissions (maximum that may not be exceeded) for an activity, such as driving a car for one kilometre. The $I=P A T$ equation is then balanced, and sustainability has been achieved for that activity. In the case of a house, $T$ is the $\mathrm{CO}_{2}$ emissions (maximum sustainably allowable) for construction and operation. 
$\mathrm{CO}_{2}$ analysis combines six important attributes as a sustainability indicator. The first two are linked to EA, as discussed in section 4.3. The other four are linked to climate change.

1) $\mathrm{CO}_{2}$ analysis has the broad coverage of $\mathrm{EA}$, since $\mathrm{CO}_{2}$ emissions are tightly linked to energy use and general human activity, reflected in economic activity. Other environmental impacts are also reflected by their linkage to human and economic activity.

2) $\mathrm{CO}_{2}$ analysis has the specificity of EA. Energy-intensive and $\mathrm{CO}_{2}$-intensive activities are reflected in the $\mathrm{CO}_{2}$ total.

3) $\mathrm{CO}_{2}$ analysis is directly linked to the principal environmental impact, climate change.

4) Through the climate change linkage, $\mathrm{CO}_{2}$ analysis is able to identify a sustainability limit, and determine how close to or far from this limit any particular activity, or group of activities, is.

5) $\mathrm{CO}_{2}$ analysis focuses attention on the (limited) supply side: global $\mathrm{CO}_{2}$ absorptive capacity.

6) The carbon-absorptive capacity of the planet is not subject to major uncertainty.

The measurement of $\mathrm{CO}_{2}$ and equivalent GHGs thus becomes a prime measure of sustainability.

Using a $\mathrm{CO}_{2}$ limit as a sustainability measure, a functional definition can be stated:

\section{Sustainable development is development that meets the needs of the present without annual $\mathrm{CO}_{2}$ emissions exceeding what the planet can absorb in that year.}

By such a definition sustainability can be readily put into practice, and recognised both as a long term state of the ecosphere and in daily action. At a conceptual level it leaves little room for misunderstanding. It is also consistent with a wide range of definitions of sustainability and sustainable development. 
It is consistent with Brundtland because it is an essential step in not compromising the abilities of future generations to meet their needs. If $\mathrm{CO}_{2}$ emissions do continue to rise, dangerous climatic changes either are, or are expected to increase drought, flooding, storms, and disease, and to reduce available water, arable soil and crop yields. These are all a clear threat to the ability to provide for future generations.

It is consistent with Ehrlich and Holdren's (1971) $I=P A T$ in that it specifies reduced impact of fossil-fuel technologies $(T)$. It is also likely to prompt to a reduction in consumption (affluence) (A) generally, and thus overall impact (I) (see Section 2.3.2).

It is consistent with Daly's (1977) principle that "waste emissions should not exceed the assimilative capacities of the receiving environment".

It is consistent with the WCC principle of "pollution well below the absorptive capacity of ecosystems".

It is consistent with the UNFCCC and Kyoto aim, "to achieve, in accordance with the relevant provisions of the Convention, stabilisation of GHG concentrations in the atmosphere at a level that would prevent dangerous anthropogenic interference with the climate system" (UNFCCC, 1992).

It is consistent with The Natural Step (Robert, 2002) condition that nature is not subject to systematically increasing concentration of substances extracted from the earth's crust, or substances produced by society.

It is consistent with the Ecological Footprint concept in that it specifically reduces the area needed to absorb emissions to the limits of the planet.

It is consistent with Pinchot's prescription: without curbing $\mathrm{CO}_{2}$ emissions, the "greatest good for the greatest number over the longest time" is unattainable, because climate change would preclude the 'longest time' clause for good to accrue to any significant number of people. 
Finally, it is closely consistent with, and bears similarity to Meyer's (2000) Contraction and Convergence model.

Such a definition does not deal directly with other toxic or damaging emissions to the biosphere, resource depletion, or other indicators. However, the majority of environmental impacts are the result of population times consumption times impact of the specific technology, as formulated in Ehrlich and Holdren's $I=P A T$. Reducing $\mathrm{CO}_{2}$ to what the planet can absorb also implies limits, or reductions, to all three of the terms of the equation. It is implausible that the current population can be maintained with the significantly reduced fossil-fuel use implied by reduced $\mathrm{CO}_{2}$ emissions, because of the tight link between global energy use and $\mathrm{CO}_{2}$ emissions ( $90 \%$ of energy is from fossil fuels), and the tight link between energy use and food and other essential production.

Modern agriculture, for example, is heavily dependent on fossil fuels not just for farm machinery and crop transport, but on inputs of pesticides and, particularly, fertiliser. The Haber-Bosch process has, since 1909, provided cheap nitrogen fertiliser from natural gas, greatly increasing production from arable land (Heinberg, 2003; Darley, 2004). If land were diverted from food to fuel-crop production, good yields would still be dependent on the inputs of natural gas for fertiliser production, and outputs of $\mathrm{CO}_{2}$ from this process (about 0.5t per tonne of fertiliser) (Chesworth, 2008). The familiar environmental effects of transport and other fuel uses would still have a tight correlation with $\mathrm{CO}_{2}$ emissions from crop fuels.

Because activity is $90 \%$ fossil-fuelled, reduced $\mathrm{CO}_{2}$ emissions through reduced fossil fuels means reduced consumption. Reduced impacts in all other categories can thus be expected to match the reduced consumption that reduced fossil fuel use implies.

Unless some other cheap, readily available, and quickly scaleable energy source arrives soon, restricting $\mathrm{CO}_{2}$ emissions to the global absorptive capacity implies a reduction in impact in almost all areas where energy is used. Currently there appears to be no new energy source that meets the cheap and readily scaleable requirements (Romm, 2004; Heinberg, 2003). 
Because $\mathrm{CO}_{2}$ is intimately linked to energy use, it directly addresses the broader issues described in Section 4.3 that connect general energy use with environmental damage. $\mathrm{CO}_{2}$ as an environmental indicator directly addresses the principal environmental issue: climate change, and indirectly addresses all other environment issues.

$\mathrm{CO}_{2}$ has the following attributes that make it the leading environmental indicator; it:

- $\quad$ Establishes a clear and simple upper limit for sustainability

- Avoids Jevons' Paradox

- Makes sustainability easily measured and calculated

- $\quad$ Can be easily applied to current and future activities

- Is closely linked to the principal environmental impact, climate change

- Is closely linked to general energy use, so to broad environmental damage

- Has a scientifically well founded basis

- Has been subject to thorough scientific debate

- Is readily adjustable to varying population

- Is readily adjustable to varying environmental parameters

- Is (conceptually) easy to apply to policy decisions.

Most of the requirements for a functional definition of sustainability (see Section 2.4) are addressed here. Those not specifically addressed are:

- Accommodation of conflicting interests in the sustainability debate

- Preservation of future generations' abilities to meet their needs

- $\quad$ Scientific clarity and simplicity

- Measurement or quantification

- $\quad$ Easy understanding.

The use of $\mathrm{CO}_{2}$ as an indicator does not prescribe any particular course of action, nor rule out any particular activity. What it does is allow current or future actions at individual, community, regional, national or international level, so long as they adhere to the upper limit of manageable $\mathrm{CO}_{2}$ emission. By using an objective and 
agreed limit, both development and environmental interests are accommodated but not favoured.

The interests of the development lobby are not necessarily threatened with a known and fixed level of allowable $\mathrm{CO}_{2}$ emissions. Producers might, however, need to find ways of producing goods or services that significantly reduced $\mathrm{CO}_{2}$ emissions of outputs. So long as global $\mathrm{CO}_{2}$ limits were not breached, the strategy of restricting emissions does not prescribe how those limits are achieved. Under a global $\mathrm{CO}_{2}$ limit strategy, development is theoretically fully allowed, so long as the limit is not breached. In practice, however, this would require significant reduction in development activity, at least in the short term.

The ability of future generations to provide food and other resources is substantially threatened by climate change. The preservation of the interests of future as well as current generations is thus the central rationale for using a limit that controls $\mathrm{CO}_{2}$ emissions, and climate change.

The scientific bases for measuring $\mathrm{CO}_{2}$ emissions, $\mathrm{CO}_{2}$ absorption, and population have been in use and refined for many decades. The procedures are simple, clear and trusted. Measurement for $\mathrm{CO}_{2}$ can be done at many different levels, from individual exhaust pipes to global atmospheric totals, thus allowing refinement and accuracy in the results. There is no complicated long series of calculations, with any significantly debated terms, to slow the application of the method. The method has been in public debate for many years, notably as a result of the Kyoto Protocol, so is thus easily understood, even by the lay user.

Without dealing with the climate change issue, and therefore $\mathrm{CO}_{2}$, aggregate human activity cannot be considered sustainable. Because of the tight connection of $\mathrm{CO}_{2}$ to the biggest environmental threat by far, and because of its tight connection to energy, by analysing the $\mathrm{CO}_{2}$ embodied in materials, products, or services, and by relating that to the global absorptive limit of $\mathrm{CO}_{2}$, a good guide to the sustainability of those materials, products, or services is established. 


\subsection{Conclusion}

This chapter has shown why $\mathrm{CO}_{2}$ and energy are the most useful methods of assessing sustainability. Energy is useful as a method to compare actions. $\mathrm{CO}_{2}$ can also be used to compare actions, but has the distinct advantage of being measurable against a known limit, beyond which emissions are unsustainable. $\mathrm{CO}_{2}$, then, forms the basis for the hypothesis of this thesis, that:

\section{By making strategic design and construction decisions, materials choices, and certain technology selections, the $\mathrm{CO}_{2}$ profile of houses can be brought within a target limit that can be considered sustainable.}

Chapter 5 makes $\mathrm{CO}_{2}$ an operational sustainability indicator by determining what the global limit for sustainable $\mathrm{CO}_{2}$ emissions is. From this, it derives a sustainable limit for New Zealand housing. After specific discussion of energy and $\mathrm{CO}_{2}$ analysis methods and application in Chapters 6,7 and 8, the above hypothesis is tested in Chapter 9. 


\section{$5 \mathrm{CO}_{2}$ Limits}

Uncertainty is an argument for a more, not less, demanding goal, because of the size of the adverse climate-change impacts in the worst-case scenarios.

- Sir Nicholas Stern, 2006

Climate change is for real. There is not a moment to lose. We are risking the ability of the human race to survive.

- Rajendra Pachauri, 2005

\subsection{Introduction}

Climate change and high levels of $\mathrm{CO}_{2}$ and other GHGs were discussed in Section 4.4 as the major global environmental threat. For human activity to be sustainable $\mathrm{CO}_{2}$ needs to be limited to what the planet can absorb. In order to apply a global limit to specific activities, to know if they are sustainable, a per-capita allowance can be deduced from global $\mathrm{CO}_{2}$ absorption ability and human population. This chapter investigates these aspects of determining a sustainable limit for human activity generally, and house construction in New Zealand in particular.

Firstly, current and projected population levels are reviewed. Then, current and longterm global $\mathrm{CO}_{2}$ emissions and absorptions are examined. Population and $\mathrm{CO}_{2}$ absorption are then compared to determine what a sustainable per-capita $\mathrm{CO}_{2}$ limit might be. Finally, how this per-capita limit can be applied to house construction and operation is discussed. Totals for construction and operation are combined to derive a net annual 'allowable' $\mathrm{CO}_{2}$ emission per-house for a real-world sustainability limit for houses. Chapters 6 and 7 look in detail at how to measure the energy and $\mathrm{CO}_{2}$ associated with house construction so individual New Zealand houses can be compared to this established sustainability limit.

\subsection{Population}

As discussed in Section 4.2, the only clearly viable solution to curbing environmental impact without inducing Jevons' Paradox problems (see Section 4.2) is to have caps 
on important harmful substances. The primary one is a limit on $\mathrm{CO}_{2}$ emissions. This would necessarily be a global limit, but translates into a per-capita limit.

Intergovernmental Panel on Climate Change (IPCC) climate projections, which incorporate $\mathrm{UN}$ population projections, use various atmospheric $\mathrm{CO}_{2}$ concentrations as targets, with different timelines by which climate stabilisation would be reached (Meehl et al., 2007). The scale of population and global carbon absorption both potentially affect the level at which per-capita emissions are sustainable.

\subsubsection{Uncertainty in Population and $\mathrm{CO}_{2}$ Emission Projections}

The likelihood of any of the IPCC timelines and $\mathrm{CO}_{2}$ concentration maxima being achieved depends largely on the political processes for achieving them, and the growth curves that are ultimately followed by human population. To achieve any one of the projected emission curves implies $\mathrm{CO}_{2}$ reductions of a high magnitude, whereas the recent trend has been at or above the highest projections. Le Quéré et al. (2009) note: "The human perturbation of the carbon cycle continues to grow strongly and track near [or above] the most carbon intensive scenarios of the UNIntergovernmental Panel on Climate Change." The IPCC emission scenarios, contain many uncertainties, including:

- what can be achieved by the political process

- $\quad$ oil shortage increasing coal consumption

- $\quad \mathrm{CO}_{2}$ emissions from building new energy infrastructure

- demographics and geopolitical conflict impacting on population

- $\quad$ soil loss impacting on food supply and hence population

- $\quad$ water shortage impacting on food supply

- $\quad$ oil shortage impacting on pesticide and herbicide production and food supply

- $\quad$ oil shortage impacting on food cultivation, harvesting, and distribution

- $\quad$ gas shortage impacting on fertiliser production and hence food supply

- $\quad$ energy shortage impacting on irrigation pumping capacity and food supply

- climate change impacting on food supply. 
These uncertainties in $\mathrm{CO}_{2}$ emissions are interlinked with population increase. They and other factors could reduce future population increases; the human population curve trajectory is by no means certain. $\mathrm{CO}_{2}$ emissions could easily go up if high-emitting coal becomes a replacement for oil; and consumption growth, especially in China and India, has the potential to increase faster than population might fall. Population and $\mathrm{CO}_{2}$ projections remain problematic for defining a future per-capita limit.

\subsubsection{Population Projections}

To calculate a per-capita sustainable emission, global $\mathrm{CO}_{2}$ absorption can be divided by global population. But what population figures should be used? Can a number close to the population projections of the UN and US Census Bureau be used safely? Cohen (2003) urges caution:

It is a convenient but potentially dangerous fiction to treat population projections as exogenous inputs to economic, environmental, cultural, and political scenarios, as if population processes were autonomous. Belief in this fiction is encouraged by conventional population projections, which ignore food, water, housing, education, health, physical infrastructure, religion, values, institutions, laws, family structure, domestic and international order, and the physical and biological environment.... The absence from population projection algorithms of influential external variables indicates scientific ignorance of how external variables influence demographic rates rather than any lack of influence.

Projections for peak global population vary. In 1998 the United Nations (DESA, 1998) projected the growth of world population levelling off in about 2200 :

According to the medium-fertility scenario, which assumes fertility will stabilise at replacement levels of slightly above two children per woman, the world population will grow from 5.7 billion persons in 1995 to 9.4 billion in 2050, 10.4 billion in 2100, and 10.8 billion by 2150, and will stabilise at slightly under 11 billion persons around 2200. 
DESA also made it clear, however, that while the 11 billion figure in 2200 was a medium-fertility projection, a wide range of outcomes is possible:

Although the high and low fertility scenarios differ by just one child per couple, half a child above and half a child below replacement fertility levels, the size of the world population in 2150 would range from 3.6 billion persons to 27.0 billion. If fertility rates were to stay constant at 1990-1995 levels for the next 155 years, the world in 2150 would need to support 296 billion persons. If all couples of the world had begun to bear children at the replacement-fertility level in 1995 (about 2 children per couple), the growth momentum of the current age structure would still result in a 67 per cent increase in the world population, to 9.5 billion by $2150 \ldots$ The ultimate world population size of nearly 11 billion persons, according to the medium fertility scenario of these projections, is 0.7 billion persons fewer than previously published by the United Nations in 1992, mainly due to larger-thanexpected declines in fertility in many countries.

\section{Table 5.1 UN Projections for Population In 2050, Medium Variant (billions)}

\begin{tabular}{lccc}
\hline Year of Projection & $\begin{array}{c}\text { 2050 Projected } \\
\text { Population }\end{array}$ & Stabilisation Population & Stabilisation Year \\
\hline 1992 & 10.0 & 11.6 & 2200 \\
1994 & 9.8 & & \\
1996 & 9.4 & & \\
1998 & 8.9 & 11.0 & 2200 \\
2000 & 9.3 & 10.0 & \\
2002 & 8.9 & & \\
2004 & 9.1 & &
\end{tabular}

Downward adjustments in the 2050 projections have reflected inclusion of HIV/AIDS in the calculations. Changing demographics are difficult to account for and project forward; UN projections have understandably sometimes been off the mark:

U.N. projections made in 1951 predicted the 1980 population at anywhere from 3 to 3.6 billion, but the higher limit was considered 
optimistic and unlikely. The actual figure, as best we now know, proved to be about 4.4 billion [33\% higher than medium variant estimate] (Haub, 1995).

At other times they have been remarkably accurate:

The world population projection for 2000 made by the United Nations in 1960 was 6.1 billion, which is very close to 6.05 billion estimated by the United Nations 1998 Revision [and to the UN actual figure for 2000 of 6.08 billion]....In this sense, the United Nations...projection....was fortunately appropriate in assuming future trends of fertility and mortality (Kuroda, 1999).

The Census Bureau (2006) of the US government has higher numbers. Their 2050 population projection is 9.4 billion, with 9 billion being reached in 2042. They calculate a growth rate in 2050 of $\sim 0.5 \%$, and an annual addition of $\sim 45$ million people. The IPCC Special Report on Emissions Scenarios (SRES) uses population projections of $8.4-11.3$ billion by 2050 and from $7.0-15.1$ billion by 2100 (Nakicenovic et al., 2000).

Cohen raises urbanisation and life expectancy as important demographic changes:

Worldwide urbanisation has taken place for at least two centuries and accelerated greatly in the 20th century... Of the projected 2.2-billion increase in population from 2000 to 2030, 2.1 billion will be in urban areas, and all but 0.1 billion of that urban increase will be in developing countries.

Undoubtedly there will be more slums, but urban lifestyles, with greater application of technology and infrastructure, are more energy intensive than rural lifestyles (Wei et al., 2006). Average per-capita energy use and $\mathrm{CO}_{2}$ emissions can be expected to rise along with the rising urbanisation, as Cohen observes: "Global life expectancy in $2000-05$ is estimated at 65 years; in $2045-50$, at 74 years". This increase of $\sim 14 \%$ translates into greater environmental impact, over and above the percentage from 
projected population increase, since older age groups, especially in western countries, tend to be wealthier and greater consumers, and thus have a larger impact.

Urbanisation, aging of the current global youth bulge, the trend to smaller household sizes, expanding developing world middle classes, and growing per-house energy intensity are set to increase the amount of housing and related energy use worldwide. Despite trends towards smaller household size, and single person households being the fastest growing type, average house floor area for a given number of bedrooms is rising, and higher energy use per household member with it.

Table 5.2 Energy Intensity per Household Member in USA, 2001

\begin{tabular}{ccc}
\hline Number of People in Household & Household Energy per person, GJ/year \\
\hline 1 & 69 \\
2 & 49 \\
4 & 34 \\
4 (or more) & 30 (or less) \\
\hline
\end{tabular}

Source: Battles and Hojjati (2005)

Historical data is often used to project the future, as Cohen notes. This tendency applies to other decision making beyond the realm of population, such as weather effects and engineering responses based on historical weather data.

Projections of future global population...include recurrent catastrophes to the extent that such catastrophes are reflected in past trends of vital rates, but exclude catastrophes of which there is no prior experience, such as thermonuclear holocaust or abrupt, severe climate change

Gradual climate change, at rates similar to current warming, is also excluded from projections.

The unfamiliarity of the current situation, and hence the difficulty of making reliable population predictions, is highlighted by Cohen:

The population doubled in the most recent 40 years. Never before the second half of the 20th century had any person lived through a doubling of global population. Now some have lived through a tripling. 
The human species lacks any prior experience with such rapid growth and large numbers of its own species.

Given the known exclusions from the UN projections, and applying the precautionary principle, a figure of 11 billion people as a stabilisation population is modelled in housing calculations. Other figures are reasonably likely outcomes; because of the uncertainties of population projections, no single stabilisation model is adopted in this thesis. Instead, calculations are made for different populations. Calculating a stabilisation population of 11 billion, against 6.8 billion, reduces sustainable per-capita emissions by $38 \%$. In the context of house construction this factor becomes less significant, as will be seen in Chapter 9.

\subsubsection{Equity of Per-capita $\mathrm{CO}_{2}$ Emissions}

The Brundtland Report (1987), addressing equity, states, "sustainable global development requires that those who are more affluent adopt life-styles within the planet's ecological means - in their use of energy, for example". Currently rich countries emit high per-capita levels of $\mathrm{CO}_{2}$, while poor countries emit low levels. To achieve equity, either rich countries must reduce per-capita emissions, or poor countries must be allowed to raise theirs to match rich countries, with enormous increases in energy use and hence $\mathrm{CO}_{2}$ emissions. The political and economic implications of rich countries reducing their emissions to levels equivalent to that of poor countries appear extremely challenging. It would, in effect, require an adoption of African lifestyles by rich countries. A middle ground might be reached, but given political resistance to reductions in affluence, this might be only a little below current emissions rates of rich countries. Table 5.3 shows emissions from a selection of rich to poor countries. 
Table 5.3 Selected Country and Region Carbon Emissions Per-capita

\begin{tabular}{lcc}
\hline Country/Region & Tonnes per-capita & Rank \\
\hline Australia & 5.72 & 12 \\
United States & 5.49 & 13 \\
North America average & 4.40 & \\
New Zealand & 3.20 & 29 \\
Japan & 2.72 & 49 \\
United Kingdom & 2.68 & 50 \\
Europe average & 2.22 & \\
China & 1.27 & 84 \\
WORLD AVERAGE & 1.24 & \\
Uzbekistan & 1.23 & 87 \\
Asia \& Oceania average & 0.85 & \\
Central \& South America average & 0.70 & 138 \\
Namibia & 0.37 & 158 \\
Africa average & 0.32 & 164 \\
Zimbabwe & 0.23 & 214 \\
Samoa & 0.22 & \\
Chad & 0.006 &
\end{tabular}

Source: EIA, 2008

The equity debate about where to set emissions restrictions, on the spectrum between poor and rich countries' per-capita $\mathrm{CO}_{2}$ emissions rates, remains secondary, however, to the reality of total emissions. The planet's limits do not include a tolerance for the wishes of its human inhabitants. Irrespective of Brundtland's prescriptions, the simple facts of rising $\mathrm{CO}_{2}$, rising global temperatures, consequent climate change, and consequent disruption of global life support systems, allow no room for anything other than the long-term adjustment of $\mathrm{CO}_{2}$ emissions, and thus of average lifestyles, to the planet's ability to absorb $\mathrm{CO}_{2}$.

It will be seen in Section 5.5.4 that average sustainable $\mathrm{CO}_{2}$ limits are very challenging. For part of the population to emit above the average means others must emit below it, which is an unrealistically difficult aim. Equitable per-capita emissions are adopted in this thesis as an essential feature of a sustainable world. 


\subsection{Global $\mathrm{CO}_{2}$ Emissions and Absorptions}

The amount of absorption from the atmosphere is currently large because of the suddenly high levels of $\mathrm{CO}_{2}$. Terrestrial and oceanic sinks, however, have a limited capacity to absorb at current levels.

$\mathrm{CO}_{2}$ levels are often talked about as being acceptable if they are kept to within about 450 parts per million by volume (ppmv) (Meinshausen et al., 2009; O’Neill and Oppenheimer, 2002; Onigkeit and Alcamo, 1999); recent evidence, however, suggests that destructive weather is likely to occur at $\mathrm{CO}_{2}$ levels significantly lower than this. Even with current atmospheric $\mathrm{CO}_{2}$ levels of 388 ppmv (Tans, 2010) destructive weather patterns such as hurricanes Katrina and Rita are more likely than they would be without existing warming (Knutson 2004; Emanuel 2005; Keeling 2005). Hansen et al. (2008) argue 350 ppmv is the 'safe' upper limit for atmospheric $\mathrm{CO}_{2}$ :

If humanity wishes to preserve a planet similar to that on which civilization developed and to which life on Earth is adapted, paleoclimate evidence and ongoing climate change suggest that $\mathrm{CO}_{2}$ will need to be reduced from its current $385 \mathrm{ppm}$ to at most $350 \mathrm{ppm}$.

Houghton et al. (2001), inter alia, also provide scenarios for $\mathrm{CO}_{2}$ stabilisation at a variety of concentrations. "Stabilisation at 450, 650 or 1,000 ppm would require global anthropogenic emissions to drop below 1990 levels within a few decades, about a century, or about two centuries, respectively, and continue to steadily decrease thereafter." This, however, is for stabilisation of $\mathrm{CO}_{2}$, not of the climate. Given that climate effects are noticeably increasing (Cox et al., 2000; Coxall et al., 2005; Emanuel, 2005; Adam, 2008; Hansen et al., 2008; Le Quéré et al., 2009) at current concentrations of $388 \mathrm{ppm}$ (Tans, 2010), and a rise of 0.8C (Hansen, 2006), it is hard to argue that any additional concentration of $\mathrm{CO}_{2}$ in the atmosphere would not violate the Brundtland provision, of not compromising the abilities of future generations to provide for their needs. 
Bows et al. (2006) conclude that in order to achieve the aim of the UK (DTI, 2006) and other governments, and avoid

the most damaging effects of climate change [consistent with] a global average temperature increase of no more than $2^{\circ} \mathrm{C}$ above the preindustrial level [a] radical shift onto a low-carbon pathway by 2010-12 [is necessary, followed by] driving down carbon intensity at an unprecedented $9 \%$ per-annum, for up to two decades.

Meinshausen (2006) argues that "only at levels around 400ppm $\mathrm{CO}_{2}$ equivalent or below, could the probability of staying below $2^{\circ} \mathrm{C}$ in equilibrium be termed 'likely"'. Given that we have already reached 388ppm $\mathrm{CO}_{2}$, and that other greenhouse gases have already taken us to 430ppm $\mathrm{CO}_{2}$ equivalent, by Meinshausen's argument it is already likely that we will exceed $2^{\circ} \mathrm{C}$. Metz and van Vuuren (2006) argue that "concentrations of $\mathrm{CO}_{2}$ may need to be stabilised at around 400ppm (or at about 450ppm $\mathrm{CO}_{2}$ equivalent - i.e. taking all the main GHGs into account)" (Boston, 2006).

Absorption levels are calculated from annual emissions and absorption in different parts of the carbon cycle. Figure 5.1 shows the trends of global carbon flux from 1959 to 2007. By convention, positive values are carbon fluxes $(\mathrm{Pg} / \mathrm{yr}=\mathrm{Gt} / \mathrm{yr})$ into the atmosphere, and negative values are uptake from the atmosphere (i.e., carbon sinks, or absorptions, by oceans or terrestrial plants). Most inter-annual variability is from weather variations such as $\mathrm{El} \mathrm{Nino/La} \mathrm{Nina,} \mathrm{and} \mathrm{deforestation} \mathrm{variations.} \mathrm{The}$ rise in absorptions (sinks more negative) is not due to increased $\mathrm{CO}_{2}$ absorption by terrestrial plants or marine phytoplankton, but to increased concentration of $\mathrm{CO}_{2}$ in the atmosphere, encouraging greater uptake by photosynthesisers, and by direct absorption in the ocean. It can be seen that the land sink trend changed direction to less absorption around 1999, based on available data. Calculated using a 20 year average to smooth annual variation, net global carbon absorption is $\mathbf{3 . 5} \mathbf{P g} / \mathbf{y r}$ (GCP, 2009; Le Quéré et al., 2009; van der Werf et al., 2009; Sitch et al., 2008; Keeling and Whorf, 2005; Marland, Boden and Andres, 2005). 


\section{Figure 5.1 Global Carbon Flux}

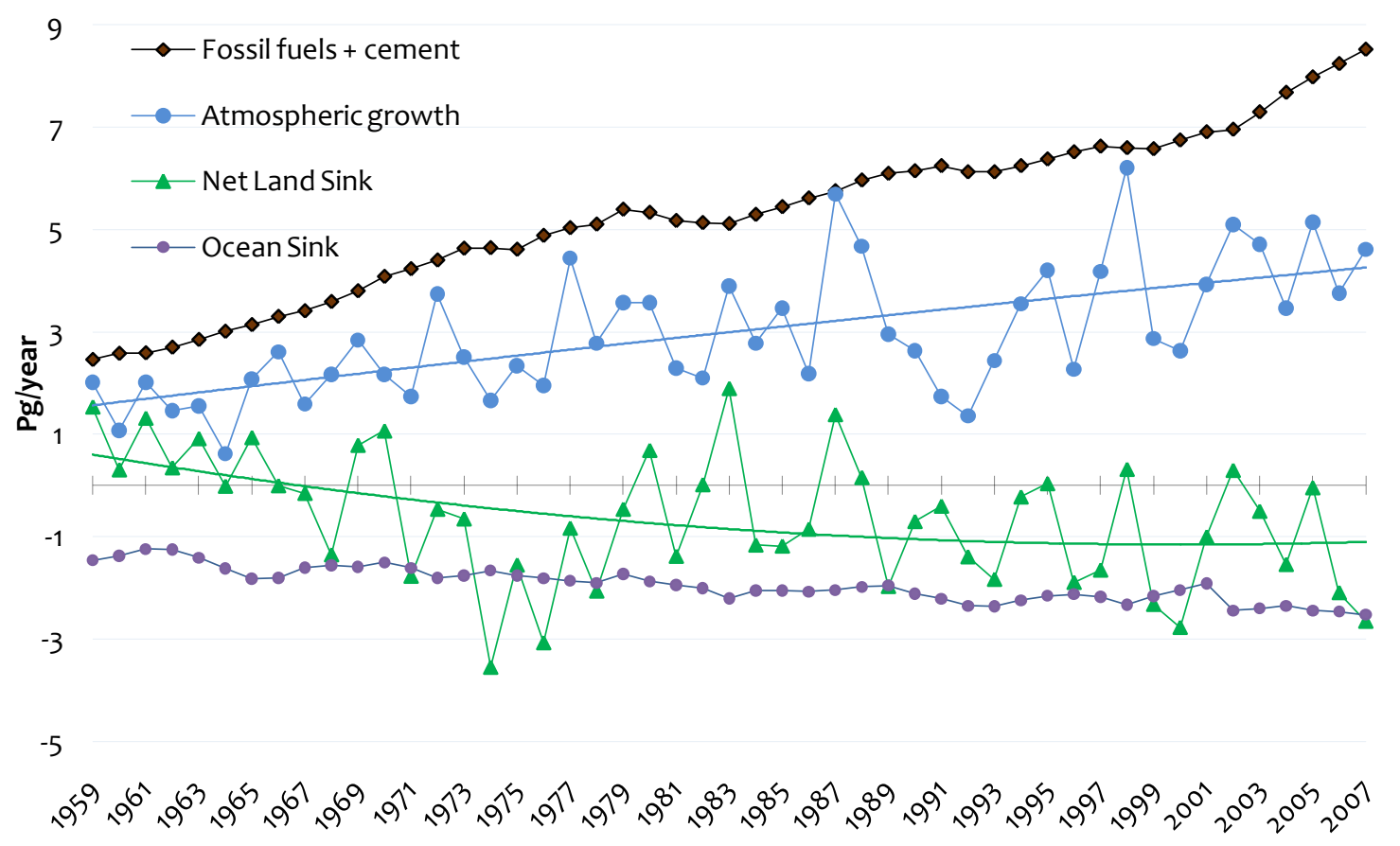

Rising temperatures and falling water availability due to drought and other hydrological changes are predicted to reduce terrestrial $\mathrm{CO}_{2}$ uptake, so that the "terrestrial biosphere is likely to become a net source of carbon during the course of this century" (Fischlin et al., 2007). It can be seen from Figure 5.1 that ocean absorption is greater than terrestrial. However, by " 2100 , ocean $\mathrm{pH}$ is very likely to be lower [more acid] than during the last 20 million years" (Parry et al., 2007); with increased ocean acidity comes reduced phytoplankton activity, and hence lower oceanic absorption. Prentice et al. (2001) observe:

The overall ability of surface seawater to take up $\mathrm{CO}_{2}$ decreases at higher atmospheric $\mathrm{CO}_{2}$ levels. The effect is large. For a $100 \mathrm{ppm}$ increase in atmospheric $\mathrm{CO}_{2}$ above today's level the DIC [dissolved inorganic carbon] concentration increase of surface sea water is already about $40 \%$ smaller than would have been caused by a similar $100 \mathrm{ppm}$ increase relative to pre-industrial levels.

Prentice et al. (2001) also note that warmer ocean waters reduce $\mathrm{CO}_{2}$ uptake: "CO 2 is less soluble in warmer water, and the equilibrium $\mathrm{pCO}_{2}$ [partial pressure of $\mathrm{CO}_{2}$ ] in seawater increases by about 10 to $20 \mathrm{ppm}$ per ${ }^{\circ} \mathrm{C}$ temperature increase". They also 
point out that warmer oceans increase stratification, and hence reduce mixing of warmed waters and dissolved $\mathrm{CO}_{2}$ to greater depths. The surface layer becomes even warmer and less able to absorb $\mathrm{CO}_{2}$. Le Quéré et al. (2007) observe that increased winds, as a result of climate change, have begun reducing $\mathrm{CO}_{2}$ absorption by the Southern Ocean. Further wind increase can be expected to exacerbate this effect.

These foreseeable oceanic changes imply halving, or more, the amount of $\mathrm{CO}_{2}$ that is absorbed by the ocean as atmospheric concentrations rise from current levels.

Terrestrial absorption of $\mathrm{CO}_{2}$ is temperature and rainfall dependent. Increased drought reduces plant growth and $\mathrm{CO}_{2}$ absorption. Higher temperatures stress plants, which then require more water. The main temperature effect, however, may be the carbon released from soil.

Cox et al. (2000), in a climate model run at the Hadley Centre for Climate Prediction and Research, calculate:

that the terrestrial biosphere takes up $\mathrm{CO}_{2}$ at a decreasing rate from about 2010 onwards, becoming a net source at around 2050...plant maintenance and soil respiration rates both increase with temperature. As a consequence, climate warming (the indirect effect of a $\mathrm{CO}_{2}$ increase) tends to reduce terrestrial carbon storage, especially in the warmer regions where an increase in temperature is not beneficial for photosynthesis. At low $\mathrm{CO}_{2}$ concentrations the direct effect of $\mathrm{CO}_{2}$ dominates, and both vegetation and soil carbon increase with atmospheric $\mathrm{CO}_{2}$. But as $\mathrm{CO}_{2}$ increases further, terrestrial carbon begins to decrease, because the direct effect of $\mathrm{CO}_{2}$ on photosynthesis saturates but the specific soil respiration rate continues to increase with temperature. The transition between these two regimes occurs abruptly at around 2050 in this experiment.

Because carbon sinks are likely to reduce during this century, current absorption levels cannot be taken as sustainable. In $2009 \mathrm{CO}_{2}$ has exceeded 388ppm (NOAA, 2009), 10\% above Hansen's 350 ppm limit. (The last year that $\mathrm{CO}_{2}$ was below 
$350 \mathrm{ppm}$ was 1987, emphasising the significance of 1990 as a benchmark year in climate calculations.) On the basis of $350 \mathrm{ppm}$, the current sustainable annual net emission level is a negative number.

The ability to achieve reduced emissions, as Hansen et al. call for, is doubtful, considering conclusions voiced by CEOs of ExxonMobil and Royal Dutch Shell that declining oil availability will not lead to a large scale shift to wind and solar energy owing to their inability to meet increased demand, but will force a greater use of coal, along with oil and gas, as "the only energy sources of sufficient size, adaptability and affordability to meet the world's needs" (Mortished, 2007). A near term rise in $\mathrm{CO}_{2}$ emissions would be a likely result of a greater use of coal, requiring larger future $\mathrm{CO}_{2}$ reductions.

Referring back to Brundtland as the guide for selecting applicable numbers from the range of arguable possibilities, the requirement to not compromise the needs of future generations is paramount. Two factors in particular point to the need to immediately reduce emissions to the long-term persistent absorptive level. The first is that even at current $\mathrm{CO}_{2}$ levels of $\sim 388$ ppmv the climate is adversely affecting populations around the world, and can clearly be regarded as already compromising the needs of future generations (Smith et al., 2001). The second is that, because of the lag in the climate system, even with an immediate cessation of $\mathrm{CO}_{2}$ emissions at the $\sim 388$ ppmv level, temperatures would continue to rise for decades or centuries, by approximately a similar amount to the rise already experienced since preindustrial levels (Schmidt, 2005). This is without considering any possible feedback mechanisms, such as $\mathrm{CO}_{2}$ release from thawing tundra or other soils, which could potentially continue the release of $\mathrm{CO}_{2}$ until a point of irreversibility is reached.

Current arguments about realistic or acceptable goals for atmospheric $\mathrm{CO}_{2}$ levels are focused to a large extent on what is politically acceptable within the near to medium term. This thesis does not attempt to select a likely sustainable atmospheric $\mathrm{CO}_{2}$ level from the current debate; it focuses instead on the long term and many future generations to come. Given that sustainability is a long-term proposition, the longterm global carbon absorption level is used, as the most appropriate for calculating a 
sustainability limit. Whatever GHG concentration is ultimately sustainable in the long term, any ongoing increase in atmospheric $\mathrm{CO}_{2}$ from anthropogenic sources, however slow, would lead to a raised level over a period that was short in terms of both geological time and the human species, with attendant environmental and sustainability risks. For long-term sustainability, therefore, emissions cannot exceed the long-term global absorptive capacity.

Albritton et al. (2001) state, "Natural land and ocean sinks with the capacity to persist for hundreds or thousands of years are small $(<0.2 \mathrm{PgC} / \mathrm{yr})$." Carbon absorption of $0.2 \mathrm{Pg} / \mathrm{yr}$ is much less than current rates, and equates to the long term deposition of carbon in the earth's crust by sedimentation on the sea floor of terrestrial and aquatic plant and animal remains. It provides an ultimate goal for a sustainable limit. This thesis therefore adopts the long-term carbon sedimentation absorption rate of $0.2 \mathrm{Pg} / \mathrm{yr}$ as the limit for calculating sustainability.

\subsection{Per-capita $\mathrm{CO}_{2}$ Emission Limits}

One advantage of using $\mathrm{CO}_{2}$ as a means of measuring sustainability is that the absorptive capacity of the planet is not subject to major uncertainty. Similarly, global population is known to quite tight limits. By simply dividing carbon absorption of $3.5 \mathrm{Pg} / \mathrm{yr}$ by the population, an allowable per-capita carbon emission limit can be derived. The raw carbon per-capita figure is thus $3.5 \mathrm{Pg} / 6.8 \times 10^{9}$ people $=0.52 \mathrm{t} / \mathrm{yr}$.

If a halving of the (20 year average) absorption by the ocean is assumed, while terrestrial absorption is maintained, the net annual allowable carbon emission, within the absorptive capacity of the planet, falls from the current 3.5 to $2.4 \mathrm{Pg} / \mathrm{yr}$, resulting in an allowable per-capita emission of 0.52 to $0.36 \mathrm{t} / \mathrm{yr}$, at current population levels.

Assuming a reduction of carbon absorption to zero by the terrestrial biosphere, without considering reduced oceanic absorption, the net allowable emissions fall to $2.3 \mathrm{Pg} / \mathrm{yr}$, with a current per-capita allowable emission of $0.33 \mathrm{t} / \mathrm{yr}$. 
If the reductions in oceanic and terrestrial absorption outlined by Prentice et al. and Cox et al. are factored in, net global carbon absorption is $1.1 \mathrm{Pg} / \mathrm{yr}$, equating to an allowable per-capita emission of $0.17 \mathrm{t} / \mathrm{yr}$.

If the low $0.2 \mathrm{Pg} / \mathrm{yr}$ figure of persistent sinks and current population are used,

\section{the current allowable per-capita carbon emission is $29 \mathrm{~kg}$}

$$
\left(0.2 \mathrm{Pg} \div 6.8 \times 10^{9}=\mathbf{0 . 0 2 9} \mathbf{t} / \mathbf{y r}\right)
$$

These lower numbers assume a population stabilised at the current 6.8 billion. Assuming a population of between 9 and 11 billion, the allowable per-capita emission level would be from $0.08 \mathrm{t} / \mathrm{yr}$ to $0.13 \mathrm{t} / \mathrm{yr}$ for a global absorption rate of $1.1 \mathrm{Pg} / \mathrm{yr}$. For the persistent long-term absorption rate the per-capita levels are $0.018 \mathrm{t} / \mathrm{yr}$ to $0.022 \mathrm{t} / \mathrm{yr}$.

If the same population ranges are applied to current absorption rates, the 9 billion population has a per-capita allowable limit of $0.39 \mathrm{t} / \mathrm{yr}$, while a population of 11 billion can emit $0.32 \mathrm{t} / \mathrm{yr}$ per-capita.

The figures used to calculate Table 5.4 rely on medium estimates from population and climate change projections. Changes in population or climate change outcomes could have significant effects on the results, in either direction. The current absorption level is a 20 year average from 1989-2008. The pink cell shows the current per-capita carbon sink limit, while the green cell shows the long-term percapita carbon sink limit, with current population. 
Table 5.4 Global Per-capita Carbon Limit for Absorption Capacities \& Populations

\begin{tabular}{|c|c|c|c|c|c|c|c|}
\hline \multicolumn{2}{|c|}{$\begin{array}{l}\text { Population (billions) } \\
\text { Approximate Year }\end{array}$} & $\begin{array}{c}0.8 \\
1750 \\
\end{array}$ & $\begin{array}{c}2 \\
1927\end{array}$ & $\begin{array}{r}6.8 \\
2009\end{array}$ & $\begin{array}{c}9 \\
2042 \\
\end{array}$ & $\begin{array}{c}10 \\
2200 \\
\end{array}$ & $\begin{array}{c}11 \\
2200 \\
\end{array}$ \\
\hline \multicolumn{2}{|l|}{ Carbon sinks (Pg/yr) } & \multicolumn{6}{|c|}{ Global Per-capita Carbon Emission Limit (t/yr) } \\
\hline Net C sink, Average 1989-2008 & 3.5 & 4.43 & 1.77 & 0.52 & 0.39 & 0.35 & 0.32 \\
\hline Ocean sink 50\%, Land sink 100\% & 2.4 & 3.02 & 1.21 & 0.36 & 0.27 & 0.24 & 0.20 \\
\hline Ocean sink $100 \%$, Land sink $0 \%$ & 2.3 & 2.82 & 1.13 & 0.33 & 0.25 & 0.23 & 0.15 \\
\hline Ocean sink $50 \%$, Land sink $0 \%$ & 1.1 & 1.41 & 0.56 & 0.17 & 0.13 & 0.11 & 0.08 \\
\hline Long-term absorption & 0.2 & 0.25 & 0.10 & 0.029 & 0.022 & 0.020 & 0.018 \\
\hline
\end{tabular}

Sources: DESA, 1998, 2005; Census Bureau, 2009; Le Quere et al., 2009

The emission limits in Table 5.4 contrast starkly with current regional average percapita carbon emissions of $4.40 \mathrm{t} / \mathrm{yr}$ (North America); $2.22 \mathrm{t} / \mathrm{yr}$ (Europe); and $1.24 \mathrm{t} / \mathrm{yr}$ (World), as shown in Table 5.3 Only Africa at $0.32 \mathrm{t} / \mathrm{yr}$ is sustainable at current absorption levels, and still an order of magnitude above long-term sustainable levels.

While contemplating which end of the range for a per-capita $\mathrm{CO}_{2}$ emission limit, recent warnings suggest adopting stringent targets. Hansen et al. (2007) comment:

Recent greenhouse gas (GHG) emissions place the Earth perilously close to dramatic climate change that could run out of our control, with great dangers for humans and other creatures... Only intense simultaneous efforts to slow $\mathrm{CO}_{2}$ emissions and reduce non- $\mathrm{CO}_{2}$ forcings can keep climate within or near the range of the past million years.

\subsubsection{Sustainable Populations versus Emission Levels}

Using different $\mathrm{CO}_{2}$ absorption rates from Table 5.4 per-capita emission rates can indicate a sustainable world population. Figure 5.2 shows a selection of absorption and emission rates, and the resulting population level that can be sustained. The population versus emissions scenarios relate to current carbon absorption (3.5Pg/yr); absorption with oceanic absorption reduced by half (2.4 $\mathrm{Pg} / \mathrm{yr}$ ), terrestrial absorption reduced to zero $(2.3 \mathrm{Pg} / \mathrm{yr})$ and both reductions together $(1.1 \mathrm{Pg} / \mathrm{yr})$. The long-term absorption $(0.2 \mathrm{Pg} / \mathrm{yr})$ is significantly lower, assuming terrestrial and oceanic sinks have absorbed all they are able to over the long term. 
Figure 5.2 Sustainable Population at Per-capita Carbon Absorption/Emission Levels

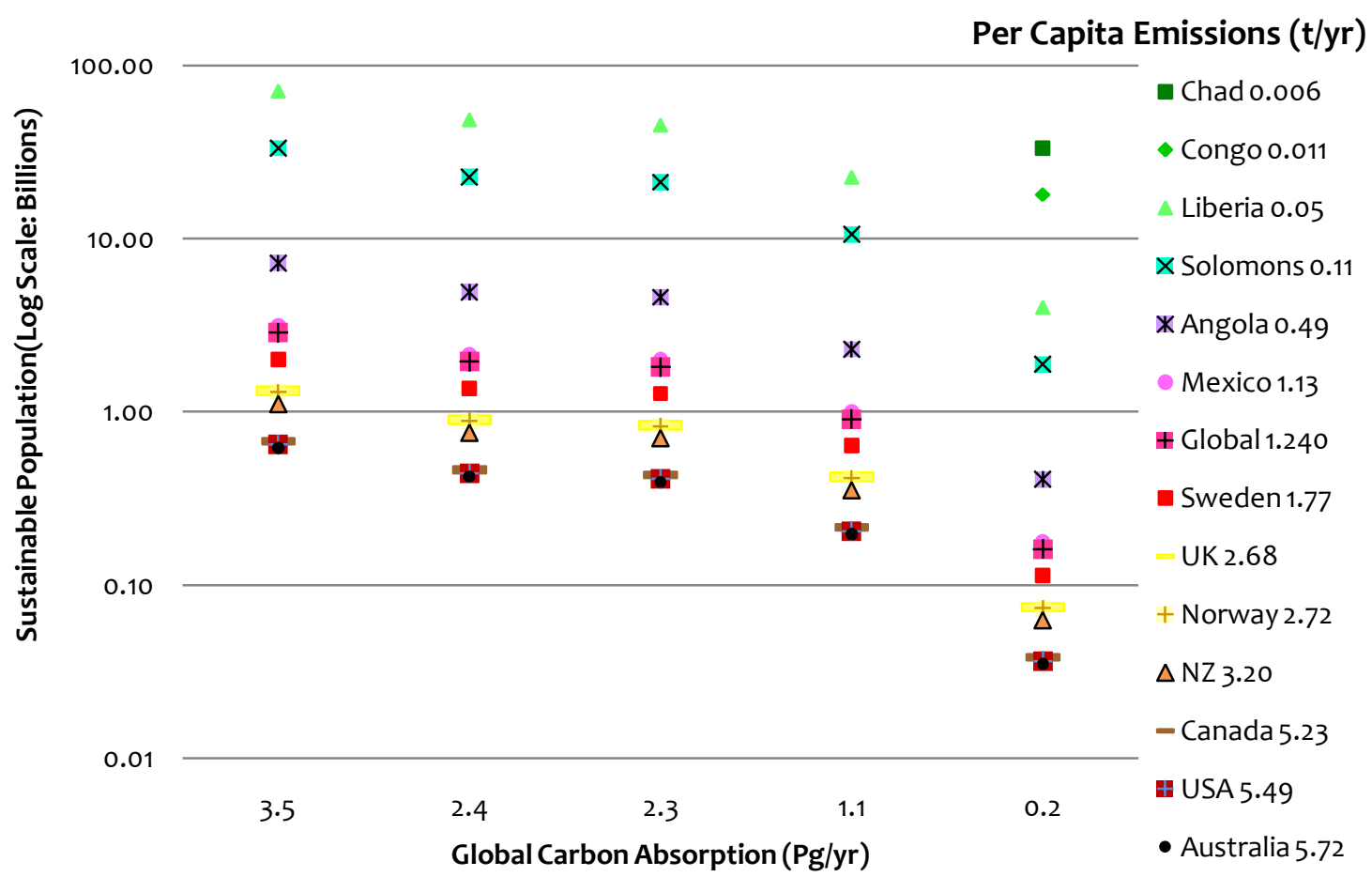

Sources: DESA 1998, 2005; Cox et al., 2000; Albritton et al., 2001; Prentice et al., 2001; EIA, 2006; Census Bureau, 2009; Le Quéré et al., 2009

At emission rates well below current rich country averages, or even below world averages, the long term $\mathrm{CO}_{2}$ global absorption level indicates a sustainable population of much less than the current 6.8 billion. The current global average percapita carbon emission (1.24 t) is slightly more than Romania and Uzbekistan (1.23) and slightly less than Panama (1.26) and China (1.27). At the current emission rate, the world population would need to stand at 160 million to be sustainable. Alternatively, the current population needs to reduce average $\mathrm{CO}_{2}$ emissions to approximately $1.5 \%$ of current levels, or to about $0.5 \%$ of the current New Zealand emission level. The per-capita emission rates of particular countries are used in Figure 5.2 to give an idea of the sort of lifestyle that currently matches particular emission levels.

The values for reductions in $\mathrm{CO}_{2}$ emissions to fit the long term absorptive capacity are noticeably lower than some recent calls for emissions cuts. The $60 \%$ emissions cut called for by Stern (2006) and other commentators relate to current absorption and population levels, but do not accommodate reduced oceanic or terrestrial 
absorption. An $80 \%$ reduction, used by Stern as an upper figure for emission reduction cuts, equates to what could be absorbed by the planet with current population and per-capita emission levels, the reduction to zero of terrestrial uptake modelled by Cox et al. (2000), and a reduced oceanic uptake of about $20 \%$. It does not account for any population increase, or the reduction to about half the current oceanic uptake level derived in Prentice et al. (2001). Neither figure accommodates either $\mathrm{CO}_{2}$ levels being reduced towards past lower levels, or the long-term absorption level. The figures used by Stern come mostly from the 2001 IPCC report. Since that time, rather than business as usual, emission levels have increased at an accelerating rate, both in global and per-capita terms (Raupach, 2006).

For the USA, carbon emissions need to drop by about $99.7 \%$ per-capita to be within the long-term global absorption ability. Alternatively, to sustain a global population with a (current) American lifestyle would imply a reduction to about 36 million people.

Given current absorption and emissions rates, the world population would need to live approximately an Angolan lifestyle to avoid increasing atmospheric $\mathrm{CO}_{2}$. Larger population is manageable under different absorption scenarios, but only with percapita emission rates in line with poor countries, as shown by the examples of Congo and Chad. In a medium term scenario, allowing for reduced oceanic and terrestrial $\mathrm{CO}_{2}$ uptake, and population rising to around 9 billion, a lifestyle similar to that of the Solomon Islands with emissions of $0.1 \mathrm{t}$ per-capita would be sustainable while oceanic carbon sinks were still absorbing $\mathrm{CO}_{2}$. In the long term, after oceanic sinks became saturated, larger populations would still be sustainable, but only with lifestyles equating with those of Chad or the Congo, emitting carbon below $0.01 \mathrm{t}$ per-capita. Under other sustainability considerations, however, such as biodiversity and soil preservation, lifestyles such as in those in Chad or the Congo are not viable.

Since large 'surprises' that may move the population trajectory up or down remain a distinct possibility, the figures at either end of the range of possibilities also need to be attended to. The upper and lower ends of the per-capita absorption range, 0.52 and $0.018 \mathrm{t} / \mathrm{yr}$, are therefore also applied to calculations in Chapter 9. 


\subsection{Housing $\mathrm{CO}_{2}$ Emissions}

\subsubsection{House and Household Size}

To assess the sustainability of houses using a per-capita emission limit, the number of people per-house needs to be known. Wealthy countries, particularly, have a trend towards smaller households. As Figure 5.3 shows, the typical household size reduction since 1971 was $\sim 20 \%$

Figure 5.3 Average Household Size 1971 - 2006, Selected Countries

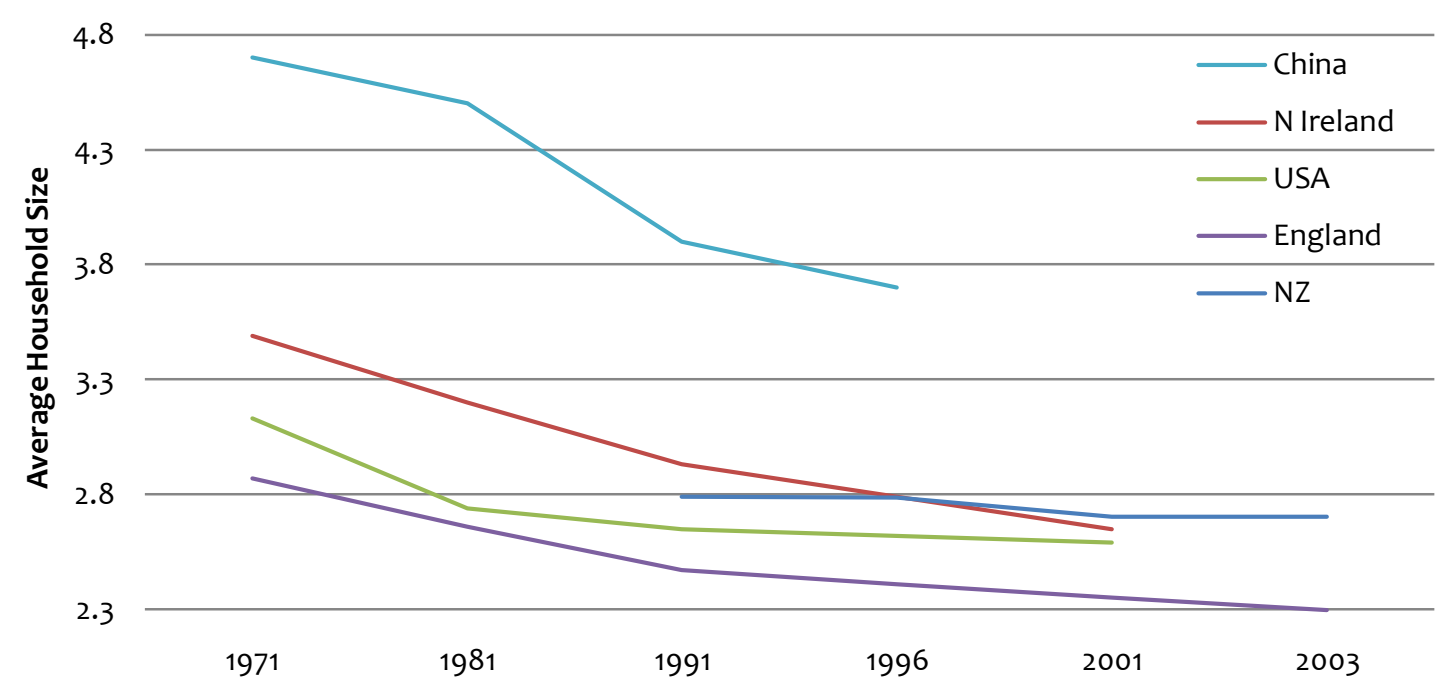

Source: Peng and Guo, 2000; Barry et al., 2005; Statistics, 2008c, 2008d

In New Zealand, household size averaged 2.7 people over the last 10 years, falling every year from 2.79 in 1991 to 2.66 in 2008, although rising in 2001 and 2002 (Statistics, 2008c; 2008e).

In the high-emitting US the percentage of three or more person households fell from 1980 to 2001. Battles and Hojjati (2005) note, "The growth in smaller household size places upward pressures on the demand for energy - as seen in energy-intensity measurements" (Table 5.2). With current energy production, this also implies upward pressure on $\mathrm{CO}_{2}$ emissions. Similar patterns exist in other developed countries. 
The average number of bedrooms per-house is slowly rising, from 2.89 in 1991 to 3.06 in 2001. At the same time, the average number of people per bedroom has slowly fallen, from 1.02 to 0.97 . Overall, total bedrooms in New Zealand dwellings are approximately equal to national population. Three bedroom houses remain by far the most common dwelling type, representing just under half of all dwellings. Two and four bedroom dwellings represent a further $22 \%$ and $18.3 \%$ respectively. Combined, these represent $89.6 \%$ of all dwellings (Pink, 2002). Because they are the most common, and because two and four bedroom dwellings represent about the same number on either side of the most common type, three bedroom houses are a good proxy for analysing New Zealand houses in general.

Household size, and the matching house size, is used in this thesis as the basis for calculation, rather than floor area. If floor area is used as the denominator, it is possible to reduce $\mathrm{CO}_{2}$ emissions by designing a larger house, since larger floor area does not require proportionately as much increase in walls, foundation, roof, or services. For a house of three or four bedrooms the opposite is true: energy and $\mathrm{CO}_{2}$ may be reduced, per bedroom, by making it smaller for the same number of bedrooms.

Averaged data from recent years is used for house and household size as the basis for calculations. Analysing different sized or otherwise atypical houses, while a valuable avenue for further research, was outside the scope of this thesis. House typology was thus assumed to remain consistent with current construction practice.

The purpose of the typical New Zealand house is to house the typical New Zealand family. A three bedroom house is required. In LCA terms, the 'functional unit' used for analyses in this thesis is:

provision of housing for 2.7 people for 1 year.

\subsubsection{Proportion of New Zealand $\mathrm{CO}_{2}$ Emissions for Houses}

At a personal level, $\mathrm{CO}_{2}$ emissions occur from all our different activities. Since people in New Zealand move house quite frequently (Johnstone, 2001) and the emissions from any particular house cannot be easily linked over its lifetime with one 
set of occupants, housing as a $\mathrm{CO}_{2}$-emitting activity can best be viewed at a national level. The percentage of national GHGs that housing currently emits is therefore appropriate in determining a percentage of allowable $\mathrm{CO}_{2}$ that houses can sustainably emit. Similar proportions of total GHG emissions could also be determined for other activities by an equivalent method, so that the global per-capita $\mathrm{CO}_{2}$ emission limit could be applied to assess the sustainability of those activities.

Are the proportions of current national GHG emissions for housing a reliable guide? It is difficult to determine what future shape the organisation of society will take. Current activity patterns are a rough guide to future activity patterns, but changes are likely in areas of energy use. Energy efficiency gains are likely in housing, but rising housing energy use (Isaacs et al., 2006) may outstrip household sizes falling, suggesting caution needs to be exercised applying current data and proportionality to medium term projections. Efficiency is rising in non-household areas including transport and industry. Potentially, with fixed limits to avoid Jevons' Paradox, total energy consumption will be reduced. In high-consumption developed countries technological efficiency may reduce energy used in some sectors, such as transport. Equally, efficiencies in housing may reduce operating energy as high insulation, solar water heating and efficient appliances become more prevalent.

The existing New Zealand housing stock is high-emitting, due especially to high operational emissions, while newer houses use less energy. The replacement rate of the housing stock therefore affects $\mathrm{CO}_{2}$ emissions from housing. The ten year average to 2008 for new dwellings was 25,300 (Statistics 2008b). At a similar rate of new construction, about $1.7 \%$ of existing stock, the number of new dwellings by 2050 will approximately equal the number of dwellings currently standing (Statistics 2008e). Although by 2050 new dwellings may only make up approximately half the housing stock, Johnstone (2001) notes that renovation on the order of once every 20 years has a material effect on the energy performance of the existing housing stock. By $2050 \mathrm{a}$ substantial proportion of the current housing stock may have been renovated to a higher performance level. Nevertheless, changes made in the performance standard of houses are slow to affect the whole housing stock, suggesting little change in the relative emissions of the residential versus other sectors. 
Higher energy costs and climate change taxes, or equivalent, are likely to see acrossthe-board reductions in energy use and $\mathrm{CO}_{2}$ emissions, not just in housing. The proportionality across different sectors is therefore assumed to remain largely unchanged; current energy usage for house construction and operation as a percentage of national energy usage is assumed to remain at trend and is used in calculations for this thesis.

\subsection{3 $\mathrm{CO}_{2}$ Emissions from New Zealand Houses}

$\mathrm{CO}_{2}$ emissions for houses can be calculated from the operating energy and construction emissions. Emissions sources include wood and gas for heating and cooking, electricity for lighting, heating and appliance operation, and other operating energy sources. Construction figures include $\mathrm{CO}_{2}$ emissions from maintenance during the building lifetime, as well as initial construction.

Operating energy is available from studies of household energy use (Isaacs et al., 2006). National energy or $\mathrm{CO}_{2}$ data for house construction has not been collected. Two methods may be employed to fill this gap. One is using economic data to estimate a proportion of national $\mathrm{CO}_{2}$ emissions. The other is a detailed process analysis of current house types and materials and the associated emissions for construction, maintenance and operation of those houses. That analysis forms part of Chapter 9, and shows that, using a ten year average of individual house emissions, national per-capita emissions, and household size, housing emissions are $6.4 \%$ of total national emissions.

Energy consumed by the residential sector accounts for $12.9 \%$ of total energy demand (MED, 2006a). Calculating an allowable $\mathrm{CO}_{2}$ emission rate for house construction using economic data is less straightforward. For construction emissions, the most representative nationally published figures are for expenditure on residential buildings, in relation to expenditure on gross domestic product (GDP).

The data comes from the Statistics New Zealand quarterly building activity survey (QBAS) which represents the cost of constructing buildings, including fees and 
ancillary work (Barnes, 2006). This methodology shows that, averaged from 1999 to 2007, the residential building sector accounts for 5.3\% of New Zealand $\mathrm{CO}_{2}$ emissions (DBH, 2006d). This percentage captures house, apartment, and renovation construction, and equated to $63 \%$ of all building activity, by consents, in 2006 (DBH, 2006c). It corresponds to the analysis done for Chapter 9 which includes construction and maintenance.

The lower proportion of $\mathrm{CO}_{2}$ that houses emit compared to the proportion of energy (5.3 versus $12.9 \%$ ), can be attributed to a widespread use of low-emitting firewood for heating, and the higher than average percentage of electricity used for household operation, along with the high percentage of hydro generation of that electricity. Electricity used by houses averaged about 33\% of national electricity use over the last five years (Dang et al., 2009). There are also variations in emissions, arising especially from electricity generation responding to dry years in hydro generation; initiating more high-emitting coal and gas generation.

The residential construction sector, and its annual $\mathrm{CO}_{2}$ emission, is influenced by the performance of the economy, as evident in Figure 5.4. Greater demand from more economic activity tends to be met with high-emitting gas and coal. The effect on houses is muted, however, since the relatively stable operating emissions for existing houses are the predominant contributor to the sector, outweighing variations in construction activity.

\section{Figure 5.4 Residential Percentage of National Emissions}

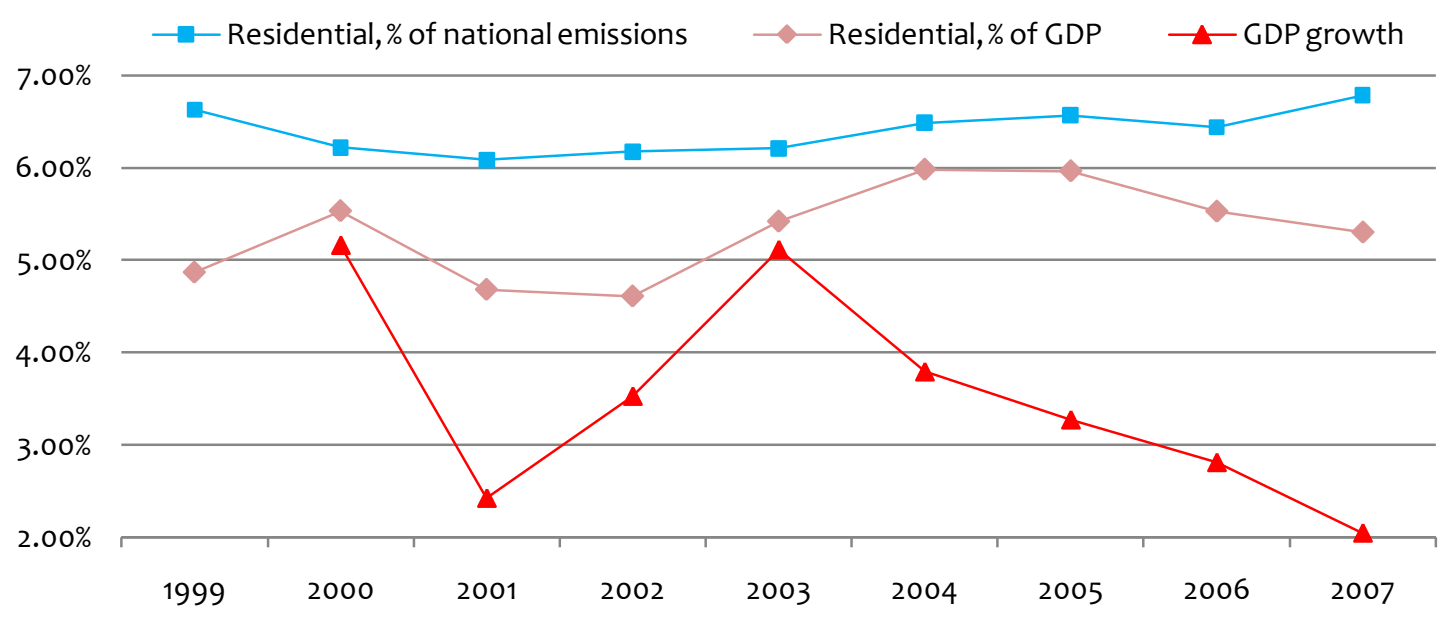

Source: MED, 2006b 
The annual New Zealand average $\mathrm{CO}_{2}$ emissions used for calculations take account of all New Zealand emissions and absorptions, including agriculture and forestry. Non-building and household sectors are included in the emissions total because it is assumed that the New Zealand economy is dependent on, or at least intimately interlinked, with all sectors and their emissions/absorptions; the whole New Zealand economy, which allows the current level of affluence enjoyed here, would be substantially different if these sectors were excluded. As participants and beneficiaries of the totality of the infrastructural, economic, and social fabric of the country, each New Zealander incurs his/her portion of the total net emissions/absorptions of $\mathrm{CO}_{2}$.

A detailed process analysis of houses, compared with economic analysis, shows a similar but slightly higher percentage (6.4 versus 5.3\%) of national emissions for housing. The greater specificity for a three bedroom house from detailed calculations was preferred to the uncertainties of combining data sets from different government bodies, different time spreads, and inherently uncertain economic input-output methodology. The total emissions value used is for the annualised emissions for construction, maintenance, and operating energy. It applies to New Zealand houses generally, assuming an average dwellings size of 3 bedrooms, and 1970s lightweight slab construction. It is a good approximation of the New Zealand housing stock, verified by national statistics. It is also representative of older houses, although their particular emissions profile and construction total will be slightly different, given the use of timber in floors and wall and roof sarking, but also including low levels of insulation. The construction and maintenance $\mathrm{ECO}_{2}$ emissions are $249 \mathrm{~kg}$, expressed as an annualised figure. Operating $\mathrm{CO}_{2}$ emissions are 2,038 $\mathrm{kg}$, giving a total annual emission per-house of 2,287 kg.

\subsubsection{Sustainable $\mathrm{CO}_{2}$ for House Operation}

The target for per-capita $\mathrm{CO}_{2}$ emissions is calculated by dividing the long-term annual global carbon absorption through sedimentation (Albritton et al., 2001), by the global population (Census Bureau, 2009), and converting this to a $\mathrm{CO}_{2}$ unit, in kilograms. Thus, using annual figures: 
Sustainable per-capita $\mathrm{CO}_{2}$ emissions $=$

where $\mathrm{k}$ is the conversion (44/12) from carbon to $\mathrm{CO}_{2}$. Thus:

$$
\text { sustainable global per-capita } \mathrm{CO}_{2} \text { emissions }=\frac{0.2 \operatorname{Pg} \times 3.67}{6,800,242,631}=108 \mathbf{~ k g}
$$

It should be recalled that current absorption is higher than the Albritton et al. value of long-term absorption. Adopting the current absorption value would give a higher allowable per-capita emission level. Conversely, population growth is not accounted for in this equation; a larger population would give a lower allowable per-capita emissions level. For 9 billion:

$$
\text { sustainable global per-capita } \mathrm{CO}_{2} \text { emissions }=\frac{0.2 \mathrm{Pg} \times 3.67}{9,000,000,000}=82 \mathrm{~kg}
$$

And for 11 billion:

$$
\text { sustainable global per-capita } \mathrm{CO}_{2} \text { emissions }=\frac{0.2 \mathrm{Pg} \times 3.67}{11,000,000,000}=67 \mathrm{~kg}
$$

With an allowable per-capita emission calculated, this value can be applied to houses. Assuming the same ratio of emissions for housing as is currently the case, the global per-capita 'allowable' figure is multiplied by the percentage emitted for housing, in New Zealand. Thus:

The $\mathrm{CO}_{2}$ target for house emissions $=$ sustainable global per-capita $\mathrm{CO}_{2}$ emissions $\mathrm{x}$ housing \% of emissions $\mathrm{x}$ average household size.

Thus, the $\mathrm{CO}_{2}$ target for total house emissions $=108 \times 0.064 \times 2.7=19 \mathbf{~ k g}$. 
Figure 5.5 Derivation of Sustainable Per-house $\mathrm{CO}_{2}$ Emissions

Global long-term annual carbon absorption. $0.2 \mathrm{Pg}$
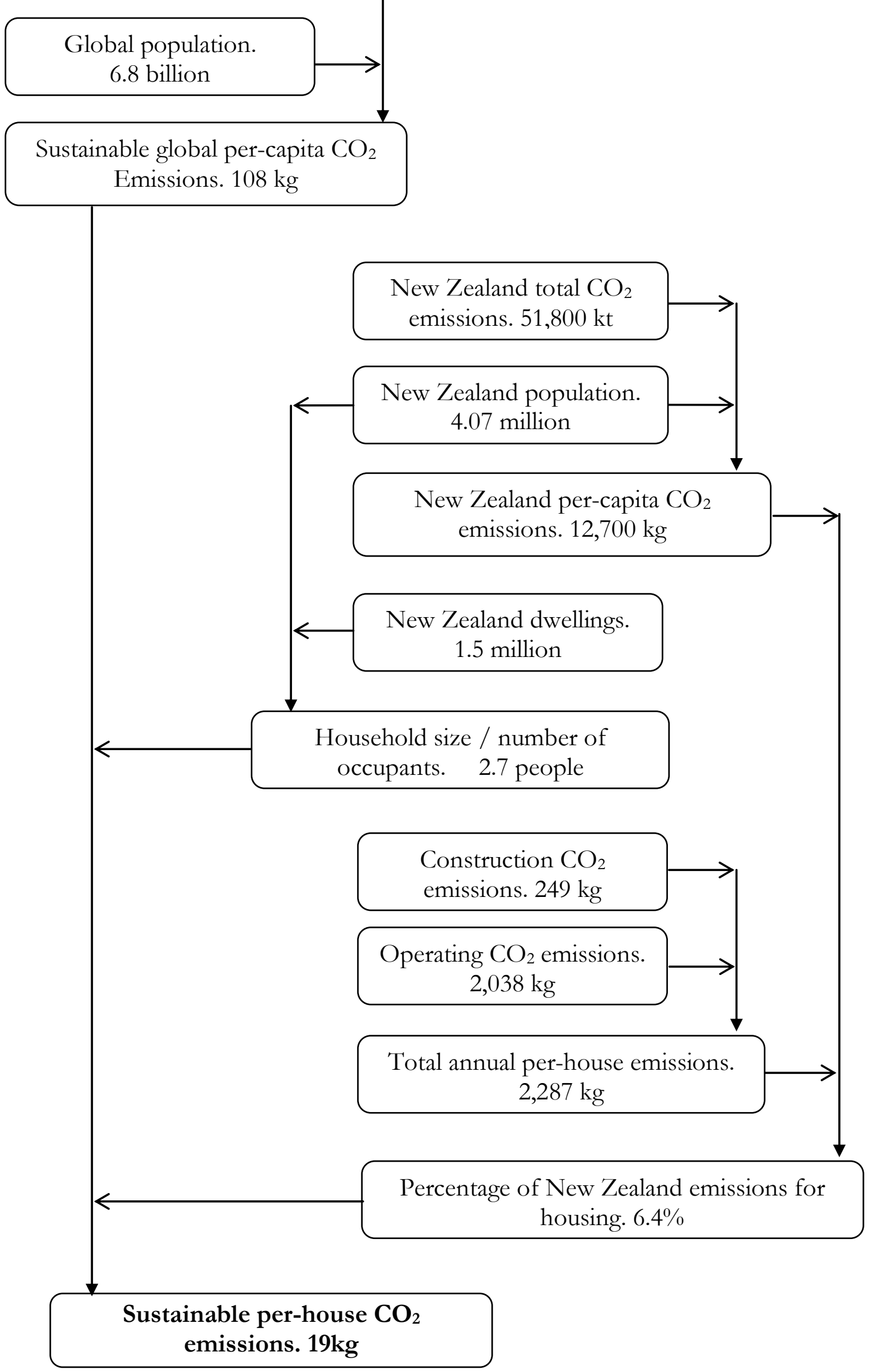
If the current rate of global absorption is used, the target is somewhat less stringent; the resulting 'soft' $\mathrm{CO}_{2}$ target is $326 \mathrm{~kg}$ per-house per-annum. Conversely, if the stabilisation population of 11 billion is applied, along with the long-term global absorption rate, the target is $11 \mathrm{~kg}$ per-house per-annum.

Table 5.5 shows a summary of the above per-capita and per-house $\mathrm{CO}_{2}$ figures, rounded to the nearest kilogram. Some of these figures are the equivalent of ones in Table 5.4, but expressed as $\mathrm{CO}_{2}$ rather than carbon. Pink cells show current per-capita and per-house absorbable emissions, while green cells show sustainable per-capita and per-house emissions absorbable over the long term, with current population.

Table 5.5 Absorbable Per-capita and Per-house $\mathrm{CO}_{2}$ Emissions

\begin{tabular}{|c|c|c|c|c|c|}
\hline \multicolumn{2}{|c|}{ Population (billions) } & 6.8 & 9 & 10 & 11 \\
\hline \multirow{6}{*}{ 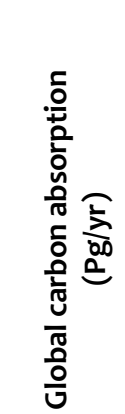 } & \multirow[b]{2}{*}{3.5} & \multicolumn{4}{|c|}{ Per-capita $\mathrm{CO}_{2}$ emissions (kg) } \\
\hline & & 1,889 & 1,427 & 1,285 & 1,168 \\
\hline & \multirow[t]{2}{*}{0.2} & 108 & 82 & 73 & 67 \\
\hline & & \multicolumn{4}{|c|}{ Per-house $\mathrm{CO}_{2}$ emissions (kg) } \\
\hline & 3.5 & 326 & 247 & 222 & 202 \\
\hline & 0.2 & 19 & 14 & 13 & 11 \\
\hline & & \multicolumn{2}{|c|}{ (Current Absorption) } & (Lor & tion) \\
\hline
\end{tabular}

Sources: Albritton et al., 2001; Prentice et al., 2001; DESA, 2005; Le Quere et al., 2009

All these house targets are far below current average New Zealand house $\mathrm{CO}_{2}$ emissions, which average just under 2,300 kg per-annum: seven times higher than the 'soft' target $(326 \mathrm{~kg})$, more than 120 times higher than the 'sustainable' target $(19 \mathrm{~kg})$, and nearly 200 times higher than the stringent target with an 11 billion population. That is, to be sustainable within the $\mathrm{CO}_{2}$ per-house target of $19 \mathrm{~kg}$, 120 houses need to be built, maintained, and operated for the current emissions of just one house. Modest changes from current house construction and operation practice are unlikely to achieve the target. 


\subsection{Conclusion}

Chapter 4 showed why $\mathrm{CO}_{2}$ is the best method of assessing sustainability, and why it has an edge over energy as a measure. This chapter has shown how a natural limit on carbon absorption can be applied as a sustainability limit on a per-capita basis. Different population levels have been incorporated to show the range of values for a sustainable carbon limit, and where the today's population stands on that scale.

A method to apply a sustainable per-capita carbon emission limit to houses has been described that could also be used as a model to apply to other activities, from global, to national, to local, to personal. The different global absorptions and population projections used for determining a $\mathrm{CO}_{2}$ limit for sustainable houses all result in very stringent targets. Nonetheless, a range of options exists that can reduce construction and operating emissions. It is therefore hypothesised that:

\section{by making strategic design and construction decisions, materials choices, and certain technology selections, the $\mathrm{CO}_{2}$ profile of houses can be brought within a target limit that can be considered sustainable.}

This hypothesis is tested in Chapter 9, using embodied energy and embodied $\mathrm{CO}_{2}$ analysis, which are discussed in Chapters 6, 7, and 8. 


\section{Embodied Energy Analysis}

The flamboyant era through which we have been passing is due not to our own merits, but to our having inherited accumulations of solar energy from the carboniferous era, so that life for once has been able to live beyond its income.

- Frederick Soddy, 1926

\subsection{Introduction}

Chapter 3 described the attributes required of sustainability measures. Chapter 4 reasoned that energy analysis (EA), along with closely allied $\mathrm{CO}_{2}$ analysis, for which it is a pre-requisite, are the most effective methods at matching those requirements. This chapter examines the history of EA and discusses general terms and definitions. The various methods of EA: statistical; input-output (I-O); process; and hybrid, are discussed separately under their own sub-headings. The term 'embodied energy analysis' is generally shortened in this chapter to simply 'energy analysis', abbreviated as EA. 'Embodied energy' is still abbreviated as EE.

A primary reason for doing EA is as a sustainability indicator, and the reason for using it in this thesis. By summing all the instances of energy used for a particular action, it is possible to form a useful overview of energy use, and by extension, the relative impact of accumulated human activities. Energy has an economic cost, but primarily it is the environmental cost associated with its provision and use that underlies its value as a sustainability indicator. By summing energy use, the environmental impact of one or a group of activities can be revealed.

The result of EE analysis is the determination of the quantity of energy sequestered (embodied) in a product or service, resulting from the many stages of production, from obtaining and distributing energy, mining through to enrichment, transporting, processing, and production. The energy of the infrastructure and production facilities, and transport of various materials and energy throughout the process, are also examined. 
The formalised definition of energy analysis stated in a report by the International Federation of Institutes for Advanced Study (IFIAS) (Slesser, 1974)1 reads:

Energy analysis is defined as the determination of the energy sequestered in the process of making a good or service within the framework of an agreed set of conventions or applying the information so obtained.

Such analyses are undertaken to different degrees of complexity and may use a variety of means. Sometimes the agreed conventions need to be re-examined and adjusted to suit the goal of the analysis.

A hybrid analysis, based primarily on process analysis, was developed for this thesis. It is described along with its application to the analysis of building materials. The methodology is made explicit, as are the conventions used, or deviated from.

\subsection{Terms, Definitions, Meanings, and Usage}

Slesser (1974) defined EE as:

the energy sequestered or embodied in a product or service resulting from the many stages of its production, from mining through enrichment, transporting, processing and production to the useable product or service, and including all supporting processes and infrastructure.

Included in this definition is the energy embodied in production facilities and machinery, as well as the facilities and infrastructure necessary to provide primary and delivered energy to the process. The energy required for the necessary parts and

1 The report from the workshop (Workshop Report No. 6) is usually cited as "IFIAS (1974)". Slesser (1974) was the author of the text, general editor of the report, and official rapporteur for the workshop, although he acknowledged he was simply attempting to represent the views of the workshop participants,. References in this thesis to the workshop are generally to "IFIAS"; references to the report are to "Slesser (1974)". The equivalent report of 1975, from the workshop "Energy Analysis and Economics", is usually cited as "IFIAS (1975)", although it is authored and edited by the workshop rapporteur, Long (1975). It is cited as "Long (1975)" in this thesis. 
processes of the supporting general economy, beyond specific supporting infrastructure, is also included within the definition.

$\mathrm{EE}$ is sometimes referred to as sequestered energy, the energy coefficient or the energy intensity of the material. Typical units used are: MJ per \$; MJ per kg; MJ per $\mathrm{m}^{3}$; or MJ per $\mathrm{m}^{2}$.

The definitions of the different analysis methods in Sections 6.2.1 to 6.2.4 are brief ones, since each method is discussed more fully under its own heading in Sections 6.4 to 6.7. Sections 6.2 .5 to 6.2 .10 discuss usage of the terms, especially as applied in this thesis.

\subsubsection{Statistical Analysis}

Statistical analysis uses published data from a variety of sources. Sparse or uneven data is a disadvantage.

\subsubsection{Input-Output Analysis}

I-O analysis uses data from national economic input-output tables, coupled with known energy data for different energy industries. The unit derived is $\mathrm{MJ} / \$$. Analyses proceed from consumer or producer prices. Inherent imprecision in the data is a disadvantage.

\subsubsection{Process Analysis}

Process analysis uses manufacturers' data for energy and materials inputs to one or more production processes plus similar upstream data from other contributory processes. A time-intensive research requirement is a disadvantage.

\subsubsection{Hybrid Analysis}

Hybrid analysis combines I-O, process, and statistical methods. The emphasis can be an I-O based method, supplemented with process and/or statistical data, or a process method, supplemented with I-O and/or statistical data. 


\subsubsection{System Boundary}

The system boundary is the chosen (or necessitated) limit to the particular analysis. In cases where data or resources for a complete analysis are absent, the system boundary may be limited. Slesser (1974) recommends this should be clearly stated.

Statistical, I-O, process, and hybrid analyses may all have varying system boundaries. I-O analysis tends to have the widest boundary, because all activities within national borders are captured in economic analysis. It does not have downstream inputs however, so its system boundary is limited compared with a process or hybrid analysis that may include, for example: warehousing and retailing of building materials; transport of materials to site; and construction energy. In an expanded system boundary for a consumer item such as a car, the operating energy of the article or system would also be considered.

Most EA uses a factory gate system boundary as Slesser recommends, making comparison of different analyses straightforward. In life cycle EA the system boundary is often described as cradle to grave, or cradle to cradle. In cradle to grave analyses inputs are traced back to the mining (and exploration) of energy and raw materials and to end of life demolition, incineration, or dumping. In cradle to cradle analysis the system boundary extends to disassembly and recycling of constituent parts.

Cradle to grave or cradle to cradle analyses make assumptions about future behaviour towards products and materials at the end of their lives. This thesis does not attempt to assess or estimate these unknowns or the methodologies for doing so. Instead, data on actual practices is adhered to, to ensure reliability and verifiability. This thesis therefore follows the cradle to factory gate system boundary convention for ingredient and energy inputs, and a cradle to grave boundary for whole houses, based on the current practice of demolition and landfilling. No assumptions are made about benefits from future potential behaviour, such as recycling or waste incineration accruing to the materials under analysis. It is incumbent on users of the results of this thesis to add further energy and materials inputs to the analysis for any process relevant to extending the system boundary. 
Slesser (1974) presented a somewhat arbitrary four-level model of system boundaries (Figure 6.1). He acknowledged it as a simplification, noting that I-O analysis may take "the energy analysis back to the fourth level and beyond". The simplification applies to the extent of the analysis activity, but could be misleading about the number of steps that might be employed in a process analysis within the different levels, which can be large.

Figure 6.1 Levels in the Definition of the System Boundary

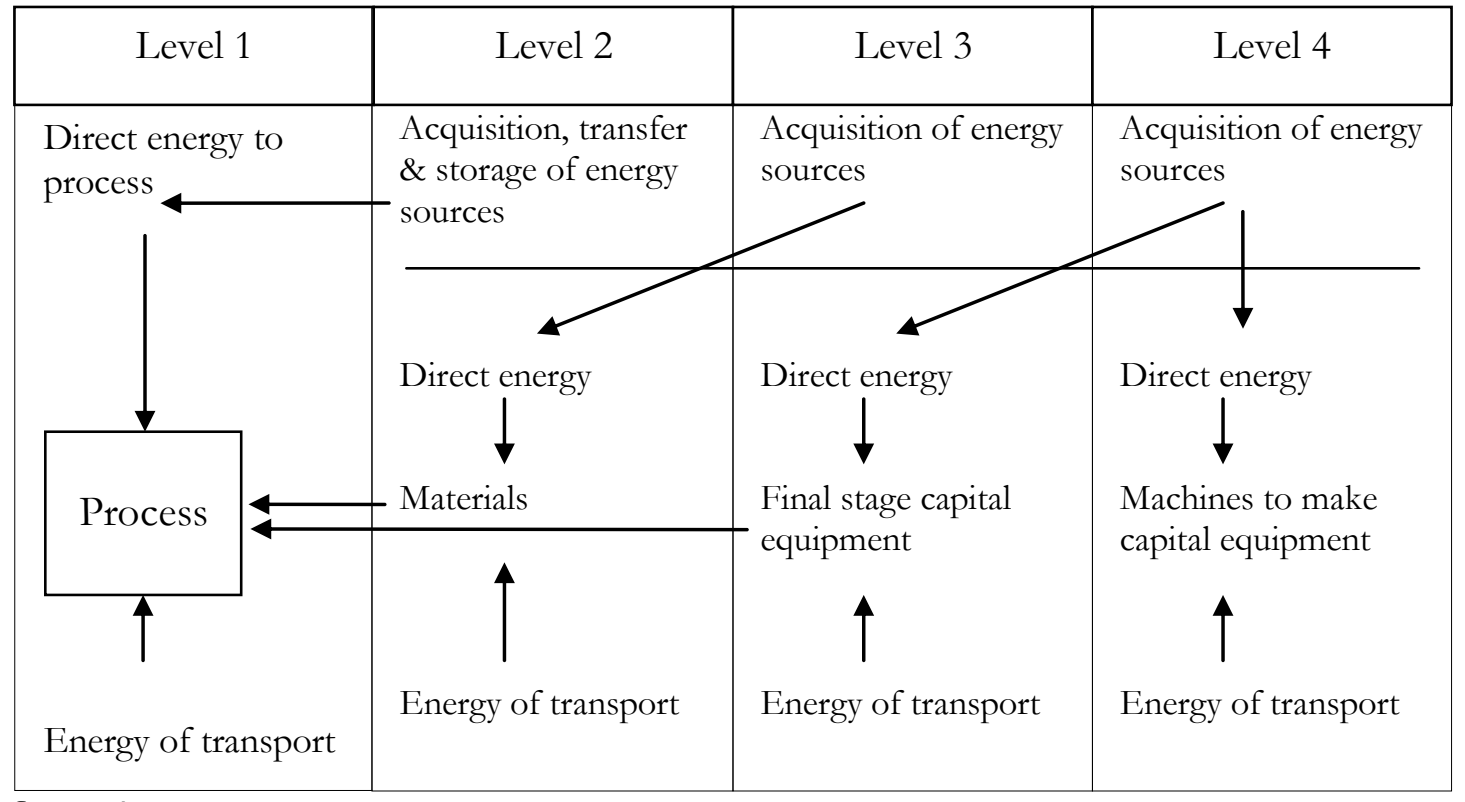

Source: Long, 1975

In a process analysis the extent of the upstream inputs is chosen according to available data, resources to do the research, and the degree of accuracy desired. The system boundary may include only levels one and two.

In practice, the system boundary level for a particular input may not be readily apparent. This is insignificant; when undertaking process or hybrid analysis, the system boundary is continually expanded until it reaches the equivalent of level four, or some other desired boundary, or until the limit of data or research resources is reached.

The principal problems of both process and I-O analysis relate to levels of system boundaries. Process analysis attempts to extend completeness by expanding the system boundary to level four, which usually requires prohibitive effort. I-O analysis 
by default has a system boundary at level four, losing data detail and accuracy mostly at levels one and two. Process-based hybrid analysis is able to use the detail of process analysis for levels one and two, supplemented by the global coverage of I-O analysis for levels three and four. Long (1975) notes that levels 1 and 2 "frequently...include 90 to $95 \%$ of the energy requirements through [to] Level 4". This was confirmed by the analysis for this thesis.

\subsubsection{Direct and Indirect Energy}

Direct energy is the energy supplied to a process in the form of electricity, geothermal fluid (steam and/or hot water), or fossil fuels. Indirect energy is the energy already embodied in the material or energy inputs to the process or the provision of other services to the process. Any energy used to obtain the energy or distribute it to the process, such as energy to drill for, process and pump natural gas through pipes to a factory, is indirect energy, while the calorific value of the gas used in a particular process is direct energy.

In this thesis indirect energy inputs, via physical ingredient inputs, were counted as part of the energy coefficient of the physical input. Direct energy inputs, however, were usually calculated separately from the indirect energy used to furnish that energy to the process, but they are not labelled separately.

Understanding direct and indirect energy is useful from a theoretical and historical perspective, but less so in the practice of EA. The important consideration is that the analysis for each material is checked at each point of the calculations, and overall, for full inclusion of direct and indirect energy. In practice this means continually asking the question "what upstream energy inputs are there for this particular input?" until the calculation has reached back to primary energy sources, or an I-O substitution has been made for a truncation of part of the analysis.

\subsubsection{Gross and Process Energy Requirement}

The gross energy requirement (GER) is the total amount of energy needed for making a product or service, including all the small tributary direct and indirect energy inputs to the upstream processes. This includes the energy required to obtain and 
distribute energy to end users. As with the many small contributing aspects to delivered energy, physical inputs have similar upstream tributaries of energy inputs that all add to the GER.

The process energy requirement (PER) is the direct energy needed for a particular process, equating to the delivered energy used by the process. If all the upstream PERs for all the tributary processes were added together they would equal the GER.

\subsubsection{Primary and Secondary Fuels}

Primary and secondary fuels are also referred to as primary and secondary energy. Boustead and Hancock (1979) defined primary fuel as "a naturally occurring raw material which can be used as a technologically useful source of energy without modifying its chemical structure prior to the reaction which releases the energy". Thus, coal, natural gas and crude oil products are primary fuels. Even though crude oil must be cracked into its constituent molecules, the chemical structure of those constituents remains the same. Wood and other plant based fuels are also counted as primary energy fuels. While uranium is not combusted in air, and its ore must be processed before being used as a fuel, it is a primary fuel because the nature of its atomic nucleus is not altered until fission, and energy liberation, occurs. Water stored in a lake or reservoir (barrage water in LCA terminology) is primary energy until it is converted into electricity. Similarly, solar radiation is primary energy before it is converted to electricity.

Secondary energy is any energy form which has been derived from a primary fuel. Electricity is the leading example. Hydrogen is often described as an energy carrier. Energy carriers, like electricity or hydrogen, are means to make energy conveniently transportable, and are examples of secondary energy. Other secondary energy sources, such as charcoal or coke, are not usually thought of as energy carriers. For EA, identifying energy forms as energy carriers is unimportant. The significance to EA of secondary energy is that upstream inputs - primary energy - need to be accounted for. 


\subsubsection{Energy Requirement of Energy}

The energy requirement of energy (ERE) is the energy used to locate, obtain, process, and deliver energy to the end user. The total energy deliverable compared to the energy necessary to obtain and deliver the energy is sometimes referred to as the energy return on energy invested (EROEI). In the case of diesel, for example, the ERE includes the energy for exploration, drilling, delivery of crude to a refinery, refining into diesel, transporting, storage of the final product, and the energy of capital equipment.

\subsubsection{Average and Marginal Energy}

There are two methods of analysing the primary energy (and resultant $\mathrm{CO}_{2}$ emissions) associated with energy: average and marginal. The concepts of marginal and average energy or emissions are similar to these concepts in economics (Slesser, 1974). Average data smoothes out the energy variations for: time of day; time of year; climatic effects on hydroelectric generation; and economic influences. Annual data that does not reflect these variations is usually used. Average data ignores the effects of consumer demand on producer activity, focusing instead on average producer activity. If energy, for example, is calculated as average, the task is to analyse each energy industry and ascertain the average associated inputs, emissions, or other factors, for that energy type. This is a relatively straightforward process and is useful for analysing the average energy requirement of particular products or services.

Marginal data, conversely, examines the effects when an increase or decrease at the margins of a market (the electricity generation or aluminium production markets, for example) causes a change in that market. For energy and $\mathrm{CO}_{2}$ analysis, the marginal amount is the energy or emissions cost of producing (or foregoing) one more unit of supply.

If a marginal ERE is used further analysis must be done to discover which energy sources are contributing to a process at the margins. If, for example, a manufacturer is able to operate a production system at night to obtain favourable electricity prices, the mix of energy types used to generate the electricity is likely to be different from 
peak generation times. This alters the ERE for the delivered electricity. It may also be assumed that at many times of the day or year any added electricity demand is going to be met by thermal generation, which has a different ERE from average electricity, which in New Zealand for example, is hydro-dominated. Thus, marginal demand will have a different ERE from average electricity generation. Marginal energy figures are useful if the question to be answered is: "What effect does manufacturing one more tonne of product X have on energy production?" Average energy values are useful to answer questions like "How much energy is embodied in New Zealand house construction each year?"

Average and marginal analysis, with an emissions focus, is further discussed in Section 7.2.

\subsection{Historical Context of Embodied Energy Analysis}

The history of EEA as influenced by environmental concerns of the last few decades focuses attention on its goals and results and assists understanding of EE as a sustainability indicator.

\subsubsection{Early Analyses}

The early roots of EA, in the 18th century, are placed by Peet (1993) especially with Quesnay's 'Tableau Economique', a forerunner of the modern I-O table of economic analysis. I-O table analysis was developed as an economic tool from the 1930s to its modern state of application, including EA, by Leontief (1986). Soddy (1926) connected economy and energy, stating that "energy was the driving force of the economy".

Many EA studies, especially studies using economic I-O data (see Section 6.5), were conducted throughout the 1970s (Peet and Baines, 1986; Wilting, 1996). Odum's (1971) Environment, Power and Society was seminal. Leontief undertook studies of embodied copper and air pollutants, but not including $\mathrm{CO}_{2}$, from 1970 (Brown and Herendeen, 1996; Leontief, 1986). Other I-O analyses in the 1970s included 
ecosystems, aluminium, fuels, food, and living (Hannon, 1973; Chapman, 1974; Chapman and Leach, 1974; Leach, 1975; Herendeen and Tanaka, 1976).

Instead of using the inevitably aggregated and out-of-date data of economic I-O tables, process analysis (see Section 6.6) sought to achieve greater accuracy and specificity for energy analyses by analysing processes within particular industries and installations. Detailed analyses of processes, which were the first LCA studies, including EA, occurred during the 1960s and 1970s (Grant 2002). Brown and Herendeen (1996) cite the Berry and Fels (1973) process analysis of car manufacture as an important early example.

By the early 1970s there was a need to standardise EA efforts to achieve comparability. In 1974 the Energy Analysis Workshop on Methodology and Conventions, held under the auspices of the International Federation of Institutes for Advanced Study (IFIAS), sought to normalise the methodology of EA (Slesser, 1974). The workshop examined methodologies and conventions for process analysis and I-O analysis within an industrial or societal context, and provided the groundwork for the methodological approach to EA that persisted until the 1990s when LCA, evolving from EA, started to become prominent. Boustead and Hancock (1979) also provided a thorough description of EA in the industrial context.

Slesser (1974) notes that there was some analysis, by a small number of researchers, of energy in physical terms, rather than as just part of economic analysis. There was little impetus to examine energy flows within economies however, since energy only represented around $5 \%$ of cost inputs to an industrial economy.

The relative insignificance of energy in the economy changed with the 'oil shocks' of 1973 and 1979, which provided major impetus to undertake further EA. Slesser (1974) notes the effect on the level of interest in EA:

$[\mathrm{W}]$ ithin the last few years an unease has been manifest, and some people have started looking at the amount of energy utilised in making goods and services, analysing processes all the way from ores in the ground to the finished article. 
The 1974 IFIAS Workshop, comprising many of the active researchers in EA at the time, debated details of methodology and laid down a series of conventions. These conventions were coloured by the prevailing concerns of the mid 1970s, especially the supply of energy and its exhaustibility. Slesser (1974) was clear that "the purpose of energy analysis was to establish how much energy is required to make or provide a good or service" and that "Energy Analysis is concerned with the use of energy sources and their depletion" (italics added). At that time the environmental impact of energy use was less of a concern. Many of the conventions laid down by the IFIAS Workshop are still extant in the 21 st century.

H.T. Odum, with an ecology background, was interested in energy beyond the realm of human activity, and extended EA to include all inputs back to solar inputs (Odum, 1971; 1996). Odum used units of Joules of solar energy, referred to as solar emjoules. The term emergy, referring to the embodied solar energy or energy memory was coined by Scienceman (Brown and Herendeen, 1996). Other EA researchers, however, retained the method described by the IFIAS workshops of 1974 and 1975, with a tighter focus on industrial activity (Slesser, 1974; Long, 1975). The two 'schools', IFIAS and Odum, remain (Wilting, 1996).

By 1996 the differences between the two schools were sufficiently entrenched, in spite of the close similarities in methodology and aim, to induce two eminent researchers to examine the differences and similarities systematically. Brown and Herendeen (1996) summarise that emergy analysis "attempts a bolder and more comprehensive synthesis of interdependencies driving ecological systems and the economic systems that depend on them". They observe the EA approach, conversely, questions the usefulness and defensibility of the examination of that interdependency; EA restricts itself to the "cultural" energies of fossil fuels and other harnessing of natural energy flows.

The various advantages of I-O analysis and process analysis attracted their respective adherents, and still do. By the late 1970s attempts were made to combine their advantages. Bullard et al. (1978) published a handbook to guide the application of a 
combined methodology, but this was limited to a careful and process-specific use of I-O analysis.

\subsubsection{Recent Hybrid Analyses}

In New Zealand Baird and Chan (1983) performed an EA of house construction using what Bullard et al. would have classified as a combined process and I-O analysis, in that a detailed breakdown of the house construction process and material inputs was undertaken. The energy figures used by Baird and Chan, were, however, primarily from published sources that used I-O data, supplemented by published statistical data.

Van Engelenburg et al. (1994) described a hybrid analysis method using process and I-O analysis. Their method used a relatively high proportion of I-O derived data to analyse the energy of a domestic refrigerator. Calculation of the energy for packaging, retail, waste, recycled material fraction at the end of life, and operation, gave this analysis a close affinity to future LCA methodology. To compare the results of van Engelenburg et al.'s analysis with other prevailing analyses these components can be removed. In this case the process analysis comprises $65 \%$ of the analysis, while I-O analysis comprises 35\%. Important components, such as the direct energy to the manufacturing process, are part of the $35 \% \mathrm{I}-\mathrm{O}$ aspect of the analysis. At the outset of the analysis a determination is made about which data will be obtained by process and which by I-O analysis methods, rather than pursuing process analysis as far as is possible before unavailability of data or lack of resources force resort to I-O analysis. The process portion of the analysis is not detailed in their paper, so no assessment can be made about the particular method used. Nonetheless, this study represents the first practical combination of mostly process data supplemented by I-O data into a hybrid analysis. The authors noted the method was "probably more accurate than the method described earlier by Bullard et al.".

In 1995 Alcorn developed a hybrid analysis that was the first to be fully processbased, using I-O analysis only where other data was unattainable. Based on a detailed comparison between Alcorn's process-based hybrid analysis results and earlier I-O results using similar data, the hybrid methodology appears significantly more 
accurate (see Section 6.7.1) Process-based hybrid analysis was used to examine a range of building materials, specifically within the New Zealand context. The methodology and was refined and data updated in publications from 1995 to 2003 (Alcorn, 1995; 1996; 1998; 2001; 2003). The hybrid methodology used differs significantly from that described by Bullard et al. (1978). The I-O fraction of Alcorn's calculations is typically in the $5-10 \%$ range, depending on the relative energy inputs compared to material inputs. Material inputs were almost always assessed by process analysis, so the principal shortcomings of I-O analysis (inaccuracies due to aggregation and price level variation) were eliminated from the material inputs. Energy inputs all carried an I-O factor for energy production and distribution, although the calculation for them was a hybrid process and I-O method. Since the energy sectors of the I-O tables dealt with one product only, the I-O factor for energy industries was very accurate, again making the accuracy of the final coefficient much more reliable. Examples of hybrid methodology are discussed in Chapter 8.

A comparison of the accuracy of process-based hybrid analysis and I-O analysis was made by Alcorn and Haslam (1996), using the hybrid coefficients that appeared in Alcorn (1995) and comparable I-O based coefficients from Baird and Chan (1983). It showed greatly improved accuracy from using the hybrid method (see Section 6.7.1.)

Treloar used hybrid analysis in 1998, but based on I-O analysis, having undertaken an I-O analysis of office buildings in 1994 (Treloar, 1994; 1998). Treloar (1998) used Bullard et al.'s definition of hybrid analysis to cite Oka et al. (1993) as having undertaken a process-based hybrid analysis. Oka et al. relied entirely on I-O data, however, so their 1993 work cannot be classified as hybrid analysis in the meaning of the term as it is used in this thesis.

Process-based hybrid methodology, incorporating economic I-O data only when process data must be truncated, has yet to find its way into widespread use in LCA practice, but this may be anticipated as LCA studies and their users seek greater accuracy. 


\subsection{Statistical Analysis}

Statistical analysis uses published statistics to determine energy use. A simple statistical analysis of New Zealand housing could be made, for example, by combining household energy end-use data, a published value for construction energy, and data on the number of New Zealand dwellings, to derive total energy for New Zealand housing. Statistical analysis is a quick method if consistent, thorough, pertinent and sufficiently detailed statistics are kept. These conditions have not often been met in New Zealand energy statistics.

National data for New Zealand energy use and production of building materials was found, during this study, to be incomplete. National and local organisations hold variable amounts of data, but this was seldom sufficient to establish energy coefficients. Industry member associations such as the Cement and Concrete Association hold national production statistics, but not individual manufacturing data. Some city councils hold annual reticulated water statistics, but little on the water infrastructure or energy inputs.

Difficulties experienced during this study, such as data incompleteness, meant a statistical analysis approach was unviable. Statistical data was useful, however, in adding to parts of the hybrid analyses.

\subsection{Input-Output Analysis}

Statistics New Zealand, as in other countries, publishes economic inter-industry studies approximately every five years. The resulting I-O tables are an economic tool used to examine dollar flows between sectors of national economies.

By examining dollar flows to and from energy producing sectors of the economy, and comparing these with known amounts of energy produced by each energy industry, energy flows can be traced within the national economy, and equated with dollar output of each sector with its energy usage, producing $\mathrm{MJ} / \$$ values for the outputs of each sector. Once a good or service has been classified as belonging to a 
particular industrial sector it can be assigned the relevant energy intensity for that sector. This is the essence of I-O analysis.

A derivation of $\mathrm{MJ} / \$$ (or equivalent energy and monetary units) from the economic I-O tables is referred to by Bullard et al. (1978) as I-O analysis. Bullard et al. detail a hypothetical example of EA whose first iteration includes only this step. Subsequent steps in the example involving a breakdown of the costs items to the process and an appropriate selection of an industry sector from the I-O tables to determine a $\mathrm{MJ} / \$$ figure for each item is referred to by Bullard et al. as a hybrid analysis. Thus, to them, I-O analysis only involves the general analysis of the economy for energy intensity in each industrial sector. This is consistent with the economic use of the term I-O analysis.

Following Bullard et al. (1978), Treloar (1998) used a definition of process analysis that treated inputs to a process, based on prices converted to an energy value by way of I-O table manipulation, as process analysis. In practice, this method achieves an enhanced degree of specificity and disaggregation, and is thereby an improvement on I-O analysis based simply on standard industrial classifications. It remains dependent on I-O data, however, and therefore should be regarded as a form of I-O analysis, not process analysis. In contrast, the definition used in Slesser (1974) for 'process energy' describes "the energy sequestered in order to promote a given process". In this case it is the energy delivered to a process that is measured, not the price paid for that energy, or any other input.

It can be seen that, although Slesser (1974) was very clear in the definition of process energy, and hence what can be understood as process analysis, confusion entered the EA lexicon when Bullard et al. used process analysis to mean what should have been regarded as a subset of I-O analysis: using a method that disaggregates coarse industrial classifications by substituting them with a more refined combination of industrial classifications.

In this thesis, the term I-O analysis is used to mean any derivation of an energy coefficient for a particular good or service that incorporates data derived from the 
economic I-O tables. This definition is used howsoever the tables have been manipulated or modified to yield an energy coefficient, and whether analysis of a process has been undertaken to yield a more detailed use of the I-O data, or not. This meaning and use of the term I-O analysis has been common since the early 1980s, although there has been some confusion surrounding the way in which I-O data has been applied.

The term I-O analysis was further confused when it came to be used in the LCA field. In that context it is used to describe the examination of inputs and outputs to and from a unit-process, or emissions to a part of the environment, such as the atmosphere, soil, or water. It should be noted that in its LCA context it is used as a form of process analysis - even if that process includes flows to and from natural reservoirs. The LCA usage of the term is thus completely different from economic I-O as it has been used in EA. LCA analyses may also use economic I-O as part of their process analysis.

\subsubsection{Problems with Input-Output Analysis}

The disadvantages associated with I-O analysis are listed by Bullard, Penner and Pilati (1978) as:

- $\quad$ price level changes

- technology changes

- aggregation

- $\quad$ producer's price versus purchaser's price

- $\quad$ energy cost of capital

- $\quad$ uncertainty in base year data

- $\quad$ physical flows assumed proportional to dollar values

- $\quad$ errors due to secondary products and linearity assumptions.

\subsubsection{Price Level Variation}

There may be significant variation in the price of different products within one sector or to a given product over time, due to market or other forces, irrespective of the energy requirements of the products. Using a single $\mathrm{MJ} /$ figure for all the 
output of that sector may hence produce distortions. If the value of a particular good rises because of a rising market demand for that product or one of its ingredients, as products using oil as a feedstock may during generally rising oil prices, $\mathrm{I}-\mathrm{O}$ analysis would reflect this as a rise in energy per unit since a fixed $\mathrm{MJ} / \$$ figure applied. General adjustments may be made for inflation, but this does not correct for price movement within one industry that is greater or less than the price movement of the general economy. Similarly, there may be a glut of a certain material or a temporary shortage which would move the world price for that material down or up. Some base metals, for example, experience significant volatility on the world market. Using a $\mathrm{MJ} / \$$ basis for calculation makes this method vulnerable to the particular price of a material or product at the time of the data collection. Beyond global market effects, the prices for a particular factory or industry may be affected by factors quite unrelated to the costs of inputs. There may, for example be a price war within a certain industry causing significant distortions. Conversely, a particular operator may enjoy little competition and be able to include a large profit margin which would have nothing to do with the energy inputs to the process but would apparently raise the energy intensity of the product.

\subsubsection{Producer Price versus Purchase Price}

The producer price is a better reflection of the energy attributable to a process than purchase price, since the I-O tables are based on basic industry prices (Statistics, 2001). However, manufacturers are usually unwilling to disclose this information. Purchase price must then be used, but with uncertainty about profit margins along the chain from producer, through wholesaler, to retailer. The potential for distortion in the energy coefficient when it is dependent on consumer purchase price is large.

\subsubsection{Physical Flow versus Dollar Values}

I-O tables map the dollar flows between industrial sectors. Because of inevitable aggregation of products within a sector, each product with the same value therefore has the same energy value attributed to it. The physical scale of products may be quite different, however, with relatively high energy products having a similar value to low energy products that may have some other high value input, such as labour. I-O analysis however, is unable to make the distinctions between aggregated 
products without effectively conducting a process analysis to compare products within the one sector.

\subsubsection{Technology Changes}

There may be from five years to a decade or more between when I-O data is collected and when it is applied to an EA. Within these time frames significant changes may occur in technology and equipment used to manufacture products. This is not reliably the case, however, so it is difficult to make any adjustment for the technology changes, given the age of the I-O data. In some industries technology and capital equipment change may be fast, in others slow, or an industry may have equal representation of manufacturers using old and new technology. The change in energy inputs resulting from newer technology may be very large. The production of ceramic building products in New Zealand, for example, has shown over recent years very wide differences in installed technology and energy use per unit of product.

\subsubsection{Aggregation}

If each product or service had its own category, I-O analysis would eliminate much of the need for process analysis. The economy is, however, divided into relatively few categories. In small countries like New Zealand industries are typically aggregated into fewer than 100 categories (Statistics, 1995). In large countries, with aggregation into as many as 300 categories (Stein, 1976), many dissimilar products with significant variation in their energy requirements are still grouped together. Severe distortions can occur.

In larger economies the variations between individual producers are averaged out over more players. A more representative assessment of national values for the energy intensity of individual sectors is obtained. If the question is one about the effects of using a product from a particular manufacturer or area of the country with markedly different energy intensity, however, averaging across a large industry may not be preferable. In larger economies I-O analysis thus has a further potential aggregation shortcoming. 


\subsubsection{Age of Data}

The most recent New Zealand I-O tables, at a 126 industry level, were compiled by Statistics New Zealand (Statistics) from 1995/1996 data and published in 2001 (Statistics, 2001). An update of the 1987 tables at an 80 industry level was carried out by Statistics from 1991 data and made available in January 1995. I-O surveys are available "irregularly" in New Zealand (Statistics, 2007). Typically they are not conducted at less than five year intervals, and take a similar number of years to be released. Data may thus easily be a decade old. Using data from I-O sources in combination with other data therefore presents obvious problems. This applies not only to hybrid analyses but to simple adjustments for inflation, to relate I-O data with current prices. Over a decade there may significant variations in the rate of inflation for prices from particular industries, as compared with the available figures for general inflation.

The age of I-O data makes it difficult to compare with current prices, energy data, and any other industry data that may be applied to an analysis. Using I-O data to supplement a process analysis requires adjusting for inflation, using dollar values for the appropriate years applying to other data. This may, for example, involve applying price deflators to I-O MJ/\$ figures to calculate the energy input attributable to the capital required to build a factory some decades in the past. Choosing applicable relative dollar values for some other data, especially if it is of mixed age or source, may be even more difficult than the capital equipment example.

\subsubsection{Energy Allocation for Secondary Products}

The difficulty in allocating a proportion of total energy consumption to a secondary product may be time consuming in a process analysis. In an I-O analysis, however, the problem is even greater, due to the complexity of the industries that are aggregated into a particular category. In the I-O case, individual facilities may produce more than one product; there may be a number of producers in a particular industry, each with a different product mix; and within an I-O sector there may be a number of disparate industries with an even greater range of disparate products. An assumption may be made that products typical of that sector have the same energy value per dollar of product. Where there are atypical secondary products, such as 
slag from a steel mill that is used as aggregate for roading or other construction, the assumption of equivalent energy for a dollar value of product becomes even more tenuous. Allocation, especially in LCAs, may be done by physical quantity, such as mass, rather than by dollar value. In this case the use of a dollar based I-O energy unit is likely to be even further removed from the actual energy value.

\subsection{Process Analysis}

Bullard et al. (1978) refer to the steps they take to break down the cost items of a major capital investment into separate industrial classifications, and the subsequent analysis of these items using I-O data, as process analysis. Process analysis is used in this thesis, however, to describe an industry-based study of the energy directly and indirectly applied to a process, including that embodied in inputs, but without reference to economic I-O data.

Process analysis involves the systematic examination of the direct and indirect energy inputs to a process. The analysis usually begins with the final production process and works backwards as the energy of each contributing material or energy input needs to be ascertained. In spite of the considerable time required, process analysis is the most common method of EA. This is because the data required can usually be obtained, albeit with considerable delving and persistence, and because it affords the most accurate results. The time and effort required is the main disadvantage of the method. Although there are likely to be particular pieces of data that cannot be obtained, process analysis produces results that are specific, detailed, and accurate.

\subsubsection{Problems with Process Analysis}

Aggregation and allocation are problems common to process analysis, I-O analysis, and hybrid analysis. Process analysis otherwise has a different range of problems, pertinent to different analysis resources and goals. 


\subsubsection{Large Research Effort}

The main problems with process analysis are the almost infinite resources (time and money) required to capture each small piece of energy flowing into the process, and the lack of data for many of the upstream stages. Each successive step in gathering data for the upstream inputs tends to yield a smaller contribution to the total. Process analyses are therefore truncated; the system boundary is restricted to enable the analysis to be of a manageable size.

\subsubsection{Undercounting from Ignored Ancillary Inputs}

The exclusion of small upstream inputs leads to undercounting, which is seen as a major objection by some researchers, causing them to prefer other methods, such as I-O analysis (Treloar, 1998). Without calculating them, the size of the ignored or excluded inputs is unknown. The cumulative total of "ancillary inputs", as Boustead and Hancock (1979) call them, unobtainable because of the research effort required, may be significant. Using other studies or industries as a guide to the size of the ignored inputs may be misleading: significant surprises frequently occur in EA, in both directions. Both the problems of a large research effort, and undercounting, are addressed by hybrid analysis.

\subsubsection{Data Acquisition}

In addition to the time and resources required to gather process data, it may be subject to confidentiality or other restrictions. Business operators may not have the data in a useable form. Even if a business operator can furnish the required data and is willing for it to be used, he may not be willing or able to devote the time to extract and forward the data, nor be willing for on-site examinations of records by a researcher. Operators frequently cite commercial sensitivity as a reason not to divulge data.

Some data is best obtained from other sources, such as industry umbrella organisations, or local authorities. This data is not always easily accessed or easy to disaggregate. Careful checking is frequently required. 


\subsubsection{Aggregation}

Ideally, varying production data is linked to specific outputs. For example, a precast concrete plant may have a contract to produce a series of concrete units for a building project. Because of technical complexity these may require a greater energy input than standard precast T-beams. If possible, given time and resources, the specific energy intensity of particular units would be analysed. Average energy intensity is often analysed from aggregated data; this is frequently aggregated annual inputs of ingredients and energy, against aggregated annual output, from a particular production facility.

Aggregation prevents process or hybrid analyses from being able to provide both average and accurate marginal energy coefficients. I-O analysis, however, uses data that is necessarily averaged, so cannot produce marginal energy coefficients.

\subsubsection{Process Variability}

A particular industry may have a wide range of different sized manufacturers. There may also be a wide range of installed technology, including both old and modern equipment, or equipment with widely ranging energy efficiencies. In practice, many manufacturers may be sampled, with a consequent increase in research effort, or just a few manufacturers may be sampled and chosen to be as representative of the industry as possible. Sometimes the manufacturers able to furnish data, however, do not fit the selected sampling profile. New Zealand fortunately has a relatively small number of operators in each industry. This makes it easier to cover the whole range, or to sample a representative range of manufacturers.

Processes may also vary over time, as business or the prevailing economic conditions change, or in the shorter term, due to seasonal variations, supply or price variation, or other factors. An EA may thus be a snapshot for a particular time period only. The averaging effect of I-O analysis, by comparison, tends to smooth out any anomalies. 
While changes occur in throughput at any factory, some energy is required to maintain certain functions irrespective of output. This may in some cases significantly affect the EE.

\subsubsection{Energy Allocation for Secondary Products}

Individual processing facilities may produce more than one type of product. A timber mill, for example, may produce not only sawn, but also sawn treated timber which requires a variety of further energy inputs. Tracing the energy inputs to an individual product from that mill may thus require careful analysis of the process, with individual machines needing energy accounting for specific energy consumption and throughput. This may be prohibitively time consuming. Alternatively, the average energy intensity per product for that operator needs to be allocated to the various products, using physical, economic or other parameters. The precision of these methods may be poor.

\subsection{Hybrid Analysis}

Confusion entered the definition of hybrid analysis when Bullard et al. (1978) used the term in their publication "Net Energy Analysis: Handbook for Combining Process and Input-Output Analysis". While the title clearly refers to process analysis as separate from I-O analysis, and a description of each is given, the example provided of "hybrid" analysis, aimed at combining process and I-O analysis, uses exclusively I-O data. By their example, hybrid analysis appears to define a process of disaggregating parts of a process so that appropriate sectors of the I-O tables can be used to identify the relevant energy inputs. The example given does not use physical energy data, although this is discussed in the handbook.

Discussing reasons to adopt either process or I-O analysis, Bullard et al. note that "each technique is most useful for a particular type of problem. Aggregated nationwide problems are well suited to I-O analysis because the database for this analysis is a 368 sector model of the entire US economy." 
Unfortunately, many countries have I-O tables divided into many fewer sectors; seldom more than 100 in New Zealand. This additional problem makes I-O analysis less attractive, and process analysis more so.

Bullard et al. note that "process analysis is more suited to specific processes, products, or manufacturing chains for which physical flows of goods and services are easy to trace". They also identify the main problems with process and I-O analysis, disclosing a potential prejudice in their description: "[process analysis] is tedious and involves adding all the inputs individually and is subject to error because some inputs are inevitably neglected". Treloar (1998) elaborates on incompleteness, citing neglect of activities such as storage; administration and packaging; banking and insurance; and non-energy inputs to the provision of energy. Treloar's assessment and the description of Bullard et al. validly identify problems of process analysis. While there are always ignored inputs in process analysis, a process-based bybrid analysis eliminates these problems by identifying incompleteness and using I-O data to fill the gaps. Bullard et al. identify the truncation aspect of process analysis, but do not discuss or identify the substitution of I-O data to replace the truncated upstream inputs.

Hybrid analysis incorporates the useful features of I-O, process and statistical analysis. A process-based hybrid analysis begins with the readily available data from a process. These are usually the direct energy inputs of the final production stage and perhaps of the materials acquisition stage immediately upstream of that final stage. Where the acquisition of data for continuing the process analysis further upstream presents a rapidly escalating effort which outweighs any improvement in accuracy, the process analysis is truncated and a figure from an I-O analysis is substituted. Bullard et al. (1978) comment succinctly on hybrid analysis:

The errors associated with truncating a process analysis can be minimised using the results of I-O analysis. The truncation error is replaced by a smaller aggregation error associated with energy-costing the higher order inputs....In practice, by carefully choosing the number of stages, hybrid analysis can reduce the error in both techniques and produce the most accurate result possible. The truncation error is 
eliminated from the process analysis and the aggregation error is minimised in the I-O analysis.

In this thesis, bybrid analysis is used to describe a combination of process analysis, where physical energy units are used, and I-O analysis, where I-O data is used in some way to contribute to a final energy coefficient. Process-based bybrid analysis describes analysis that is primarily a process analysis, but where I-O analysis is used to supplement that process analysis. This completion of the truncated process analysis is carried out at the point at which the increased accuracy of further steps in the process analysis is not achievable with available data, or is not justified by the large effort or time necessary to achieve that incremental improvement in the process analysis. A process-based hybrid analysis was adopted to yield the energy coefficients in this thesis.

\subsubsection{Comparison of Hybrid and Input-Output Results}

I-O has drawbacks, but its great advantage is that every dollar transaction, and hence every energy transaction, across the entire national economy is captured. Every small contribution, such as the energy for truck tyres, is accounted for. The relative importance of the problems and advantages can be gauged by a direct comparison between I-O and process-based hybrid analysis.

The Baird and Chan (1983) study of houses in New Zealand and the hybrid study of New Zealand building materials by Alcorn (1996) provide a useful opportunity to compare the practice, results, and accuracy of I-O analysis with process-based hybrid analysis. The 13 year time interval is not so large that methodological effects are swamped by changing technology and energy efficiency. Between 1983 and 1996 there were general gains in energy efficiency in all areas of manufacturing, consistent with rising energy prices, and. improvements in machinery. An across the board improvement could therefore have been expected in the EE coefficients of building materials between the first and second studies. This was not the case, however, as illustrated by Table 6.1, in which the EE coefficients of a selection of materials are compared. 
Table 6.1 EE Coefficient Changes 1983-1996

\begin{tabular}{|c|c|c|c|c|}
\hline Material & Units & Baird \& Chan & Alcorn & $\%$ Change \\
\hline Aggregate, general & $\mathrm{MJ} / \mathrm{kg}$ & 0.3 & 0.1 & -66.7 \\
\hline Aluminium, virgin & $\mathrm{MJ} / \mathrm{kg}$ & 129.5 & 191 & +47.5 \\
\hline extruded & $\mathrm{MJ} / \mathrm{kg}$ & 145 & 201 & +38.6 \\
\hline foil & $\mathrm{MJ} / \mathrm{kg}$ & 154 & 204 & +32.5 \\
\hline sheet & $\mathrm{MJ} / \mathrm{kg}$ & 145 & 199 & +37.2 \\
\hline Brass & $\mathrm{MJ} / \mathrm{kg}$ & $49 \cdot 3$ & 62 & +25.8 \\
\hline Cement & $\mathrm{MJ} / \mathrm{kg}$ & 8.98 & 7.8 & -13.1 \\
\hline cement mortar & $\mathrm{MJ} / \mathrm{m}^{3}$ & 5980 & 3200 & -46.5 \\
\hline Concrete-pre-cast & $\mathrm{MJ} / \mathrm{m}^{3}$ & 4780 & 4700 & -1.7 \\
\hline Concrete-ready mix, $17.5 \mathrm{MPa}$ & $\mathrm{MJ} / \mathrm{m}^{3}$ & 3840 & 2350 & -38.8 \\
\hline Copper & $\mathrm{MJ} / \mathrm{kg}$ & 45.9 & 70.6 & +53.8 \\
\hline Glass float & $\mathrm{MJ} / \mathrm{kg}$ & 31.5 & $15 \cdot 9$ & $-49 \cdot 5$ \\
\hline Insulation-fibreglass & $\mathrm{MJ} / \mathrm{kg}$ & 150 & 30.3 & -79.8 \\
\hline Lead & $\mathrm{MJ} / \mathrm{kg}$ & 25.2 & 35.1 & $+39 \cdot 3$ \\
\hline Paint & $\mathrm{MJ} / \mathrm{m} 2$ & 15 & 6.5 & -56.7 \\
\hline solvent based & $\mathrm{MJ} / \mathrm{m} 2$ & 12 & 6.1 & -49.2 \\
\hline water based & $\mathrm{MJ} / \mathrm{m} 2$ & 7.5 & 7.4 & -1.3 \\
\hline Paper-building & $\mathrm{MJ} / \mathrm{m} 2$ & 7.46 & 4.97 & -33.4 \\
\hline Paper-wall & $\mathrm{MJ} / \mathrm{m} 2$ & 14.92 & 12.74 & -14.6 \\
\hline plaster board & $\mathrm{MJ} / \mathrm{m}^{3}$ & 5000 & 5890 & +17.8 \\
\hline Plastics, low-density polyethylene & $\mathrm{MJ} / \mathrm{kg}$ & 112 & 103 & -8.0 \\
\hline Plastic, polypropylene & $\mathrm{MJ} / \mathrm{kg}$ & 175 & 64 & -63.4 \\
\hline Plastics, polystyrene, expanded & $\mathrm{MJ} / \mathrm{kg}$ & 100 & 117 & +17.0 \\
\hline Plastics-PVC & $\mathrm{MJ} / \mathrm{kg}$ & 96 & 70 & -27.1 \\
\hline Rubber-synthetic & $\mathrm{MJ} / \mathrm{kg}$ & 148 & 110 & -25.7 \\
\hline Sand & $\mathrm{MJ} / \mathrm{kg}$ & 0.04 & 0.1 & +150.0 \\
\hline Steel, recycled, reinforcing, sections & $\mathrm{MJ} / \mathrm{kg}$ & 59 & 8.9 & -84.9 \\
\hline Steel, recycled-wire rod & $\mathrm{MJ} / \mathrm{kg}$ & 35 & 12.5 & $-64 \cdot 3$ \\
\hline Steel, virgin, general & $\mathrm{MJ} / \mathrm{kg}$ & 35 & 32 & -8.6 \\
\hline galvanised & $\mathrm{MJ} / \mathrm{kg}$ & 37 & 34.8 & -5.9 \\
\hline Timber, air dried, roughsawn & $\mathrm{MJ} / \mathrm{m}^{3}$ & 848 & 165 & -80.5 \\
\hline air dried, dressed & $\mathrm{MJ} / \mathrm{m}^{3}$ & 4692 & 638 & -86.4 \\
\hline hardboard & $\mathrm{MJ} / \mathrm{m}^{3}$ & 20626 & 13310 & $-35 \cdot 5$ \\
\hline glulam & $\mathrm{MJ} / \mathrm{m}^{3}$ & 4500 & 2530 & -43.8 \\
\hline particle board & $\mathrm{MJ} / \mathrm{m}^{3}$ & 12892 & 5694 & -55.8 \\
\hline plywood & $\mathrm{MJ} / \mathrm{m}^{3}$ & 9439 & 5720 & -39.4 \\
\hline
\end{tabular}


Nearly three-quarters of the materials show a drop in EE, by an average of $41 \%$; the remainder show a rise averaging 46\%. Although energy efficiency improvements occurred, the large percentage decrease in EE of over $40 \%$ does not reflect an efficiency improvement of that scale. The increase in more than a quarter of the figures of a similar magnitude also suggests other factors are operating. The main factor is the EE analysis methods employed by the two studies. Examination of some specific materials is instructive.

\subsubsection{Cement and Concrete}

Baird and Chan (1983) used process analysis results for cement and pre-cast concrete (Noble et al., 1976). Equivalent figures in Alcorn (1996), using hybrid analysis, showed a moderate decrease, not inconsistent with the changes in the cement and concrete industry. For cement mortar and ready-mix concrete, however, Baird and Chan used I-O analysis. Alcorn's hybrid analysis figures are significantly lower: $46.5 \%$ and $38.8 \%$ respectively.

The I-O figures used by Baird and Chan were derived from a 1971/72 interindustry study of the New Zealand economy (Department of Statistics, 1972). This means that the data was twelve years old at the time of the Baird and Chan study. This is an inherent problem with I-O analysis.

The relevant industry category for cement and concrete in New Zealand, "NonMetallic Minerals", also includes clay, glass, plaster, masonry and asbestos products such as crockery, porcelain fixtures, pottery and earthenware, ceramic bricks and pipes, mirrors, masonry products, fence and telegraph posts, and tiles. This leads to serious problems of aggregation and price level variation.

The quarrying of limestone, clay and marl - used in the manufacture of cement - is not included in the "Non-Metallic Minerals" industry category, but in the "Other Mining and Quarrying" category. This illustrates the problem of placing a material within an industry category: often it simply can not be done accurately. The $\mathrm{MJ} / \$$ attributed to a material are likely to be significantly different as a consequence of choosing one category over another. 
These are problems typical of I-O analysis that make it unsurprising to find a large difference between the pure I-O figures and the process-based hybrid analysis figures.

\subsubsection{Sand and Aggregate}

Baird and Chan used I-O analysis for sand and aggregate. Their figure for sand is very high when compared to the figure for aggregate. Both materials generally come from the same physical source, but sand can be expected to require slightly more processing to produce, either in crushing or simply in extra sieving, and consequently can be expected to have a very slightly higher energy coefficient. In this case a MJ/\$ figure for the "Mining and Quarrying" category was used. Since sand and aggregate cost the same to produce and buy, and are sold by volume, $1 \mathrm{~m}^{3}$ of sand and $1 \mathrm{~m}^{3}$ of aggregate will have equal EE attributed to them. Since sand is some $60 \%$ heavier, however, the energy per $\mathrm{kg}$ will appear to be much lower for sand instead of slightly higher. Other factors, such as rounding errors associated with such relatively small numbers are likely to be operating in this, as well as other examples, but are not traceable. This example illustrates the inherent problem of assuming physical amounts to be proportional to dollar amounts in I-O analysis.

\subsubsection{Steel}

Steel is unusually consistent in energy coefficients across many studies, varying by 'only' about $20 \%$ around approximately $30 \mathrm{MJ} / \mathrm{kg}$. Hence a drop of $8.6 \%$ for general steel between 1983 and 1996 is not surprising. The figures for steel sections and rod, however, illustrate problems of adapting data from overseas economies. Baird and Chan used I-O figures from the United States (Stein et al., 1976) and applied them to New Zealand I-O data. This did not take account of the technology relating to the New Zealand steel industry, however, where wire rod and structural sections are produced from recycled steel only, whereas virgin steel is only used for making coiled sheet, plate, and tube steel.

\subsubsection{Other Metals}

The figures for the other metals do show a rise between 1983 and 1996. Brass, copper and lead are all derived from the "Metal Products NEC" category. Since 
these metals are not produced in New Zealand in their virgin form, the energy intensity attributed to them comes from remanufacturing into other products of the raw metals. This is clearly a much less energy intensive operation than the smelting of raw materials. Hence the presentation of the EE figures as for general metal is misleading without specific reference to and understanding of the data source. When they are compared to the later figures which include the energy of smelting overseas it is not surprising to see a rise in the comparative figures.

\subsection{Embodied Energy Analysis in Practice}

Statistical analysis, I-O analysis, and process analysis all had some useful contribution to a realistic methodology for this thesis. None of them was suitable on its own, however. A combination of these methods was required: process-based hybrid analysis was adopted.

The starting point was a process analysis of the final production stage. Direct energy and raw materials inputs were ascertained. Process analysis of each raw material was next undertaken where the amount of the raw material in the final figure justified the effort. At the point that the increasing effort in achieving detailed figures outweighed the small increase in accuracy provided, the process analysis was truncated. A figure from the I-O coefficients was then substituted to complete that part of the process analysis to IFIAS level 4.

By using a hybrid analysis, comprising primarily a process analysis supplemented with an I-O analysis, and with statistical data used where beneficial, the end result was achieved more quickly and accurately than with other analysis methods.

\subsubsection{Conventions}

The reason for undertaking a specific EA has a material effect on the methodology and conventions adopted. In Slesser (1974) the concern of EA was "the use of energy sources and their depletion". This reflected the awareness and concerns of the time, when actual and potential energy shortage had been highlighted by the 
1973 oil shock. In 2010, however, the overriding concern is with environmental damage, especially climate change.

Many of the conventions established by the 1974 IFIAS Workshop have persisted to the present day. Some are now out of date; some are ignored. Slesser (1974) acknowledged that "depending upon the objective of the analysis ... different conventions [are chosen] and such conventions [are] by no means universally agreed on". It is important, therefore, to clearly state in an EA which conventions and assumptions are being used. Slesser specifically recommended that "each calculation of energy data be accompanied by an explicit statement of the assumptions and method of calculation". Failure to state assumptions makes it difficult to compare data from different sources and to assess the veracity and reliability of reported data.

\subsubsection{Energy of Human Labour}

It has been a convention to ignore the energy input of labour. Slesser (1974) recommended:

Where the analysis refers to developed or industrialised economies it is not necessary to consider the energy for life-support of man-power. Where the analysis considers low intensity agriculture man-power considerations play an important role in the calculations. However, the problem of partition between household and labour or labour and its life support system was a matter the workshop did not resolve.

The basis for Slesser's conclusion was an analysis of the energy purchased per household, and thereby attributable to each worker. In an industrialised economy, this becomes dwarfed by the energy inputs via machinery, and the materials that have been produced with machinery. In industrialised society, machines, and the energy used to run them, have mostly supplanted muscle energy. It is not surprising therefore, that the IFIAS Workshop found that the energy of manpower was so low it could be ignored. Conversely, and not surprisingly, it was found that in high labour, low energy agriculture, man-power was significant. 
Boustead and Hancock (1979) observe that the convention to exclude the energy of labour is often a conceptual one. "It is argued that if humans are included in an industrial system then not only are they producers of goods and services but they are also consumers...so that there is no net output." They then refute this concept arguing that it is:

more apparent than real because it presupposes that an industrial system is defined solely in terms of physical components...[T] he nature of a system [however] is defined in terms of identifiable functions and not in terms of physical components. There is no reason therefore why the production aspect of human behaviour cannot be separated from the consumption behaviour and included within the defined system.

The IFIAS Workshop approach to answering the energy of labour question was based on a narrow concern of counting energy inputs to a process. Boustead and Hancock, in a similar analysis, also conclude the energy of labour is a small proportional input. If, however, the energy of labour problem is approached as: "What is the effect (on sustainability) of the labour input to the process?", then a wider consideration needs to be given to the labour input. It is not merely the energy purchased by the average household, but the energy that is embodied in the infrastructure and entire economy that contributes to the support of those households and enables them to provide workers to particular industrial or service processes. In this case it is effectively the entire economy that is relevant, so it is (unusually) preferable to use I-O analysis as the appropriate source of data.

The New Zealand I-O tables include a "compensation of employees" category for labour (Statistics, 2001). Labour payments in turn get spent back into the general economy, thereby involving an energy expenditure per dollar equivalent to the average $\mathrm{MJ} / \$$ figure for the whole economy, as revealed by an analysis of the I-O tables. From the perspective of an individual household, the allocation of this money and the energy it represents, amongst different household members and between specifically work-related purchases and recreational or other purchases remains debateable. How the money gets spent into the economy, and by whom, is irrelevant however, when the payments are viewed from the perspective of the industrial or service process. If 
the process needs to spend money on employing labour in order to operate, it does not then make any difference how that expenditure finds its way back into the general economy. In effect, the labour payment represents the proportion and aspects of the general economy that need to be in existence to enable the process to operate. The process cannot operate in the absence of those aspects of the economy and infrastructure. As well as supplying a service directly to the process, the infrastructure of, for example, reticulated water and sewerage and the electricity grid are necessary to enable the existence of households that can supply employees to the process. Purchasing services from infrastructure providers is one example of how the labour payment gets spent back into the economy. The energy represented by compensation of employee payments is thus an equally relevant input to the process under analysis as are the ingredients or direct energy inputs.

\subsubsection{Energy of Profit and Taxes}

One of the problems of I-O analysis is the difference between producer's and consumer's prices. The difference includes profit, while taxes and labour would normally be included in the producer's price. In accounting for the energy to a process using I-O analysis, it has usually been the producer's price that has been preferred, since that represents the dollars paid for direct energy and for material inputs, and hence, using a $\mathrm{MJ} / \$$ figure, the energy attributable to the process. Bullard et al. (1978), discussing consumer's versus producer's price, also include "wholesale and retail margins, transport ... costs, insurance, etc., required to market the product".

It is easy to understand how the items Bullard et al. list are part of the process of providing a product to the consumer. It can be more difficult to understand the role of profits and taxes in the final supply of the product, as theoretically a production process could be run as a non profit operation, or be exempt from taxes. When profits or taxes are made or paid however, they form part of the operation that has an effect on the environment, whether or not the energy used as a result of the spending of those profits or taxes is remote from the production process. In the case of most production systems, profits and taxes are normally a necessary or unavoidable condition: without them there would be no production process. 
Operation of the economy in general requires energy, with an average energy value per dollar being derived from I-O data. Each dollar of profit made thereby represents an amount of energy input to the process as a necessary condition of operation. Likewise, each dollar of tax paid represents a similar amount of energy attributable to general economic and energetic activity.

Considering profits and taxes amounts to an expansion of the system boundary; the rationale for ignoring increasingly wide system boundaries provided by Slesser (1974) is the "impractically large amount of information [required] before an [energy requirement] may be evaluated". The subdivision of a production system into Levels $1-4$ indicates the preference of expanding the system boundary as far as possible, given the ability to gather the required data. Slesser suggested that the four level model was "a useful guide [but] emphasised that how far one took the analysis depended on the question asked. For example if...one wished to include environmental considerations, some inputs at levels 3 and 4 might be quite large". The difference between a pure interest in energy depletion, as most of Slesser (1974) was concerned with, and environmental impact, was obviously understood.

If the question asked is: "What is the energy required to operate the production machinery and the upstream production machinery?" profits and taxes may be ignored. When, however, a question is framed as: "What is the effect (on sustainability) of operating the process?", the effects of profits, taxes and consumption of fixed capital need to be considered. Fortunately data is easily available from the I-O tables to be included as inputs.

For the sake of being comparative with other studies, and because of the excessive time required, this thesis nonetheless calculates coefficients using the more conventional methodology that ignores the energy of human labour, profit and taxes. A small selection of materials were analysed including these aspects, however, for comparative purposes. 


\subsubsection{Methodology for Energy of Profits and Taxes}

The total of: employees' compensation (wages and salaries), profit, and taxes, is referred to as the value added (Statistics 2001). Each sector, including "Residential Building Construction", spends money buying goods and services from other sectors to produce its output. In addition, each sector spends money on wages and salaries, profit, and taxes. For every dollar that is spent on purchasing goods and services from other sectors by the "Residential Building Construction" sector, a further 29.1 cents, or $22.6 \%$ of total expenses, is spent on wages and salaries, profit, and taxes. For each of the other sectors that "Residential Building Construction" buys goods and services from, $39.2 \%$ of expenditure goes to wages and salaries, profit, and taxes, based on a weighted average. (For the whole economy, the average of total expenditure that goes to wages and salaries, profit, and taxes is $46 \%$, showing that construction is a relatively low wage/low profit sector.) Thus, a total of $52.9 \%$ of total expenditure by the "Residential Building Construction" sector goes, directly and indirectly, to wages and salaries, profit, and taxes, as summarised in Table 6.2.

Table 6.2 Residential Building Construction: Wages, Salaries, Profits, and Taxes

\begin{tabular}{lcc}
\hline Expenditure & $\%$ & Formula \\
\hline Residential Building Construction direct to Wages, Salaries, Taxes (\%) & 22.6 & A \\
Residential Building Construction to other sectors (\%) & 77.4 & B (100\%-A) \\
Other sectors direct to Wages, Salaries, Taxes (\%) & 39.2 & C \\
Residential Building Construction indirect to Wages, Salaries, Taxes (\%) & 30.3 & D (Bx C) \\
Total Residential Building Construction to Wages, Salaries, Taxes (\%) & 52.9 & E (A + D) \\
\hline
\end{tabular}

Thus, for a million dollar house, $\$ 471,000$ goes into the products and services needed for the house, with the specific energy intensities of those industries, and $\$ 529,000$ goes directly into the economy, via wages and salaries, dividends, and taxes, at the average energy intensity of the economy. For completeness, the energy of wages and salaries, profit, and taxes needs to be factored in to analyses using relevant percentages and the average energy intensity of the economy.

\subsubsection{Energy of Feedstock}

If the feedstock to a particular process has a potential energy value that could be obtained by burning the feedstock instead of using it as a manufacturing ingredient, 
that energy value is sometimes counted in the energy coefficient of that material or product. A significant example is plastic. As Slesser (1974) comments,

if one was comparing the energy to make a glass bottle as opposed to a plastic one, one could reasonably argue that it was necessary to consider the energy sequestered in the plastic bottle itself because the input feedstock has an alternative use as a fuel.

Alternatively, it could be reasonably argued that the energy sequestered in the bottle still remains available as a fuel. Indeed, in many cities, municipal waste, consisting of a range of materials, but certainly including plastic of various sorts, including bottles, is burnt as a way of obtaining the energy value available in the waste, as well as reducing landfill material (Hartenstein and Horvay, 1996).

The argument for including the energy sequestered in the bottle in the energy coefficient again reflects the concern in the mid 1970s for the depletion of energy, rather than the impact on the environment. From an environmental impact perspective, there is little impact in sequestering a potential energy source in the bottle, beyond the usual impact of obtaining the feedstock necessary. This latter impact would normally be included in the process analysis of the bottle manufacture anyway. When the bottle was burnt as municipal waste the environmental impact of that operation would be analysed and attributed to the resulting consumer energy, usually either electricity or heat. The environmental impact is principally associated with the release of $\mathrm{CO}_{2}$ and other pollutants, when the hydrocarbons, in whatever form, are burnt. Because this thesis has a primary interest in sustainability, it is therefore appropriate to regard the combustion stage of the use of crude oil as relevant, rather than the manufacturing of it into a product.

This thesis therefore departs from normal practice and excludes the potential energy of feed-stocks. The energy used, say, to explore for, extract, process and deliver crude oil or natural gas to a processing facility as a feedstock to the manufacture of plastic, is included however, in the energy coefficient of materials. 
The exclusion of feedstock energy makes the methodology for analysing plastic products consistent with that for analysing timber products, and others that use naturally occurring feedstock that has an energy value. It is conventionally the case that because timber products' feedstock is derived from solar radiation, and therefore does not deplete available energy resources, it is treated as having zero energy sequestered in the feedstock material (timber). Coefficients for timber analysed in this way, however, have often stood alongside coefficients for plastics analysed as including the energy of the feedstock. The methodology used in this thesis resolves this inconsistency.

\subsubsection{Solar Energy}

Odum (1971) was concerned to trace all energy sources back to solar inputs; it has been a convention however, to ignore solar inputs in most EA, especially among those following the IFIAS school. While the IFIAS Workshop did not discuss the inclusion or exclusion of solar energy in detail, because the principal concern in 1974 was about depletion of energy resources, solar energy was regarded as a flux; Slesser (1974) states that "the word "resource" should not be used for a flux source".

From a sustainability perspective, the use of solar energy is without impact, since it occurs whether utilised or not, and the consequences of diverting some of it to a process have a neutral effect. In this thesis, what has no environmental impact is excluded, while what does have impact is included. Consequently the energy input to growing and harvesting trees, from fertilisers, saws, and logging trucks, for example, is included in the energy coefficient for timber, whereas the solar energy absorbed by the tree to grow is not. Similarly, the solar energy obtained by a passive solar building to heat and light the building is not counted.

\subsubsection{Energy Allocation for Secondary Products}

Methods of appropriately allocating the total energy use for a factory to different products may include a mass volume, or price breakdown of the total output. Alternatively, the marginal energy savings available from producing less of the product may be used. Slesser (1974) recommended allocation by physical parameter "for use whenever possible". 
In practice, a combination of methods was used in this study, with the most detailed data obtainable being used. For most materials it was not necessary to choose an allocation method. Either there were no secondary products, or the energy inputs to each product were easily distinguished. If allocation was necessary this was done in the way which best reflected the energy demands of the secondary product, with a preference for allocation by weight or other physical measure.

The scale of difficulties associated with allocation, which are assumed by some analysts to accompany process analysis, are in practice a minor problem. Treloar (1994), for example, gives considerable space to the issue when discussing process analysis, but does not discuss the greater issue when addressing I-O analysis.

The risk of overstating the energy assigned to a primary product by ignoring a secondary product, suggested by Treloar, is small. The methodological choice to ignore a secondary product may be made if that product is a very small part of the output, or if its energy requirement is small. Even if the secondary product may require significant additional energy, allocation of energy for the secondary product to the primary product is unlikely to overwhelm the undercounting common to process analysis. Furthermore, because of the normally focused nature of industrial output, any errors that may be associated with a poorly chosen or executed allocation method are still likely to be small.

\subsubsection{Second-Use Materials}

At the end of their normal life, for example as virgin materials in use in a building, materials may be recycled for a second use or re-processed into another product for use elsewhere. Typically, the energy needed to collect and re-process materials is significantly less than making products from virgin materials. Sometimes the energy 'saving' from using recycled or reused products is subtracted as a 'credit' from the energy of the virgin, first-use product, because the potential exists for such second use. Sometimes the energy obtained from the calorific value of a waste or recycled product is counted as a 'credit' when it 'displaces' the 'normal' alternative. Such credits are arbitrary or rely on an assumption about uncertain future behaviour. 
This thesis, therefore, does not attribute such credits but counts the energy of materials when energy is used, attributing it to the process which uses the energy. The energy of waste or recycled products is treated as zero for physical ingredients, but the additional energy of collection or re-processing is attributed to them. Waste products with a calorific value which are used as fuels have that calorific value plus the energy of collection included in their second-use. For example, the energy of waste steel is treated as zero, but has the energy of collection included. The energy of waste lubricating oil, used as a fuel for cement calcining has its calorific value, as well as the energy of collection, included in the coefficient for cement manufacture, but not the energy of extraction and processing of crude oil into lubricating oil, which was counted for its first use.

\subsubsection{Gross and Net Calorific Values}

The energy content of a fuel may be expressed either as the gross calorific value or the net calorific value. The difference is "the energy necessary to evaporate the water that is present either in the combustible material (moisture content), or formed in the combustion reaction where hydrogen and oxygen combine" (Baines, 1993). The net calorific value indicates the amount of useful heat available from combustion (Ibid). This figure is therefore useful for many practical applications. However, the gross calorific value "more correctly measures the total energy release to the biosphere and ... the effect of release on climate" (Slesser, 1974). Baines (1993) also observes that

"for energy accounting purposes and generally in New Zealand statistical recording, the convention is to use gross calorific values". For these reasons all calculations in this thesis use gross calorific values.

\subsubsection{Data acquisition}

The research experience for this thesis illustrates the EA process. It is consistent with commentary in Boustead and Hancock (1979).

Companies producing building materials provided much useful data. Very few companies had data available in a form from which energy coefficients could be deduced immediately. Even fewer had done calculations to establish the amount of 
energy they were using to produce their total output or individual products. None had applied other factors, such as the energy cost of producing electricity, to the calculation of the energy intensities of their product(s). Interest, support and practical help for acquiring energy data was nonetheless strong, albeit with a reticence to release potentially commercially sensitive information. Even where commercial sensitivity prevented data provision, there was considerable interest in the outcomes.

Commercial sensitivity varied. Some firms were prepared to release information if the original form of the figures remained confidential and only an energy coefficient was produced. Some firms were prepared to release data, as long as the firm was not identified.

Many companies had relevant data in some areas but not others. Sometimes the willingness to help was not sufficient to overcome the barrier of time and effort required to locate what often seemed obscure information. Often, information existed, but finding it, or the right person to find it, was difficult.

The above factors meant information frequently had to be sourced from several places for one material. Sometimes overseas data was used for part of calculations. When this occurred adjustments were made to New Zealand conditions. This 'extra' data was used when data could not be obtained from New Zealand sources.

In many instances, overseas data was appropriate when, for example, raw materials were imported. Sometimes overseas data was appropriate but unavailable, and equivalent New Zealand data had to be applied.

When published figures varied and New Zealand data was unobtainable, consistency and age of the data, and the level of analysis detail were used as guides to the best data to apply.

Industry was the preferred source of relevant data. Occasionally national statistics were readily available and preferable, because of their greater comprehensiveness. 
Industry, national and overseas figures were often combined to give an accurate and realistic coefficient.

Because New Zealand is small, there are often only a few manufacturers of each type of building material; sometimes only one, and sometimes none. Whenever feasible all participants in an industry were invited to contribute data. In industries with a large number of participants a representative sample of firms was canvassed, covering variations in origins of raw materials (such as aggregate from river and virgin rock sources), type of technology used, and size of operation. Many New Zealand manufacturing industries were found to have a few large players and a few small players. Where only one firm could be sampled, larger operations were usually regarded as being more representative of the industry, and less likely to be affected by local anomalies such as materials supply.

Where all or virtually all of a particular product was imported, figures from that country or from a country having similar manufacturing conditions were used.

Boustead and Hancock (1979) discuss the advantages and disadvantages of collecting data directly from industrial operators. It is preferable to obtain as much data as possible, but the minimum data necessary to perform a process analysis is quite small. The basic information needed is the material input types and amounts, the energy input types and amounts, and the output. This data is usually best gathered on the basis of annual amounts, although it can often be reliably extrapolated from different time frames.

Documented data often provides greater detail, provides the opportunity to refer back to it at later dates, and gives some certainty about its reliability, but the hurdle of providing documents often deters operators from giving any data at all. The telephone was found to be the most effective means for obtaining data. This involved discovering the person within an organisation best placed to provide the information. They often required a sufficient level of authority within the company. Sometimes the general manager was the most appropriate person, especially in smaller organisations. In larger organisations top management usually did not know 
the required data or were too busy, and an operations manager, accountant or engineer was the best person to provide it. Frequently it took several attempts to find the best person to furnish the data. Receptionists often proved to be in the best position to direct enquiries to the appropriate person. Gauging some of the organisational structure and culture over the phone was usually necessary to successfully navigate through the information, security, and staff networks.

As Boustead and Hancock (1979) point out, being able to query data after it has been supplied is a significant advantage in obtaining data directly from industrial operators, and is facilitated by the analyst obtaining the data themselves. This method also enables a much better understanding of the operation, and the ability to adjust and improve the analysis.

The process analyses undertaken consisted firstly of establishing the direct energy inputs to a process, then examining the raw materials inputs to the process. These two steps equate to the first two levels shown in Figure 6.1 (Section 6.2.5).

In most cases this meant obtaining an energy figure for each constituent material. This was sometimes easy to do, as in the case of the bitumen input to asphalt. In other cases the effort involved was considerable, as in the case of aggregate, which is sourced either from river dredging or blasting and crushing virgin rock. Each of these sources required its own process analysis. Another process analysis was in turn required for the production of explosive and its ingredients. Finally, river and virgin rock data were combined pro-rata for a national average.

For large volume or extensively used materials, such as concrete, it was worthwhile putting considerable time into obtaining accurate energy figures for constituent raw materials. For other materials the effort was too great to be justified, or the small percentage that the constituent material represented in the overall energy coefficient did not warrant the additional work. The figure used instead was from published sources or from the I-O coefficients, despite inherent aggregation errors. 


\subsubsection{Energy Requirement of Energy}

This thesis does not label energy inputs as either primary or secondary, but ensures that any energy source is traced back to its natural source to include all energy necessary to produce or deliver it. With gas, for example, the gross energy requirement (GER) includes the energy invested in exploration, drilling, establishing, and maintaining the pipeline and other infrastructure, processing to remove impurities, pumping of gas through the pipeline, plus any flaring and leakage that may occur. For coal, oil and its derivative fuels, and gas the energy requirement was calculated with a hybrid analysis using industry and I-O data (Baines and Peet, 1995).

Electricity was also calculated using I-O data, but was re-calculated using statistical and process analysis. Because electricity generation has its own I-O industry category the two results were very similar. The average energy requirement of energy (ERE) for electricity was found to be $\mathbf{1 . 5 4} \mathbf{M J} / \mathbf{M J}$. The marginal electricity ERE was $\mathbf{1 8 . 7}$ $\mathrm{MJ} / \mathrm{MJ}$.

By using hybrid analysis all direct energy inputs to a process are traced back to include all ERE inputs. All figures used for the coefficients are thus in primary energy terms. To achieve primary energy values, the direct energy to each process needed only to be multiplied by the energy coefficient for the appropriate energy source to take that part of the calculation to IFIAS level 4 (see Figure 6.1, Section 6.2.5).

\subsubsection{Transport Energy}

An erroneous view of energy contributions could be gained by the appearance, in visually equal terms in the IFIAS system boundary diagram (Figure 6.1, Section 6.2.5), of the energy input of transport. A common misconception throughout society, as exemplified by the food miles debate, is that the energy of transport is a significant input to the total energy coefficient of different products or materials (Saunders et al, 2006). In reality transport energy typically accounts for less than 5\% of the total energy coefficient, and usually no more than $2 \%$ (see Table 8.1, Section 8.2.4). The IFIAS diagram of system boundary levels (Figure 6.1) thus needs to be viewed with caution. 
The limit of analysis for each material was the factory gate. This meant production of some materials such as river dredged aggregate had no transport component: the diesel used to move the gravel from the river bed to the screening plant was part of the overall diesel usage of the operation. Other materials had very large transport components, such as imported stone which is sometimes transported long distances from the country of origin to a cutting and polishing site before being re-exported to New Zealand.

Because of the factory gate system boundary used in this thesis, the energy of local transport to the manufacturing site is included in the inputs to the process, but not the energy of transport from the factory gate to the point of use. For example the energy of transporting clay to a brick factory in Southland is included, but not the energy of transporting bricks to a construction site in Wellington. The energy of transporting cement from a cement factory in Northland to a concrete block manufacturer in Wellington is included, but not the energy of transporting the concrete blocks to a construction site in Upper Hutt.

In national accounts the energy of international transport is generally excluded. In this thesis, however, the energy for international transport of ingredients is included in the inputs to the process, irrespective of where the ship was fuelled. For example, the energy of transporting gypsum from Australia for use in cement production is counted in the cement figure.

The energy for international shipping by bulk carrier, such as for gypsum used in cement or wallboard manufacture, was calculated from specific data for a transTasman shipping operation. Various studies exist for transport energy with quite consistent estimates for different modes. The energy for mixed shipping operations was taken from published sources for New Zealand conditions, as was the energy for local transport modes (Collins, 1993). Calculations were typically done on a tonne.kilometre basis. Exceptions were where specific data existed or where a weight based calculation did not accurately reflect the energy used. 


\subsubsection{Capital Equipment Energy}

Very few companies had available data on the capital value of their plant that was relevant to their output during the period examined. Some companies were able to estimate the residual value of their plant, but it was impossible for them to estimate with any useful accuracy how long their current plant would be in production, and therefore the period over which the costs of the plant should be amortised.

Carter, Peet and Baines (1981) used the Gross Fixed Capital Formation (GFCF) column from the I-O tables to estimate the energy component attributable to capital. GFCF includes the consumption of fixed capital (depreciation). Carter, Peet and Baines comment that their estimate is approximate, which is possibly the reason that many energy analysts have not included the energy of capital equipment, as well as the "unavailability of reliable data". Using a similar approach, this thesis found that the percentage of the final figure that was due to the energy of capital equipment was typically less than the margin of error for the analysis procedure.

By using I-O data at the point that a process analysis becomes impractical, capital equipment is automatically included in the relevant inputs, since the I-O method has complete coverage of energy inputs.

If the value of the production plant was known, I-O data was applied to account for capital equipment. If the plant was specific to the industry the $\mathrm{MJ} / \$$ value of that industry was used. In some cases the predominant capital equipment was machinery so that the 'machinery production' sector of the I-O tables was used. In other instances the predominant capital input was for the buildings housing the process, so that the 'buildings and construction' figure was used. If the value of the plant was not known, I-O data relating the average gross fixed capital formation to total output value for that industry was applied, as a percentage of the sub-total of all other inputs for that product.

\subsubsection{Weighting of Data}

Data used for EA is seldom perfect. An infinite amount of time and resources allowing gathering of all data for all inputs from all industry participants, as well as 
for national data impacting that industry may produce something approximating a perfect data set. In reality these conditions do not occur. Data may be collected from a variety of sources, with variable reliability or applicability. For example, overseas data may be available but with uncertain accuracy, or with different conventions used in its derivation. This may stand alongside New Zealand data which may have some other less-than-ideal characteristic, such as being from a small number of industry participants, rather than from the large number available in a larger economy. Highly specific data may be available for a process, but for only one, or a few, participants in a wider industry. Wider coverage of an industry may be available, but with less specific data. Choices must consequently be made about the most appropriate data to use. Factors in the reliability or applicability of data used to produce an EE coefficient for a particular building material include:

- The country of origin of the data

- The country where a material or ingredient is produced

- The size of the organisation producing the data

- Political or market forces affecting the organisation producing the data

- Market or other factors influencing the period in which the data was gathered

- The relative size within an industry of the organisation producing the data

- The completeness of the data

- The completeness of records from which the data is drawn

- The reliability of records from which the data is drawn

- The age of the data

- The relevance of the time period of the data

- The consistency of time periods for different pieces of data

- The level of detail of the data

- The representativeness of the factory or plant producing the data.

This is not an exhaustive list but indicates the factors that need to be considered in weighting, giving credence to, or choosing one set of data over another. The ultimate aim of the exercise is to produce results that most accurately reflect the current state of production of a particular material for the whole of New Zealand, in terms of energy used. The decision about whether to include particular data is made by the 
researcher at each step of the analysis. The question to be answered each time is: "Does this data accurately reflect, or is it likely to accurately reflect, the current New Zealand position for this material, or is there other data available which would give a better representation of the position?" If better data is available, within the resources to hand, it must be used.

There may be cases where data exists without any other comparable or alternative data being available, but because of the degree of uncertainty of its accuracy it should be discarded.

\subsubsection{Data Limit}

Some analysts, especially in LCA, place an arbitrary limit on minor inputs that account for only a small percentage of the total. This is done to reduce the effort to collect data and calculate a coefficient. In this thesis, however, all known inputs were accounted for, even if only by substituting I-O data.

\subsection{Summary}

$\mathrm{EE}$ analysis has been used for many decades to understand resource use, and more recently environmental impact. The techniques used have evolved and been refined to the present day. Between the earlier days of its application as a resource use assessment method and its more recent use for environmental impact determination, EE analysis lost some of its appeal as a reliable indicator. Recently, however, it has enjoyed a resurgence of interest as an environmental impact indicator. This is due in part to the recognition of energy as a central aspect of environmental impact, especially as it relates to the pre-eminent problem of $\mathrm{CO}_{2}$ emissions and climate change.

Large variations in results for similar materials were a feature of early EE analyses. The accuracy and reliability of EE analysis has improved significantly and been demonstrated here to be much more accurate when process-based hybrid analysis replaces I-O analyses. Although there are still problems of data selection and reliability for the analyst to resolve, process-based hybrid analysis as developed and 
used for this thesis provides a method that is suitable as a design and policy tool, in enabling a reduction in EE, and environmental impact.

This chapter has discussed the historical and practical context of EE analysis, and detailed how to conduct it. Chapter 7 extends the results of EE analysis to embodied $\mathrm{CO}_{2}$ analysis. Chapter 8 provides detailed examples of analysis for some building materials. 


\section{$7 \quad$ Embodied $\mathrm{CO}_{2}$ Analysis}

The fifth revolution will come when we have spent the stores of coal and oil that have been accumulating in the earth during hundreds of millions of years. ... Whether a convenient substitute for the present fuels is found or not, there can be no doubt that there will have to be a great change in ways of life.

- Charles Galton Darwin, 1953

\subsection{Introduction}

Chapter 4 presented the case for using energy and $\mathrm{CO}_{2}$ as sustainability measures. Embodied $\mathrm{CO}_{2},\left(\mathrm{ECO}_{2}\right)$, like embodied energy (EE) and linked with it, can be used as a measure of environmental impact. Chapter 6 presented EE analysis in detail. This chapter presents the detail of $\mathrm{ECO}_{2}$ analysis, and the (sometimes) complex relationship between energy and $\mathrm{CO}_{2}$ emissions. It begins by discussing the implications of using marginal or average emission factors (the amount of $\mathrm{CO}_{2}$ emitted for each unit of energy, in units of grams per megajoule).

Because $\mathrm{CO}_{2}$ is the major greenhouse gas, and because climate change is the major environmental threat, now and in the foreseeable future (see Sections 2.5 and 4.4.3), the amount of $\mathrm{CO}_{2}$ resulting from the provision of goods and services is highly significant when measuring relative and ultimate sustainability levels.

Energy analysis (EA) is a useful sustainability measure because it reflects a complex web of activity that is linked with environmental impact. EA cannot, however, identify a limit for sustainable activity. $\mathrm{ECO}_{2}$ is an even more useful measure of sustainability than EE because of its ability to calculate proximity to a sustainability limit, because of the direct link between $\mathrm{CO}_{2}$ and climate change, and because the different levels of atmospheric $\mathrm{CO}_{2}$ and their respective effects can be calculated, including an upper level of absorbable atmospheric $\mathrm{CO}_{2}$ emissions. $\mathrm{EE}$ and $\mathrm{ECO}_{2}$ may be used either separately or together for different applications, and to answer different questions. 
Since $\mathrm{ECO}_{2}$ is derived from $\mathrm{EE}$ analysis, the methodology for determining $\mathrm{ECO}_{2}$ is the same as for EE, but with the further step of calculating and applying the $\mathrm{CO}_{2}$ profile associated with the various energy inputs and other parts of a process that may have emissions (or absorptions) related to them.

Electricity has a complex emissions profile and is a major energy type. Differences between average and marginal emissions for electricity can be large, and are not always well represented in government publications (MED 1997a-2009b). Electricity is thus afforded a detailed examination.

The main part of the chapter discusses emission factors for different energy types, and for industry. Some energy types, such as refined liquid fossil fuels, have predictable emissions, which are obtainable from published sources (Baines, 1993). Others, such as natural gas, vary in their emissions profile according to the extracted gas composition and source (MED, 2006b).

Finally, $\mathrm{CO}_{2}$ absorption and long-term sequestration are discussed.

\subsection{Choosing Average or Marginal $\mathrm{CO}_{2}$ Emissions Analysis}

A principal aim of embodied energy and $\mathrm{CO}_{2}$ analysis is to enable people to make decisions about materials choices to reduce overall environmental impact. The choice of average or marginal analysis (see Section 6.2.10) usually follows the question asked about a process; in this case, house construction. That question might be, "How much energy was used (and $\mathrm{CO}_{2}$ emitted) in building, maintaining, and operating a typical three bedroom New Zealand house for one year?" This question usually prompts analysis using average energy data. Although it could be argued that for a new house marginal energy data is appropriate to answer this question, analysing an average house usually elicits use of average data. Alternatively, the question asked may be, "What is the effect of building this particular house, with these particular materials, and operating it with these energy demands, for one year?" 
The effect of one house-lot, say, of material X, may get swamped by other changing conditions in the market for that material, and become insignificant. An approach used by Concept (2003) (see Section 7.3.5.1) overcomes this problem: a tranche of demand sufficiently large to affect producer behaviour is assumed. The individual choices of building specifiers can be seen as part of such a tranche.

Increased demand causes manufacturers to increase production, using more energy per factory, and raising total energy demand, although there may be other production influences. Increased energy demand affects particularly the $\mathrm{ECO}_{2}$ calculation with respect to electricity, where marginal demand is met primarily by thermal generation.

For some materials, for example aluminium, the market for the product is international. If a decision is made to use timber rather than aluminium window frames, for example, total New Zealand aluminium demand is smaller by that quantity needed for the (avoided) aluminium window frames.

New Zealand's aluminium smelter operates according to capacity, maintenance requirements, and other factors unrelated to local aluminium demand. More than 90\% of the product is exported (Rio Tinto, 2007). If local demand reduces by one tonne, then one more tonne of plant output is exported. According to the International Aluminium Institute (IAI), world aluminium demand is generally rising, with more smelters planned (IAI, 2000). Variation in marginal demand is therefore met by new smelters coming on-stream, or not.

Current and projected near-future proportions of electricity generation for aluminium are: hydro, 55\%; coal, 30\%; and gas, 15\% (IAI, 2000). As can be observed in the New Zealand electricity market however, the effect of increased demand in one industry, particularly one with high electricity use such as aluminium smelting, is to increase overall electricity demand. This is met at the margins by a different mixture of generation types, depending on the country, but predominantly by fossil fuel. As long as some thermal generation meets supply, and assuming thermal generation would be curtailed before hydro or other renewables with cheap 
'fuel' inputs, marginal electricity should be regarded as thermally generated. If demand dropped to preclude thermal generation, and hydro or other renewable supply were reduced to meet the lower demand, then, and only then, could marginal supply be regarded as from renewable, low emission generation. Thus, no matter where production occurs in a global market such as aluminium, the effect of demand fluctuation is for thermally generated electricity, and global $\mathrm{CO}_{2}$ emissions, to increase, or reduce. This can be assumed to apply to any material manufactured within a world market.

Exact emission factors are unknown for average and marginal electricity for worldwide aluminium smelters. The world aluminium marginal electricity emission factor is, however, likely to be similar to fossil-generated electricity, whereas New Zealand's marginal emission factor is likely to be lower because of the hydro portion in the marginal electricity mix. Nevertheless, in the absence of world data, New Zealand's marginal emission factor was used in this thesis as a proxy for fossilderived electricity for aluminium. Both average and marginal emissions for aluminium were calculated in this thesis.

In building production, marginal electricity generation is a relevant parameter. If a New Zealand building specifier decides to use paint rather than, say, a natural oil finish, the extra demand for electricity to meet the extra production of high-EE paint will come primarily from thermal generation, since the base-load generation by hydro (and other 'fuel' types with a low 'fuel'-input cost such as renewables) is essentially fully exploited. In calculating the $\mathrm{ECO}_{2}$ for the building using paint the marginal electricity figure should therefore be used for greatest accuracy. The same applies to most specific materials. Exceptions would include where a manufacturer generates their own electricity and is thus de-linked from the national grid profile.

If the question to be answered is not about the effect of specific buildings and the materials they are made of, but a wider one, the average $\mathrm{CO}_{2}$ emission coefficient may be the appropriate one to use. The question, "What are the total $\mathrm{CO}_{2}$ emissions embodied in the New Zealand housing stock?" for example, should thus be answered using average emission factors. 
For materials embodying significant amounts of electricity, the difference between average and marginal emissions will also be significant, and proportional to the ratio of electricity to other energy inputs. Since marginal electricity emissions are significantly higher than average ones, materials that have high electricity inputs show marginal $\mathrm{CO}_{2}$ emissions closer to what would be expected with high fossil fuel inputs, with less benefit from the relatively low emissions of hydro electricity.

\section{3 $\mathrm{CO}_{2}$ Emission Factors for Energy}

Specific $\mathrm{CO}_{2}$ emissions for each energy type in New Zealand are not always available in a form that is complete to the end-use point. For this thesis $\mathrm{CO}_{2}$ emissions figures were from a combination of three sources: the New Zealand Energy Data File (EDF) (MED, 1997a...2008a); New Zealand Energy Greenhouse Gas Emissions (EGGE) (MED, 2000b...2009b); and the New Zealand Energy Information Handbook (Baines, 1993). Figures for emissions from coal, petroleum products, and LPG were taken directly from Baines. Figures for biogas and wood were taken from the EDF (MED, 2006b). A combination of information from the EDF and EGGE was used to establish emission factors for natural gas and electricity. Unless otherwise indicated, a five year average of emission factors and related figures was used to smooth variations, primarily in hydro inflows. A longer, say ten-year, average was avoided because changes in trends could be lost, and too much emphasis given to outmoded data.

\subsubsection{Coal}

Coal emission factors vary with different grades, as shown in Table 7.1. For known grades in a specific application, the relevant emission factor was used; average New Zealand emission factors were used in other cases. These factors are given in Table 7.1 Emission Factors for Coal. The precision to one decimal place reflects the precision in Baines (1993), and is followed for similar values throughout this chapter. 
Table 7.1 $\mathrm{CO}_{2}$ Emission Factors for Coal

\begin{tabular}{lcl}
\hline Coal Type & $\mathrm{CO}_{2}(\mathrm{~g} / \mathrm{MJ})$ & Source \\
\hline Coal, bituminous & 88.8 & Baines, 1993 \\
Coal, sub-bituminous & 91.2 & Baines, 1993 \\
Coal, lignite & 95.2 & Baines, 1993 \\
Coal, All New Zealand production & 90.4 & Baines, 1993 \\
Coal for electricity generation & 90.0 & MED 2005b,c; MED 2006b,c; This thesis \\
\hline
\end{tabular}

Fugitive emissions of $\mathrm{CH}_{4}$ are associated with coal production; non-combustion $\mathrm{CO}_{2}$ emissions are associated with mining and transport. All emissions were included in the final coefficients, by using an I-O analysis of coal production (Baines and Peet, 1995).

The 36\% thermal efficiency of coal fired electricity generation was derived from coal use and electricity outputs quoted in the EDF, which include co-generation (MED, 2002c; 2005c; 2006c). The $\mathrm{CO}_{2}$ emission factor of $\mathbf{9 0 . 0} \mathbf{g} / \mathbf{M J}$ from coal combustion for electricity generation was derived from "coal use" and emissions for "electricity generation by coal", which include some, but not all, co-generation (MED, 2005b; 2006b).

\subsubsection{Gas}

The stated five year average $\mathrm{CO}_{2}$ emission factor for gas as a general fuel is $\mathbf{5 2 . 4}$ g/MJ (MED, 2006d), slightly higher than the $\mathbf{5 2 . 1} \mathbf{g} / \mathbf{M J}$ figure for gas used to generate electricity, which was calculated from electricity generation gas use and emissions figures (MED, 2005b; 2006d). This small difference reflects more than statistical imprecision: it stems from the mix of gas sources for electricity generation and average distributed gas. For processes that are highly dependent on gas, the difference can become significant. When gas production and transmission losses are included the $\mathrm{CO}_{2}$ emission factor for average distributed gas at the end use point is

\section{$54.2 \mathrm{~g} / \mathrm{MJ}$.}

Extracted gas shows a varying composition over both the short (daily) and long term. The $\mathrm{CO}_{2}$ component of the gas stream has trended down over recent years; a variation not found in other fuels (MED, 2000b). High $\mathrm{CO}_{2}$ concentrations in the gas stream are removed from some distributed gas. Incomplete combustion while 
flaring, and leakage during maintenance and distribution lead to 'fugitive' emissions (MED, 2000b). 'Own-use' energy, used by the gas production industry to extract and distribute gas through pipelines, is derived from gas and is responsible for 'own-use' emissions. The final $\mathrm{CO}_{2}$ emission factor for gas was the sum of combustion, 'fugitive', and 'own-use' emissions.

Table 7.2 $\mathrm{CO} 2$ Emission Factors for Gas

\begin{tabular}{lcl}
\hline Gas Type & $\mathrm{CO}_{2}(\mathrm{~g} / \mathrm{MJ})$ & Source \\
\hline Gas for electricity generation & 52.1 & MED, 2005b; MED, 2006d; This thesis \\
Average gas produced & 52.4 & MED, 2006d \\
Average end-use gas & 54.2 & MED, 2005b; MED, 2006d; This thesis \\
\hline
\end{tabular}

\subsubsection{Geothermal}

Geothermal fluid (hot water and steam) contains $\mathrm{CO}_{2}$. Electricity generation from geothermal steam has a low thermal efficiency $(\sim 15 \%)$. The 5 -year average $\mathrm{CO}_{2}$ emission factor for geothermal electricity is thus a significant $23.6 \mathrm{~g} / \mathrm{MJ}$, although this is still low compared with fossil fuels. For direct use of geothermal heat the emission factor is much lower: $3.3 \mathrm{~g} / \mathrm{MJ}$.

Table 7.3 CO2 Emission Factors for Geothermal

\begin{tabular}{lll}
\hline Geothermal Product & $\mathrm{CO}_{2}(\mathrm{~g} / \mathrm{MJ})$ & Source \\
\hline Electricity from geothermal & 23.6 & MED, 2006c; MED, 2006d; This thesis \\
Delivered geothermal heat & 3.3 & MED, 2006d; This thesis \\
\hline
\end{tabular}

\subsubsection{Liquid Fuels}

Emission factors for liquid fuels and transport were from New Zealand sources (Baines, 1993; Collins, 1993). A detailed analysis of bulk shipping, however, was done for this thesis to refine the calculations for important items, such as alumina and gypsum from Australia.

\subsubsection{Electricity}

Electricity has multiple inputs which complicate its emissions profile, requiring careful assessment to derive an accurate and transparent emission factor, especially because it is a ubiquitous energy source. Other fuel sources have reasonably clear emissions rates, but for electricity, the particular mix of generation sources has a 
marked effect on $\mathrm{CO}_{2}$ emitted for a particular demand level. The fuel mix varies more in New Zealand than many countries because of a high hydro percentage, which is affected by large inter-annual variations in precipitation.

\subsubsection{Marginal Electricity Emissions}

Projecting a $\mathrm{CO}_{2}$ emission factor into the future with an uncertain electricity mix is problematic. Concept Consulting (Concept) modelled a 50MW tranche of generation (to ensure a noticeable alteration in generator behaviour) being added to the market, and a similar amount being removed (Concept, 2003). The modelling projected $\mathrm{CO}_{2}$ emissions from a modified mix of fossil fuel and renewable sources.

The marginal generation of electricity is dependent principally on the marginal cost of operating a generation plant, associated primarily with the cost of the fuel. The marginal cost of hydro and wind 'fuel' is very low, compared with thermal generation, allowing these generators to continue profitable operation when spot electricity prices are low. High spot prices, during high demand, prompt thermal generators to increase output. Fossil fuel entering the generation mix varies with the timing, and effects of dry years on hydro generation. Figure 7.1 shows the effect of dry and wet years on hydro and fossil fuel generation, especially 1992 and 2001 as dry years, and 1995 and 2004 as wet years. It also shows a trend towards higher coal contributions, especially in dry years; the long-term flat supply from hydro; and the rising trend for combined fossil fuels, consistent with rising total demand and the flat trend for gas generation. 
Figure 7.1 New Zealand Fossil Fuel Electricity $\mathrm{CO} 2$ versus Hydro Generation

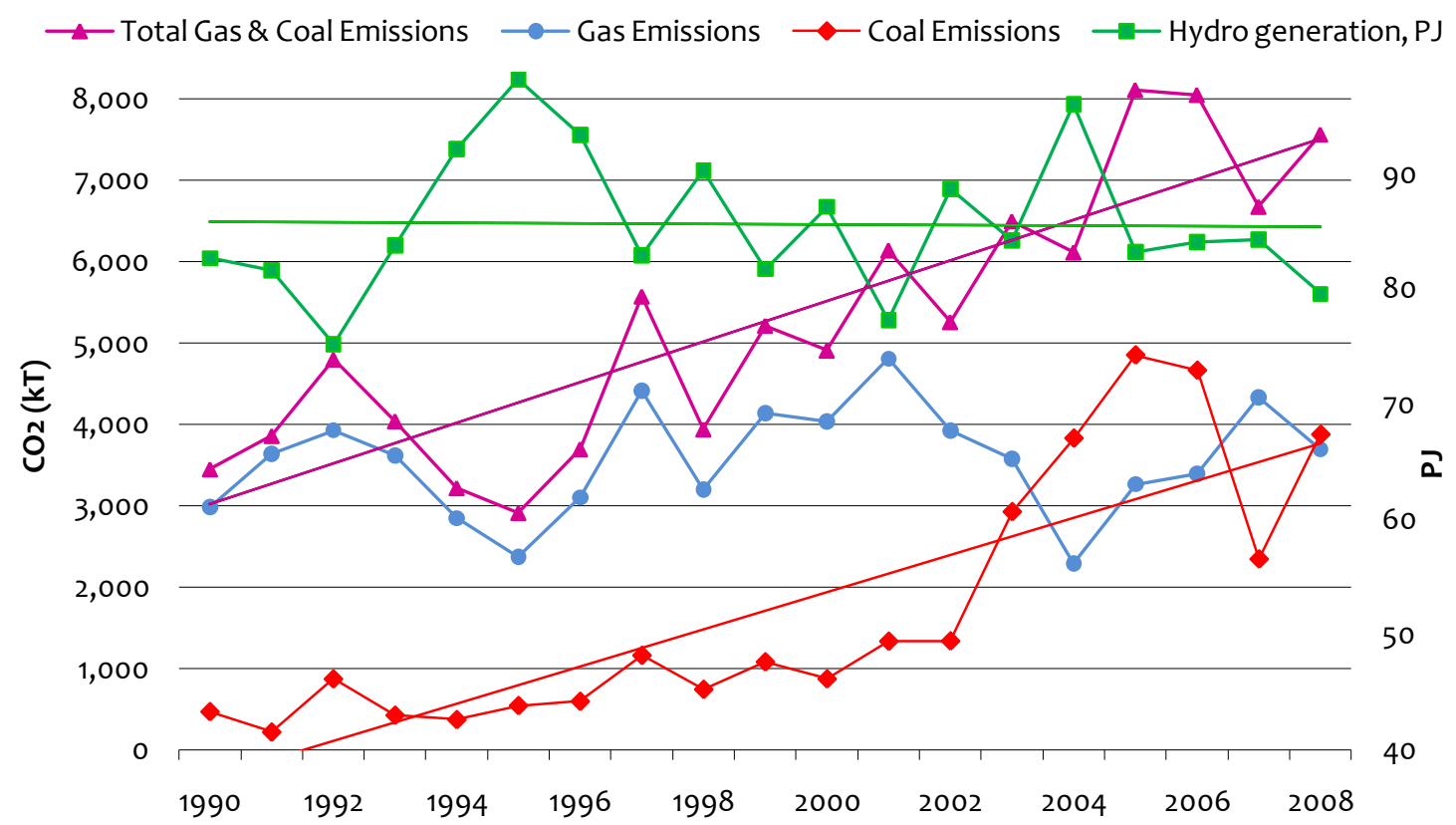

The availability of coal, gas, and oil and their relative prices affect the order of response of thermal generators: generators with lower marginal operating costs come on-stream first. Until recently gas has been the dominant thermal fuel, but dwindling availability has seen prices rise, encouraging greater coal use, since it is now the cheapest fossil fuel, and the first to meet marginal demand. The amount of electricity generated by gas combustion in 1990 was approximately 10PJ to every 1PJ generated from coal. Figure 7.2 shows this ratio has trended from about eight in 1990 to average about two for the last five years.

Figure 7.2 Ratio of Electricity Generation from Coal and Gas

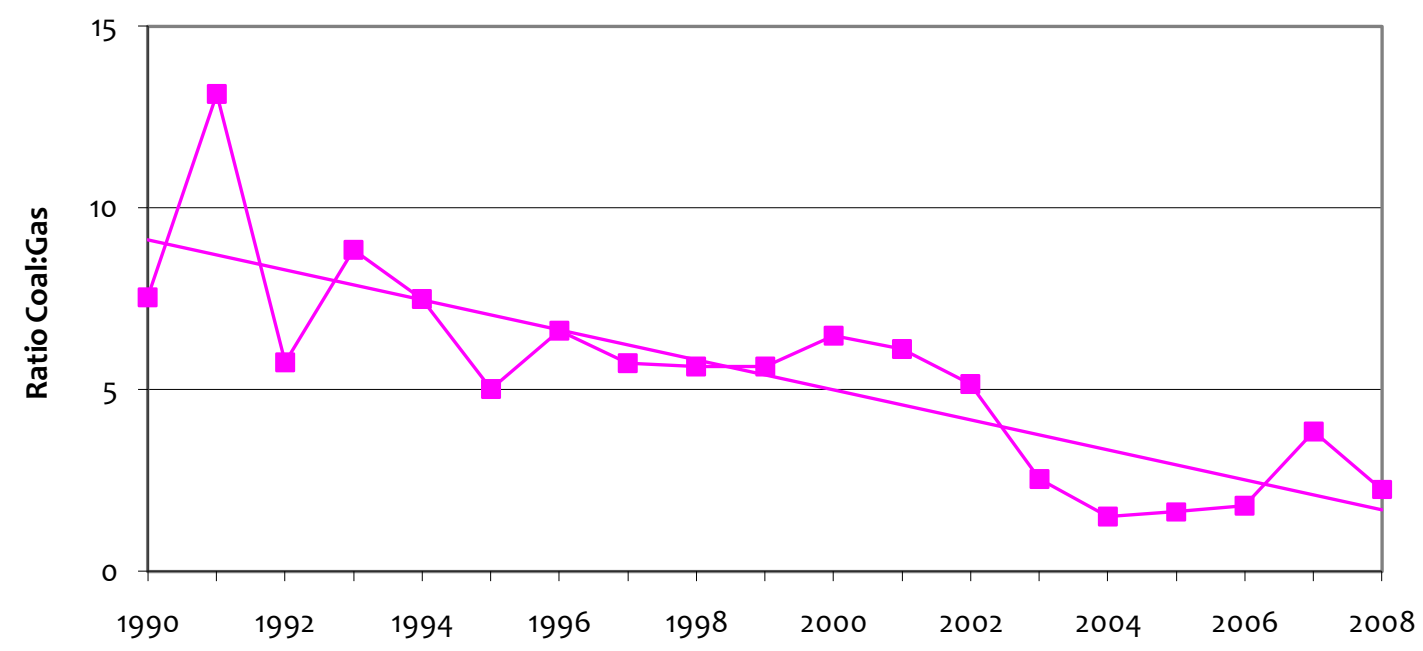


For $\mathrm{CO}_{2}$ emissions, the change in fuel type is significant, per PJ emissions of $\mathrm{CO}_{2}$ from coal combustion are, on average, 1.74 times higher than from gas combustion, and more than twice as high when used for electricity generation. Both fuels do, however, show a slow decline in emissions, due mostly to a general improvement in plant technology and efficiency. As gas becomes more expensive and less is burnt, the least efficient plants operate less, further reducing emissions for gas generation. There is also a slow decline in $\mathrm{CO}_{2}$ content of gas used for electricity generation.

After coal, gas remains the next most flexible fossil fuel source likely to come onstream. Finally, with higher demand and prices, oil is burned to meet demand. The order of fuels introduced to meet rising marginal demand is therefore coal, gas, and finally oil. Oil's emission factor is higher than gas, but not as high as coal.

As coal replaces gas for thermal generation, average $\mathrm{CO}_{2}$ emissions for New Zealand electricity will rise overall. The rise in coal use will result in a much higher emission factor for marginal electricity.

\subsubsection{Electricity $\mathrm{CO}_{2}$ Emission Factor Methodology}

The EDF and EGGE reports share electricity generation and GHG data that can be cross-referenced (MED, 1997a; 2006a; MED, 2000b...2006b). Tables of values are sometimes reported differently however, making direct comparisons difficult, such as the values for gas used in electricity generation. The EDF tabulates gas used for electricity generation, distinguishing gas used in power stations and co-generation at industrial sites (MED, 2005b, Table B.2). The EGGE report however, lists gas use for electricity generation which includes some co-generation, but not all, depending on whether the principal use for gas is electricity generation, with heat as a byproduct, or to drive an industrial process, with electricity generated as a side benefit (Black, 2006). EGGE figures for $\mathrm{CO}_{2}$ emissions also relate to gas principally used for electricity generation plus some for co-generation. The EGGE report, however, does not list how much electricity is generated from the quantity of gas burned, or $\mathrm{CO}_{2}$ emitted. The losses associated with electricity generation and transmission thus cannot be accounted for using just EGGE figures for gas use and $\mathrm{CO}_{2}$ emissions. 
To surmount this data problem, a series of factors was developed for each stage of production of electricity from gas combustion. Firstly, the raw emission factor for gas combustion was established from the EGGE gas fuel use and $\mathrm{CO}_{2}$ emissions figures (MED, 2005b, tables 2.2.1 and 2.2.3). Efficiency factors were then applied to this figure. Gas combustion $\mathrm{CO}_{2}$ emissions ranged from 51.9 to $53.2 \mathrm{~g} / \mathrm{MJ}$ over 15 years, with a 5-year average of $51.3 \mathrm{~g} / \mathrm{MJ}$.

The efficiency of gas production and transmission was derived from the total gas production figure, and the production losses and own-use figure (MED, 2005c, table E.3). The quantity of gas re-injected was subtracted from total gross gas production. This value was then divided by the sum of the flared gas, and production losses and own-use to establish the overall production efficiency, in $\mathrm{CO}_{2}$ emissions terms.

In other analyses the flared gas may not be counted since it is a necessary part of production and does not equate to gas lost or used that could otherwise be distributed to an end user. In a $\mathrm{CO}_{2}$ analysis, however, this amount must be included for completeness, even though it is relatively small.

LPG, extracted from the gas stream, was subtracted from gross production figures to arrive at a net natural gas amount. The LPG portion is, however, included in the production figure, divided by the losses and own-use figure, to reflect the gas 'cost' of producing both the LPG and natural gas stream, rather than attributing all the 'cost' to the natural gas alone. Gas production and transmission efficiency has stayed within a range of 96 to $97 \%$ since 1990, averaging $96.7 \%$ over 5 years.

The thermal efficiency of gas-fired power stations depends on their design: open cycle gas turbine, steam cycle, or combined cycle (Concept, 2003). Average generation efficiency was derived by dividing the electricity generated from gas combustion by the net gas used for that generation. Since the figure for gas used includes co-generation (MED, 2005c, table G.4), the overall electricity from gas combustion combined the general electricity from gas figure and the co-generation from gas (MED, 2005c, table B.2). Generation efficiencies range from 31 to $41 \%$ over 11 year, averaging 39\% over 5 years, with a rising trend. 
The EDF tabulates overall gas energy production, as well as losses and own-use. A figure for consumed gas energy was calculated from these two figures. Figures for observed consumed gas energy, and the "statistical differences" between the two, are also presented. Since this "statistical difference" varies over the years, the variation appears likely to be more than just statistical.

To ensure all losses are captured, the observed consumer energy figure was set against the overall production of electricity figure. The co-generation figure was included to be consistent with other EDF figures. The resulting efficiency includes line losses as well as production losses and own-use. Electricity production efficiency ranged from 84 to $92 \%$ over 11 years, with an $87 \%$ 5-year average and a slowly rising trend.

The overall $\mathrm{CO}_{2}$ emission factor, using a 5 year average to smooth variations but reflect trends, was thus derived as:

- $\quad 51.3 \mathrm{~g} / \mathrm{MJ}$, the basic combustion emission factor, divided by

- $\quad 0.97$, the gas production and transmission efficiency factor, divided by

- $\quad 0.39$, the gas generation efficiency factor, divided by

- $\quad 0.87$, the production and transmission efficiency factor,

to give an overall emission factor for gas generated electricity at the end use point of $161 \mathrm{~g} / \mathrm{MJ}$, or $580 \mathrm{~g} / \mathrm{kWh}$. All the above figures will vary year-to-year.

\subsubsection{An Electricity $\mathrm{CO}_{2}$ Emission Factor}

The average electricity $\mathrm{CO}_{2}$ emission factor from the EDF and EGGE figures (638 $\mathrm{g} / \mathrm{kWh}$ ) is consistent with the Concept (2004) figures which range from $600 \mathrm{~g} / \mathrm{kWh}$ to $660 \mathrm{~g} / \mathrm{kWh}$ for a 5 year average, if "new supply assumptions" were reduced. Concept concludes an appropriate range is 600 to $650 \mathrm{~g} / \mathrm{kWh}$, if their assumptions remain valid. They suggest a figure of $660 \mathrm{~g} / \mathrm{kWh}$ is appropriate if their 2003 supply assumptions are used, also noting that their sensitivity analysis indicates a tendency for variations in their assumptions "to push the [emission] factor up rather than down". 
$\mathrm{CO}_{2}$ emissions from hydro electricity are low, but not nil, once the emissions from dam construction and flooded land are calculated. The amount of vegetation on flooded land, and the climate at the lake site, affects methane emissions. Hondo (2000) reported a $\mathrm{CO}_{2}$ emission factor of from 3 to $5 \mathrm{~g} / \mathrm{MJ}$, using I-O analysis. Gagnon and van de Vate (1997) reported a global average of $5.5 \mathrm{~g} / \mathrm{MJ}$, using statistical analysis. An emission factor of $4 \mathrm{~g} / \mathrm{MJ}$ was used in this thesis for hydro electricity.

The hydrological variations examined by Concept necessarily use historical weather data. Given the possibility of increased weather variation due to climate change, especially the increase of drought, and the limited lake storage capacity of the hydro system to utilise increased occurrence of intense rainfall, the impact on hydro output is more likely to be at the reduced generation end of the range.

Shifting the upper figure of the Concept range from $650 \mathrm{~g} / \mathrm{kWh}$ to $660 \mathrm{~g} / \mathrm{kWh}$ thus seems reasonable. This would account for some of the likely increased weather variation that Concept do not include, as well as for other unforeseen variations in their supply assumptions. The 5-year average figure for gas-generated (marginal) electricity, $580 \mathrm{~g} / \mathrm{kWh}$, is below the projected range from Concept.

Concept (2003), however, use the generation efficiencies of different power plant types to calculate emission factors, rather than the observed fuel used and electricity generated, and used, according to Ministry of Economic Development (MED) reports. Gas production, own-use, and transmission losses are excluded, as are line and other losses for electricity transmission. The Concept figures are thus a calculated 'factory gate' analysis.

The Concept figures also include coal and oil generation. Coal and oil, derived using the same methodology as for gas, can be proportionately factored in according to the relative responses to demand from the different generation types. Concept (2004) conclude the percentages of new supply to meet an additional 50MW of demand would be from: coal $44 \%$; gas $35 \%$ and oil $8 \%$. The remaining $13 \%$ is 
due to hydro but, since it is primarily the fossil fuels that affect $\mathrm{CO}_{2}$ emissions, this is not significant.

Using 'real' consumption and generation data from the EDF and EGGE reports, rather than theoretical generation efficiencies, but excluding production and transmission losses for gas, and line and own-use losses for electricity transmission, the marginal $\mathrm{CO}_{2}$ emission factor for electricity is $710 \mathrm{~g} / \mathrm{kWh}$. This figure assumes the same proportion of marginal generation from gas, coal and oil that Concept (2004) projects. When production and transmission losses for gas and line and ownuse losses for electricity transmission are included, the marginal emission factor for electricity is $751 \mathrm{~g} / \mathrm{kWh}$, or $209 \mathrm{~g} / \mathrm{MJ}$.

There is, however, some uncertainty about the amounts of co-generation that are included in the EDF and EGGE electricity generation and use figures. In Table G.4 of the EDF, electricity generation from gas combustion is quoted at $23.6 \mathrm{PJ}$ for 2004, which is noted as including co-generation. Gas use for electricity generation is quoted in the Energy and Greenhouse Gas Emissions publication as 44PJ in Table 2.2.1. This figure apparently does not include co-generation. In the Energy Data File, Table B.2l for the 2004 year quotes gas use as 39.8 PJ for electricity generation, and 20.6 PJ for co-generation. If these two are added together and it is assumed that the electricity produced in co-generation is part of the national electricity supply, the total gas use for electricity is 60.4 PJ. If the upper figure is used over-counting may result. While the lower figure may understate the emissions for average and marginal electricity use, this conservative figure was used for calculations in this thesis.

When the figures are conservatively revised down, the result for marginal electricity $\mathrm{CO}_{2}$ emissions is $\mathbf{1 9 9} \mathbf{g} / \mathbf{M J}$, or $716 \mathrm{~g} / \mathrm{kWh}$. This is the appropriate figure to apply to observed end-use consumption for materials manufacture, to determine actual $\mathrm{CO}_{2}$ emissions resulting from marginal increased demand.

\subsubsection{Average Electricity Emissions}

Analysing the EGGE document for electricity generation, and using a small amount of data from the Energy Data File to apportion the amount of fossil fuel used for 
electricity generation, the $\mathrm{CO}_{2}$ emissions value is $51 \mathrm{~g} / \mathrm{MJ}(184 \mathrm{~g} / \mathrm{kWh})$ averaged over the years 2001-2005. There are some factors that do not appear to be included in the EGGE publication, however, including transmission losses and own-use. A report by the Parliamentary Commissioner for the Environment (Webb, 2005) calculates a higher than usually quoted transmission loss figure of $15.5 \%$ averaged over three years. This is partly because it is expressed as a percentage of electricity end use consumption, rather than as a percentage of generation. This is important to remember, since it indicates the percentage that must be added to any end-use consumption figure to factor in the extra electricity generated, and the emissions resulting, from the apparent end use electricity.

There is significant variation and inconsistency within the MED publications from year to year for the same data items. These differences are not addressed in the MED reports. They make it difficult to trace all the factors contributing to emissions, with a resulting tendency towards undercounting. Using both the EGGE and EDF publications, the $\mathrm{CO}_{2}$ emissions value for electricity is $\mathbf{6 8} \mathbf{g} / \mathbf{M J}$ $(243 \mathrm{~g} / \mathrm{kWh}$ ), compared to the national average for energy use of $74 \mathrm{~g} / \mathrm{MJ}$ (MED, 2006a; MED, 2006b).

\subsection{Industry Emission Factors}

For some inputs, such as some chemicals, where a process analysis figure was unavailable, an industry-wide emission factor was calculated. A hybrid analysis was undertaken, using I-O analysis (Baines and Peet, 1995) and emissions specific to the energy types in the I-O tables. These hybrid industry emission factors for relevant industries, using New Zealand Standard Industrial Classification (NZSIC) are shown in Table 7.4. They formed small parts of the hybrid analyses for some materials. By using values for: dollars; $\mathrm{MJ} / \$$; and $\mathrm{g} / \mathrm{MJ}$, a $\mathrm{CO}_{2}$ emission factor could be calculated for minor inputs for example, or capital equipment.

Statistics New Zealand (SNZ) tables of emission factors for 25 industries show some results closely related to those from Baines and Peet (Statistics, 2008a). Because of the aggregation of disparate inputs, however, such as in "Electricity, Water and Gas Supply", not all the SNZ coefficients are meaningful. 
Table 7.4 NZSIC Industry $\mathrm{CO}_{2}$ Emission Factors

\begin{tabular}{lc}
\hline NZSIC Category & $\mathrm{CO}_{2}(\mathrm{~g} / \mathbf{M J})$ \\
\hline Other Mining and Quarrying & 73 \\
Machinery manufacture & 66 \\
Water Works and Supply & 67 \\
Building and ancillary building services & 64 \\
Other construction & 67 \\
Non-metallic Minerals Manufacture & 80 \\
Basic Chemicals Manufacture & 68 \\
Basic Metal Industries & 84 \\
Fabricated Metal Products Manufacture & 87 \\
\hline
\end{tabular}

\section{5 $\mathrm{CO}_{2}$ Absorption}

The production of most materials involves the use of fossil fuels somewhere in the process, resulting in an embodied $\mathrm{CO}_{2}$ content for the finished good. Plant based materials, however, also absorb $\mathrm{CO}_{2}$ from the atmosphere as the plants grow. $\mathrm{CO}_{2}$ emissions as part of a production process count positively towards an $\mathrm{ECO}_{2}$ coefficient, whereas $\mathrm{CO}_{2}$ absorbed counts against this coefficient. Negative values, representing sequestered carbon, are therefore possible where the amount of $\mathrm{CO}_{2}$ absorbed exceeds the amount emitted during production.

The foremost building material with significant $\mathrm{CO}_{2}$ absorption is timber. While there are $\mathrm{CO}_{2}$ emissions from the machinery and equipment used for planting, sylviculture, harvesting and processing of timber, these emissions are lower than the $\mathrm{CO}_{2}$ absorbed as the trees grow. Even timber products with higher energy inputs, such as glulam or plywood, still have negative $\mathrm{CO}_{2}$ coefficients; that is, there is more carbon stored in the finished product than was emitted during the production of that product.

In the production of complex products, such as houses, therefore, a greater inclusion of plant based materials can offset the $\mathrm{ECO}_{2}$ from other materials. Timber framed walls are an obvious way to reduce the total $\mathrm{ECO}_{2}$ coefficient for a house. Timber used for piles, weather boards, lining materials, beams and other structural items, cellulose based insulation, and shakes or shingles are other items that also lower the total $\mathrm{ECO}_{2}$ for a house, because of the negative $\mathrm{ECO}_{2}$ coefficient for plant based products. 
McLaren (2001) determined the carbon content of Pinus radiata in New Zealand conditions. A value of $771 \mathrm{~kg} \mathrm{CO} 2 / \mathrm{m}^{3}$ is consistent with similar calculations on Australian Pinus radiata by Gifford (2000), although McLaren's figure is a little lower. Calculation of the exact carbon content depends on the density of the timber, which varies between sapwood and deepwood (Gifford, 2000). The figure used in this thesis was the more conservative figure which is also New Zealand specific. It has been calculated on a dry density of $420 \mathrm{~kg} / \mathrm{m}^{3}$. A typical density for pine timber in dry Wellington buildings was measured at closer to $460 \mathrm{~kg} / \mathrm{m}^{3}$. The additional moisture of in-use timber does not affect the carbon content calculation.

\subsection{Long Term Carbon Sequestration}

Carbon sequestration in bio-based materials, either in buildings, or after end-of-life, in landfills, can persist at least for the decades or centuries that are crucial for climate control to mitigate global warming (Hasselmann, 2002). When organic materials are landfilled, they may decompose, producing $\mathrm{CH}_{4}$ and $\mathrm{CO}_{2}$, and other trace gases. Certain conditions in landfills may inhibit decomposition. Micales and Skog (1997) surveyed literature on carbon loss from landfilled wood, concluding a $0-3 \%$ rate. Ximenes et al. (2008) excavated landfill sites, concluding a loss rate of $18 \%$ for hardwoods and 17\% for softwoods. The methodologies of both studies were deficient; Micales and Skog making arithmetical errors, and Ximenes et al. relying on a single site excavation of unusually wet soil. Chapter 9 uses portions of each study, appropriately recombined, to derive a carbon loss rate for New Zealand landfilled timber, and straw. 


\subsection{Conclusion}

$\mathrm{CO}_{2}$ emissions and absorptions for energy and production processes are crucial for measuring sustainability. This chapter has described the methods of $\mathrm{ECO}_{2}$ analysis used in this thesis. The high precision of some of the analysis and its results will not always significantly affect the total emission for a house, as will be seen in Chapter 9 . Small differences in applied emission factors can be important, however, for comparing different materials, house designs, and operating energy options. This chapter has presented particular methodologies for deriving average and marginal $\mathrm{CO}_{2}$ emissions, and when one or the other may be appropriately used. Chapter 8 will apply the $\mathrm{ECO}_{2}$ and $\mathrm{EE}$ methodologies from this chapter and Chapter 6 to a selection of building materials, to show their practical application. 


\title{
$8 \quad$ Selected Material Analyses
}

\author{
Genius is nothing more than common faculties refined to a greater \\ intensity. There are no astonishing ways of doing astonishing things. All \\ astonishing things are done by ordinary materials.
}

- Benjamin Haydon, 1876

\subsection{Introduction}

Chapters 6 and 7 presented $\mathrm{EE}$ and $\mathrm{ECO}_{2}$ analysis, respectively. The process-based hybrid analysis methodology described in them was used to analyse a range of building materials, forming a spreadsheet-based database of embodied energy (EE) and embodied $\mathrm{CO}_{2}\left(\mathrm{ECO}_{2}\right)$ coefficients for materials relevant to the construction of houses modelled in Chapter 9 (see Appendix B). The details of each production process, the inputs of energy and ingredients, the size and number of players in an industry, and many other factors vary considerably from one material to another. The analysis of every material could usefully be elucidated, except for the size limits of this thesis. There is, however, sufficient similarity in the analyses to enable a selection of materials to illustrate the procedure and avoid excessive repetition.

This chapter describes the analysis methods applied to specific materials. General methods are firstly described; then three commonly used materials (recycled steel used in reinforcing; timber; concrete) and one product system (wind generator) are selected, as significant contributors to the embodied energy and $\mathrm{CO}_{2}$ totals in the construction of a house, to show the detailed application of the method. Sample spreadsheets, and details from them, are shown to illustrate methods used.

\subsection{Methodology}

The analyses in this thesis treat the whole process of producing a material as one operation. The analyses are organised into ingredients, energy inputs, transport, capital equipment, outputs, and other information. Other methods (Jaques, 2001; Forintek, 1993) sometimes analyse production in stages, for example: raw materials extraction; transport; and subsequent production stages, examining inputs to each of 
these stages for the sake of simpler analysis steps. Because the distinction between stages can be arbitrary and indistinct, such a method can cause more problems than it solves. Energy, transport, and capital equipment are frequently part of each production stage, making it easier to separate the analysis into these categories, rather than production stages.

Each analysis began with an assessment of readily available data. There may have been industry or overseas data available. More often, however, enquiries needed to be made into the structure of a particular industry in the local context. Once the range of industry players was established, a choice was made about which players to obtain data from. Machinery, energy inputs and economies of scale can have a noticeable effect on the energy and $\mathrm{CO}_{2}$ coefficients for products from different sized manufacturers. It was important, therefore, to reflect the relative importance in national industries of large and small manufacturers. Preferably, a representative range of players was chosen that included large and small manufacturers, reflecting ratios in the national situation. In some industries, such as timber products, a wide range of manufacturers exists, with many small sawmills, and fewer large mills.

Data was sought from manufacturers in order of importance. In some cases manufacturers cooperated in supplying data initially, but became less willing to find and deliver less-straightforward data as the effort for them increased. In these cases missing data could often be obtained from other sources. Data that could only be gained from specific manufacturers was given priority. For each new material analysed, the range of data sought, in order of priority, included:

1 Total annual output, usually in tonnes, but preferably in units commonly used in the building industry

2 Direct input ingredients, in the commonly used units, according to the annual throughput, or per-unit of product

3 Inputs of each energy type, preferably on an annual basis

4 Transport inputs, where relevant

5 Capital inputs, such as buildings and machinery

6 Other relevant data, such as the density of the material produced. 
An example of the full list of data normally collected is shown in Figure 8.1.

Data was gathered in the most expeditious way, but with regard to data quality. This meant obtaining data in a form that required minimum work or manipulation by the manufacturer, both to improve the rate of data being provided and to reduce errors by manufacturers.

Some small inputs are inevitably neglected in any analysis. At any analysis stage where there is a range of figures for some input, be it physical or energy, there is a therefore a justification for using the higher figure, to compensate for minor inputs that are known to be missing. Treloar (2001) argues that the missing inputs from process analysis, which does not have the global coverage that I-O analysis does, is significant, and greater than the increase in total embodied energy arising from using data from the upper end of inputs-data ranges. Accordingly, unless there was a clear reason for using an average or lower figure from a range of inputs-data, the upper end of any such range was used in this thesis.

\subsubsection{Annual Output}

Output was compared with the totals for all other inputs to derive a per-unit coefficient. Annual totals were preferred, to minimise calculation or measuring inaccuracies by the manufacturer. Similarly, data was obtained in the units normally used by the manufacturer to reduce arithmetic errors.

\subsubsection{Ingredient Inputs}

Once the data was gathered, units required standardising for calculation of the input amounts. If all input data was in annual tonnages this was simple. Sometimes, however, inputs were in units of production, such as aggregate, cement and water, per $\mathrm{m}^{3}$ of concrete production. This could then be compared to annual output in a similar, or different unit, to relate it to annual energy inputs.

Frequently ingredients required upstream analysis, such as cement, where there are inputs of limestone and marl, clay, and gypsum. Each such input ingredient also required its own analysis. This was sometimes simple, as in the case of the bitumen 
input to asphalt, where a specific energy input to the bitumen plant was available. In other cases extensive analysis was required, such as aggregate (Section 8.5.1).

For large volume or extensively used materials, such as concrete, it was worthwhile putting considerable time into obtaining accurate energy figures for constituent raw materials. For some materials the time required to obtain data to conduct an analysis of a small upstream input ingredient was large. Where a constituent material represented a small part of the overall energy coefficient, and did not warrant the work required to obtain it, a figure derived from input-output analysis was used. Without a full process analysis it is impossible to be certain just what percentage a particular input represents. With experience, however, it is possible to recognise that an ingredient will be a small part of the total, and to justify the use of a (less precise) input-output figure to represent it. The oxygen used in the oxy-acetylene gas cutting equipment during scrap steel collection and recycling is an example. Scrap steel that required gas cutting was known to be a small proportion of the cut scrap, and all cutting and handling steps were known to be a small part of the total scrap collection figure.

\subsubsection{Energy Inputs}

After ingredient inputs, the direct energy inputs to a process were examined. This was mostly a simple matter of applying known energy coefficients for each energy type (Baines, 1993; Baines and Peet, 1995). For some materials, such as extruded aluminium, data for electricity inputs came from two or more sources: the aluminium and extrusion manufacturers. Occasionally, unusual energy types would require their own analysis, such as waste oil used in cement manufacture.

The production energy requirement of the different energy types was included, by I-O analysis (Baines and Peet, 1995). This incorporates exploration, extraction, processing and distribution of the energy to the end-use point. In some analyses, energy is differentiated into primary and secondary energy (Bullard, 1975; Weir, 1998). That is, it may be quoted as delivered or end-use point energy, which is secondary energy. Conversely, energy may be quoted as primary energy, which is the total energy of a 'primary' source, such as coal, necessary for production, conversion, 
such as coal combustion, and delivery, to the end-use point. In this thesis the energy used to produce and deliver end-use energy was always included in calculations at the earliest opportunity. If a quantity of end-use energy was known, it was converted to a 'primary' energy figure forthwith by multiplying it by the appropriate factor. Thus, all the figures quoted in the total coefficients, and for most steps in each analysis, are in primary energy terms.

Data for energy inputs came via different routes. Frequently manufacturers determined energy inputs from purchased energy, such as electricity bills. This sometimes required applying tariffs to dollar amounts to derive electricity quantities in $\mathrm{kWh}$. This was difficult, given the varying tariffs according to changing electricity prices. While prices for other energy types also varied, such as gas or diesel, these prices were more consistent and easier to apply to annual purchases in dollar figures. Thus, obtaining energy inputs by units of energy, such as litres of diesel or kWh of electricity, was preferable, but required greater effort on the part of the manufacturer, or a member of their staff. This extra effort reduced the likelihood of the data being provided at all, however, and could necessitate collection of data in a less easily usable form.

Sometimes energy use could be determined by analysing various parts of the operation and the energy inputs to them. Scrap steel shredding, for example, was known to use electric motors of a specific size, operating for a known number of hours each day, and days each month.

In some instances, energy use could be determined on a batch basis. Batching concrete, for example, used a specific amount of energy, which could be related to known annual product output to determine annual energy inputs.

\subsubsection{Transport}

Energy intensities for different transport types were mostly from published sources (Collins, 1993). For large operations, or where transport was a large percentage of inputs to a process however, specific analyses using industry data were undertaken for this thesis, such as trans-Tasman bulk-carrier transport of alumina. 
The analysis limit was the factory gate. Some materials therefore, such as river dredged aggregate, had no transport component, since diesel used to move gravel from river bed to screening plant was part of overall diesel usage for the operation.

Some materials had complicated transport inputs. It was found that recycled steel, for example, has a range of transport types: small and large truck, coastal barge and ship, and rail, applied to different parts and proportions of scrap collection.

Some materials had large transport components, such as imported stone, which is heavy, and is often transported long distances, from the source country, to a cutting and polishing site, before being re-exported to New Zealand. Transport energy was calculated on a distance $\mathrm{x}$ weight basis (tonne.kilometre).

I-O analysis matches dollar costs with energy use; for transport however, there is a distinct divergence between cost and energy. Transport charges are generally made on a volume basis, which is not very relevant to the energy required to move a tonne of sea-cargo, and the proportion of a ship attributable to it, through the water. It was found during the analysis of bulk-carrier trans-Tasman shipping that ship fuel usage is not affected by cargo volume but by weight, but then only slightly: the energy used to propel a ship does not vary greatly between full and empty. Air transport energy (and cost) is influenced by cargo weight; however, it accounts for only a small percentage of building material inputs by weight.

Materials often have a variety of sources. It was necessary to determine an average or typical transport distance for each input, such as the sea distance from point of origin to New Zealand. No account was taken of ships diverting to other destinations while en-route or otherwise taking indirect routes to New Zealand. Any potential variations that may result from such exclusions are likely to be very small, due to the averaging of transport distances and because transport is a small part of most production processes. 
Table 8.1 shows a selection of materials and the percentage of total energy that is attributable to transport. Energy of transport is usually less than $5 \%$ of the total energy coefficient for building materials.

Table 8.1 Energy Percentage of Transport for Selected Materials

\begin{tabular}{lc}
\hline Material & Energy of Transport (\%) \\
\hline Aggregate, average & 0 \\
Aluminium, virgin & 0.6 \\
Cement, average & 0.7 \\
Ceramic brick & 1.4 \\
Concrete, 17.5MPa & 14.4 \\
Glass, toughened & 8.7 \\
Steel & 3.2 \\
Steel, recycled & 8.4 \\
Stone, imported & 33 \\
Timber, kiln dried & 4 \\
\hline
\end{tabular}

\subsubsection{Capital Equipment}

The term 'capital equipment', first used in EA in 1974 (Slesser), is used here to refer to the machinery used in manufacturing, the buildings used to house the manufacturing process, and any other capital items, such as vehicles, that are part of the operation.

Very few companies had available data on the capital value of their plant, which was relevant to their output during the period examined for establishing energy use. Some companies were able to estimate the residual value of their plant, but it was impossible for them to estimate with any useful accuracy how long their current plant would be in production, and therefore the period over which the costs of the plant should be amortised. Where the value and lifespan of the plant could be usefully ascertained, this data was used with an I-O figure for the appropriate industry. Where the principal capital equipment was heavy machinery, a figure for 'Machinery Manufacture' was used (Statistics, 1995). If the predominant capital equipment investment was for buildings housing the process, the 'Building \& Ancillary Building Services' category was used.

Where a value for buildings and/or machinery was unavailable, a percentage of the total economic activity attributable to 'gross fixed capital formation' for the relevant industry was calculated from the I-O tables (Statistics, 2001). This percentage was 
then applied to the sub-total of all other inputs to a process, as a proxy for the energy and emissions attributable to the capital equipment.

Carter et al. (1981) used the Gross Fixed Capital Formation (GFCF) column from the input-output tables to estimate the energy component attributable to capital. The GFCF is a gross figure which includes the consumption of fixed capital (depreciation). A similar approach was used for this analysis. Carter et al. comment that their estimate is approximate, which is possibly the reason that many energy analysts have not included the energy of capital equipment, as well as the unavailability of reliable data . Using a similar approach to Carter et al., it was found that the percentage of the final figure due to the energy of capital equipment was small and often less than the margin of error for the analysis procedure.

Twenty-three representative materials were analysed for capital equipment energy. Materials of the same type or from the same factory, such as various concrete products, with similar capital equipment percentage were represented by one typical material, in order not to distort the average. The range of values for the percentage of energy of capital equipment was from $0 \%$, for a very old plant with high throughput that had effectively no residual value; to $6.0 \%$ for the highest. The average was $1.2 \%$. Most materials were below $1 \%$. 
Table 8.2 Energy of Capital Equipment for Selected Materials

\begin{tabular}{ll}
\hline Material & Energy of Capital Equipment (\%) \\
\hline Aggregate, river & 1.4 \\
Aluminium, extruded, factory painted & 4.3 \\
Asphalt (paving) & 0.82 \\
Cellulose pulp & 0.52 \\
Cement, wet process & 0.81 \\
Fibre cement board & 0.82 \\
Brick, new technology & 6 \\
Brick, old technology & 0.00 \\
Concrete, ready mix, 17.5 MPa & 0.82 \\
Copper sheet & 1 \\
Copper tube & 4.3 \\
Clay, raw & 1.5 \\
Glass, laminated & 2 \\
Insulation, cellulose & 0.52 \\
Insulation, fibreglass & 3.7 \\
PVC & 0.09 \\
Steel, virgin, general & 0.03 \\
Steel, stainless, average & 0.01 \\
Timber, air dried, roughsawn & 0.0005 \\
Timber, air dried, dressed & 0.0004 \\
Timber, kiln dried, gas fired, dressed & 0.00014 \\
Timber, kiln dried, waste fired, dressed & 0.00013 \\
Timber, glulam & 0.00010 \\
\hline
\end{tabular}

\subsubsection{Other Data}

Other data collected for materials included a range of information relevant to the specific material where it was available. This data included annual manufacturer output, annual industry output, and percentage of national output represented by a specific manufacturer. Physical characteristics of the material were noted, including density - to allow conversion between $\mathrm{MJ} / \mathrm{kg}$ and $\mathrm{MJ} / \mathrm{m}^{3}$. The major players in a particular industry were noted, where this was known and relevant.

The age of the data was noted. Often data age was mixed: energy and ingredient inputs were usually for the most recent calendar or financial year, while any I-O data, such as capital equipment, could be many years old. Data age differences required reconciliation, such as corrections for inflation, to make accurate calculations. 


\subsubsection{Data Confidentiality}

The source of data was noted, as was any comparative data if it was available. The confidentiality of data was also noted. In most cases, data was only provided because an undertaking was made that it would remain confidential. Some manufacturers still refused to provide data because of concerns that it could reach the hands of competitors who may use it to their advantage. This problem is more apparent in periods of tight economic conditions where manufacturers are watching for any small advantage, or difficulty. Withholding of data also increased if manufacturers were very busy, because they were reluctant to divert time away from production effort.

Confidentiality of data reduces transparency, and sometimes the detail of the data itself. This problem could be surmounted if companies were required to furnish energy and relevant production data, as they are with certain financial data. If a central agency, such as Statistics New Zealand, collected specific company data on energy and other relevant data in a consistent manner, it would facilitate reliable energy and $\mathrm{CO}_{2}$ analysis of New Zealand produced materials. Confidentiality could thereby be maintained, but allow close scrutiny of energy and greenhouse gas data for analysts.

\subsubsection{Data Gathering}

Some companies were forthcoming with information, although obtaining the required data frequently involved many phone conversations, faxes and emails. Useful information sometimes came from a process engineer, whose expertise may have been identified via contact with various other employees, or via the industry umbrella organisation. Other personnel best placed to provide data were variously the general manager; production manager; accountant; shop foreman; or sales staff. It was found that, typically, several phone calls were necessary to discover the person within an organisation who was best placed to provide data. Initially, the most important data was sought: major inputs of materials and energy. Subsequent data was sought as the analysis proceeded and as clarification was needed for various aspects. Such multi-step data gathering prevented 'overloading' the data provider with requests, and ensured that if requests were declined or communication 
terminated at some point, then the major information had been gathered. Conversely, questionnaires were found to be an ineffective way of acquiring data. Data gathering for each material typically required sporadic communications over several weeks.

\subsubsection{Data Checking}

The database design for EE information was developed over the course of multiple analyses, using a spreadsheet format. Even with good records of data and calculations, however, errors can still occur. Remedies include external review. Effective review, however, requires an intimate understanding of the analysis and a large time commitment, not much less than required for the initial analysis. Thus, this remedy is unlikely to happen regularly, given the limited time and resources available when material and product analyses are done, under current funding conditions. Nonetheless, at least a partial review from an external reviewer is valuable.

During analyses for this thesis checking and double checking was used for all working. This was mostly done at a (slightly) later date, to enable a fresher view of the analysis. Quick mental calculations were routinely undertaken to review the sense of individual calculations and help avoid errors.

\subsubsection{Specific Materials Methodology}

The methodology described in Section 8.2 was generally applied, but analysis requirements were unique for each material. Sections 8.3 to 8.6 describe the application of the general method to representative materials and show examples of variations in methodological approach.

Materials are substantially different in the analysis steps required, making a checklist approach to ensure complete coverage of inputs impossible. Because each material and process is unique, it is therefore important to keep checking for completeness: at each analysis step to keep asking, "Is there anything that has been missed?" For recycled steel, for example, it was necessary to ask, "Has transport been missed for any ingredients other than scrap?" The other ingredients were about $6.5 \%$ of the scrap input. Including their transport would have required considerably more work. 
Since transport for scrap represents around 6\% of total inputs, however, and the other inputs are around $6 \%$ of scrap, the energy represented by transport of these ingredients is close to the margin of error for the whole calculation. Thus, the analysis was truncated to exclude transport for other ingredients. Importantly, the aspects that were included (transport as part of the scrap analysis) and omitted (transport of minor ingredients) were checked during and at the end of the analysis. Thus, while transport does not appear as a separate item on the spreadsheet for recycled steel (Figure 8.1) it is checked and known to be considered.

\subsection{Example Analysis - Recycled Steel}

Recycled steel was chosen as an example because it has a complicated but transparent production that illustrates the complexities of a hybrid analysis. Additionally, data was provided without a confidentiality restriction, which enables it to be discussed publicly and in detail. Each step is described to illustrate the gathering and handling of data in the analysis process.

Initial research determined the producers of steel in New Zealand. Blue Scope Steel produces steel from local iron sands which is typically used in sheet form, such as for corrugated roofing. In New Zealand, structural steel, such as beams and columns, is mostly imported. Pacific Steel produces steel from mainly New Zealand sourced scrap, which is collected countrywide. Variations in scrap supply and use are met by importing or exporting, in relatively small amounts. A steel mill furnace supplies billets to a bar mill, producing reinforcing bar and small-section structural items, and a rod mill, producing wire products, such as nails and fencing wire.

Some of the scrap is shredded by machines at Christchurch and Auckland. Larger scrap items are gas cut to a size suitable for the furnace. Balers compress the scrap ready for transporting from collection points.

Scrap is the main input to Pacific Steel's plant. Other ingredient inputs are silicomanganese (SiMn), lime, carbon, ferro-silicon (FeSi), burnt lime and oxygen. Energy inputs are electricity and gas. Most of the water used at the plant is recycled. Output 
is steel bars and rods. Some slag is used as roading material, while the rest goes to landfill.

The spreadsheet data in Figure 8.1 is approximately in the order that data and figures are collected or calculated, from top to bottom, and left to right. Items that appear in the spreadsheet are identified in the explanatory text in bold, for column headings, and italics for ingredient inputs. Details from Figure 8.1 (Figure 8.1a, Figure 8.1b, etc) are used in Sections 8.3.1 to 8.3.5 to illustrate each step of the analysis. 
Figure 8.1 Spreadsheet for Recycled Steel Reinforcing

\begin{tabular}{|c|c|c|c|c|c|c|c|}
\hline & A & B & $\mathrm{C}$ & $\mathrm{D}$ & $\mathrm{E}$ & $\mathrm{F}$ & G \\
\hline \multirow[t]{5}{*}{1} & \multicolumn{7}{|c|}{ Steel, recycled, reinforcing and sections } \\
\hline & & & \multicolumn{3}{|c|}{ Total Energy } & \multicolumn{2}{|c|}{ Total $\mathrm{CO}_{2}$} \\
\hline & & & MJ/kg: & 8.6 & & g/kg: & \\
\hline & & & $\mathrm{MJ} / \mathrm{m}^{3}:$ & 67,423 & & $\mathrm{~kg} / \mathrm{m}^{3}:$ & 4,531 \\
\hline & & Quantity & $\begin{array}{c}\text { EE } \\
\text { coefficient } \\
\text { of } \\
\text { ingredient } \\
(\mathrm{MJ} / \mathrm{kg}) \\
\end{array}$ & $\begin{array}{c}\text { I/O } \\
\text { factor } \\
\text { (MJ/MJ) }\end{array}$ & $\begin{array}{c}\text { EE } \\
\text { coefficient } \\
\text { of product } \\
(\mathrm{MJ} / \mathrm{kg}) \\
\end{array}$ & $\begin{array}{c}\mathrm{CO}_{2} \\
\text { emission } \\
\text { factor } \\
(\mathrm{g} / \mathrm{MJ}) \\
\end{array}$ & $\begin{array}{c}\mathrm{CO}_{2} \\
\text { emissions } \\
\text { of } \\
\text { product } \\
(\mathrm{g} / \mathrm{kg}) \\
\end{array}$ \\
\hline 8 & Ingredients (unit) & & & & & & \\
\hline 9 & Scrap steel (t) & 157,500 & 704 & & 0.72 & 67.8 & 49.0 \\
\hline 10 & $\operatorname{SiMn}(t)$ & 4,200 & 42,700 & & 1.17 & 72.8 & 85.0 \\
\hline 11 & FeSi (t) & 1,400 & 42,700 & & 0.39 & 72.8 & 28.3 \\
\hline 12 & Lime $(t)$ & 2,170 & 1,280 & & 0.02 & 72.8 & 1.3 \\
\hline 13 & Burnt Lime (t) & 750 & 7,430 & & 0.04 & 79.6 & 2.9 \\
\hline 14 & Carbon $(\mathrm{t})$ & 1,800 & 29,700 & 1.04 & 0.36 & 90.4 & 32.7 \\
\hline 15 & Oxygen $\left(\mathrm{m}^{3}\right)$ & $1,900,000$ & 0.9 & 43.7 & 0.49 & 67.8 & 33.0 \\
\hline 16 & Water (\$) & 1,700 & & 6.27 & 0.0001 & 67.1 & 0.0 \\
\hline 17 & Billets, steel to bar (t) & 116,270 & & & & & \\
\hline 19 & Output, steel plant & & & & & & \\
\hline 20 & Slag (t) & 5,020 & & & & & \\
\hline 21 & Billets to mills (t) & 170,510 & & & & & \\
\hline 22 & Output, steel plant (t) & 175,530 & & & & & \\
\hline 23 & Energy sources & & & & & & \\
\hline 24 & Electricity $(\mathrm{kWh} / \mathrm{t})$ & 520 & 3.6 & 1.55 & 3.0 & 67.4 & 200.7 \\
\hline 25 & Electricity (MJ) & $31,000,000$ & & 1.55 & 0.5 & 67.4 & 30.8 \\
\hline 27 & Natural Gas (MJ) & $134,000,000$ & & 1.13 & 1.5 & 54.5 & 79.1 \\
\hline 29 & Transport $(\mathrm{MJ} / \mathrm{t})$ & 704 & & & & & \\
\hline 31 & Sub Total & & & & 8.1 & & 533.2 \\
\hline 33 & Capital equipt. energy & & & & & & \\
\hline 34 & Steel plant (MJ) & $30,517,200$ & & & 0.2 & 66.2 & 13.2 \\
\hline 35 & Bar mill (MJ) & $33,410,000$ & & & 0.3 & 66.2 & 21.1 \\
\hline 36 & CFC & & & & & & \\
\hline 37 & GFCF, as percentage & & & & & & \\
\hline 39 & Total & & & & 8.6 & & 567.5 \\
\hline 41 & Other Information & & & & & & \\
\hline 42 & Prices $(\$)$ & & & & & & \\
\hline 43 & Annual Output, NZ (t) & & & & & & \\
\hline 44 & Output, bar mill (t) & 104,680 & & & & & \\
\hline 45 & $\%$ of National Output & 100 & & & & & \\
\hline 46 & Density (kg/m3) & 7,850 & & & & & \\
\hline 47 & Other Characteristics & & & & & & \\
\hline 48 & Manufacturers/Players & Pacific Steel & & & & & \\
\hline 49 & Manufacturing Process & & & & & & \\
\hline 50 & Age of Data & 1995 & & & & & \\
\hline 51 & Source of Data & Pacific Steel & & & . & . & \\
\hline 52 & Confidentiality & No & & & & & \\
\hline 53 & Comparative Data & \multicolumn{3}{|c|}{ (Nebel, Alcorn \& Wittstock, 2009) } & 8.4 & & 449 \\
\hline 54 & Other notes & \multicolumn{6}{|c|}{ See Alcorn $(1995 ; 1998)$ scrap steel collection data. } \\
\hline
\end{tabular}




\subsubsection{Ingredient Inputs - Recycled Steel}

Firstly, as with the other materials analysed, data for recycled steel production was collected for ingredients.

Scrap is the main ingredient for recycled steel. To obtain the scrap collection figure, the operations of Sims Pacific Metals, were analysed. A full process analysis of their scrap collection process was undertaken: where it is sourced, how it is collected, how it is transported to the different collection centres, and where and how it is cut up, baled, etc. The details of the scrap collection analysis can be found in Alcorn (1995).

Appropriate scrap transport modes were analysed: truck for small amounts; rail for larger amounts to Christchurch and Wellington; and barge to Auckland, where the smelting is done. Transport energy was subsumed into the scrap figure during further analysis.

In column C (Figure 8.1), the coefficients came from different sources. Scrap was calculated by a detailed analysis of the collection process (Alcorn, 1995).

Figure 8.1a EE coefficient of ingredient

\begin{tabular}{|l|c|c|c|c|}
\hline \multicolumn{1}{|c|}{ A } & B & C & D & E \\
\hline & Quantity & $\begin{array}{c}\text { EE coefficient of } \\
\text { ingredient } \\
(\mathrm{MJ} / \mathrm{kg})\end{array}$ & $\begin{array}{c}\text { I/O factor } \\
(\mathrm{MJ} / \mathrm{MJ})\end{array}$ & $\begin{array}{c}\text { EE coefficient } \\
\text { of product } \\
(\mathrm{MJ} / \mathrm{kg})\end{array}$ \\
\hline \hline Ingredients (unit) & & & & 0.72 \\
\hline Scrap steel (t) & 157,500 & 704 & & \\
\hline
\end{tabular}

EE coefficients for SiMn and FeSi (Column C, Figure 8.1b), used overseas data, since the production of these occurs overseas anyway. New Zealand figures were unobtainable for lime and burnt lime but would be similar to other countries; overseas data was therefore used.

The $0.9 \mathrm{MJ} / \mathrm{kg}$ value for oxygen was derived from I-O data using current costs, inflation-adjusted to the I-O table data period. 
Figure 8.1b Silico-manganese, ferro-silicon, lime and oxygen

\begin{tabular}{|c|c|c|c|c|}
\hline$A$ & B & C & D & $E$ \\
\hline & Quantity & $\begin{array}{l}\text { EE coefficient of } \\
\text { ingredient } \\
(\mathrm{MJ} / \mathrm{kg})\end{array}$ & $\begin{array}{l}\mathrm{I} / \mathrm{O} \text { factor } \\
(\mathrm{MJ} / \mathrm{MJ})\end{array}$ & $\begin{array}{l}\text { EE coefficient } \\
\text { of product } \\
(\mathrm{MJ} / \mathrm{kg})\end{array}$ \\
\hline \multicolumn{5}{|c|}{ Ingredients (unit) } \\
\hline $\operatorname{SiMn}(\mathrm{t})$ & 4,200 & 42,700 & & 1.17 \\
\hline $\mathrm{FeSi}(\mathrm{t})$ & 1,400 & 42,700 & & 0.39 \\
\hline Lime $(t)$ & 2,170 & 1,280 & & 0.02 \\
\hline Burnt Lime (t) & 750 & 7,430 & & 0.04 \\
\hline Oxygen $\left(\mathrm{m}^{3}\right)$ & $1,900,000$ & 0.9 & 43.7 & 0.49 \\
\hline
\end{tabular}

The carbon EE coefficient $(29,700 \mathrm{MJ} / \mathrm{t}$ ) (Figure 8.1c) used New Zealand coal data (Baines, 1993). The $\mathbf{I} / \mathbf{O}$ factor (column D) for carbon is $1.04 \mathrm{MJ} / \mathrm{MJ}$, representing the energy for coal mining, while 29,700 MJ/t represents coal's calorific value (Baines, 1993).

Water was calculated from I-O tables because the category "water works and supply" specifically relates to it. The usual problems of aggregation of disparate products were therefore minimal. Additionally, Pacific Steel knew water input only as a cost, not volume. With a dollar figure, I-O analysis was thus the appropriate method.

Figure 8.1c Carbon and Water

\begin{tabular}{|l|c|c|c|c|}
\hline \multicolumn{1}{|c|}{ A } & B & C & D & E \\
\hline & Quantity & $\begin{array}{c}\text { EE coefficient of } \\
\text { ingredient } \\
(\mathbf{M J} / \mathrm{kg})\end{array}$ & $\begin{array}{c}\text { I/O factor } \\
(\mathrm{MJ} / \mathrm{MJ})\end{array}$ & $\begin{array}{c}\text { EE coefficient } \\
\text { of product } \\
(\mathrm{MJ} / \mathrm{kg})\end{array}$ \\
\hline \hline Ingredients (unit) & & & & 1.04 \\
\hline Carbon (t) & 1,800 & 29,700 & 6.27 & 0.36 \\
\hline Water (\$) & 1,700 & & & 0.00 \\
\hline
\end{tabular}

The I-O factor (column D) primarily represents the energy used to obtain and deliver energy, for the energy industries, in $\mathrm{MJ} / \mathrm{MJ}$. The values are derived from I-O tables, where the energy industries have an industrial classification category each. The column was also used in cases, such as oxygen and water in the recycled steel example (Figures $8.1 \mathrm{~b}$ and 8.1c), where I-O was the only analysis method employed (as opposed to the usual hybrid method) for a particular ingredient. 
The EE coefficient of product (column E) calculates the coefficients for inputs in $\mathrm{MJ} / \mathrm{kg}$. This is normally done by just multiplying the input quantity, EE coefficient, and I-O factor from columns B, C, and D. For recycled steel the process is slightly more complicated because inputs must be apportioned between the furnace, rod and bar mills. Thus, in this case, referring to Figure 8.1, the column E number for carbon (E14) is derived by, firstly in the normal way, multiplying B14 x C14 x D14 to obtain $55,598,400$. This interim result must then also be divided by the total output of billets to the rod and bar mills (B21), multiplied by the input of billets to the bar mill only (B17), divided by the product output from the bar mill (B44), and finally divided by 1,000 to state the units in MJ/kg. Thus: $(1,800 \times 29,700 \times 1.04) /(170,510$ $\mathrm{x} 116,270 / 104,680 / 1000)=0.36$.

The $\mathbf{C O}_{2}$ emission factor (column F) (Figure 8.1d) shows the emission factor for scrap. $74 \%$ of scrap EE comes from fuel for transport, and the $26 \%$ from shredding with electric machinery. The $\mathrm{CO}_{2}$ emission factors for transport (petroleum fuel at $68 \mathrm{~g} / \mathrm{MJ}$ ), and shredding (electricity at $67.4 \mathrm{~g} / \mathrm{MJ}$ ) are thus multiplied by 0.74 and 0.26 respectively, and added together.

Figure 8.1d $\mathrm{CO}_{2}$ emissions

\begin{tabular}{|c|c|c|c|c|c|c|}
\hline \multicolumn{1}{|c|}{ A } & B & C & D & E & F & G \\
\hline & Quantity & $\begin{array}{c}\text { EE coefficient } \\
\text { of ingredient } \\
(\mathrm{MJ} / \mathrm{kg})\end{array}$ & $\begin{array}{c}\mathrm{I} / \mathrm{O} \\
\text { factor } \\
(\mathrm{MJ} / \mathrm{MJ})\end{array}$ & $\begin{array}{c}\mathrm{EE} \\
\text { coefficient } \\
\text { of product } \\
(\mathrm{MJ} / \mathrm{kg})\end{array}$ & $\begin{array}{c}\mathrm{CO}_{2} \\
\text { emission } \\
\text { factor } \\
(\mathrm{g} / \mathrm{MJ})\end{array}$ & $\begin{array}{c}\mathrm{CO}_{2} \\
\text { emissions } \\
\text { of product } \\
(\mathrm{g} / \mathrm{kg})\end{array}$ \\
\hline \hline Ingredients (unit) & & & & & & \\
\hline Scrap steel (t) & 157,500 & 704 & & 0.72 & 67.8 & 49.0 \\
\hline
\end{tabular}

The emission factors for some ingredients are more complicated. To derive emission factors from I-O tables, it was necessary to establish the percentage that different energy types contributed to each industry. Coal contributes $22.5 \%$ of energy inputs to "Other Mining and Quarrying", which is the applicable industrial classification for carbon. The case was the same for the other energy types. 
The percentage of energy contribution to each industry category was multiplied by the emission factor for that energy type, using Baines (1993) data. The results were added together to yield a $\mathrm{CO}_{2}$ emission factor for different industries, in $\mathrm{g} / \mathrm{MJ}$ units.

The $\mathbf{C O}_{2}$ emissions of product (column G, Figure 8.1d) is simply the EE coefficient multiplied by the $\mathrm{CO}_{2}$ emission factor.

\subsubsection{Allocation}

Principal outputs from the steel furnace are internal, to the rod and bar mills at Pacific Steel. There is, however, a slag output, which goes to roading, amounting to $3 \%$ by weight of the steel output. It is important to note portions such as this which are not at first glance what is being sought. At the least, they provide completeness, from inputs through to outputs. In some analysis they may be relevant.

The question of allocating or apportioning energy, or $\mathrm{CO}_{2}$, to different outputs can be problematic. There are a number of different ways it can be calculated. In this case, all energy and $\mathrm{CO}_{2}$ was attributed to the steel output. Thus the slag, as an example, used for roading, has no energy or $\mathrm{CO}_{2}$ attributed to it, since the purpose of the Pacific Steel operation is to produce steel products.

Other approaches could be argued. For example, if the steel plant were not there, aggregate would be sourced elsewhere. Thus, the energy and $\mathrm{CO}_{2}$ of other aggregate production is saved by using the slag as aggregate. Using consequential analysis and asking the question "what is the effect of doing this, of using this, or not?" is often instructive. If the slag were not used, it would be land-filled, with some energy cost. Steel production would be unchanged. If anything, using the slag thus has a beneficial energy and $\mathrm{CO}_{2}$ effect, by the reduced production of aggregate. Allocating zero energy and $\mathrm{CO}_{2}$ to the slag thus seems justified.

In energy terms the influence of slag on the final recycled steel coefficient is very small $(0.01 \%)$, but it illustrates the allocation question. Allocation is, and will remain, a debated issue. 


\subsubsection{Energy Inputs - Recycled Steel}

In the case of the steel plant, electricity usage was quoted as being a "30MVA transformer running for 50-55 minutes for a 50 tonne output". This translates to $550 \mathrm{kWh} / \mathrm{t}$.

Calculating the theoretical energy required to melt steel, using its known specific heat, typical efficiencies of the plant, and known throughput, however, suggests that while the transformer has a 30MVA capacity it is not operating at that capacity. Using furnace efficiency data gives a figure of $520 \mathrm{kWh} / \mathrm{t}$ including minor electricity usage, such as lighting and machinery operation.

The next energy input on the spreadsheet is also electricity, to the bar mill. This was quoted in GJ, translated into MJ. Working predominantly in the same units, say MJ and $\mathrm{kg}$, rather than also using related units, say GJ and tonnes, or kWh, helped to avoid errors and facilitates an easy mental grasp of the analysis at hand. However, retaining quoted units well into a calculation can help make retracing easier at a future date.

Energy I-O factors in Alcorn (1995) are solely from I-O analysis (Baines and Peet, 1995). That analysis yielded MJ/\$ figures for different industries, but MJ/MJ figures for the energy industries, which, other than electricity, were used in this thesis. The Baines and Peet I-O value for electricity was 1.53 MJ/MJ. By comparison, the detailed statistical analysis of the electricity industry conducted in this thesis yielded a value of $1.546 \mathrm{MJ} / \mathrm{MJ}$. This minor change is indicative of I-O analysis' reliability when the industry analysed (electricity) is specific. The small increase is also consistent with the rise in fossil generated electricity in the intervening years (see Figure 7.1).

In the column E (Figure 8.1e) the first electricity figure (to the steel mill) is multiplied by the conversion factor (3.6) and the I-O factor (1.55). The result is multiplied by the sum of the outputs of slag and billets, to capture the electricity total; divided by the output from the steel mill, to attribute all the energy to the steel billets; and finally divided by 1,000 to get from tonnes to $\mathrm{kg}$. 
Figure 8.1e $\mathrm{CO}_{2}$ emissions

\begin{tabular}{|l|r|r|r|r|}
\hline \multicolumn{1}{|c|}{ A } & B & \multicolumn{1}{c|}{ C } & D & \multicolumn{1}{c|}{ E } \\
\hline & Quantity & $\begin{array}{c}\text { EE coefficient of } \\
\text { ingredient } \\
(\mathbf{M J} / \mathbf{k g})\end{array}$ & $\begin{array}{c}\text { I/O factor } \\
(\mathbf{M J} / \mathbf{M J})\end{array}$ & $\begin{array}{c}\text { EE coefficient } \\
\text { of product } \\
(\mathbf{M J} / \mathbf{k g})\end{array}$ \\
\hline \hline Energy sources & & & & \\
\hline Electricity (kWh/t) & 520 & 3.6 & 1.55 & 3.0 \\
\hline Electricity $(\mathrm{MJ})$ & $31,000,000$ & & 1.55 & 0.5 \\
\hline Natural Gas $(\mathrm{MJ})$ & $134,000,000$ & & 1.13 & 1.5 \\
\hline
\end{tabular}

The electricity to the bar mill $(31,000,000 \mathrm{MJ})$ is multiplied just by the I-O factor, since it is already in MJ; divided by the output from the bar mill $(104,680 t)$; and divided by 1,000 to get to $\mathrm{kg}$. In this instance it was preferable to stay in the original units, as supplied, until it was necessary to change to $\mathrm{kg}$. This was partly to keep the numbers in the earlier columns small, and to preserve the original data far into the analysis. Often, numbers quoted are annual totals for industries, which are generally in tonnes, whereas when dealing with a product (or its coefficient) small amounts are being contemplated, so kg is more suitable.

Natural gas was treated exactly as for electricity to the bar mill: amount of input times I-O factor; divided by output; divided by 1,000. Natural gas was quoted in GJ and translated to MJ.

For $\mathrm{CO}_{2}$ emissions, the gas factor comes from Baines (1993), while the electricity emission factor comes from an analysis of New Zealand electricity generation carried out for this study. For consistency the average New Zealand electricity factor was used. Results could be expressed in both marginal and average emission factors, because the best approach depends on the question that the results are trying to answer.

The $\mathrm{CO}_{2}$ emissions for the product (the contribution represented by each energy input) is simply the EE coefficient times the emission factor. 


\subsubsection{Transport - Recycled Steel}

Because the EE coefficient for scrap comprises transport almost entirely, it was not given a separate entry under the transport heading. The total for scrap transport is noted because it is needed to calculate the percentage that transport contributed to the total. At $8.4 \%$ of the total, transport is a relatively high component (see Table 8.1), reflecting the inherently low EE of recycled materials themselves, and the large transport requirement for scrap collection.

\subsubsection{Capital Equipment - Recycled Steel}

The Capital equipment energy in the buildings, plant and machinery was calculated from a dollar value estimate provided by Pacific Steel. Reasonably reliable building and refurbishment costs for the steel and bar mills were available, together with dates. Pacific Steel estimated the plant's life at 20-25 years.

The capital equipment figure was converted to relevant year dollars for the I-O tables. In the case of the bar mill, Baines and Peet (1991) had published an energy analysis of the 1987 I-O tables, which was the year (1987) the plant was built, so the analysis related to the energy going into "machinery manufacture" in that year. The "machinery manufacture" category was used rather than that for buildings, since most of the capital was in the machinery, not the buildings. Furthermore, the $\mathrm{MJ} / \$$ value for the "building and ancillary building services" category closely matched the "machinery manufacture" category. In other analyses the buildings may be the dominant capital input. The energy of capital equipment is thus: the value of the plant in 1987; multiplied by the MJ/\$ figure for "machinery manufacture"; divided by 20 for the expected life of the plant. Varying the 20 -year lifespan by $+/-20 \%$ changed the capital equipment percentage of the total by less than $1 \%$.

The $\mathrm{CO}_{2}$ emission factor for capital equipment was derived from the I-O tables. Proportions of different energy types going into "machinery manufacture" were calculated, and emission factors applied for relevant energy types and proportions. As with other inputs, $\mathrm{CO}_{2}$ emission for the capital equipment part of the output is a simple product of the EE coefficient and emission factor for capital equipment. 
Figure 8.1f Capital equipment

\begin{tabular}{|c|c|c|c|c|c|c|}
\hline A & B & C & D & $\mathbf{E}$ & $\mathbf{F}$ & G \\
\hline & Quantity & $\begin{array}{c}\text { EE coefficient } \\
\text { of ingredient } \\
(\mathrm{MJ} / \mathrm{kg})\end{array}$ & $\begin{array}{c}1 / 0 \\
\text { factor } \\
(\mathrm{MJ} / \mathrm{MJ})\end{array}$ & $\begin{array}{c}\text { EE } \\
\text { coefficient } \\
\text { of product } \\
(\mathrm{MJ} / \mathrm{kg}) \\
\end{array}$ & $\begin{array}{c}\mathrm{CO}_{2} \\
\text { emission } \\
\text { factor } \\
(\mathrm{g} / \mathrm{MJ}) \\
\end{array}$ & $\begin{array}{l}\mathrm{CO}_{2} \\
\text { emissions } \\
\text { of product } \\
(\mathrm{g} / \mathrm{kg})\end{array}$ \\
\hline Sub Total & & & & 8.1 & & 533.2 \\
\hline \multicolumn{7}{|l|}{ Capital equipt. energy } \\
\hline Steel plant (MJ) & $30,517,200$ & & & 0.2 & 66.2 & 13.2 \\
\hline Bar mill $(\mathrm{MJ})$ & $33,410,000$ & & & 0.3 & 66.2 & 21.1 \\
\hline \multicolumn{7}{|l|}{ CFC } \\
\hline \multicolumn{7}{|l|}{ GFCF, as percentage } \\
\hline Total & & & & 8.6 & & 567.5 \\
\hline
\end{tabular}

For recycled steel, dollar values for capital equipment were known, so I-O values were easily applied. In many other material analyses capital equipment values are unknown. In those cases the I-O category "gross fixed capital formation" is used as a percentage of the total for the relevant industry category. This percentage is applied to the sub-total to give a figure for capital equipment. This is the primary reason to insert a sub-total before the capital equipment inputs (Figure 8.1f). The total is then simply the sub-total plus the capital equipment figure(s).

\subsubsection{Other Data - Recycled Steel}

Finally, any other available figures or information were entered in the rows below the total. The most commonly used of these figures was annual output. The density of the finished material was recorded and used in calculations converting from weight to volume. The source and age of data was recorded here, along with the confidentiality status.

\subsection{Timber}

Timber is a common building material with some unusual embodied energy and $\mathrm{CO}_{2}$ characteristics. The main one is its absorption of $\mathrm{CO}_{2}$ from the air. Another important characteristic is the significant energy input in the creation of timber that comes from sunlight. Thirdly, in some timber processing plants a significant energy input is from timber waste - sawdust, chips, bark and off-cuts - which have the same unique energy and $\mathrm{CO}_{2}$ characteristics as the timber itself. Finally, there is some non-fuel petroleum input, which is relatively unusual. 


\subsubsection{Ingredient Inputs - Timber}

The physical inputs to timber production are for the planting, pruning, fertilisation and harvesting of timber. The biggest of these is fertiliser, both in energy and $\mathrm{CO}_{2}$ terms. A variety of fertilisers are used (Gifford et al., 1997). In the New Zealand I-O tables, these would all be included in the 'fertiliser manufacture' category. It was preferable, however, because of aggregation problems, to use process analysis results from a study by Dawson (1978) of inputs to New Zealand agriculture, in spite of the age of the data, and the small percentage $(<0.2 \%)$ of the total.

Figure 8.2 Timber

\begin{tabular}{|c|c|c|c|c|c|c|}
\hline A & B & $\mathrm{C}$ & $\mathrm{D}$ & $\mathrm{E}$ & $\mathrm{F}$ & G \\
\hline \multicolumn{7}{|c|}{ Timber, pine, air dried, dressed } \\
\hline & & \multicolumn{3}{|c|}{ Total Energy } & \multicolumn{2}{|c|}{$\mathrm{Net} \mathrm{CO}_{2}$} \\
\hline & & \multicolumn{2}{|c|}{ MJ/kg: } & 2.8 & g/kg: & $-1,669$ \\
\hline & & \multicolumn{2}{|l|}{$\mathrm{MJ} / \mathrm{m}^{3}:$} & 1,283 & $\mathrm{~kg} / \mathrm{m}^{3}:$ & -694 \\
\hline & Quantity & $\begin{array}{c}\text { EE coefficient } \\
\text { of ingredient } \\
\mathrm{MJ} / \mathrm{kg}\end{array}$ & $\begin{array}{c}\mathrm{I} / \mathrm{O} \\
\text { factor } \\
\mathrm{MJ} / \mathrm{MJ} \\
\end{array}$ & $\begin{array}{c}\text { EE } \\
\text { coefficient } \\
\text { of product } \\
\mathrm{MJ} / \mathrm{m}^{3}\end{array}$ & $\begin{array}{c}\mathrm{CO}_{2} \\
\text { emission } \\
\text { factor } \\
\mathrm{g} / \mathrm{MJ}\end{array}$ & $\begin{array}{c}\mathrm{CO}_{2} \text { emissions } \\
\text { of product } \\
\mathrm{g} / \mathrm{m}^{3}\end{array}$ \\
\hline \multicolumn{7}{|l|}{ Ingredients (unit) } \\
\hline Chain bar oil (kg) & 0.05 & 43.1 & 1.2875 & 0.62 & 68 & 42.1 \\
\hline Water (litres) & 33.92 & 0.0033 & & 0.11 & 67.1 & 7.6 \\
\hline Fertiliser (kg) & 0.07 & 34 & & 2.38 & 67.8 & 161.4 \\
\hline Chemicals (kg) & 0.014 & 1.8 & & 0.25 & 67.8 & 1.71 \\
\hline \multicolumn{7}{|l|}{ Energy sources } \\
\hline Diesel (MJ) & 750 & & 1.2875 & 965. & 68.7 & 66,338 \\
\hline Electricity $(\mathrm{MJ})$ & 181.2 & & 1.55 & 280 & 67.4 & 18,869 \\
\hline Petrol (MJ) & 20 & & 1.2875 & 25.75 & 66.6 & 1714 \\
\hline Engine oil $(M J)$ & 0.998 & & 1.2875 & 1.28 & 74.8 & 96 \\
\hline \multicolumn{7}{|l|}{ Transport } \\
\hline Sub Total & & & & 1275 & & 8,7231 \\
\hline \multicolumn{7}{|c|}{ Capital equip. energy } \\
\hline \multicolumn{7}{|l|}{ CFC } \\
\hline GFCF, (\%) & 0.55 & & & 7.0 & 66.2 & 0.36 \\
\hline Total & & & & 1,282 & & 8,7231 \\
\hline \multicolumn{7}{|c|}{ Other Information } \\
\hline \multicolumn{7}{|c|}{ Annual Output, NZ (t) } \\
\hline \multicolumn{7}{|l|}{ Output (kg) } \\
\hline \multicolumn{7}{|c|}{$\%$ of National Output } \\
\hline Density $\left(\mathrm{kg} / \mathrm{m}^{3}\right)$ & 460 & & & & & \\
\hline Other & & & & & & \\
\hline
\end{tabular}


Chain bar oil, used during thinning, felling, and limbing, is the next most significant physical input. It is included as an input, not a fuel, since it is not burnt. Its potential energy as a fuel is therefore not realised. An approximate calorific value is assigned by using the bunker oil value. However, this figure is only used to calculate the relative energy used for extraction and processing of the oil, while the calorific value is ignored (see Section 6.9.1.4. Energy of Feedstock).

Other inputs are water and chemicals for pesticides and herbicides. The values for water are derived from a hybrid analysis of municipal water reticulation (Alcorn and Wood, 1998). The values for chemicals are from process analysis (Dawson, 1978).

\subsubsection{Energy Inputs - Timber}

Diesel is used for preparation and logging operations, and for the transport of logs to the mill. Diesel is not separated out into a transport component separate from logging operations.

Petrol is primarily for chainsaw operation. Along with the petrol, two-stroke lubricating engine oil is burnt in chainsaws. While this is used for its lubricating properties, it also forms part of the calorific content of the petrol/oil mix, and part of the $\mathrm{CO}_{2}$ emissions from operating chainsaws. The $\mathrm{CO}_{2}$ emission factor assigned to two-stroke oil was that for fuel oil, while the petrol was assigned the usual factor (Baines, 1993).

At the mill, electricity is the major energy input. Depending on the mill, this may be derived partly from combustion of bio-fuel (bark, sawdust, off-cuts, and other wood waste). In the spreadsheet electricity purchased externally was noted separately from the bio-fuel input to enable appropriate inclusion of different energy and emission factors. The electricity and bio-fuel values are averages over many mills (Gifford et al., 1997).

Inclusion of bio-fuel from wood waste in the inputs ensures the total net $\mathrm{CO}_{2}$ absorptions (resulting from absorbed $\mathrm{CO}_{2}$ in timber exceeding $\mathrm{CO}_{2}$ emitted from all 
ingredient and energy inputs) do not include the absorbed $\mathrm{CO}_{2}$ present in the wood waste that is subsequently released during combustion.

\subsubsection{Transport - Timber}

The transport component, including trucking logs from the forest to the mill, is included in the diesel energy input.

\subsubsection{Capital Equipment - Timber}

Data for timber came from a study of many mills (Gifford et al., 1997) which did not include capital values for the mills. An I-O value was thus used. The percentage of GFCF as an input to the New Zealand Standard Industrial Classification (NZSIC) category, "Log sawmilling and timber dressing" (Statistics, 2001), was applied to the sub-total of energy inputs to a cubic meter of timber. This gives an energy figure for the capital equipment and allows calculation of the percentage $(0.5 \%)$ that capital equipment represents in the total energy coefficient. Because the NZSIC category is tightly specific to sawmilling there is little room for aggregation and other errors that often compromise I-O figures as energy proxies.

\subsection{5 $\mathrm{CO}_{2}$ Absorption - Timber}

For timber products, and for any other plant-based or other material that absorbs $\mathrm{CO}_{2}$ during its production, a negative $\mathrm{CO}_{2}$ coefficient may result (Table 8.3). Total $\mathrm{CO}_{2}$ emissions were recorded, both from conventional inputs, and including bio-fuel inputs where appropriate. The $\mathrm{CO}_{2}$ absorbed, on a dry weight and volumetric basis, is then subtracted. For more highly processed timber products, the inputs may bring the negative emissions (net $\mathrm{CO}_{2}$ absorptions) back up towards zero. In the case of medium density fibreboard (MDF), the $\mathrm{CO}_{2}$ emissions are greater than zero when the marginal $\mathrm{CO}_{2}$ emissions for electricity in New Zealand are factored in. For other timber products, the $\mathrm{CO}_{2}$ emissions are significantly less than zero.

The importance of a negative $\mathrm{CO}_{2}$ emissions coefficient is in the implications for building construction: the more timber and other plant-based products are used in construction, MDF excepted, the more they will counteract the $\mathrm{CO}_{2}$ emissions of other materials. This is seen in the results presented in Chapter 9. 
Table 8.3 $\quad \mathrm{CO}_{2}$ Emissions, Average Electricity

\begin{tabular}{lrr}
\hline Material & $\mathrm{CO}_{2}$ Emissions $(\mathrm{g} / \mathbf{k g})$ & $\mathrm{CO}_{\mathbf{2}}$ Emissions $\left(\mathbf{k g} / \mathbf{m}^{3}\right)$ \\
\hline Timber, dried, dressed & $-1,601$ & -662 \\
Aggregate, average & 3 & 4.5 \\
Stone & 81 & 197 \\
Concrete, 17.5MPa & 118 & 277 \\
Ceramic brick & 191 & 375 \\
Steel, recycled & 577 & 4,531 \\
Cement, average & 1,025 & 2,000 \\
Steel & 1,242 & 9,751 \\
Glass, toughened & 2,452 & 6,179 \\
Aluminium, virgin & 14,201 & 38,344 \\
\hline
\end{tabular}

\subsection{Concrete}

Concrete is manufactured in a variety of forms: different mixes for different applications. These include high strength concrete and concrete block filling mix. Concrete mixes have generally similar ingredients, varying primarily in the ratios of these. $17.5 \mathrm{MPa}$ concrete is the standard mix for general purposes and is used as the basis for section 8.5 .

Two notable characteristics of concrete are the relatively high transport component, attributable primarily to the cement content, and the high $\mathrm{CO}_{2}$ emissions from an ingredient input, rather than just the fuel inputs.

\subsubsection{Ingredient Inputs - Concrete}

Aggregate is the main ingredient by weight. It may be river sourced, or crushed from virgin rock in quarries. Each of these sources required its own hybrid analysis plus analyses for the production of explosive, and its individual ingredients. The figure used is a weighted average of river and virgin sources. Concrete batching plants are typically located close to quarries to minimise transport costs of the primary ingredient.

Sand is normally sourced from the same quarry as the aggregate. It has a somewhat higher energy coefficient because of the extra screening or crushing required to manufacture it. 
Cement makes the greatest contribution to the overall energy coefficient for concrete, although it is typically only between 8 and $18 \%$ by weight for different concrete products. Cement is produced by different New Zealand manufacturers, using either a wet or dry process. The wet process uses more heat during manufacture and, as with any process that must generate significant heat, uses significantly more energy. The energy coefficient used is a weighted average of the wet and dry processes.

While cement accounts for approximately $70 \%$ of the energy coefficient for standard concrete, it represents approximately $85 \%$ of emitted $\mathrm{CO}_{2}$. The high $\mathrm{CO}_{2}$ coefficient for cement is accounted for partly by the high heat input for calcining, and partly because of the $\mathrm{CO}_{2}$ released while calcining calcium carbonate $(\mathrm{CaCO} 3)$ to calcium oxide $(\mathrm{CaO})$.

\subsubsection{Energy Inputs - Concrete}

In wet cement production, a minor part of the energy input is derived from waste oil, while coal remains the major energy input. The energy emission used to calculate the oil input is the calorific value for light fuel oil. The energy used to extract, refine, and deliver the oil is not included, as this energy would be attributed to its first use, as lubricating oil. This approach ensures waste oil is treated in a similar manner to plastics, which use crude oil as a feedstock, but which may subsequently be burnt in a power station. That is, the calorific content of a feedstock is not included in the coefficient unless it is being realised, by combustion, during the production process.

Diesel and electricity are the energy inputs to concrete batching, but are dwarfed by the ingredient inputs.

\subsubsection{Transport - Concrete}

The transport modes for cement to different batching plants and manufacturing sites around New Zealand are: coastal shipping, rail, and truck. Australasian data was used to calculate a weighted average figure for cement transport. Grant (2003) lists urban articulated trucks (applicable to main centre batching plants) at $1.37 \mathrm{MJ} / \mathrm{t} . \mathrm{km}$. Collins (1993) lists general freight trains at 0.6 and branch-line trains at 1.7, averaging at 1.2 
$\mathrm{MJ} / \mathrm{t} . \mathrm{km}$. Collins lists coastal shipping at $1.4 \mathrm{MJ} / \mathrm{t} . \mathrm{km}$. Because more detailed data was unavailable, and because the energy intensity of the respective transport modes is similar, the major transport mode to the main centres of population, coastal shipping, was used as a proxy for all cement transport. An average distance of $670 \mathrm{~km}$, on a population-weighted basis, was used for cement transport from north and south island manufacturing sites to main-centre batching plants. $\mathrm{A} \mathrm{CO}_{2}$ emission factor of $68 \mathrm{~g} / \mathrm{MJ}$, for all petroleum products, to cover shipping, rail and truck fuel, was used. Specific transport calculations are necessary for delivery of concrete from batching plant to building site.

\subsubsection{Capital Equipment - Concrete}

Because the study relates to a wide number of batching plants, capital equipment was calculated using I-O data, as for timber in section 8.4.4.

\subsection{Wind Generator}

For most building materials, production processes are sufficiently similar to average a number of sets of process data, or to select a single representative process. The further down the chain from basic material, such as aggregate or cement, to off-the shelf product, such as multi-component systems, the more variation there is in process data. In the case of ceramic brick manufacture, for example, the number of participants in the market is small, but the variation in technology used from one end of the market to the other produces quite different results. In that case, the best procedure is to list coefficients for the differently produced products, although their appearance, functional ability, and use, is the same.

In the case of wind generators, there are many possible manufacturing solutions for the generator, tower, installation, and controls that are part of a complete system. To have a precise idea of the embodied energy or $\mathrm{CO}_{2}$ of a particular system, it is therefore necessary to have specific process data for each system, be it locally manufactured, or imported. Currently, resources and funding have not enabled this level of analysis. 
Nonetheless, the analysis for this thesis of a widely used wind generator provides sufficient indication of energy and $\mathrm{CO}_{2}$ to be useful in assessing the impacts of installing such a system. Since there is potentially significant variation in different aspects of an installation, subtotals are provided for each item: generator, tower, and cable. Other possible components, such as an inverter, are not considered.

\subsubsection{Ingredient Inputs - Wind Generator}

Data was not available for a full analysis of the manufacturing process, nor was there a suitable I-O category to obtain data accurate enough to represent manufacture of a wind generator. The analysis was therefore on the basis of ingredient weights, using data for each ingredient. Because some of the ingredients, such as copper for the windings, and for the cable connecting generator to building, are high embodied energy ingredients, the energy inputs to the production factory would be small in comparison. A detailed analysis that included manufacturing inputs was undertaken for solar hot water systems, and illustrates the materials/manufacturing energy balance: materials constituted approximately $91 \%$ of energy and emissions, whereas manufacturing energy represented $4 \%$.

A major input is copper $(3,979 \mathrm{MJ})$, primarily because of the length and heavy weight of cable needed to carry current from generator to building without appreciable loss. Cable length was calculated at $100 \mathrm{~m}$, as a typical house-to-generator distance (SOMA, 2004). PVC for the cable insulation was a significant item. Copper in the generator itself was also significant.

Steel for the rotor and casing and tail arm was the greatest input to the generator in energy terms. Fibreglass for the blades, tail vane and nose cone, was the second highest energy item in the ingredients, but the highest in $\mathrm{CO}_{2}$ terms. Stainless steel, for fasteners and leading-edge protection, is the minor generator ingredient in both energy and $\mathrm{CO}_{2}$ terms.

Steel for the tower was another major input (4,344MJ), and the greatest in energy terms. One reason to separate out the different items is that the tower may be made of another material, such as a timber pole. Similarly, there are different commonly 
used tower designs, typically either a lattice construction, or a pole with multiple guy wires, the steel for the former would be considerable more than for the latter.

Concrete for the tower foundations was the third biggest input in energy terms $(2,181 \mathrm{MJ})$ and equal biggest, with copper, in $\mathrm{CO}_{2}$ terms. Other foundation solutions, such as ground plates and rock anchors, could reduce the concrete requirement.

\subsubsection{Transport and Capital Equipment - Wind Generator}

It was found that the transport energy for importing a wind turbine from Australia and installing it in a New Zealand main centre was 3.4\% of total energy. This is consistent with transport percentages for many materials and components (see Section 6.8.4). Compared to the energy output from the generator, however, the transport energy equated to $0.1 \%$ of the total.

A value for capital equipment was added, using the same method as in Section 8.4.4.

\subsubsection{Other Data - Wind Generator}

The lifespan of wind generators is dependent not only on quality of the generator but also the specific site and the related turbulence of the wind. New Zealand as a maritime and mountainous nation is frequently exposed to strong and gusty winds which can shorten the life of blades, gears, alternators, etc. A typical life for a domestic wind generator in New Zealand is thus about 10 years (Dunford, 2004).

There are no figures available for the typical lifespan of steel towers. However, it seems likely they would gradually suffer from rust or poor maintenance. There is also a risk of damage from wind. A lifespan of 25 years was assigned to reflect these risks. Careful design, construction, and maintenance could extend this interval.

There is no long term evidence of the lifespan of copper/PVC cables. Older cables with early types of insulation have not lasted 50 years. Cables installed in domestic situations since the introduction of PVC sheathing are in good condition (Page, 2005). In the instance of cables for wind generators, which are likely to be underground, there are risks of damage from mechanical disturbance, either of 
human or natural origin, or potentially from fauna or flora. An estimate of an average 100 year lifespan was assumed.

Manufacturer's literature quotes an average daily output of 14,200Wh for an average wind speed of $9 \mathrm{~m} / \mathrm{s}$, and an output of 12,000Wh for an average wind speed of $8 \mathrm{~m} / \mathrm{s}$ (Bartley, 2004). EECA quote an average monthly wind speed for Wellington of $9 \mathrm{~m} / \mathrm{s}$, with the average not dropping below $8 \mathrm{~m} / \mathrm{s}$. To allow for Wellington's windy reputation and a degree of maintenance downtime, a wind speed of $8 \mathrm{~m} / \mathrm{s}$ has been assumed (see Section 9.6.3). This compares to windy parts of California with an average wind speed of $7.5 \mathrm{~m} / \mathrm{s}$ (EECA, 1995; Soma, 2004). The annual output was also recorded in $\mathrm{MJ}$ to facilitate calculation with other terms. Energy and $\mathrm{CO}_{2}$ 'returns' on 'investment' are recorded.

\subsubsection{Discussion - Wind Generator}

The energy outputs, for the calculated wind resource, overwhelm the energy inputs, on an annual basis. The same is true of the $\mathrm{CO}_{2}$ emissions. This serves to reduce the impacts of any potential variation or errors in the energy and $\mathrm{CO}_{2}$ analyses, and makes it less likely that other generators with significantly different embodied energy or $\mathrm{CO}_{2}$ will produce very different net results. Simply, the energy obtained from wind far outweighs the energy used to manufacture the generator systems. The energy return on energy invested (EROEI) is $\sim 33$. The energy derived from the generator exceeds the total energy to manufacture and install it in less than one year.

The $\mathrm{CO}_{2}$ emitted by producing and delivering electricity on the national grid also far outweighs the $\mathrm{CO}_{2}$ emitted by the manufacture and installation of wind generator systems, in this case by a factor of 8.5 , when average electricity emission values are used. If marginal electricity values are calculated, the $\mathrm{CO}_{2}$ emissions for national grid electricity on a per MJ or per kWh basis are over 92 times greater than the emissions associated with manufacture of the wind generator on an equivalent basis of $\mathrm{MJ}$ of available electricity.

A significant caveat for wind is that not all locations in New Zealand (or other countries), and not all sites in wind-rich locations, are suitable for wind generators, 
especially many urban locations where turbulence from obstructions may reduce output significantly from what has been calculated in this analysis (see Section 9.6.3).

\subsection{Other Materials}

The coefficients for materials, products, and systems that were analysed for this thesis can be found in Appendix B. Not all the materials and products were used for calculating the sustainability of houses, as discussed in Chapter 9. The coefficients in Appendix B show a trend of rising emissions compared to equivalent coefficients in Alcorn (2003). This is principally due to the ubiquity of electricity in manufacturing and its rising emission factor since 2003 as coal generation increases.

The data in Appendix B is as correct as possible at the publication date. Some input data is identical to 2003 conditions, such as New Zealand economic I-O data which has not been recently updated by Statistics New Zealand. Some data inputs are subject to constant change, such as electricity ERE and emission factors. Care should be exercised in using the data, since it will gradually lose accuracy with time, to varying degrees of significance.

\subsection{Conclusion}

Analysing building materials for $\mathrm{EE}$ and $\mathrm{ECO}_{2}$ may appear different from analysing, say, aspects of primary production in New Zealand, but the steps are essentially the same. The examples in this chapter covered a range of materials, problems, and solutions to illustrate the process-based hybrid analysis method as it has been used in this thesis. The problems and solutions are typical of the full range of material analyses. The main construction materials were described, along with an example of a complex product.

Chapter 5 established a sustainable $\mathrm{CO}_{2}$ emissions limit for New Zealand houses. Chapter 9 assembles the coefficients for materials from this chapter, and other analyses performed for this thesis, plus other data and methodologies, into a calculator that assesses house designs against the $\mathrm{CO}_{2}$ limit. 


\section{$9 \quad$ Calculating House Sustainability}

We shape our buildings; thereafter, our buildings shape us.

- Winston Churchill, 1943

I'd put my money on solar energy... I hope we don't have to wait till oil and coal run out before we tackle that.

- Thomas Edison, 1931

\subsection{Introduction}

The research question for this thesis was: How do you build a sustainable house in New Zealand? In Chapter 4 an hypothesis was developed: that by making strategic design and construction decisions, materials choices, and certain technology selections, the $\mathrm{CO}_{2}$ profile of houses can be brought within a target limit that can be considered sustainable. This chapter tests that hypothesis.

The methodologies and outcomes from earlier chapters contribute to the means of testing the hypothesis. Chapter 2 provided a definition of sustainability. Chapters 3 , 4 and 5 described methods of measuring sustainability; defined what needed to be incorporated in any useful method and identified two preferable methods; and set a target for sustainability. Chapters 6 and 7 took the methods identified in Chapter 4 for measuring sustainability and described specific means of applying them: embodied energy and $\mathrm{CO}_{2}$ analysis. Chapter 8 demonstrated how embodied energy and $\mathrm{CO}_{2}$ analysis are put into practice.

This chapter combines the sustainability limit, embodied energy, $\mathrm{CO}_{2}$, and population and household size methodologies from earlier chapters, along with methods for determining lifetime of houses and materials, operational energy use, and construction material quantities, together with their effects on individual houses. A series of specific house designs is used, within a spreadsheet-based calculator, to gauge how closely the allowable per-house emissions limit and the defined 
sustainability target of Chapter 5 can be approached. Modifications to the house designs are used to further approach the sustainability target.

\subsection{House Model}

A design that reflected current practice for housing New Zealand's typical family size was needed, on which to base calculations. Two main considerations drove the choice of a model for testing house sustainability. The first was the functional unit: the provision of housing for 2.7 people for 1 year, as discussed in Section 5.5.1. With a goal of achieving a sustainable house design, starting with a small footprint house might seem a good first step. Such an assumption would need testing, however. Beginning from current practice enabled this and a series of other tests of different design strategies. As Section 9.8.2 shows, in certain cases, such as when bio-materials use is maximised, a larger house can be an advantage for reducing net emissions.

The second consideration was that thermal performance data was needed to fully account for house operational energy. Because deriving such data was outside the scope of this thesis, an existing dataset was required.

Different houses from earlier research projects were considered. Baird and Chan (1983) used the Building Industry Advisory Council Standard House and the New Zealand Institute of Valuers Modal House. Both these houses, the NOW House (Beacon, 2005) and the Exemplar House (Wilson, 2002) all had valuable data associated with them, and were all considered. These houses, however, had no published detailed thermal analyses, so were rejected.

The only available detailed dataset for the thermal performance of current housing styles was from the Zero and Low Energy House (ZALEH) project (see following section). This was used as a starting point, from which changes could be made, to test the Chapter 4 hypothesis.

\subsubsection{Selected House: ZALEH}

ZALEH provided extensive data about heating energy along with sufficient detail for structure and materials. The ZALEH project examined and explicitly 
documented household type and size, as well as the size and plan of the house (Roose and Gowland, 2005; Stoecklein, 2005a, 2005b). The household types were related to heating patterns, and household size, not house size. The household types were:

- People on domestic purposes benefits (DPB): relatively low temperatures throughout the day to $18^{\circ} \mathrm{C}$ with a night-time drop to $16^{\circ} \mathrm{C}$

- Families: Heating throughout the day to medium temperature levels to $20^{\circ} \mathrm{C}$ with a night-time drop to $16^{\circ} \mathrm{C}$

- $\quad$ Retired people: Heating throughout the day to high temperatures to $22^{\circ} \mathrm{C}$ with a night-time drop to $18^{\circ} \mathrm{C}$

- Working singles: Heating in the morning and in the evening to $20^{\circ} \mathrm{C}$ with little demand during the day $\left(16^{\circ} \mathrm{C}\right)$ and a night-time drop to $16^{\circ} \mathrm{C}$.

Having a choice of household sizes from ZALEH enabled matching household size, and consequently heating demand, to the average household size determined in Chapter 5. The 'Families' household size and heating regime were used as the basis for modelling.

\subsubsection{The ZALEH Model}

The ZALEH design followed thermal modelling needs, rather than architectural considerations. In its architectural design it is, nonetheless, adequately representative of common New Zealand housing for the purposes of sustainability analysis. ZALEH included both single and two storey models of $80 \mathrm{~m}^{2}, 100 \mathrm{~m}^{2}$ and $200 \mathrm{~m}^{2}$. Single storey construction is more common and was therefore chosen for modelling in this thesis. The $200 \mathrm{~m}^{2}$ model was chosen to match current house and household size (see Sections 9.5.3 and 9.5.4).

Figure 9.1 shows the general layout of the single storey $200 \mathrm{~m}^{2}$ ZALEH house (Roose and Gowland, 2005). The model included an open-plan kitchen/living area, three bedrooms, bathroom, and garage. The master bedroom included an en-suite. A short hallway linked garage, bathroom, minor bedrooms, and living areas. A study/4 $4^{\text {th }}$ bedroom, in the early ZALEH designs, was not part of the final thermal modelling, and was not included in the analyses. 
The basic ZALEH house had a timber frame and steel roof. Floors were either concrete slab or suspended timber. The step-out walls, consistent with common design practice, require additional studs, foundation, and roof materials for a given wall length. The garage had a concrete floor in all models analysed.

\section{Figure 9.1 House Model}

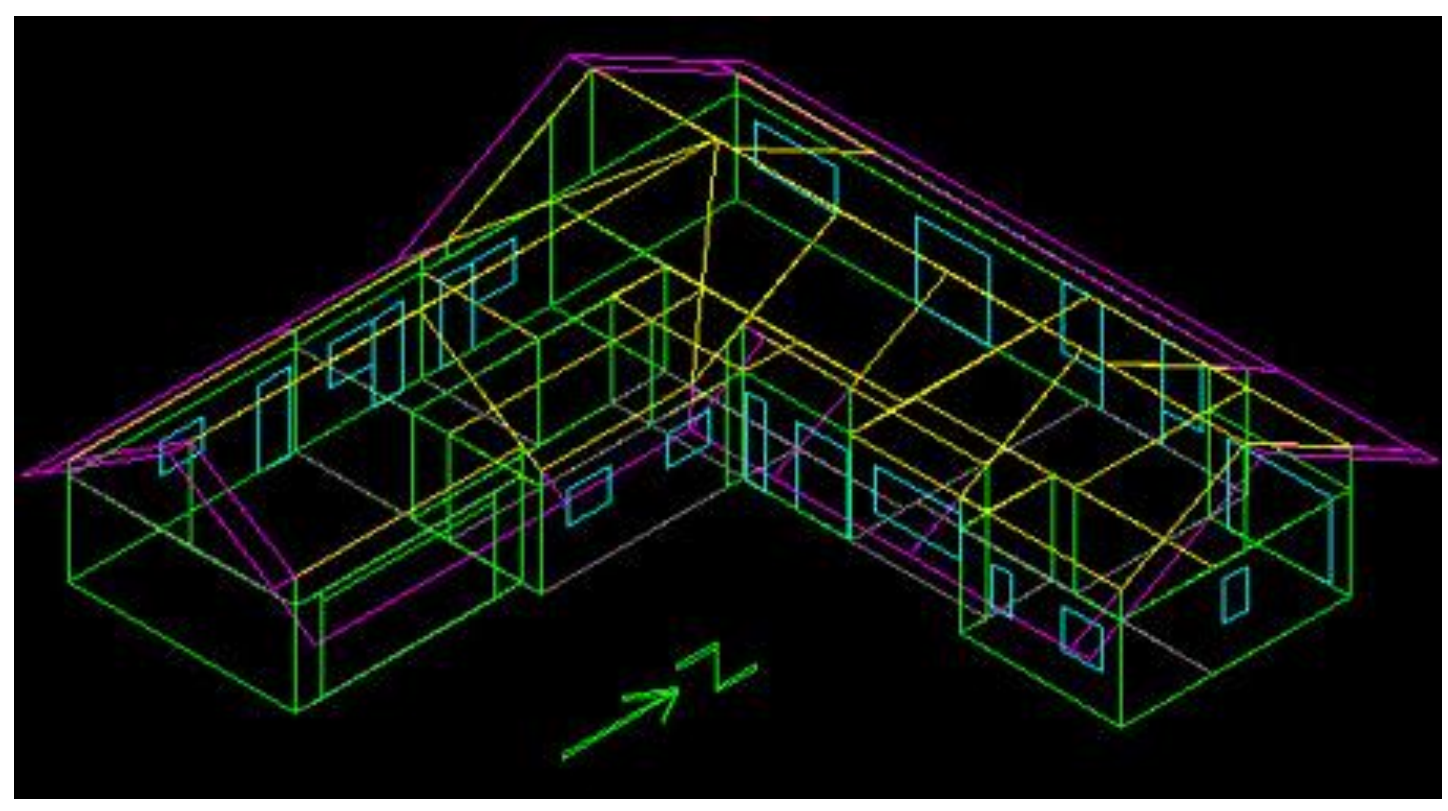

\subsection{Modelling the Houses}

ZALEH modelled houses for four time periods: the 1970s, 2000s, 2010s, and 2020s. These periods were used by ZALEH to represent changes in construction, especially insulation levels, using the 2020s to model super insulation levels. The same divisions were adopted for this thesis.

Some aspects of ZALEH construction details were crude (see Section 9.6.1). Thermal R-values were specified, for example, but not any associated insulation type or construction details. Where materials were not specified or where the specification was not buildable, materials and details were altered to match common New Zealand construction practice, but staying as close as possible to the ZALEH models to maintain the applicability of the thermal data. To accommodate the implied insulation thickness in some ZALEH models, framing solutions outside of NZS3604 (Standards, 1999a), but still using common materials and methods, were 
adopted. Polystyrene insulation was used as the readily available insulation material with greatest $\mathrm{R}$ value per unit of thickness, to keep wall thickness as small as possible. Even so, $\sim 200 \mathrm{~mm}$ was required to accommodate the implied insulation for the highest R-values, and accordingly, a double row of studs. Using polystyrene to minimise wall thickness avoided, as much as possible, extra materials for framing, roof, and foundations. The influence of the extra R-values could thus be more equitably compared across the different ZALEH models without the confounding factors of altered construction systems (see Section 9.6.5). Conventional fibreglass insulation, for example, would have required thicker walls. Foundation, framing, fenestration, and roofing solutions more divergent from current construction practice, from the solar access assumptions within the ZALEH thermal models, and across the model years, would then have been needed.

While the houses were modelled in detail, including, for example, the quantity of nails, or hinges and screws for doors and windows, other items were not modelled, due to a lack of data, such as plumbing, wiring, and carpet. Carpet would have altered the ZALEH thermal performance results, so could not have been included given this analytical constraint.

\subsubsection{0s House}

A 1970s house was modelled with: concrete slab foundations, timber framing, weatherboard cladding, a corrugated steel roof, and low levels of insulation. Total insulation values were: ceiling R3; walls R1.5; and floor R0.2. Older New Zealand houses have even less or no insulation, while houses from the 1980s and 1990s have more. Pre-1970s, and 1980s and 1990s houses, thus tend to balance each other when considering average New Zealand housing stock. The 1970s house was thus considered typical and representative of pre 2000s New Zealand houses.

\subsubsection{0s Houses}

Two 2000s houses were modelled, representing current levels of insulation. One was identical to the 1970s house, except for the increased insulation: ceiling R3; walls R1.9; and floor R1.3. The other 2000s house had a suspended timber floor, with insulation of R2.7, instead of concrete slab. This combination of models allowed 
comparison between the 1970s and 2000s insulation levels, and between the concrete slab and suspended timber floors.

\subsubsection{0s House}

The 2010s house had concrete slab floor and still more insulation, requiring minor changes to the framing and area of roof. Insulation levels were: ceiling R5.5; walls R3.6; and floor R1.9.

\subsubsection{0s Houses}

The 2020s ZALEH slab-floor house had insulation to: ceiling R10.5; walls R7.7; and floor R7.2. The suspended floor version had floor insulation of R10.6. The extra insulation required greater associated changes to framing and roof area. In all other respects the 2020s ZALEH houses were the same, including design internal temperatures for the occupants, and other operating energy levels.

After modelling two ZALEH 2020 designs, different strategies were incrementally introduced to the 2020s houses, such as concrete tiles displacing a steel roof, to attempt to reach the sustainability target. Large or modest gains towards the target from each change were used to guide further strategy variations. Modelling stopped when the sustainability target was finally reached.

\subsubsection{Modelling Strategies}

A total of fourteen 2020s houses with different design strategies were modelled and compared. The houses and their design strategies, in descending order of total annual emissions were:

1. Heavyweight: concrete slab floor, concrete walls, steel roof with timber frame

2. Concrete slab floor, lightweight timber framed walls, lightweight steel roof

3. Slab floor, timber walls, concrete tile roof

4. Heavyweight: slab floor, earth walls, steel roof

5. Lightweight suspended timber floor, timber walls, steel roof

6. Slab floor, timber walls - strawbale insulation (SB walls), steel roof

7. Slab floor, timber walls, steel roof, solar hot water (SHW) 
8. Timber floor, SB walls, steel roof

9. Timber floor, $\mathrm{SB}$ walls, timber shingle roof (shingle roof)

10. Timber floor, SB walls, shingle roof, SHW

11. Timber floor, SB walls, shingle roof, SHW, timber window frames

12. Timber floor, SB walls, shingle roof, SHW, timber windows, photovoltaic (PV) panels

13. Timber floor, SB walls, shingle roof, SHW, timber windows, PV, low-emission materials and finishes (low-E)

14. Timber floor, SB walls, shingle roof, SHW, timber windows, PV, low-E materials, wind generator.

House 14 was the only sustainable house of those modelled: the only one that reached the sustainability target. The results of the earlier analyses in the list indicated opportunities to further refine the house designs and progress towards the sustainability target, with advantageous features pursued, and detrimental ones rejected, until the target was reached.

\subsection{The Calculator}

A spreadsheet based calculator was developed to combine and manage the different methodologies and data inputs from earlier chapters, and specific data related to the houses chosen for modelling. It was used to find a combination of design features, or strategies, which made gains towards the sustainability target. The results identified when a strategy or combination of strategies reached that target.

The central functions of the calculator were organised in a series of spreadsheets, one for each set of houses: 1970s, 2000s, 2010s, and 2020s. Each of the House spreadsheets drew on data and sub-calculations contained in a Data spreadsheet. The results from each House spreadsheet were linked to a Parameters and Results spreadsheet. Variable parameters, adjustable in the Parameters and Results spreadsheet, fed back into the House spreadsheets and Data spreadsheets.

The calculator was firstly used to model ZALEH houses from the 1970s to 2020s. In all, 18 houses were modelled to assess them against the sustainability target from 
Section 5.5.4: 6 from ZALEH, and 12 progressively modified from the ZALEH 2020 designs, as shown in Figure 9.4a. The first four houses modelled - one 1970s house; two 2000s houses; and one 2010s house - were used as a baseline for comparing subsequent modelling.

The 1970s, 2000s and 2010s houses are referred to by year and construction details; the 2020 s houses are referred to by number ( 1 to 14$)$, shown in Figure $9.4 \mathrm{~b}$. The houses and strategy variations are described in detail in following sections.

The calculator provides a large number of possibilities for investigating materials and operating energy in houses. For example, the relative effects of thermal mass became apparent, and could be compared with other strategies in a number of different ways. Slab floors might be compared with timber floors; 'super' insulation could be compared in some detail with modest insulation; low, medium and high mass could be combined and compared with low, medium and high insulation. These other analyses enabled by the calculator, while interesting and worthwhile, are not followed more than superficially for reasons of space in this thesis, and because they are not central to the research question.

\subsubsection{House Calculation Spreadsheets}

Within each House spreadsheet, a series of worksheets (one per-house) listed the physical inputs of each house, along with inputs for operating energy. Figure 9.2a is a screenshot showing the main calculation section of the worksheet for the 2000s house, with suspended timber floor, timber walls, and steel roof as a typical example. Some rows and columns that are insignificant for this example have been hidden, to fit an A4 page while retaining legibility. They represent summary data for house dimensions, blank cells for an upper storey option, and totals for a timber (versus aluminium) window frame option. Some columns are also hidden, representing percentages of energy and $\mathrm{CO}_{2}$, negative (absorption) values for emissions converted to absolute (positive) values; and relative (ranked) impacts of materials, all of which are used elsewhere for charting purposes. 
Figure 9.2a shows detail from Figure 9.2b, identifiable in Figure 9.2b by the orange highlighted row and column numbers and letters and corresponding heavy border. The colour coding of pink for energy and blue for $\mathrm{CO}_{2}$ emissions is used throughout the calculator. Figure 9.2b shows the complete layout for a typical worksheet, including the hidden rows and columns from Figure 9.2a. Because of the size of each worksheet ( 66 columns $\times 254$ rows) it is not possible to show a complete one at a legible scale, even in A3 format. Figure 9.2b therefore merely shows the scale of the spreadsheet and where details from it are located. Figures 9.3a and 9.3b are screenshots of a worksheet with traces of the precedent and dependent cells visible, to show generally the interlinked nature of the calculations.

The remaining area below the highlighted section in Figure 9.2b shows the calculation data, manipulated and arranged for different outputs and for charting purposes. There are additional inputs for operating energy values, and an area of results for energy, emissions, and distance-to-target, that are copied to the front page of the Parameters and Results spreadsheet. A series of charts, examining the results in different ways, appear at bottom right. Some of these charts are referred to and displayed later in this chapter. 
Figure 9.2a Typical Calculator Worksheet Layout: Detail

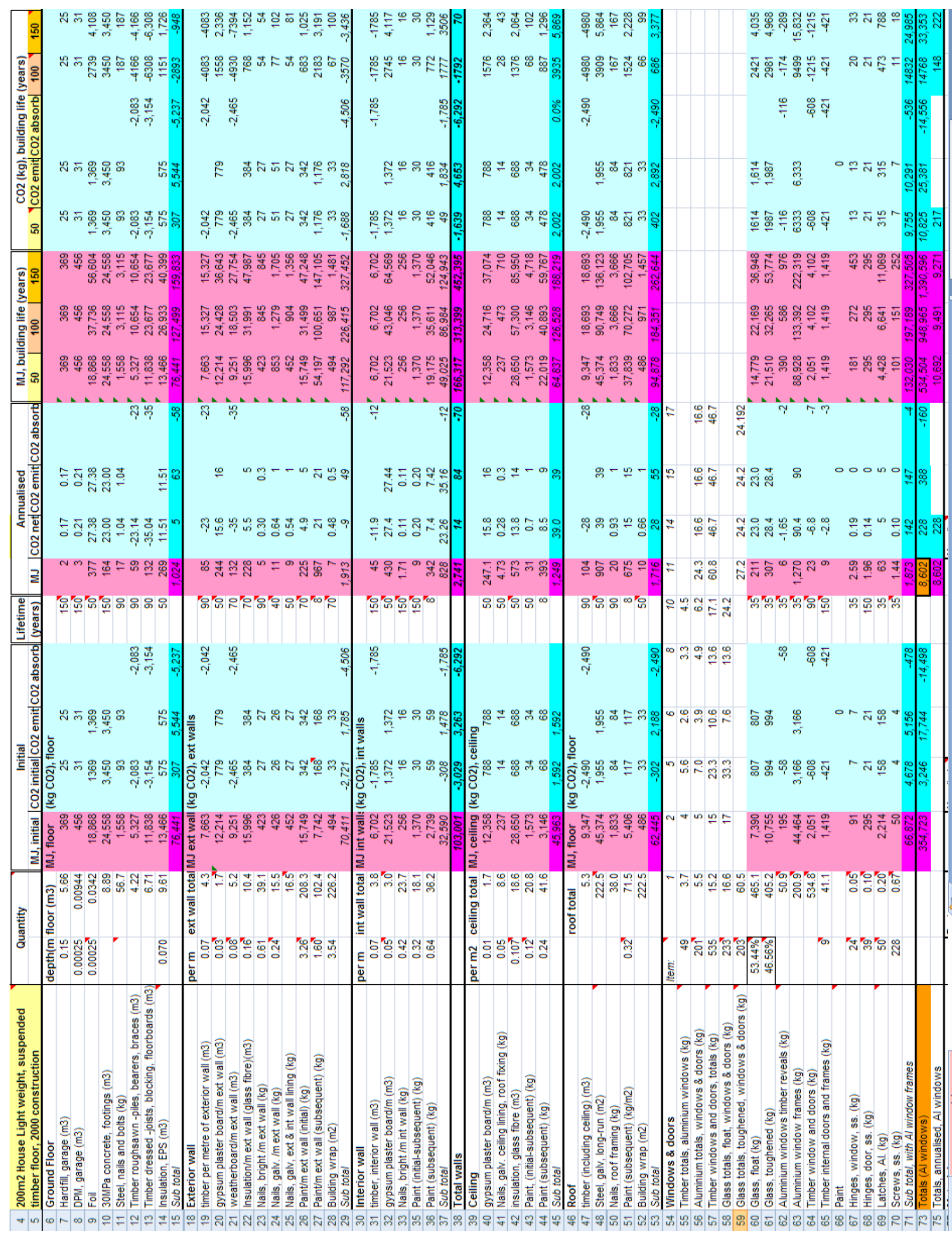

Energy (MJ)

$\mathrm{CO}_{2}$ Emissions and Absorptions ( $\mathrm{kg} / \mathrm{yr}$ ) 
Figure 9.2b Calculator Worksheet Layout: Overall View

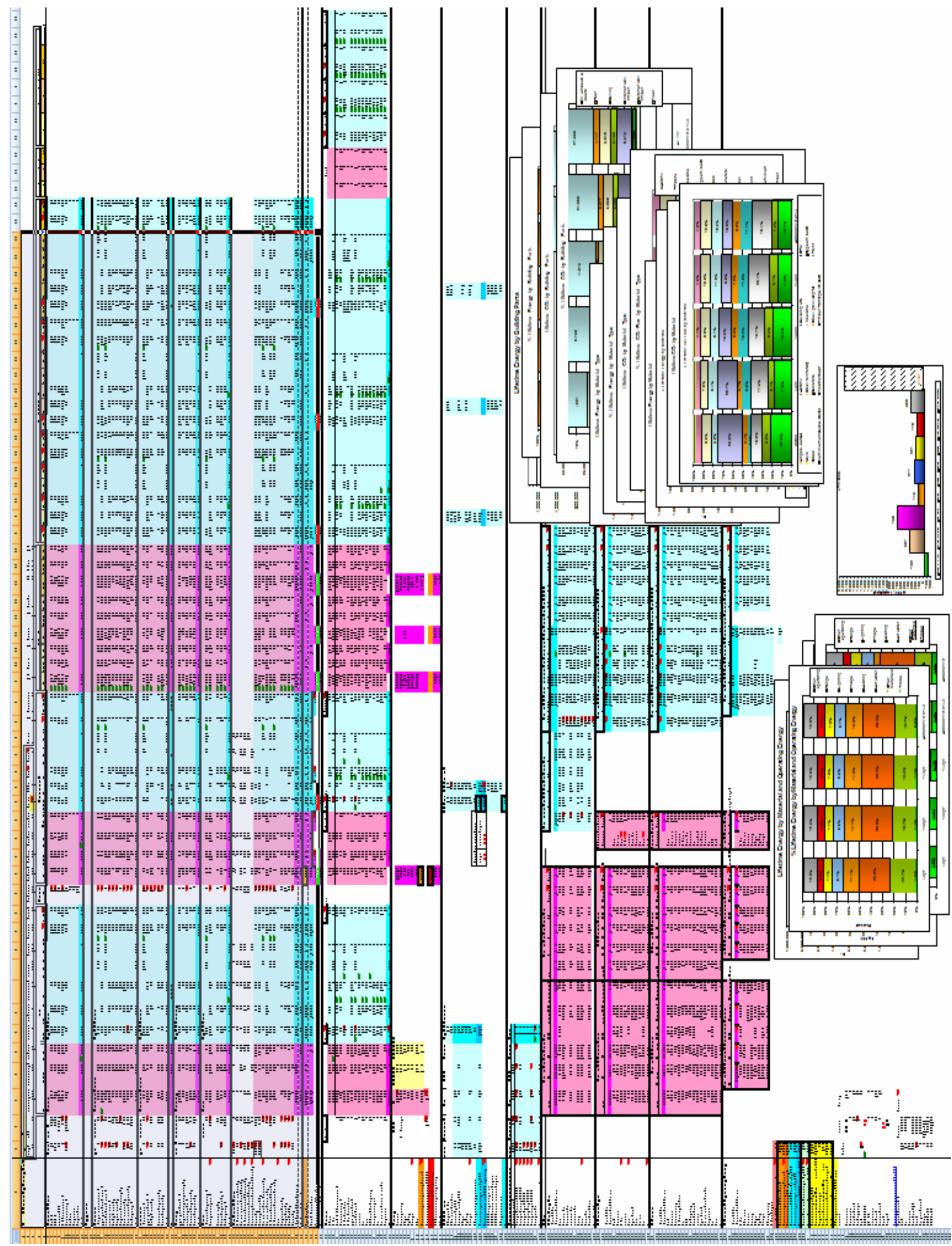


Figure 9.3a Precedent and Dependent Cell Traces in a Typical Worksheet: Detail

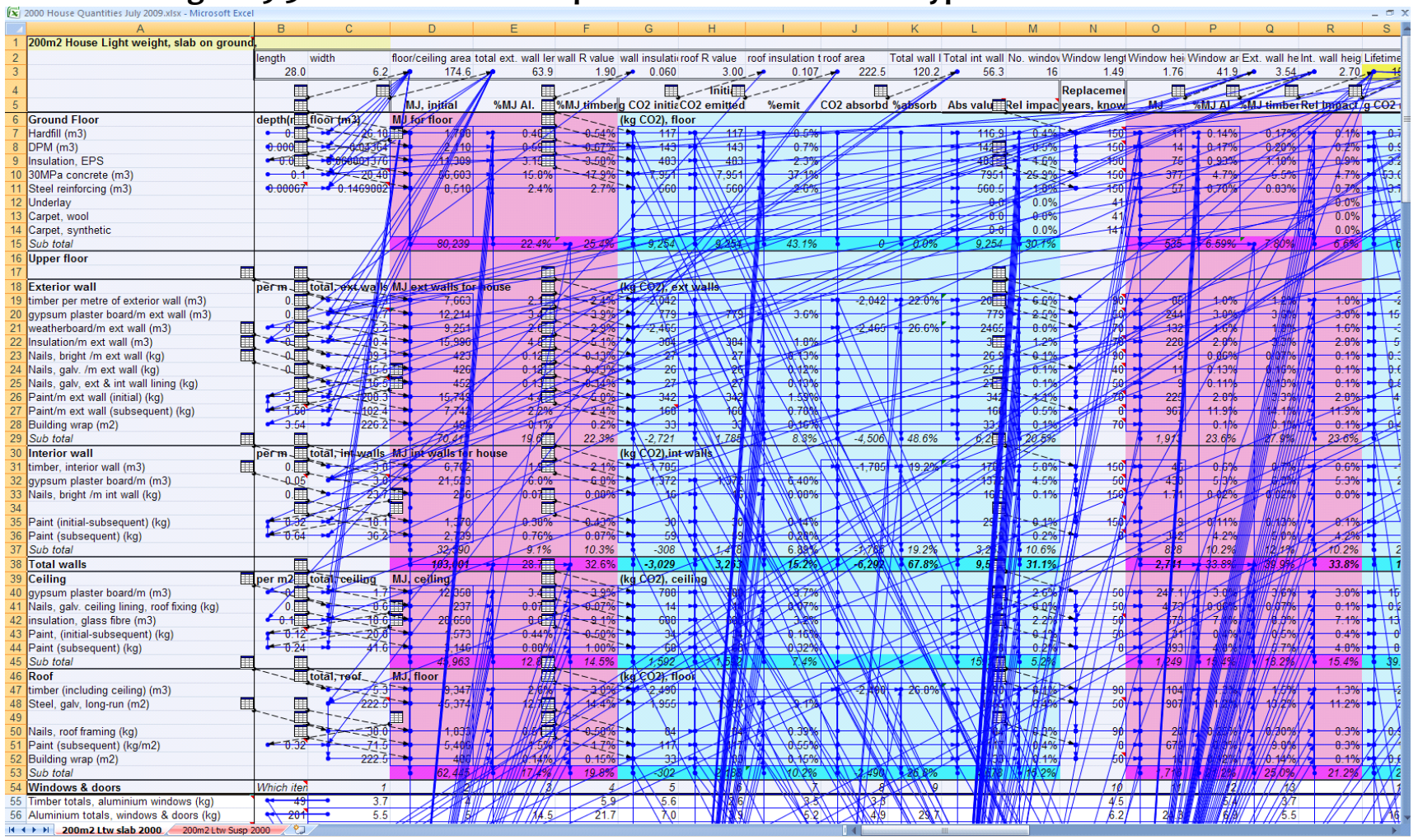

Figure 9.3b Precedent and Dependent Cell Traces in a Typical Worksheet

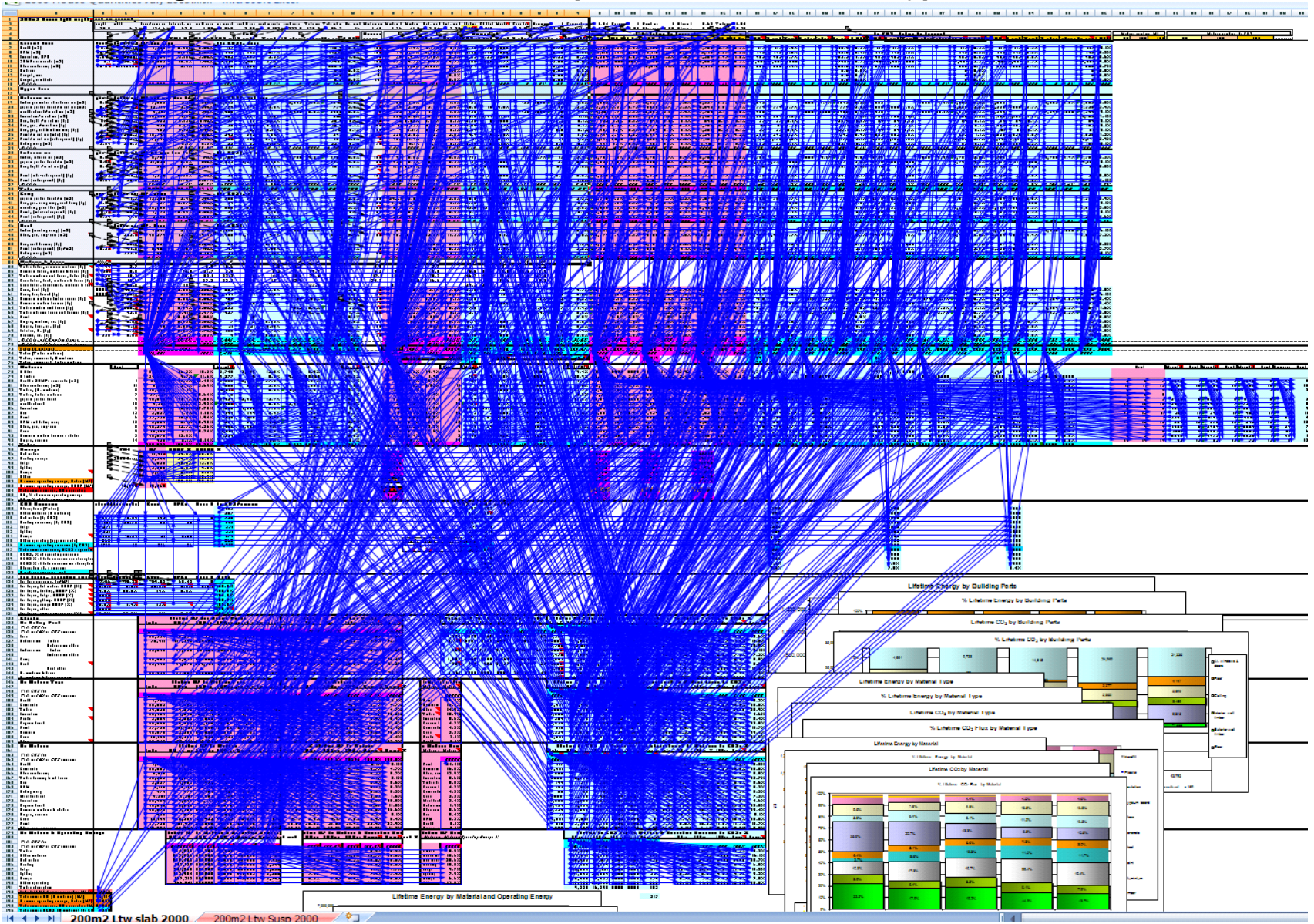




\subsubsection{Data Spreadsheet}

Input values in the House spreadsheets were derived from worksheets within the Data spreadsheet, which recorded user inputs and spreadsheet formulae. These included:

- Overall house dimensions

- $\quad$ Framing and fasteners quantities

- Window and door quantities

- $\quad$ Paint quantities

- Life expectancy of individual materials/components

- $\quad$ Operating energy and emissions

- Landfilled materials carbon loss/retention

- $\quad$ Global and per-house $\mathrm{CO}_{2}$ limits

In turn, these Data worksheets drew upon a database of embodied energy (EE) and embodied $\mathrm{CO}_{2}\left(\mathrm{ECO}_{2}\right)$ emissions, developed following the methodology described in Chapters 6, 7 and 8. Materials emitting or absorbing $\mathrm{CO}_{2}$ were treated separately, so that total emissions and absorptions for the whole building could be calculated.

The Data spreadsheet also drew on spreadsheets for:

- $\quad$ Electricity emission factors for national grid electricity

- Housing emissions (MED, 2000b; 2001b; 2002b; 2003b; 2004b; 2005b; 2006b)

- $\quad$ Thermal resistance $(\mathrm{R})$ values for building materials

- $\quad$ Thermal analyses of houses (Roose and Gowland, 2005).

\subsubsection{Parameters and Results Spreadsheet: Front Page}

A selection of important results from the calculation spreadsheets was copied to a front page in a Parameters and Results spreadsheet. Figures $9.4 \mathrm{a}$ and $9.4 \mathrm{~b}$, show the front page layout of selected data from the linked spreadsheets. This data included: results headings; numerical values under each heading for all houses modelled; numerical averages for a range of selected houses; a thumbnail graph for each of the houses modelled showing the annual $\mathrm{CO}_{2}$ emissions for the materials and operating energy; numerical values for each strategy intervention; and a series of 131 variable parameters to test the effects of selected changes on the different houses. 
Figure 9.4a Calculator Front Page: Overall View

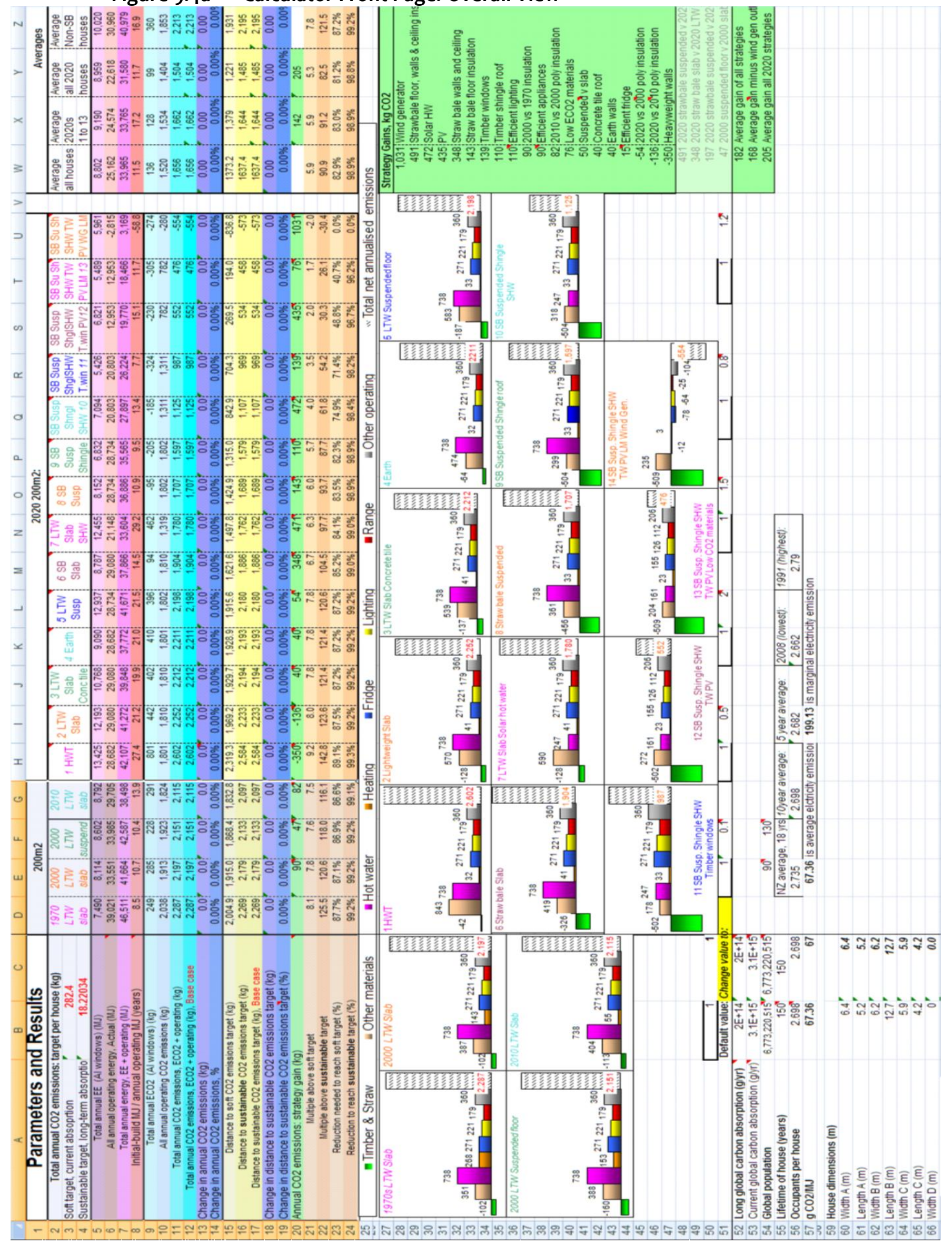


The results for the 1970s, 2000s and 2010s houses (highlighted by orange rows and columns in the upper left corner of Figure 9.4a) are shown as a detail in Figure 9.5. Other screenshots showing discreet parts of this front page, at a legible scale, are illustrated in subsequent figures.

Figure 9.4b Calculator Front Page: 2020s Houses Detail

\begin{tabular}{|c|c|c|c|c|c|c|c|c|c|c|c|c|c|}
\hline \multicolumn{14}{|c|}{$2020200 \mathrm{~m} 2:$} \\
\hline $1 \mathrm{HWT}$ & $\begin{array}{c}2 \text { LTW } \\
\text { Slab }\end{array}$ & $\begin{array}{c}\text { Slab } \\
\text { Conc tile }\end{array}$ & 4 Earth & $\begin{array}{l}5 \text { LTW } \\
\text { Susp }\end{array}$ & $\begin{array}{l}6 \mathrm{SB} \\
\text { Slab }\end{array}$ & $\begin{array}{l:}7 \mathrm{LTW} \\
\text { Slab } \\
\mathrm{SHW}\end{array}$ & $\begin{array}{l}8 \text { SB } \\
\text { Susp }\end{array}$ & \begin{tabular}{c|c}
$9 \mathrm{SB}$ \\
Susp \\
Shingle
\end{tabular} & $\begin{array}{c}\text { SB Susp } \\
\text { Shngl } \\
\text { SHW 10 }\end{array}$ & $\begin{array}{l}\text { SB Susp } \\
\text { ShglSHW } \\
\text { T.win } 11\end{array}$ & $\begin{array}{c:}\text { SB Susp } \\
\text { ShglSHW } \\
\text { T.win PV12 }\end{array}$ & $\begin{array}{l}\text { SB SU Sh: } \\
\text { SHW TW } \\
\text { PV LM 13 }\end{array}$ & $\begin{array}{c}\text { SB SU Sh } \\
\text { SHW TW } \\
\text { PV WG LM }\end{array}$ \\
\hline 13,425 & 12,193 & 10,768 & 9,090 & 12,937 & 8,787 & $\overline{12,455}$ & 8,152 & 6,832 & 7,094 & 5,426 & 6,821 & 5,489 & 5,961 \\
\hline 28,682 & 29,080 & 29,080 & 28,682 & 28,734 & 29,080 & 21,148 & 28,734 & 28,734 & 20,803 & 20,803 & 12,953 & 12,953 & $-2,815$ \\
\hline 42,107 & 41,272 & 39,848 & 37,772 & 41,671 & 37,866 & 33,604 & 36,886 & 35,565 & 27,897 & 26,224 & 19,770 & 18,466 & 3,169 \\
\hline $27.4^{!}$ & 21.2 & 19.9 & 21.0 & 21.5 & 14.5 & 29.2 & 10.9 & 9.5 & 13.4 & 7.7 & 15.1 & 11.7 & -58.8 \\
\hline 801 & 442 & 402 & 410 & 396 & $\overrightarrow{94}$ & 462 & -95 & -205 & -185 & -324 & -230 & -305 & -274 \\
\hline 1,801 & 1,810 & 1,810 & 1,801 & 1,802 & 1,810 & 1,319 & 1,802 & 1,802 & 1,311 & 1,311 & 782 & 782 & -280 \\
\hline 2,602 & 2,252 & 2,212 & 2,211 & 2,198 & 1,904 & 1,780 & 1,707 & 1,597 & 1,125 & 987 & 552 & 476 & -554 \\
\hline 2,602 & 2,252 & 2,212 & 2,211 & 2,198 & 1,904 & 1,780 & 1,707 & 1,597 & 1,125 & 987 & 552 & 476 & -554 \\
\hline $0.0 \%$ & 0.0 & $0.0 \%$ & 0.0 & $0.0^{7}$ & $0.0 ?$ & $0.0 ?$ & 0.0 & 0.0 & 0.0 & $0.0 ?$ & $0.0 ?$ & 0.0 & 0.0 \\
\hline $0.00 \%$ & $0.00 \%$ & $0.00 \%$ & $0.00 \%$ & $0.00 \%$ & $0.00 \%$ & $0.00 \%$ & $0.00 \%$ & $0.00 \%$ & $0.00 \%$ & $0.00 \%$ & $0.00 \%$ & $0.00 \%$ & $0.00 \%$ \\
\hline $2,319.3$ & $1,969.2$ & $1,929.7$ & $1,928.9$ & $1,915.6$ & $1,621.6$ & $1,497.8$ & $1,424.9$ & $1,315.0$ & 842.9 & 704.3 & 269.5 & 194.0 & -836.8 \\
\hline 2,584 & 2,233 & 2,194 & 2,193 & 2,180 & 1,886 & 1,762 & 1,689 & 1,579 & 1,107 & 969 & 534 & 458 & -573 \\
\hline 2,584 & 2,233 & 2,194 & 2,193 & 2,180 & 1,886 & 1,762 & 1,689 & 1,579 & 1,107 & 969 & 534 & 458 & -573 \\
\hline 0.0 & $0.0 ?$ & 0.0 & 0.0 & $0.0^{r}$ & 0.0 & 0.0 & 0.0 & 0.0 ? & 0.0 & 0.0 & 0.0 & 0.0 & 0.0 \\
\hline $0.00 \%$ & $0.00 \%$ & $0.00 \%$ & $0.00 \%$ & $0.00 \%$ & $0.00 \%$ & $0.00 \%$ & $0.00 \%$ & $0.00 \%$ & $0.00 \%$ & $0.00 \%$ & $0.00 \%$ & $0.00 \%$ & $0.00 \%$ \\
\hline-350 & -136 & 40 & 40 & 54 & 348 & 471 & 143 & 110 & 472 & 139 & 435 & 76 & 1031 \\
\hline 9.2 & 8.0 & 7.8 & 7.8 & $7.8 !$ & 6.7 & 6.3 & 6.0 & 5.7 & 4.0 & 3.5 & 2.0 & 1.7 & -2.0 \\
\hline 142.8 & 123.6 & 121.4 & 121.4 & 120.6 & 104.5 & 97.7 & 93.7 & 87.7 & 61.8 & 54.2 & 30.3 & 26.1 & -30.4 \\
\hline $89.1 \%$ & $87.5 \%$ & $87.2 \%$ & $87.2 \%$ & $87.2 \%$ & $85.2 \%$ & $84.1 \%$ & $83.5 \%$ & $82.3 \%$ & $74.9 \%$ & $71.4 \%$ & $48.8 \%$ & $40.7 \%$ & $0.0 \%$ \\
\hline $99.3 \%$ & $99.2 \%$ & $99.2 \%$ & $99.2 \%$ & $99.2 \%$ & $99.0 \%$ & $99.0 \%$ & $98.9 \%$ & $98.9 \%$ & $98.4 \%$ & $98.2 \%$ & $96.7 \%$ & $96.2 \%$ & $0.0 \%$ \\
\hline
\end{tabular}

\subsubsection{Assessing Strategy Gains}

To assess each house and its introduced strategy, total net emissions of each house design were compared to the defined allowable $\mathrm{CO}_{2}$ (target) limit per-house. The difference between the total net emissions and allowable limit, for any particular house design, was the distance to the target emission limit (distance-to-target). This difference was the amount to be made up in improvements to the design for it to reach the sustainability target.

The sustainable emissions target is based on long-term global $\mathrm{CO}_{2}$ absorption. A soft target allows current global emissions to equal current absorption. The distance-totarget of the total emissions for each house was measured in three ways:

- The net $\mathrm{CO}_{2}$ emitted above the target emissions (distance to target), in $\mathrm{kg} / \mathrm{yr}$ 
- The emissions reduction needed in percentage terms for emissions to reach the target

- The net $\mathrm{CO}_{2}$ emissions as a multiple of the target.

Figure 9.5 shows these assessments in rows: 15 and 16, 23 and 24, and 21 and 22, respectively.

Figure 9.5 Front Page Detail: Results

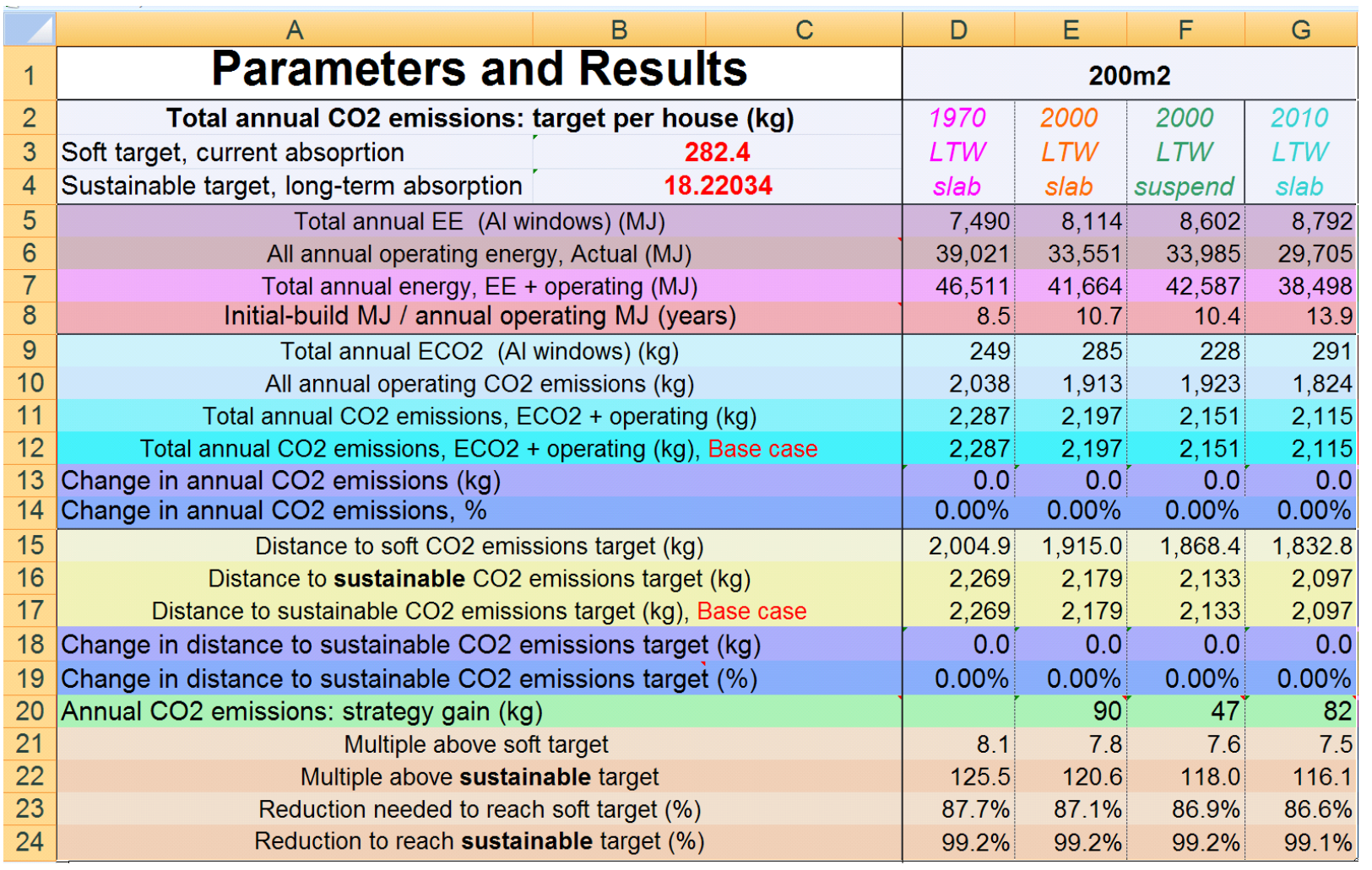

When changes were made to various parameters the significance of the change was assessed. Two indicators for this assessment were useful:

- change in total net $\mathrm{CO}_{2}$ emissions, in $\mathrm{kg} / \mathrm{yr}$ above (or below) the target value, and

- $\quad$ percentage difference between a modified and unmodified (or base-case) value.

\subsubsection{Strategy Gains: Examples}

It was initially assumed that as insulation levels increased there would be a progressive reduction in total emissions. When the houses with lightweight walls and concrete slab floors were compared across the age groups - 1970s, 2000s, 2010s and 
2020s however, it was found that the 2010s house performed better than both the 2000 s and 2020s houses. This was primarily because the emissions associated with a greater thickness of insulation in the 2020s house exceeded the reduction in heatingrelated emissions for the 2020s house over the 2010s house (see Figure 9.10).

The 2000s timber floor house outperformed the equivalent concrete slab house in total emissions. This was due to the balance of gains and losses related to the floors. While the concrete floor did reduce heating-related emissions by having higher thermal mass, this reduction was modest $(10 \mathrm{~kg} / \mathrm{yr})$, while the absorptions from more timber in the suspended floor reduced net $\mathrm{CO}_{2}$ emissions by $58 \mathrm{~kg} / \mathrm{yr}$. The other materials, excluding timber, showed almost identical emissions (only $1 \mathrm{~kg} / \mathrm{yr}$ difference), because the high concrete floor emissions balanced the high insulation emissions.

The net result is that the suspended timber floor house, with modest (R2.7) floor insulation had total net $\mathrm{CO}_{2}$ emissions $47 \mathrm{~kg} / \mathrm{yr}$ less than the slab floor house. This result is contrary to much current thinking in the industry that believes that high mass floors reduce environmental impact. This is based on the correct understanding that a high-mass floor reduces heating and total energy use (total annual energy of 41,664 MJ for the slab floor, versus 42,587 MJ for the suspended floor), but does not account for the relative emissions of the different materials, where high timber $\mathrm{CO}_{2}$ absorptions and high concrete emissions are decisive.

The base-case 2010s house with slab floor, timber walls and steel roof had $\mathrm{CO}_{2}$ emissions of 2,115 kg/yr, and a distance-to-target of 2,097 kg/yr (Figure 9.5: G12; G17). This meant total $\mathrm{CO}_{2}$ emissions were 116.1 times the target $(18.6 \mathrm{~kg} / \mathrm{yr})$ and a percentage reduction of $99.1 \%$ of the total emissions was needed to reach the target (Figure 9.5: G22; B4; G24). Insulation levels were altered so heating energy use increased from the 'low' 2010s value back to the 2000s value. The change in percentage reduction needed to reach the target rose accordingly from 99.1 to $99.2 \%$ - a change in value too small to be quickly understandable (Figure 9.6: G24). Assessing the heating increase as the change in $\mathrm{CO}_{2}$ emissions, by kilograms and by percentage, however, showed that total emissions increased by 88.1 to $2,203 \mathrm{~kg} / \mathrm{yr}$, 
or by $4.17 \%$, respectively (Figure 9.6: G13; G11; G14). These numerically larger changes are more easily appreciated.

Figure 9.6 2010s House: Heating Energy Increase to 2000s Level

\begin{tabular}{|c|c|c|c|c|c|}
\hline 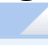 & A & C & $\mathrm{E}$ & $\mathrm{F}$ & G \\
\hline 1 & Parameters al & ults & \multicolumn{3}{|c|}{$200 \mathrm{~m} 2$} \\
\hline 2 & \multicolumn{2}{|c|}{ Total annual CO2 emissions: target per house (kg) } & 2000 & 2000 & 2010 \\
\hline 3 & Soft target, current absoprtion & 282.4 & LTW & LTW & LTW \\
\hline 4 & Sustainable target, long-term absorption & 18.22034 & slab & suspend & slab \\
\hline 5 & \multicolumn{2}{|c|}{ Total annual EE (Al windows) (MJ) } & 8,114 & 8,602 & 8,792 \\
\hline 6 & \multicolumn{2}{|c|}{ All annual operating energy, Actual (MJ) } & 33,551 & 33,985 & 33,551 \\
\hline 7 & \multirow{2}{*}{\multicolumn{2}{|c|}{$\begin{array}{l}\text { Total annual energy, EE + operating (MJ) } \\
\text { Initial-build } \mathrm{MJ} \text { / annual operating } \mathrm{MJ} \text { (years) }\end{array}$}} & 41,664 & 42,587 & 42,343 \\
\hline 8 & & & 10.7 & 10.4 & 12.3 \\
\hline 9 & \multicolumn{2}{|c|}{ Total annual ECO2 (Al windows) (kg) } & 285 & 228 & 291 \\
\hline 10 & \multicolumn{2}{|c|}{ All annual operating $\mathrm{CO} 2$ emissions $(\mathrm{kg})$} & 1,913 & 1,923 & 1,913 \\
\hline 11 & \multicolumn{2}{|c|}{ Total annual CO2 emissions, ECO2 + operating (kg) } & 2,197 & 2,151 & 2,203 \\
\hline 12 & \multicolumn{2}{|c|}{ Total annual $\mathrm{CO} 2$ emissions, ECO2 + operating $(\mathrm{kg})$, Base case } & 2,197 & 2,151 & 2,115 \\
\hline 13 & \multicolumn{2}{|l|}{ Change in annual $\mathrm{CO} 2$ emissions $(\mathrm{kg})$} & 0.0 & 0.0 & 88.1 \\
\hline 14 & \multicolumn{2}{|l|}{ Change in annual $\mathrm{CO} 2$ emissions, \% } & $0.00 \%$ & $0.00 \%$ & $4.17 \%$ \\
\hline 15 & \multicolumn{2}{|c|}{ Distance to soft CO2 emissions target $(\mathrm{kg})$} & $1,915.0$ & $1,868.4$ & $1,920.9$ \\
\hline 16 & \multicolumn{2}{|c|}{ Distance to sustainable $\mathrm{CO} 2$ emissions target $(\mathrm{kg})$} & 2,179 & 2,133 & 2,185 \\
\hline 17 & Distance to sustainable $\mathrm{CO} 2$ emissi & g), Base case & 2,179 & 2,133 & 2,097 \\
\hline 18 & \multicolumn{2}{|c|}{ Change in distance to sustainable $\mathrm{CO} 2$ emissions target $(\mathrm{kg})$} & 0.0 & 0.0 & 88.1 \\
\hline 19 & \multicolumn{2}{|c|}{ Change in distance to sustainable $\mathrm{CO} 2$ emissions target (\%) } & $0.00 \%$ & $0.00 \%$ & $4.20 \%$ \\
\hline 20 & \multicolumn{2}{|l|}{ Annual CO2 emissions: strategy gain $(\mathrm{kg})$} & 90 & 47 & -6 \\
\hline 21 & \multicolumn{2}{|c|}{ Multiple above soft target } & 7.8 & 7.6 & 7.8 \\
\hline 22 & \multicolumn{2}{|c|}{ Multiple above sustainable target } & 120.6 & 118.0 & 120.9 \\
\hline 23 & \multirow{2}{*}{\multicolumn{2}{|c|}{ Reduction needed to reach soft target (\%) }} & $87.1 \%$ & $86.9 \%$ & $87.2 \%$ \\
\hline 24 & & & $99.2 \%$ & $99.2 \%$ & $99.2 \%$ \\
\hline
\end{tabular}

\subsubsection{Checking Robustness: Validity of the Calculator}

The calculator contains some assumptions and many variables. If the variables had a large influence on the results, any errors or alternative assumptions could alter the results and conclusions available. To assess the reliability of the calculator results, these variables and assumptions were tested for their relative significance as inputs.

\subsubsection{Sensitivity Analysis}

Variables for the different designs were subjected to a sensitivity analysis to establish a rank of importance for the various parameters and strategies. Each significant parameter was altered by $+/-20 \%$, to gauge the importance of each variable. In this way, the options for building and operating real houses were also assessed for their ability to influence the $\mathrm{CO}_{2}$ emissions towards, or away from, a sustainable limit. The $+/-20 \%$ variation tested the veracity of the calculator by identifying anomalous changes to the totals for all 18 houses modelled. The anomalies were examined and 
all identified errors resolved. Table 9.1 shows the percentage change in the total net annual $\mathrm{CO}_{2}$ emissions for the top 12 parameters, $>4 \%$.

Table 9.1 Net Annual $\mathrm{CO}_{2} \%$ Change with $+/-20 \%$ Parameter Variation

\begin{tabular}{lc}
\hline Variable & Net Annual $\mathrm{CO}_{2} \%$ change \\
\hline Electricity $\mathrm{CO}_{2}$ factor, marginal, g/MJ & $196.4 \%$ \\
Wind generator rated output, $\mathrm{W}$ & $27.5 \%$ \\
$\mathrm{PV}$ panel area, $\mathrm{m}^{2}$ & $23.6 \%$ \\
Electricity $\mathrm{CO}_{2}$ factor, average, g/MJ & $20.1 \%$ \\
Solar water heater area, $\mathrm{m}^{2}$ & $19.9 \%$ \\
Hot water energy, $\mathrm{MJ}$ & $14.1 \%$ \\
Straw bale carbon retention factor, $\%$ & $10.8 \%$ \\
Straw Bale lifetime, years & $10.0 \%$ \\
Other operating energy, $\mathrm{MJ}$ & $6.9 \%$ \\
Fridge energy, MJ & $5.2 \%$ \\
Timber carbon retention factor, $\%$ & $5.1 \%$ \\
Lighting energy, MJ & $4.2 \%$ \\
\hline
\end{tabular}

$\mathrm{A}+/-20 \%$ change in the input parameter was averaged across all houses, except the electricity $\mathrm{CO}_{2}$ emission factor, which is changed from its average value of $67 \mathrm{~g} / \mathrm{MJ}$ to its marginal $199 \mathrm{~g} / \mathrm{MJ}$ value (a nearly 300\% increase).

The top five parameters in Table 9.1 were related to grid electricity, or its replacement by an energy technology. A further four of the remaining seven parameters were related to grid electricity use. The carbon retention factor for landfilled straw and timber were also significant. Because straw is an important material for $\mathrm{CO}_{2}$ absorption, its life expectancy, and thus the number of replacements that can store further $\mathrm{CO}_{2}$, is also significant.

The average variation of all parameters when each was changed by $+/-20 \%$ was $5.4 \%$, and $3.6 \%$ when the outlier from variation of the average/marginal electricity emission factor was removed. Only the top six of the 135 variables showed more than $5 \%$ change in annual $\mathrm{CO}_{2}$ emissions.

\subsubsection{Average versus Marginal Electricity}

To enable questions to be asked, and answered, which depend on the electricity rate being based either on average or marginal data (see Sections 6.2.10 and 7.2), the 
calculator included the electricity emission factor as a variable on the front page. To be comparable to other studies, the average emission factor was used and reported on. The difference in New Zealand between marginal and average electricity $\mathrm{CO}_{2}$ emissions is large: $199 \mathrm{~g} / \mathrm{MJ}$ versus $67 \mathrm{~g} / \mathrm{MJ}$. The effect of using the marginal rate in place of the average electricity emission factor was to increase the average distanceto-target for all except House 14, by much more than double; an average of $167 \%$. House 14, with negative net $\mathrm{CO}_{2}$ emissions, showed even more negative emissions when the marginal factor was used. That is, once the emissions target was exceeded, the 'saved' emissions attained by exporting excess electricity to the grid 'saved' even more grid emissions if the higher marginal emission factor was assigned to grid electricity.

\subsection{General Input Parameters}

Before individual house designs could be assessed in the calculator, a number of contextual parameters that relate to all houses needed to be applied. Sections 9.5, 9.6, and 9.7 address those parameters. The parameters examined were:

- A global and per-house sustainability limit

- Global population

- Household size in New Zealand

- $\quad$ House size (floor area) in New Zealand

- $\quad$ Lifetime of houses

- Lifetime of materials and components

- $\quad$ Operating energy categories and fuel types.

\subsubsection{Sustainability Limit}

The $\mathrm{CO}_{2}$ limit per-annum per-house was derived in Section 5.5.4. It is used in the calculations to derive both a sustainable $\mathrm{CO}_{2}$ target of $19 \mathrm{~kg} / \mathrm{yr}$, for construction, maintenance, and operation, and a soft $\mathrm{CO}_{2}$ target of $282 \mathrm{~kg} / \mathrm{yr}$ (see Section 9.4.4). Both $\mathrm{CO}_{2}$ targets are a long way from current practice $(\sim 2,200 \mathrm{~kg} / \mathrm{yr})$ implying large reductions and similarly bold design and construction strategies to reach them. 
Altering the definition of sustainability by allowing for different published population projections or near-term global $\mathrm{CO}_{2}$ absorption rates left the results from the 18 houses modelled essentially unchanged. Halving and doubling the long-term global carbon absorption rate changed the sustainable target by 9.1 and $18.6 \mathrm{~kg} / \mathrm{yr}$, respectively. Since the distance-to-target is so large, however, this only represented a change of 0.7 and $1.4 \%$, respectively. Both the long-term sustainable and current soft sustainability targets showed similar results.

Easing the sustainable target by a whole order of magnitude eased the distance-to-target by between $6.3 \%$ and $36 \%$. A target one order of magnitude more stringent increased the distance-to-target by between $0.63 \%$ and $3.6 \%$. Even with these large variations introduced to account for possible inaccuracies it was found that the final sustainability results for the individual house designs remained unaltered.

\subsubsection{Global Population}

The sustainability target is dependent on population: a rising population, while the absorptive capacity of the planet remains the same, means a falling allowable percapita emission rate. Section 5.5.4 and Figure 5.5 showed how global population is related to sustainability and New Zealand houses.

Data from the US Census Bureau (2009) was used for global population and was placed on the calculator front page as a variable parameter, to enable modelling of future population levels. Changing population levels had only a small effect on the sustainability target. Increasing population by $50 \%$ to over 10 billion had less than $0.4 \%$ effect on the distance-to-target, on average, for the houses modelled, while halving population to 3.4 billion reduced the distance-to-target by just over $1 \%$. These small effects are because current houses are so far above the sustainability target. Even larger changes would be required to substantially alter the sustainability equation. At current New Zealand per-capita emission levels the global population would need to fall to just 54 million people, to be at or within the sustainability limit. That is to say, New Zealand, like much of the developed world, is currently about two orders of magnitude beyond sustainability, in its $\mathrm{CO}_{2}$ emissions. Either very large population reductions are required, or other changes to all aspects of lifestyles, 
such as house construction and operation improvements, need to occur to reach sustainability (see Section 4.2.5). The implications of changes to lifestyle aspects outside of housing however, are not the subject of this thesis.

\subsubsection{Household Size}

Section 5.5.1 set out the argument for household size as the basis for calculating the construction and operating emissions for houses. The specific size of New Zealand households was calculated from national statistics (Statistics 2008c; 2008d; 2008e), by dividing the population by the number of dwellings, from 1991 to 2008. As with other western countries, the trend is towards smaller households (see Figure 5.3). There is, however, a fluctuation over the years, so an average from the last ten years was used. The influence of this assumption was tested by substituting the lowest and highest household size from the last 18 years. This had little effect on the sustainability target, reducing and increasing it by 1.3 and 3.3\% respectively. Halving or doubling the household size also halves or doubles the sustainability target, since the target is based on allowable per-capita emissions. Because the distance-to-target is so large for most of the houses, however, even halving or doubling the household size has little effect on the distance-to-target: at most, the distance-to-target increases or decreases by between 2 and 4\%, respectively.

Because the distance to the 'soft' target is smaller, the effect of changing household size is more pronounced. Even so, for the 'soft' target to be reached by the 'second best' house (13), an increase in household size of 70\%, to 4.6 people, is required. For a 'standard' 2020s house to achieve just the 'soft' target by only changing household size, an increase of an unlikely $780 \%$ is required, to 21 people per-house. While important, adjusting household size is not a leading means by which sustainability can be attained in New Zealand houses.

\subsubsection{House Size}

In New Zealand, the average size of house has been steadily rising for decades. When Baird and Chan (1983) did their analyses, the New Zealand Building Industry Advisory Council (BIAC) house was used as a benchmark in the industry, at $94 \mathrm{~m}^{2}$. Currently, while house sizes vary, larger houses, of over $200 \mathrm{~m}^{2}$, are increasingly 
common. The non-apartment dwellings milestone of $200 \mathrm{~m}^{2}$ average area was reached in June 2003, when dwellings including apartments averaged $176 \mathrm{~m}^{2}$ (Davidson, 2004). Figure 9.7 shows the rising trend of house sizes to 2007 (Statistics 2003, 2008b).

Figure 9.7 Average Floor Areas of New Dwellings

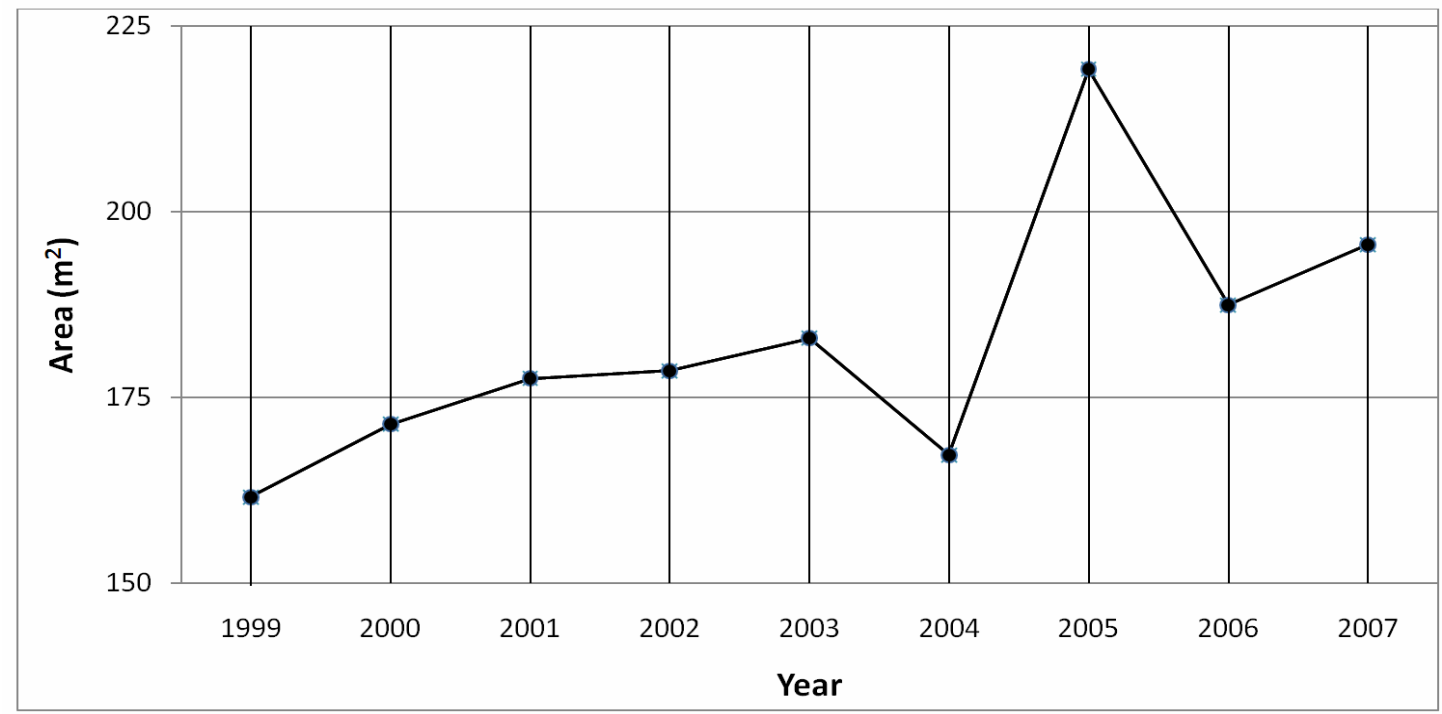

House size could be altered within the calculator to any size for a three bedroom house. The calculator did not model variations in the number of rooms. Increasing the number of rooms would increase the relative quantity of materials for internal walls, relative to increased floor and roof area. Even with common finishing materials such as painted gypsum board, the net effect of timber framed internal walls is to absorb more $\mathrm{CO}_{2}$ than is emitted: more rooms would reduce overall emissions.

\subsubsection{Lifetime of Houses}

Lifetimes of 50,100, or 150 years were initially adopted as a way of comparing the effects of house lifetime on net emissions. Total energy use and $\mathrm{CO}_{2}$ emissions were calculated for each of these lifetimes, along with an annualised rate, achieved by dividing energy and emissions by the house lifetime. In this way, the influence of different design strategies became clear for the given design life of the house, with longer lived houses showing reduced annual emissions. Some problems arose from this strategy, however. 
Lifetimes of $50,100,150$, or any other interval are arbitrary, although matching current life expectancies. While 50 years is a common design life, prompted in part by building code requirements, the average life expectancy of New Zealand houses built from 1860 to 1980 is 90 years, while houses built from the 2000s are expected to last for up to 130 years (Johnstone, 2004). As regulation, building knowledge and practice, and climate awareness all improve, average construction quality may be expected to further increase with continually rising house life expectancy.

As well as the uncertainty over the lifetime of any individual house, there is uncertainty over exactly how long individual construction items will last. If a house lasts for exactly its 50 year design life, it can be expected to require just the one steel roof it was built with, given steel roofing's average life expectancy. If, however, the roof lasts only 45 years, for environmental (e.g. close to the coast) or other reasons (e.g. poor maintenance), two roofs will be needed for a 50 year house. The second roof, although it has 45 years of useful life left, becomes part of the total emissions of the 50 year house. This would significantly affect the total embodied energy and $\mathrm{CO}_{2}$ results.

To avoid anomalies of this sort and to credit each construction item with its full durability potential, unaffected by arbitrary life expectancies of house or item, life expectancies were annualised (see Section 9.6.2). This also made it simpler to compare construction life with annual operating energy, and annual global $\mathrm{CO}_{2}$ absorption figures.

Impacts over a specific design life, such as 50 years, could still be assessed, by multiplying the annualised energy and emission values by the house lifetime. By doing this, it was found that as the design life increased there was a reduction in the anomalous influences of construction items, which did not neatly fit the design life such as weatherboards at 70 years life expectancy or cladding nails at 40 years. That is, the relative importance of each construction item or operating energy input came closer, for a longer lifetime, to the relative importance indicated when using an annualised approach. The 150 year house had values that were close to the 
annualised rate multiplied by 150 . If the design life was extended to 250 years, it was found that the values of each individual input came even closer to those calculated by the annualised method.

Figure 9.8 shows the relative importance of operating energy and materials for emissions or absorptions (flux) of $\mathrm{CO}_{2}$. The first three columns show the percentage of $\mathrm{CO}_{2}$ flux attributable to each construction/operating energy category, for houses with design lives of 50, 100, and 150 years. As the design life increases from 50 to 150 years, the construction $\mathrm{CO}_{2}$ is amortised over a longer period, thus becoming relative less significant and progressively closer to the annualised percentages. The right-hand column shows the percentages for each category using annualised values, representing, for comparison, a house with a design life of 150 years in this instance.

Figure 9.8 $\mathrm{CO}_{2}$ Flux: Percentage by House Lifetime

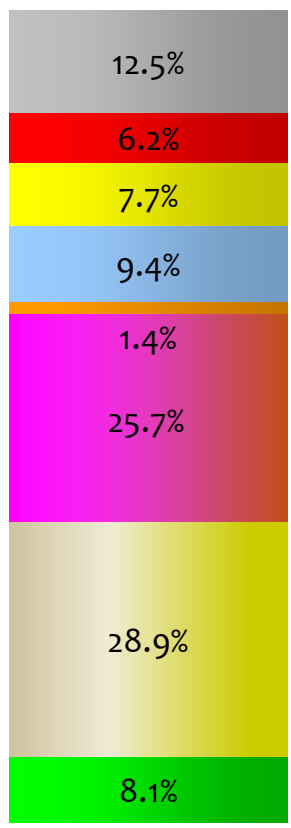

$50 y r$

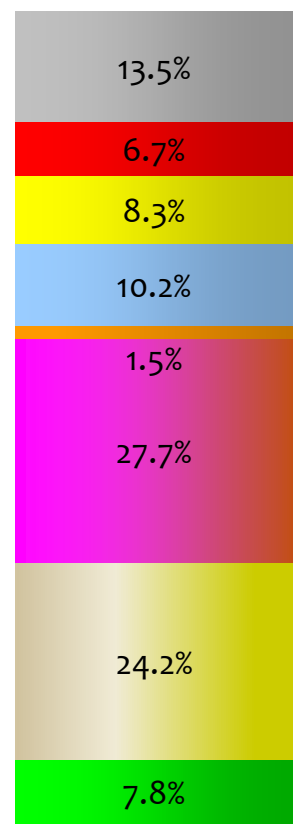

100yr

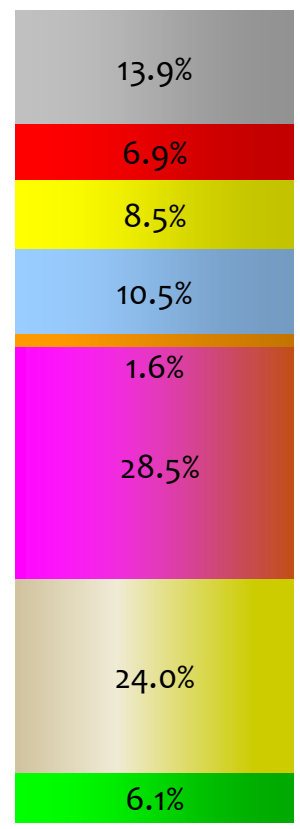

$150 y r$

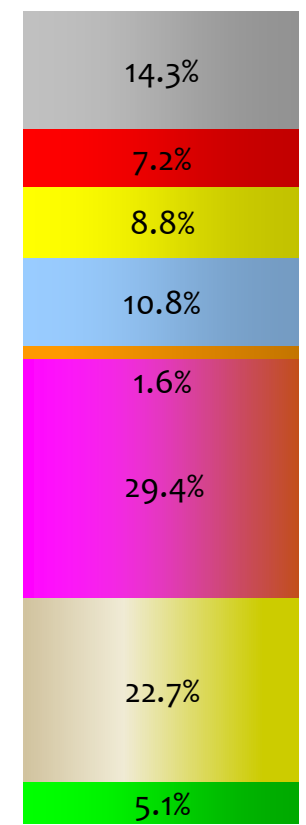

Other operating

nange

Lighting

Fridge

Heating

Hot water

11 Emitting materials

Absorbing materials

Annualised x150

\subsection{Input Parameters: Construction Methods, Materials, and Components}

Construction design followed NZS3604 for the concrete slab, timber floor, timber wall, and roof framing. NZS4229:1999 (Standards, 1999b) was used for the concrete house, and NZS4299:1998 (Standards, 1998) for the earth house. Allowance was 
made in the calculator for varying the floor and wall dimensions but still retaining the appropriate spacing and sizing of framing members, as required by the relevant standards for each construction technology.

\subsubsection{Materials}

The materials used in ZALEH were adopted as far as possible for the calculation models. ZALEH however, only specified materials and detailing sufficient to meet the requirements of thermal modelling. ZALEH, for example, treated the hard-fill below the concrete slab as part of the ground, and ignored any sand blinding and a damp-proof membrane (DPM), because of their thermal triviality. Other similar adaptations were made as necessary for other building components.

The materials discussed in this section are the ones used for construction of the modelled houses, from the ground up:

- Hard fill

- $\quad$ DPM

- Insulation, expanded and extruded polystyrene (EPS and XPS)

- $\quad$ Concrete

- $\quad$ Steel reinforcing

- $\quad$ Timber, treated sub floor framing

- $\quad$ Timber floorboards

- $\quad$ Fasteners

- $\quad$ Foil

- $\quad$ Timber, treated framing

- $\quad$ Timber, treated weatherboard

- $\quad$ Building wrap

- Insulation, fibreglass

- Gypsum plasterboard

- $\quad$ Paint

- Cement plaster

- Adobe

- Adobe mortar and plaster

- $\quad$ Corrugated zincalume steel. 


\subsubsection{Lifetime of Components and Materials}

To calculate an annualised rate, each item in the house was assigned a life expectancy, according to available data (Alsema, 2000; EECA, 2001; Dunford, 2004; Johnstone, 2004; Page, 2005; Bennet, 2008; Greenspec, 2009). The energy and $\mathrm{CO}_{2}$ totals for each item were divided by their life expectancy to derive an annual embodied energy or $\mathrm{CO}_{2}$ emission value.

The important design strategies to reach the sustainable target were only slightly affected by materials' lifetimes. Some materials, such as concrete floors and the hardfill under them, became relatively less significant as house lifetimes increased, and their impact was amortised over a longer time. Others, such as paint, which get replaced at shorter intervals, became relatively more significant. Appendix A lists lifetimes for various materials used in this thesis. Table 9.2 shows a selection.

Some of the values, for which there is no published life expectancy data, are necessarily estimates, based on experience by construction professionals. These are discussed in the following sub-sections on certain materials. Some published lifetimes seem unlikely, such as 50 years for any insulation, in Bennet. In the absence of other data, however, these lifetimes were applied.

Table 9.2 Life Expectancy of Selected Materials (years)

\begin{tabular}{lc|lc}
\hline Material & Life expectancy & \multicolumn{1}{c}{ Material } & Life expectancy \\
\hline Aluminium windows & 35 & Steel roofing & 50 \\
Concrete in floors & 150 & Timber, external framing & 90 \\
Gypsum plaster board & 50 & Timber, internal framing & 150 \\
Insulation & 50 & Timber, cladding & 70 \\
Paint & 8 & Solar hot water system & 20 \\
\hline
\end{tabular}

\subsubsection{Aluminium}

Material lifetime figures are especially important for high EE and high emissions materials. Bennet, for example, quotes 25-40 years for aluminium windows. 35 years is assumed in this analysis. It is conceivable that with careful maintenance aluminium windows could last for, say, 70 years. Lasting that long, aluminium windows showed a moderate emissions decrease, of up to $6.7 \%(78 \mathrm{~kg} / \mathrm{yr})$. 


\subsubsection{Concrete, Earth and Associated Materials}

Bennet quotes a 100 year lifetime for concrete in walls, and 80 years for concrete masonry. Concrete floors are not mentioned. For this analysis, floors were rated as lasting the 150 year life of the house. Hardfill, sand blinding, and DPM were given this same 150 year rating.

Bennet says the durability of earth walls is, "over 100 years... where the walls are well protected". Because of their susceptibility, earth walls are accorded special weather protection, now formalised in the Earth Building Standards (Standards, 1998), and consequently have a relatively long life expectancy. There are many earth houses in New Zealand over 150 years old, in spite of variable design and maintenance standards. 150 years was adopted as the lifetime for earth walls.

\subsubsection{Insulation}

All the insulation materials covered in Bennet are given "serviceability" intervals of 50 years, except macerated paper, which is known to move with draughts. Underfloor foil, while not listed by Bennet, was also accorded a 50 year life, consistent with other insulation. Although polystyrene has a 50 year serviceability rating in Bennet, historically very little polystyrene was used as insulation that long ago, giving little information to base such durability findings on. The actual performance-in-place of the many different insulation materials covered in Bennet would vary. More precise insulation lifetimes may show significantly different results for thermal analyses, especially for wall insulation, for example, but such data was unavailable.

A 50 year life expectancy is used for insulation, except where surrounding materials make it unlikely to be replaced at that interval. Insulation under floor slabs is given the same life as the floor, and in walls the same life as masonry or the cladding on timber walls, as applicable.

\subsubsection{Framing Timber}

The significance of inorganic insulation lifetimes is high because of their high EE and $\mathrm{ECO}_{2}$ coefficients. The uncertainty around structural materials' lifetimes, 
especially framing timber, accentuates insulation's significance. Bennet does not quote expected lifetimes for framing timber. Page (2005) quotes 90 years, which coincides with Johnstone's figure for life expectancy of pre-1980 houses. Anecdotal evidence suggests that while some framing timber may need replacement, the majority of the frame will remain in good condition for the life of the house, at least to the 150 year period. In the absence of more certain data, however, the 90 year interval of Page and Johnstone is adopted for the lifetime of external framing timber, and 150 years for internal wall framing. Framing nails were given the same life expectancy as the respective framing.

A 90 year framing lifetime also has implications for the insulation below the floor, and in walls and ceiling. If insulation, which is a big contributor to the overall $\mathrm{CO}_{2}$ total, is replaced more often - along with, and at the replacement times for framing timber for floor, walls, or ceiling, then bio-based insulation such as strawbale, gives a significant reduction in the overall emissions total, while manufactured insulation such as XPS gives a significant increase.

\subsubsection{Other Timber}

Timber floorboards are not addressed specifically by Bennet. They were assumed to be capable of lasting the life of the house, since many exposed original floorboards in old houses are still in sound condition.

Page (2005) gives treated radiata weatherboard a 70 year life expectancy. External windows and doors are generally of a stronger, more stable and durable timber. They are given a 90 year life expectancy, which matches that of window glass and timber framing. Timber internal doors are expected to last the life of the house.

\subsubsection{Strawbale}

Strawbale is known to last at least 100 years in buildings (Steen et al., 1994). It may last longer if properly installed and maintained. It was given a 90 year life expectancy, however, to match that of timber framing. 
While most materials are net emitters of $\mathrm{CO}_{2}$, bio-based materials are net absorbers. A longer lifetime for most materials reduces annualised emissions, but for bio-based materials, a shorter lifetime reduces emissions, because more $\mathrm{CO}_{2}$ is stored and ultimately sequestered in landfill despite some carbon release from decomposition. Reducing framing timber and strawbale insulation lifetimes to 50 years reduces annual emissions for the 2020 s strawbale houses on average by $19 \%$ and $22 \%$ respectively.

\subsubsection{End-of-Life Carbon Loss in Landfills}

Landfilled bio-materials partially rot, releasing some of their sequestered carbon. To calculate long-term sequestration of land-filled timber and straw materials, carbon loss rates need to be known. Studies by Micales and Skog (1997) and Ximenes et al. (2008) were used to derive an appropriate carbon loss rate for bio-materials. Ximenes et al. determined a carbon loss rate of $18 \%$ for hardwoods and $17 \%$ for softwoods, but based on only a single very wet site. Without correcting for the higher loss rate from this anomalously wet site, but averaging all their sampled sites, the carbon loss rate was 5.7\%. Micales and Skog (1997) conducted a meta-study of carbon loss in landfilled wood materials, concluding a 0-3\% rate. Re-working their calculations to remove arithmetical mistakes showed a carbon loss rate slightly over $5 \%$ - close to the Ximenes et al. result. The carbon loss rate adopted for calculating net $\mathrm{CO}_{2}$ absorption was thus $5.7 \%$. Micales and Skog showed a carbon loss rate of $7.0 \%$ for straw, which was adopted.

These carbon loss rates translate into $\mathrm{CO}_{2}$ retained in the long-term, or sequestered, at a rate of $70 \%$ for timber and $63 \%$, for straw. This may, however, understate actual sequestration of carbon in bio-based building materials in well-managed landfills.

\subsubsection{Paint Rates}

Paint re-coating frequency is related to the length of house ownership. Page (2005) estimates life of paint to be 9 years. Resene (2007) estimate exterior paint to be renewed at 7-10 years. Bennet quotes 5-10 years for external paint life, depending on colour and placement. The interval of 8 years coincides with the average time of usual residency of 8 years and the painting of houses in preparation for sale. An 8 year re-painting interval was adopted. 
Paint rates included wastage and leftovers of $10 \%$. For re-coating, a $20 \%$ equivalent area was allowed for spot priming. The painted area for corrugated steel roofs was calculated as $10.5 \%$ greater than the roof area to allow for the extra surface of corrugations. Coverage rates in $\mathrm{kg} / \mathrm{m}^{2}$ are from manufacturer's literature (Resene, 2007). All paint was assumed to be water based.

\subsubsection{Insulation and $\mathrm{R}$ Values}

The principal difference in the increasing 'age' of the ZALEH houses was increasing insulation and glazing $\mathrm{R}$ values, shown in Table 9.3 (Roose and Gowland, 2005). The 2020s house was conceived in ZALEH as super-insulated and triple glazed, to model the effects of high thermal performance and minimal heating requirements.

Table 9.3 ZALEH Insulation R Values: $200 \mathrm{~m}^{2}$ House

\begin{tabular}{lcccc}
\hline & 1970s & 2000s & 2010s & 2020s \\
\hline Slab floor & 0.19 & 1.33 & 1.89 & 7.19 \\
Suspended floor & 1.33 & 2.69 & 3.79 & 10.59 \\
Heavy wall & 0.60 & 1.00 & 3.62 & 7.68 \\
Light wall & 1.50 & 1.90 & 3.62 & 7.68 \\
Ceiling + roof & 3.12 & 3.12 & 5.61 & 10.61 \\
\hline
\end{tabular}

The minimum required thickness of insulation was assessed, for all houses, based on the ZALEH model for the whole-wall. This accounted for the $\mathrm{R}$ values of the: timber framing (typically 15\% of the area); external surface; weatherboard; building wrap; gypsum plaster board; the internal surface; and masonry wythes, as appropriate. After including these contributions, the insulation thickness was that which was required to bring the whole-wall to the specified ZALEH R value.

The 2020s R7.68 for walls was too much for the specified $100 \mathrm{~mm}$ studs. Even with XPS, $204 \mathrm{~mm}$ of insulation was required, with doubled 94 x $47 \mathrm{~mm}$ studs, spaced apart to create the necessary thickness. Similar adaptations were made as needed to other ZALEH construction details, consistent with normal construction practice. 
Fibreglass was used for wall and ceiling insulation for the 1970s, 2000s, and 2010s houses. It should be noted that New Zealand data for fibreglass insulation has not been obtainable from New Zealand manufacturers. This necessitated the use of some overseas data, which is likely to be a good proxy for New Zealand conditions, although the high hydro content of local electricity is likely to show $\mathrm{CO}_{2}$ emissions lower than overseas values if appropriate local data could be included. Wool insulation was considered at the outset, but sufficient data for wool production and processing was unobtainable.

EPS was used as floor insulation for the 2000s and 2010s houses, while the 1970s houses had no floor insulation other than the concrete slab and hardfill, and foil for the suspended floors. For the 2020s houses, XPS was used for floor, wall and ceiling insulation, except for the straw bale houses, which used straw for wall, ceiling and suspended timber floors. Floors and ceilings had more capacity for insulation thickness but XPS was still used to remain within feasible dimensions for the highly insulated houses and to keep the 2020 houses similar to the earlier ones. The 2020s houses' suspended floor insulation thickness was still $273 \mathrm{~mm}$ with XPS, and the ceiling $289 \mathrm{~mm}$.

Insulation was calculated to the nearest millimetre because of the significance in emissions of assuming more than necessary to achieve specified R-values. Other materials quantities, EE, and emissions were calculated accordingly. In practice, insulation would be supplied at standard thicknesses - perhaps to the nearest $10 \mathrm{~mm}$. Using the nearest standard size above the minimum would increase $\mathrm{R}$ values, decrease heating energy, and increase EE and emissions. These factors were not accounted for, but may be assumed to accentuate the impact of inorganic insulation, and the comparative benefits of bio-based insulation. A local company makes "concertina" shaped polystyrene insulation which is readily cut to the nearest $10 \mathrm{~mm}$, and is laterally compressible, to firmly fit different framing gaps (Isaacs, 2010). 


\subsubsection{Floors}

\subsubsection{Concrete Slab Floors}

Hard-fill and sand under concrete slabs were treated as distinct from the levelled ground, with their energy and $\mathrm{CO}_{2}$ coefficients accounted for. They were treated as one for analytical purposes, however, since both have similar emission rates, similar production methods and sources, and because they form a very small part of the emissions total $(0.03 \%)$. DPM was included, but the energy and emissions for site levelling or other site preparation were not.

The insulation specified in ZALEH was followed for the 2000s and 2010s houses, but the 2020s floor insulation was only described as "super insulation". XPS was used to achieve the required R 7.19 within a manageable $200 \mathrm{~mm}$ thickness and with minimum change to other foundation details. The concrete slab floor for the garage was un-insulated in all the houses modelled.

$30 \mathrm{MPa}$ concrete was used to represent the high density and high thermal mass concrete specified in ZALEH. While 17.5 MPa concrete would be more common for floor slabs, using it instead of $30 \mathrm{MPa}$ concrete would reduce the distance-totarget by less than $1 \%$, and $\mathrm{CO}_{2}$ by $15 \mathrm{~kg} / \mathrm{yr}$, for each concrete floor house.

The reinforcing steel for concrete slabs was calculated as $100 \%$ recycled steel, following New Zealand manufacturing practice.

Table 9.4 shows the materials used in concrete slab floors, and the houses to which each material applies. The 1970s houses had no insulation under the slab.

\section{Table 9.4 Concrete Slab Floor Materials}

\begin{tabular}{lcccc}
\hline Materials modelled & 1970s & 2000s & 20105 & 2020s \\
\hline Hard-fill & $\mathrm{X}$ & $\mathrm{X}$ & $\mathrm{X}$ & $\mathrm{X}$ \\
DPM & $\mathrm{X}$ & $\mathrm{X}$ & $\mathrm{X}$ & $\mathrm{X}$ \\
Insulation EPS & & $46 \mathrm{~mm}$ & $72 \mathrm{~mm}$ & \\
Insulation XPS & & $\mathrm{X}$ & $\mathrm{X}$ & $\mathrm{X}$ \\
30MPa concrete & $\mathrm{X}$ & $\mathrm{X}$ & $\mathrm{X}$ & $\mathrm{X}$ \\
Steel: reinforcing & $\mathrm{X}$ & & & \\
\hline
\end{tabular}




\subsubsection{Suspended Timber Floors}

Rough-sawn softwood timber, pressure treated with copper-chrome-arsenic, was assumed for piles, braces and bearers. Timber piles were set in $30 \mathrm{MPa}$ concrete to match the concrete specified in ZALEH. Dressed, treated, softwood timber was assumed for joists and blocking. Floorboards were assumed to be dressed, untreated timber, rather than particle board or other sheet material. This strategy followed the goal of minimising emissions, and the absence of carpet. Bolts and nails for all floor and subfloor timber were assumed to be galvanised, from recycled steel.

XPS was used in 2020s suspended floors to achieve R10.59 within a manageable thickness. For 2000s and 2010s houses, EPS was sufficient. The 1970s houses only had reflective foil. Table 9.5 shows the materials modelled for timber floors.

Table 9.5 Suspended Timber Floor Materials

\begin{tabular}{lcccc}
\hline Materials modelled & 19705 & 20005 & 20105 & 2020s \\
\hline 30 MPa concrete: footings & $X$ & $X$ & $X$ & $X$ \\
Timber, rough-sawn: piles, bearers, braces & $X$ & $X$ & $X$ & $X$ \\
Timber, treated, dressed: joists, blocking & $X$ & $X$ & $X$ & $X$ \\
Timber: floorboards & $X$ & $X$ & $X$ & $X$ \\
Steel, galvanised: nails and bolts & $X$ & $X$ & $X$ & $X$ \\
Foil & $X$ & $X$ & $X$ & $X$ \\
Insulation, EPS & & $70 m m$ & $76 \mathrm{~mm}$ & \\
Insulation, XPS & & & & $273 m m$ \\
\hline
\end{tabular}

\subsubsection{Walls}

\subsubsection{Lightweight Exterior Walls}

Weatherboards were modelled as $180 \times 18 \mathrm{~mm}$ bevel-back, with a cover of $148 \mathrm{~mm}$. External wall framing timber and weatherboard were assumed to be treated dressed pinus radiata, kiln dried with predominantly waste firing. Rough-sawn timber for framing would give greater $\mathrm{CO}_{2}$ absorption, due to the larger member dimensions, and would have lower embodied $\mathrm{CO}_{2}$ from lower machining requirements. For houses with timber framed walls and floors the $\mathrm{CO}_{2}$ emissions difference for roughsawn is up to $16.9 \mathrm{~kg} / \mathrm{yr}$, a $0.77 \%$ reduction in the distance-to-target. Dressed timber was modelled, however, to be consistent with current construction practice. 
Polyethylene sheet building wrap was calculated, rather than bitumen building paper, according to current practice. At $<0.1 \%$ of total annual emissions for polyethylene wrap, the difference between it and building paper was too insignificant to calculate.

Ten millimetre gypsum plasterboard was calculated for walls and ceilings. Mining and transporting of overseas raw materials, but local manufacture of the sheet material was included in the energy and emissions coefficients.

Coefficients for nails included all New Zealand recycled steel content. Nail quantities and types for framing, cladding, and lining were in accordance with nailing schedules in NZS3604. Framing nails were mild steel; cladding and lining nails were galvanised. Screw fastening would show virtually no difference in embodied energy or emissions because of the similar quantities and material.

Initial and subsequent painting coverage rates and re-coating frequency are in accordance with manufacturers' recommendations (Resene, 2007). Weatherboard paint included initial coats on both sides, and top and bottom edges, but with subsequent coats only on the exposed surfaces of in-place boards.

Table 9.6 shows the materials modelled for timber framed walls. Fibreglass insulation was sufficient to achieve the R values specified in ZALEH for the 1970s, 2000s and 2010s houses. For the 2020s house, XPS was needed to achieve the high $R$ values in a manageable wall thickness.

Table 9.6 Lightweight Exterior Wall Materials

\begin{tabular}{lcccc}
\hline Materials modelled & 1970s & 2000s & 2010s & 2020s \\
\hline Timber, dressed, framing & $94 \mathrm{~mm}$ & $94 \mathrm{~mm}$ & $144 \mathrm{~mm}$ & $94 \mathrm{~mm} \times 2$ \\
Nails, bright, framing & $\mathrm{X}$ & $\mathrm{X}$ & $\mathrm{X}$ & $\mathrm{X}$ \\
Building wrap & $\mathrm{X}$ & $\mathrm{X}$ & $\mathrm{X}$ & $\mathrm{X}$ \\
Timber, weatherboard & $\mathrm{X}$ & $\mathrm{X}$ & $\mathrm{X}$ & $\mathrm{X}$ \\
Nails, galvanised, cladding & $\mathrm{X}$ & $\mathrm{X}$ & $\mathrm{X}$ & $\mathrm{X}$ \\
Insulation, fibreglass & $37 \mathrm{~mm}$ & $60 \mathrm{~mm}$ & & \\
Insulation, XPS & & $\mathrm{X}$ & $\mathrm{X}$ & $\mathrm{X}$ \\
Gypsum plaster board & $\mathrm{X}$ & $\mathrm{X}$ & $\mathrm{X}$ & $\mathrm{X}$ \\
Nails, galvanised, lining & $\mathrm{X}$ & $\mathrm{X}$ & $\mathrm{X}$ & $\mathrm{X}$ \\
Paint & $\mathrm{X}$ & & & \\
\hline
\end{tabular}




\subsubsection{Heavyweight Exterior Walls}

Heavyweight construction was only modelled for 2020s houses. The materials modelled were:

- $\quad$ Concrete outer wythe, $17.5 \mathrm{MPa}$

- $\quad$ Concrete inner wythe, $30 \mathrm{MPa}$

- Cement plaster

- Adobe

- $\quad$ Adobe mortar and plaster

- Insulation, XPS

- Steel reinforcing

- Paint.

Two heavyweight houses were modelled: concrete and earth. To match the thermal mass properties specified in ZALEH, "high density" $30 \mathrm{MPa}$ concrete was employed for the inner wythe of the concrete external walls. To achieve the insulation values specified in ZALEH, $210 \mathrm{~mm}$ of XPS was necessary. This thickness of XPS was deemed too vulnerable to damage with simply a coat of cement plaster. A second, outer wythe of $17.5 \mathrm{MPa}$ concrete masonry was therefore modelled, with the insulation sandwiched between. ZALEH specified $150 \mathrm{~mm}$ of concrete for the inner wythe. The outer wythe was modelled as $100 \mathrm{~mm}$. Internal walls were $150 \mathrm{~mm}$ single wythe only.

To match the thermal specifications of ZALEH, the adobe earth walls were treated the same as the concrete walls, with two $150 \mathrm{~mm}$ wythes tied together. Insulation was slightly thinner, at $202 \mathrm{~mm}$, because of earth's slightly higher R value. Internal walls were modelled as single wythes of $300 \mathrm{~mm}$ (Standards, 1999b). The thermal capacity of earth and concrete are sufficiently similar $(\sim 0.75 \mathrm{~kJ} / \mathrm{kg} . \mathrm{K})$ to not affect the ZALEH thermal results (Houben and Guillard, 1994).

Steel reinforcing for concrete and earth walls followed NZS4229:1999 and NZS4299:1998, respectively (Standards, 1999b; 1998). 
Concrete and earth walls were finished with cement based or earth plaster, respectively, of $5 \mathrm{~mm}$ thickness. The earth plaster was assumed to be the same material as the adobe mortar and the adobe blocks themselves for energy and emissions purposes.

Adobe typically contains a small amount of straw, conferring a slight net $\mathrm{CO}_{2}$ absorption. Houses using rammed earth, poured earth, pressed brick, or cement stabilised adobe, of similar dimensions, would have higher annual $\mathrm{CO}_{2}$ emissions.

Paint rates for the concrete walls were calculated in the same way as lightweight walls: initial undercoats were calculated as lasting the life of the wall, and subsequent coats lasting 8 years. The earth walls were unpainted.

\subsubsection{Roofing}

Steel roofs, for all the 2000s and 2010s, and most of the 2020s houses, were calculated as pre-painted $0.4 \mathrm{~mm}$ zincalume, with re-painting every 8 years. Prepainted long-run steel that gets repainted can last 50 years (Page, 2005), which is the adopted roof life for 2000s, 2010s, and 2020s houses. It was assumed that 1970s houses did not have pre-painted steel, so a life of 30 years was adopted. It should be noted that while re-painting can extend the life of pre-painted steel roofs, re-painting may be done at less than optimum intervals. While this would reduce the emissions from paint, it is likely that the increased emissions from more frequent roof renewal would increase emissions more.

For the single 2020s concrete tile roof example, the tile mass was modelled as $55 \mathrm{~kg} / \mathrm{m}^{2}$ (CSR, 2009). An increase of 30\% was allowed for the timber framing to accommodate the extra roof weight (Standards, 1999a).

For the 2020s houses with timber shingle roofs, $400 \mathrm{~mm}$ treated radiata shingles were assumed, $10 \mathrm{~mm}$ thick at the butt, tapering to $2.5 \mathrm{~mm}$ thick at the tip, with triple overlap. 
The quantity of fasteners for tile and shingle roofs was not re-calculated relative to steel roofs, since roof fasteners account for only $1.6 \%$ of all the fasteners in the house, and $0.01 \%$ of all materials emissions.

Polyethylene based building paper was adopted for all roofs.

\subsubsection{Framing Calculations}

The timber framing for each of the lightweight houses is based on NZS3604. To acknowledge the likelihood of increasing strong wind events related to climate change, a high wind zone was assumed when determining framing member dimensions. Floor joist, stud, ceiling joist, rafter, purlin, blocking, and dwang spacings were chosen to match NZS3604 requirements, standard sheet sizes, and to maximise the use of member sizes. The maximum permitted cantilever of bearers beyond outer piles was employed to minimise the number of piles necessary. The strategy of maximising the potential of individual framing members, given NZS3604 specifications, reduces the amount of timber that might be used to construct a house, and thereby reduces the sequestered carbon and the ability of the house to reach the sustainability target. However, maximising individual framing members' potential matches common design and construction practice.

The ZALEH house plan was modelled as three rectangles, with each rectangle calculated separately for member size and spacing. The dimensions of each rectangle could be separately altered in the calculator, with the number of framing members for the changed dimensions computed accordingly. In this way, it was possible to readily model a house of greater or lesser floor area to show the consequent changes to overall embodied energy and $\mathrm{CO}_{2}$ emissions.

Stud height was $2.7 \mathrm{~m}$, following the ZALEH model. Internal walls and wall surfaces, and consequent materials such as linings and paint, were calculated on this basis. External wall heights were the basis of cladding calculations, however, so were calculated with $150 \mathrm{~mm}$ above and below ceiling and floor levels for weatherboards. $540 \mathrm{~mm}$ was allowed below the wall cladding for sub-floor enclosure with spaced boards. Additional studs were included for window and door openings, and corners 
of walls. Top and bottom plates, and window and door lintels, were as per NZS3604. Door widths were taken as $900 \mathrm{~mm}$ for external doors and $800 \mathrm{~mm}$ for internal ones.

All timber sizes were based on actual finished dimensions. Thus, a nominal $100 \times 50$ stud was calculated as $94 \times 47 \mathrm{~mm}$. These were variable in the calculator, to accommodate specific sizes, such as roughsawn studs at $100 \times 50 \mathrm{~mm}$.

Stud sizes followed NZS3604, except where insulation required greater than $100 \mathrm{~mm}$ wall thickness. Ex 150 x 50 studs were calculated for the external walls of the 2010s houses. For the 2020s houses two ex 100 x 50 studs were employed in the external walls, to accommodate the insulation, with dwangs to connect both rows of studs. The straw bale walls were treated similarly, except that stud spacing was increased from 600 to $900 \mathrm{~mm}$ to suit straw bale dimensions. The straw bale walls thus had less timber in them than the XPS insulated walls, although the sequestered $\mathrm{CO}_{2}$ in the straw was greater than that in the 'missing' studs.

Roof framing member sizes and spacings were calculated on the basis of a light roof, except for the concrete tile roof. Eaves and verges were calculated as $300 \mathrm{~mm}$ for timber walls, and $600 \mathrm{~mm}$ for earth and straw bale walls but could be further varied within the calculator. Ceiling joist and rafter lengths were changed accordingly. The number of purlins depended on rafter length according to the varying wall thicknesses. The heavyweight 2020s house, with thick insulation or masonry walls, requiring longer roof framing members used proportionately more roofing materials. The thick straw bale walls necessitated even more roof area. The earth house, with thick insulation and wythes, required the largest roof. Floor materials quantities were increased according to the varying wall thickness for the different insulation materials.

Strutting beams and struts were calculated to suit the ZALEH house design, utilising internal walls for support where possible. Other designs may have a higher, or lower, ratio of these members, although such variations are unlikely to have a large impact 
on the results. Using strutting beams for the ZALEH designs instead of internal wall supports affected total emissions by only $0.17 \%$.

A wastage rate for all timber items of $4 \%$ was included, based on findings of the NOW HOME (Beacon, 2005). Beacon note that nearly all timber wastage is landfilled.

The numbers and dimensions of nails for every joint between all framing members were according to NZS3604. Z nails were calculated as two $100 \mathrm{~mm}$ nails, to simplify calculations.

The variations described were included in all dependent calculations for each house.

\subsubsection{Windows and Doors}

Window and external door frames were calculated as factory painted aluminium extrusions, except for Houses 11 to 14, which were timber, using the same painting regime as for weatherboards. The quantities for each of the 18 windows were calculated from their dimensions and the measured mass for each different extrusion, according to results of a survey of finished-window manufacturers, undertaken for this thesis. ZALEH did not specify window details beyond the overall dimensions. Mullions and opening sashes were therefore assigned to each window, to account for the number of individual extrusions. Hinges were assumed to be stainless steel, and latches aluminium. Window reveals were assumed to be timber, and replaced at the same interval as the windows.

ZALEH employed single glazing in the 1970s house, double in the 2000s house, double with low-e coating in the 2010s house, and triple glazing in the 2020s house. The respective $\mathrm{R}$ values were $0.18,0.33,0.50$, and 0.60 . These glazing specifications were observed in calculations, with appropriate thicknesses for the individual glass sheets. Glass thickness could be altered in the calculator, to reflect different wind loadings, for example. A decrease in glass thickness of $20 \%$ from $6 \mathrm{~mm}$ to $4.8 \mathrm{~mm}$ showed a reduction in annual $\mathrm{CO}_{2}$ emissions, on average, of nearly $1.5 \%$, and over 
$1.8 \%$ for optimised houses with triple glazing. This is currently a possibility only for certain window dimensions, but illustrates the scale of possible emissions reductions.

The ZALEH dimensions and positions of windows were followed to maintain heating data validity, which is affected by solar gain. All glazing from floor level to one metre must be safety glass. Toughened glass was assumed for parts of windows and glass doors that had a piece of glass at this level. Ordinary float glass was 53\% by weight, and toughened glass $47 \%$. Because more energy (typically gas) is used to reheat glass during the toughening process, its total embodied energy and $\mathrm{CO}_{2}$ emissions are some 65 and 40 percent higher, respectively, than float glass. Laminated glass, which could be used instead of toughened, has only slightly higher embodied $\mathrm{CO}_{2}$ emissions, but is less commonly used because of cost. Using laminated glass where safety glass is needed reduced overall emissions by $0.5 \%$, on average, and by up to nearly $0.9 \%$ for the optimised houses.

External doors were aluminium, except in the houses with timber joinery. Internal doors were all timber. Aluminium doors and windows were given the same life expectancy.

\subsection{Input Parameters: Energy}

\subsubsection{Operating Energy}

Operating energy data was taken from the household energy end-use project (HEEP) (Isaacs et al., 2006). This was modified using heating data from ZALEH. The HEEP energy types for heating were applied to the ZALEH heating values to derive emissions. Because of the ZALEH specificity, the heating energy was different from the average HEEP heating energy, and thus the total operating energy was different from the HEEP total.

The HEEP energy types and proportions for each of the operating energy categories were used to determine emissions for each category. The hot water value used was a national average using HEEP proportions for hot water, and regional energy use figures. Specific hot water values for the different regions were not stated in HEEP. 
A similar method was used to derive national averages for refrigeration, lighting, cooking, and "other" operating energy. Each of these was variable within the calculator to enable application of regional energy patterns. It should be noted that the cooking category is labelled "Range" in the Figures, using HEEP terminology. Cooking energy only applies to the range, and not to other cooking appliances, such as toasters or microwave ovens, which are counted under "Other operating".

\subsubsection{Photovoltaics}

Multi crystalline PV panels were analysed for the embodied energy and $\mathrm{CO}_{2}$ emissions for both the panel and mounting frame, to derive an annual net energy and $\mathrm{CO}_{2}$ balance. An area of $10 \mathrm{~m}^{2}$ was assumed, adjustable within the calculator. Cell efficiency was $16 \%$, with globally average insolation of $1,700 \mathrm{kWh} / \mathrm{m}^{2} / \mathrm{yr}$ (Alsema, 1998). The contribution of PV panels towards reducing $\mathrm{CO}_{2}$ emissions was $435 \mathrm{~kg} / \mathrm{yr}$, for panels of $10 \mathrm{~m}^{2}$. By adding PV to House 11, total $\mathrm{CO}_{2}$ emissions were reduced from $987 \mathrm{~kg} / \mathrm{yr}$ to $552 \mathrm{~kg} / \mathrm{yr}$, or $44 \%$. This shows that although PV panels have a high embodied energy and a relatively short lifetime of 25 to 35 years (Alsema, 1998), they are able to make a major contribution to net $\mathrm{CO}_{2}$ emissions reductions on an annualised or lifetime basis.

\subsubsection{Solar Hot Water}

A commonly available commercial solar hot water heater was analysed, including materials, transport, manufacturing, and capital equipment inputs. A per $\mathrm{m}^{2}$ output was calculated to enable alteration within the calculator for different collector panel areas. The average annual contribution of the solar collector to water heating was $63 \%$, using a collector area of $3.75 \mathrm{~m}^{2}$.

The contribution of solar hot water towards reducing $\mathrm{CO}_{2}$ emissions was $472 \mathrm{~kg} / \mathrm{yr}$, second only to a wind generator as the single most effective strategy for reducing emissions. By adding solar hot water to House 9, net $\mathrm{CO}_{2}$ emissions were reduced from $1,598 \mathrm{~kg} / \mathrm{yr}$ to $1,126 \mathrm{~kg} / \mathrm{yr}$, a $30 \%$ change. In spite of the short 20 year lifespan, solar hot water heaters are able to make a major contribution to net $\mathrm{CO}_{2}$ emissions reductions on an annualised or lifetime basis. 


\subsubsection{Wind}

A wind generator (see Section 8.6.3) was added as the final design strategy that moved the optimised House 13 beyond the sustainability target. Analysis was of a commonly used commercially available Soma 1000W wind generator, $100 \mathrm{~m}$ of copper cable for connection to the house, and a steel mounting tower with concrete foundations. The generator, cable, and tower were each assigned different life expectancies, adjustable within the calculator. $\mathrm{EE}$ and $\mathrm{ECO}_{2}$ were added to totals for the house, while the output from the generator was subtracted from the operational energy requirements and emissions profile of the house.

A wind speed of $8 \mathrm{~m} / \mathrm{s}$ was assumed, comparing, for example, to windier parts of California with an average wind speed of $7.5 \mathrm{~m} / \mathrm{s}$ (EECA, 1995; Soma, 2004). In New Zealand locations and specific sites with a lower average wind speed of $6 \mathrm{~m} / \mathrm{s}-$ equating to an average daily output of $7.3 \mathrm{kWh}$ for the Soma $1000 \mathrm{~W}$ - a larger nominal output wind generator would be needed to reach the sustainability target, or another on-site generation source, such as larger PV panels. In many urban locations wind generators are unsuitable due to turbulence from obstructions. In these instances much more PV, or other generation, would be needed to make up for wind generation.

\subsection{Significance and Implications}

\subsubsection{Hot Water, Heating and Insulation}

Hot water is the biggest contributor to $\mathrm{CO}_{2}$ emissions, across all conventional insulation strategies, emitting more than twice any other category for the 1970s house, as Figure 9.9 shows. This is due to hot water being a high energy user and predominantly heated with grid electricity, with a high emission factor. 
Figure 9.9 $\mathrm{CO}_{2}$ Emissions for Slab Floor, Timber Wall, Steel Roof Houses (kg/yr)

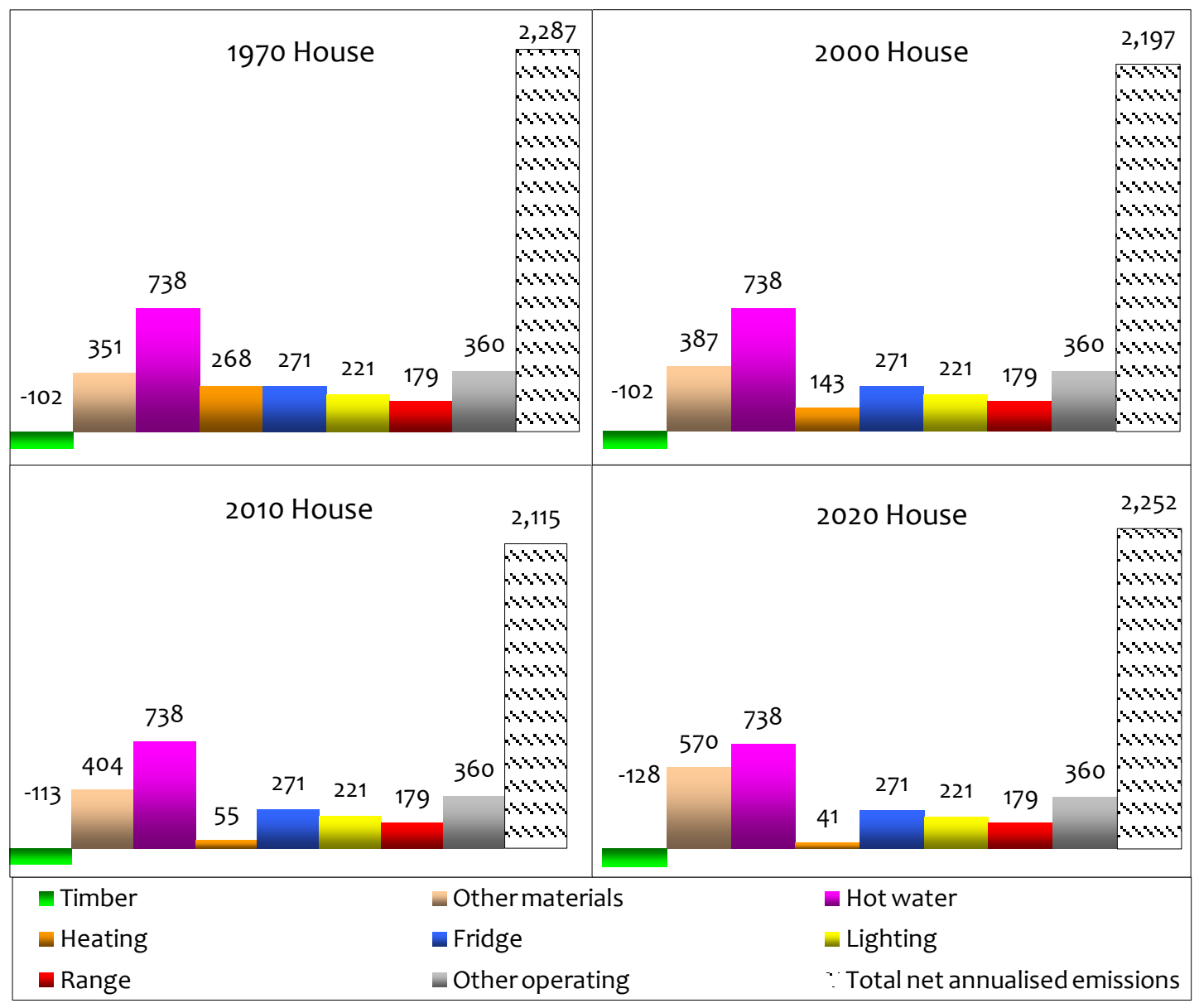

Surprisingly, heating emissions are the smallest energy-use category, for all household types and heating levels. This is largely due to firewood being the most used heating energy type in New Zealand (56\%) (Isaacs et al., 2006).

Firewood had the lowest $\mathrm{CO}_{2}$ emission factor $(-10.2 \mathrm{~g} / \mathrm{MJ})$ of all energy types. This is the net carbon balance after firewood is grown, cut, and burnt. It accounts for the carbon absorbed by the tree, carbon released by running the chainsaws and trucks, and carbon released by burning the firewood. This value should be treated cautiously, however, since variations such as wood density and moisture content could significantly change it.

Low heating emissions are dependent on firewood remaining the predominant heating energy source. If deliberate or inadvertent policy, economic, or household choices led to a greater use of electricity for heating, then total national heating 
emissions would rise. A move from firewood to heat pumps, for example, would cause national heating emission to increase, in spite of the technical efficiency of heat pumps. Given the reductions in emissions for heating from the widespread use of firewood, significant potential also exists for hot water heating emissions to benefit from this energy source.

Contrasted with firewood, electricity had the second highest emission factor (67 g/MJ), only slightly lower than LPG (68.4 g/MJ), even using average New Zealand grid $\mathrm{CO}_{2}$ emission values. The marginal electricity emission factor is $199 \mathrm{~g} / \mathrm{MJ}$. (See Section 7.3)

Changing the heating regime to the lowest level (DPB household) only resulted in total emissions reductions from $0.8 \%$ for the heavyweight House 1 , to $4.7 \%$ for House $13\left(\mathrm{CO}_{2}\right.$ of 21 to $\left.30 \mathrm{~kg} / \mathrm{yr}\right)$. Reducing heating, even by as much as 2/3, simply by heating to lower temperatures as in the DPB household, was a less effective strategy for emissions reduction than any other.

The change in emissions from the 1970s to the 2000s house came from the increase in insulation, which raises the "Other materials" total by $36 \mathrm{~kg} / \mathrm{yr}$, but reduces the heating emissions by $125 \mathrm{~kg} / \mathrm{yr}$, an overall reduction of $90 \mathrm{~kg} / \mathrm{yr}$, as Figure 9.10 shows. There is a similar change for the 2010s house, with a further net reduction of $82 \mathrm{~kg} / \mathrm{yr}$ to $2,115 \mathrm{~kg} / \mathrm{yr}$. 
Figure 9.10 $\mathrm{CO} 2$ Emissions \& Absorptions: Slab Floor, Timber Walls, Steel Roof $(\mathrm{kg} / \mathrm{yr})$

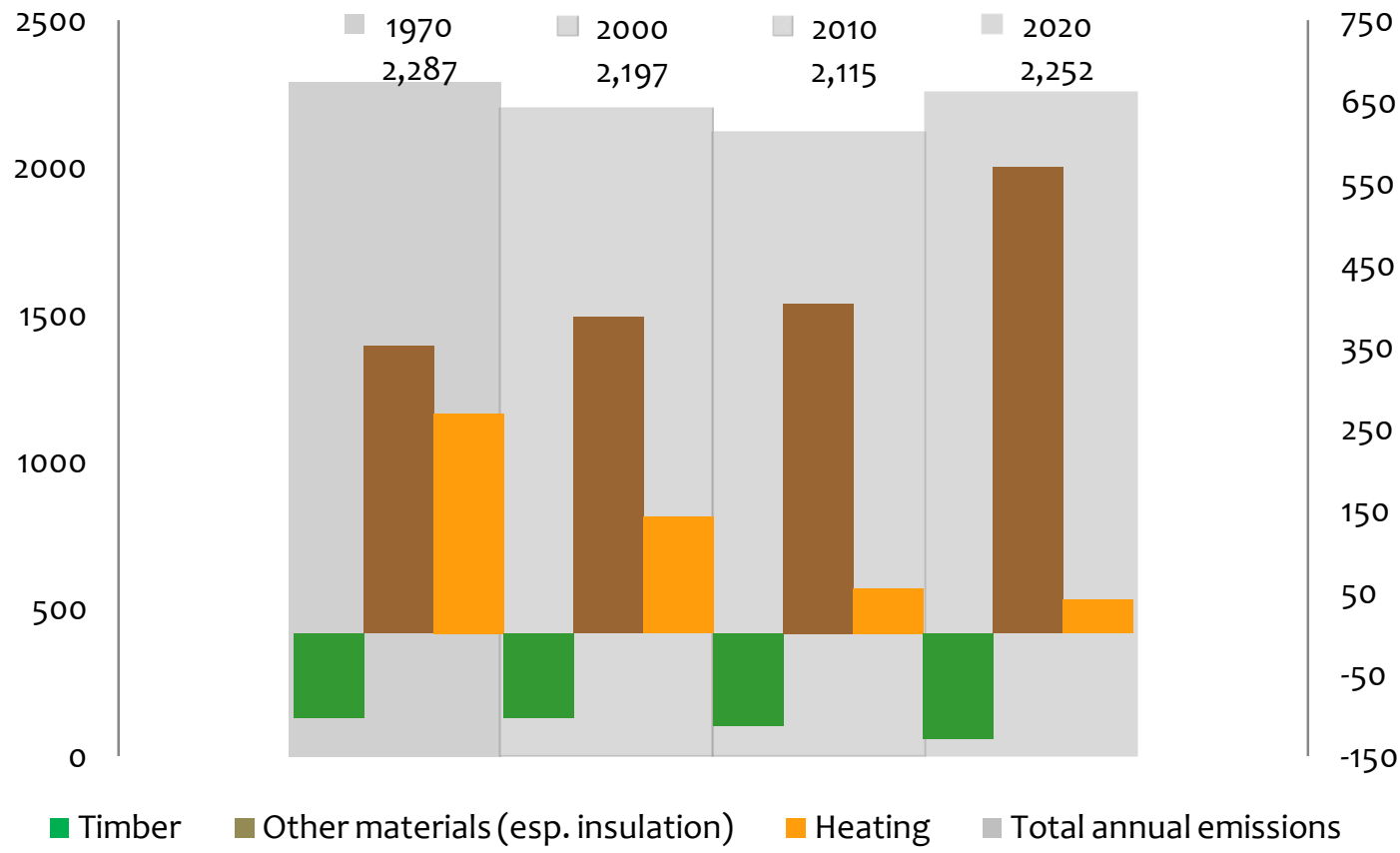

In the equivalent 2020s house, however, the net total rises again by $137 \mathrm{~kg} / \mathrm{yr}$ to $2,252 \mathrm{~kg} / \mathrm{yr}$. There is a reduction of $14 \mathrm{~kg} / \mathrm{yr}$ in heating emissions, but this is outweighed by the increased emissions from 'super' insulation.

The change in "Timber" from the 2000s to 2010s and 2020s houses (increased absorption) arises from the thicker framing required to accommodate more insulation, which contributes modestly to reduced total emissions.

When insulation is made of conventional materials such as fibreglass or polystyrene, it reduces total emissions up to but not beyond about R4 to R5 (the 2010s house). This is a different outcome than would be expected in a colder climate, where heating emissions would be more significant. The relative insignificance of heating emissions shown in this study is consistent with other warm climate analyses, such as Fay, Treloar and Iyer-Raninga's (2000) Australian study.

Further heating emissions gains can be made beyond $\sim \mathrm{R} 5$, but only if insulation is made of bio-based material, such as strawbale. For the 2020s house, using strawbale insulation in place of polystyrene reduces total $\mathrm{CO}_{2}$ emissions from 2,252 kg/yr to $1,904 \mathrm{~kg} / \mathrm{yr}$ : significantly lower than the 2010s house, as well as the 1970s and 2000s 
houses. Most of the reduction is due to the sequestered carbon in the straw, not the lower heating energy.

Figure 9.11 shows that as heating emissions fall, all other categories become relatively more significant, but only up to the 'optimal' insulation level of the 2010s house. For the 2020s house the large rise in emissions from the high amount of conventional insulation causes the "Other materials" category to grow more than the heating category shrinks, so all other categories also become proportionately smaller, back to approximately 1970 s emissions percentages. It should be noted that the timber $\mathrm{CO}_{2}$ flux in Figure 9.11 is an absorption, whereas all other $\mathrm{CO}_{2}$ fluxes are emissions.

Figure 9.11 Annualised $\mathrm{CO}_{2}$ Flux: Slab Floor, Timber Wall, Steel Roof Houses (\%)

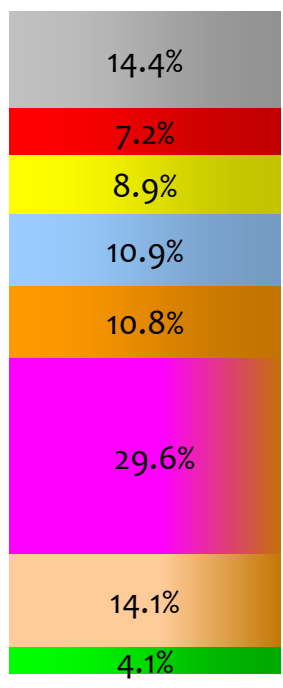

1970

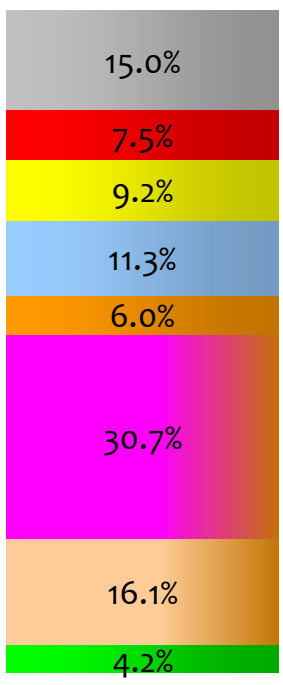

2000

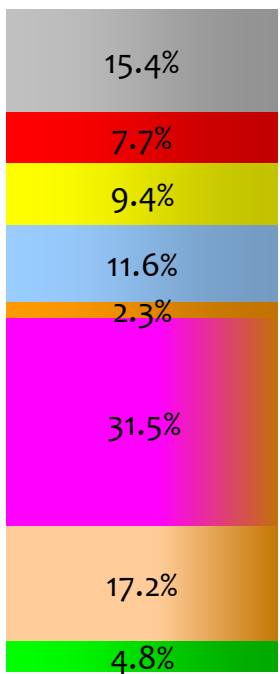

2010

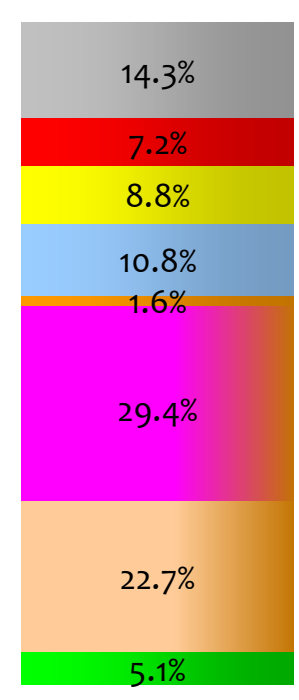

Other operating Range Lighting Fridge

Heating

Hot water

Other materials Timber

From an energy perspective, materials and hot water are by far the largest categories, totalling nearly $60 \%$ of all energy use. Heating, at a mere $4.3 \%$ is the least significant contributor. Even with current practice, in the 2000s house, heating is less significant than either hot water or materials.

These points may be summarised as:

- Hot water is the biggest emitter

- Materials are the second biggest emitter 
- When using conventional materials, insulate only to R5

- When insulating beyond R5, use only bio-based insulation materials (bio-based materials are better for lower $\mathrm{R}$ values too)

- Heating has less significant emissions than: hot water; construction materials, appliances, refrigeration, lighting, and cooking

- $\quad$ Refrigeration, lighting, and cooking all warrant further reduction effort.

\subsubsection{Emissions from Materials}

After hot water, the biggest emitter is construction materials as Figure 9.11 shows. Even in the 1970s house, where less insulation means lower materials emissions, and "Other operating" (mostly appliances) is very slightly higher than materials, actual materials emissions would still be greater, once plumbing, wiring and floor coverings were included.

Table 9.7 shows the trend in both energy and emissions, for the building fabric and for operating energy, as insulation levels are increased. The jump in embodied $\mathrm{CO}_{2}$ emissions for the 2020s house with thick polystyrene can be seen.

Table 9.7 Energy and Emissions: Concrete Floor, Timber Walls, Steel Roof

\begin{tabular}{lrrrr}
\hline & \multicolumn{1}{c}{ 1970s } & \multicolumn{1}{c}{ 20005 } & \multicolumn{1}{c}{ 2010s } & \multicolumn{2}{c}{ 2020s } \\
\hline Total annual embodied energy (MJ) & 7,490 & 8,114 & 8,792 & 12,193 \\
Total annual operating energy (MJ) & 39,021 & 33,551 & 29,705 & 29,080 \\
Total net annual Energy (MJ) & 46,511 & 41,664 & 38,498 & 41,272 \\
Total annual embodied $\mathrm{CO}_{2}$ emissions (kg/yr) & 249 & 285 & 291 & 442 \\
Total annual operating $\mathrm{CO}_{2}$ emissions (kg/yr) & 2,038 & 1,913 & 1,824 & 1,810 \\
Total net annual $\mathrm{CO}_{2}$ emissions (kg/yr) & 2,287 & 2,197 & 2,115 & 2,252 \\
\hline
\end{tabular}

It was apparent, by introducing timber floors, timber windows, straw bale insulation, and solar hot water, that reductions in materials with high emissions, increases in materials with high absorptions, and inclusion of renewable energy technologies had significant positive effects (see Table 9.8). These therefore became strategies for model variations in pursuit of the sustainability target. 
While timber framing is important in absorbing significant amounts of $\mathrm{CO}_{2}$, earth walls had smaller overall emissions than timber walls. This was due to avoided highemissions materials: insulation (that needed less frequent replacement because of the long life of the earth walls); gypsum board wall linings; and paint. Total emissions for the earth house were higher than for timber framed houses, however.

XPS, which has high embodied energy and $\mathrm{CO}_{2}$ emissions, was necessary to achieve the required $\mathrm{R}$ values for the 2020 s house within a manageable wall thickness, when common materials only were considered for selection. When the XPS was replaced with straw insulation (still an uncommon insulation material) however, the 2020s house outperformed all other houses in $\mathrm{CO}_{2}$ emissions. It was also the lowest in total energy use, with the exception of the 2020s earth house which had very slightly lower total energy use because of its high thermal mass advantage.

Until solar hot water had been added as a strategy, and timber windows had replaced aluminium ones (House 11) (see Figure 9.12), the total for "other materials" (excluding timber and strawbale) remained the largest $\mathrm{CO}_{2}$ emitting category. It fell to third lowest emitter afterwards.

\subsubsection{Lighting and Efficient Appliances}

Cutting lighting energy by $2 / 3$ achieved whole-house $\mathrm{CO}_{2}$ reductions between 5 and $31 \%$. Lighting energy in the 2020 s houses $(3,280 \mathrm{MJ})$ was more than twice the average heating energy (1,525 MJ). Reducing lighting from current levels by $2 / 3$ reduced $\mathrm{CO}_{2}$ emissions by $\sim 147 \mathrm{~kg} / \mathrm{yr}$, compared to heating at only $\sim 25 \mathrm{~kg} / \mathrm{yr}$. This is because lighting is all electric, whereas heating is only $24 \%$ electric and $56 \%$ firewood. This is consistent with the results from the top three strategy gains, which are related to grid electricity reduction. Reducing lighting electricity use in a well insulated house is thus an important strategy.

Similarly, for the top two energy consuming activities, 'other' and refrigeration, emissions reductions were significant. Cutting refrigeration energy by $2 / 3$ (approximating a top-performing fridge versus an average currently installed fridge) resulted in $\mathrm{CO}_{2}$ emissions reductions of between 7 and 38\% (181 kg/yr). 
Cutting 'other' energy use by $2 / 3$ resulted in emissions reductions of 9 to $50 \%$ if all maximum available efficiencies are applied. This is an unlikely amount however, with more realistically achievable $\mathrm{CO}_{2}$ reductions being between 3 and 19\% (90 kg/yr).

For House 13, (still beyond the sustainability target, but closer than Houses 1 to 12) the largest emitting categories were: 'other' operating (appliances); refrigeration; and lighting. By reducing appliance energy use to half the normal values to match the PV capacity, House 13 had total net $\mathrm{CO}_{2}$ emissions of $12 \mathrm{~kg} / \mathrm{yr}$. It was thus possible to reach the sustainability target without increasing the size of the PV panels, or solar water heater, or adding a wind generator.

The emissions reductions available by introducing efficient refrigeration, lighting, and appliances totalled less than the reductions available by introducing PV panels, of $10 \mathrm{~m}^{2}$, to House 12. For House 12, "other materials" was again the largest emitting category, so invited a further reduction strategy, by way of low-emitting materials substitutions (House 13).

Figure 9.12 Houses 11, 12, 13, and 14: $\mathrm{CO}_{2}$ Emissions/Absorptions (kg/yr)

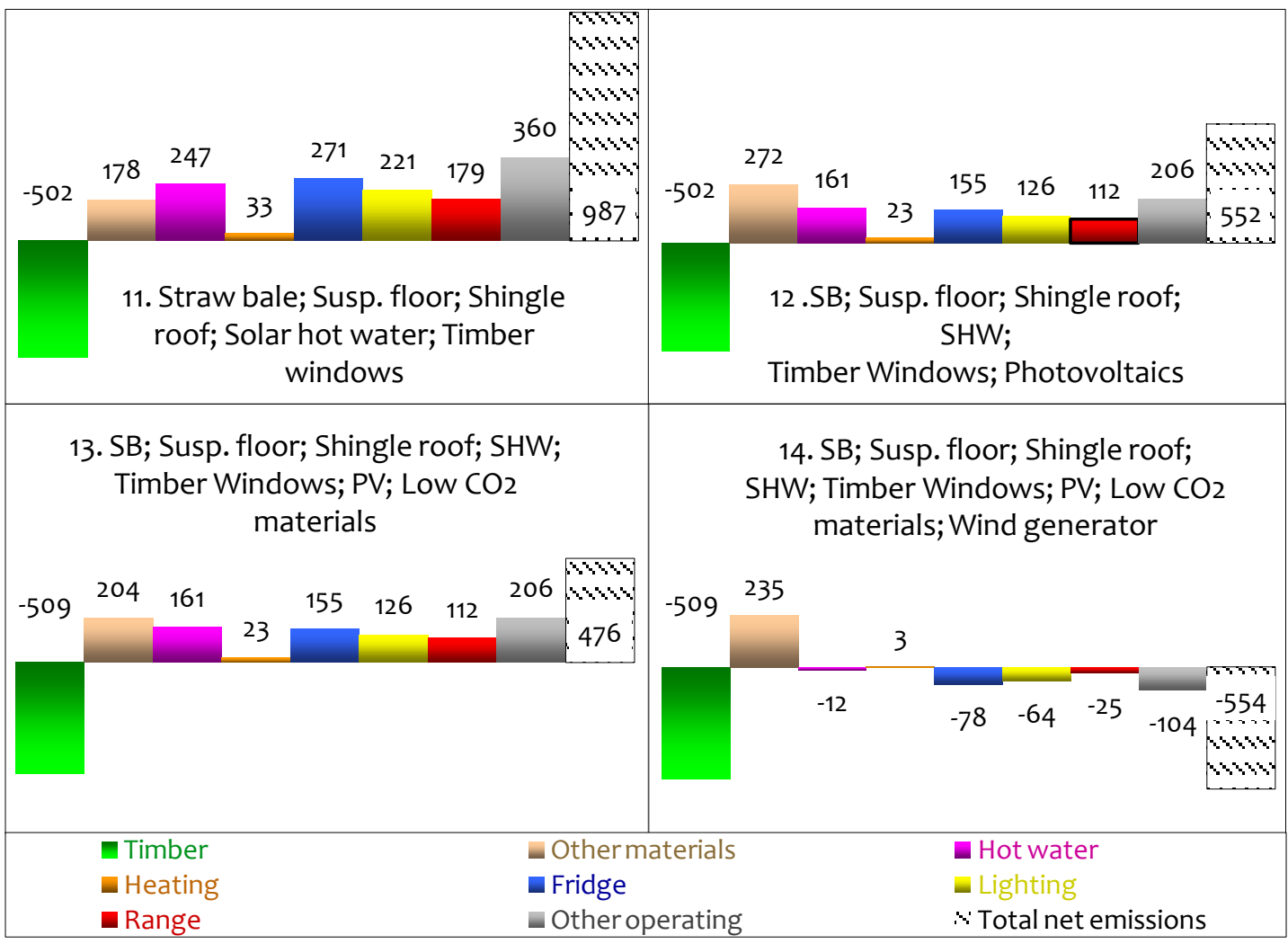


Introducing efficient refrigeration, lighting, and appliances to House 13 brought emissions below the "soft target", but not the "sustainable target". Furthermore, there was not sufficient leeway to accommodate the missing materials of carpet, wiring, plumbing and fit-out.

\subsubsection{Energy Generation}

A wind generator was introduced as the final strategy intervention to advance House 13 to both the soft and sustainable targets (House 14), and exceed them with sufficient margin to allow for the missing materials and any unaccounted for effects, such as persistent dry years in New Zealand's hydro-generation (which would increase the New Zealand grid $\mathrm{CO}_{2}$ emission factor).

The result of adding a wind generator, along with the PV panels and solar hot water system, was a negative embodied energy and emissions total for House 14. The house has not necessarily, however, achieved a net absorption of $\mathrm{CO}_{2}$. In practice, the excess generation may be exported to the national grid. This can be viewed as a national, and global, net emissions reduction, although it would be dependent on the freed-up capacity of the grid not being used by an 'additional' consumer, as described by Jevons' Paradox. The excess negative net emissions total can be seen as 'spare capacity' to allow the house to have a fluctuating emissions total, according to operational energy use, and still be under the sustainable target. Similarly, the negative net emissions total means there is a sufficient margin to account for other materials, such as wiring and plumbing that are not included in the calculator, or for data errors, and still be under the sustainable target.

Halving the tower lifespan increased net $\mathrm{CO}_{2}$ emissions by $20 \mathrm{~kg} / \mathrm{yr}$ for House 14 : net emissions for House 14, the only house to have a net absorption (i.e. negative emissions), changed from $-554 \mathrm{~kg} / \mathrm{yr}$ to $-534 \mathrm{~kg} / \mathrm{yr}$, or $3.6 \%$. Under this more pessimistic generator tower scenario, House 14 remains well within the sustainability target.

Introducing other operating energy strategies, such as gas-only cooking, greater firewood heating co-contribution to hot water, and further efficiency to lighting and 
appliances, could, in aggregate, have been used to move House 13 below the sustainable target without the need for a wind generator, and with a small margin to account for missing materials and other effects. The net effect of including carpet, wiring, plumbing, fit-out, furniture and furnishings remains unknown, however, so a larger margin to account for these may be needed for House 13, plus efficient lighting and appliances, for it to remain below the sustainable target. Further research needs to be undertaken to assess the scale of these factors.

\subsubsection{Zero Emissions without Photovoltaics or Wind}

The 1970s house required a reduction in its emissions total of $99.2 \%$ to reach the sustainability target. If this reduction is applied to both operating and construction emissions the target can only be reached without PV and wind generation if fridge, lighting, cooking and appliance emissions can somehow be reduced to near-zero levels. Even then, solar hot water, timber window frames, straw bale insulation, and all the preceding optimisation strategies are still necessary. Currently, the opportunities to include PV, wind generation and low carbon materials exist, whereas technologies to reduce operating emissions from grid-sourced electricity to less than $1 \%$ of current levels do not, and appear distant.

If the national grid used renewable sources only, thus becoming a very low $\mathrm{CO}_{2}$ emitter, the effect on house emissions, national emissions, and sustainability would be large, and individual houses could more easily reach the sustainable emissions target. This is, however, outside the scope of choosing strategies to make individual houses sustainable.

\subsubsection{Embodied Energy Importance}

Embodied energy for initial construction is equivalent to $8 \frac{1}{2}$ years of operating energy for 1970s houses (roughly equivalent to the average New Zealand housing stock); for 2000s houses (current construction practice), this rises to $10 \frac{1}{2}$ years, as operating energy drops and embodied energy rises with increased insulation. As the thermal performance and embodied energy rise concomitantly, this figure reaches nearly 14 years for 2010s houses and over 21 years for the equivalent 2020s house 
with slab floor and timber walls. That is, as the thermal performance of houses rises, at the expense of rising initial embodied energy, the relative importance of the embodied energy component increases.

This view, comparing initial embodied energy to operating energy, is distorted. A more complete view is obtained when maintenance and $\mathrm{CO}_{2}$ emissions associated with energy and materials production are considered on an annualised basis. Even if energy, and not $\mathrm{CO}_{2}$ emissions, is examined, heating can be seen to be a relatively small contributor to the whole.

Figure 9.13 shows the annualised energy percentages from construction and operating energy. In the 1970s house, operating energy is nearly $84 \%$, about 5 times initial embodied energy. This contrasts to the initial construction embodied energy/operating energy ratio of $81 / 2$, which does not annualise the embodied energy of the materials.

For the 2000s house, the operating energy is just over 4 times the embodied energy, while in the 2010s and 2020s houses the operating energy/embodied energy ratio falls to 3.4 and 2.4, respectively. In the 2020s house, the embodied energy, at just under $30 \%$, is larger than any of the operating energy categories. If the energy of floor coverings, plumbing, and wiring were included, embodied energy would be the largest category by an even larger margin, and approximately $1 / 3$ of the total.

In the 2020s house, collectively the operating energy categories are still more than double embodied energy. In picking low-hanging fruit for energy reductions, hot water and materials (excluding $\mathrm{CO}_{2}$-absorbing timber) are almost equal first choices. After them, "Other operating"; fridge; lighting; and cooking all rate greater than $6 \%$. Heating and timber are the smallest categories for seeking energy reductions, each less than $5 \%$.

\subsubsection{Embodied $\mathrm{CO}_{2}$ Importance}

The embodied $\mathrm{CO}_{2}$ perspective is broadly similar to embodied energy for houses with slab floor, timber walls and steel roofs, as shown in Figures 9.12 and 9.13. 
Materials are significantly lower, due to absorption from timber, while heating is significantly lower due to low emissions from the predominant heating energy, firewood. All other categories are therefore comparatively greater, due mostly to the smaller heating emissions, and timber absorptions.

Figure 9.13 Annualised Energy: Slab Floor, Timber Wall, Steel Roof Houses (\%)

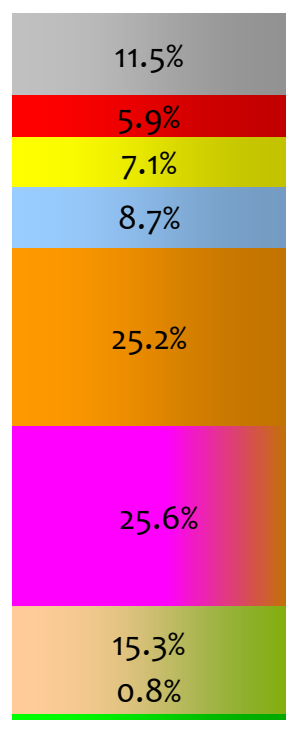

1970

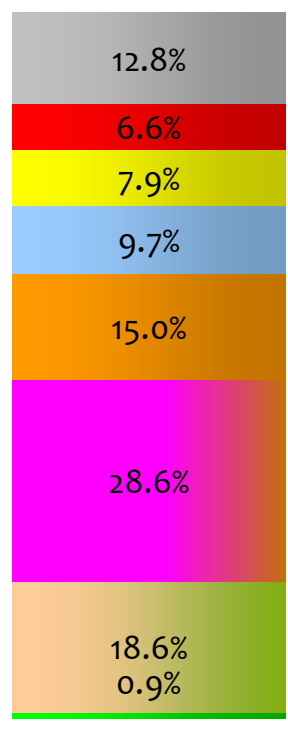

2000

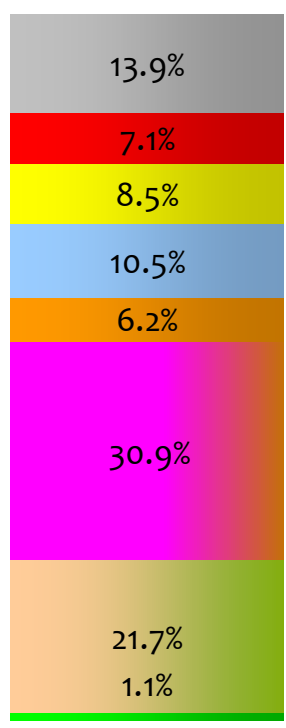

2010

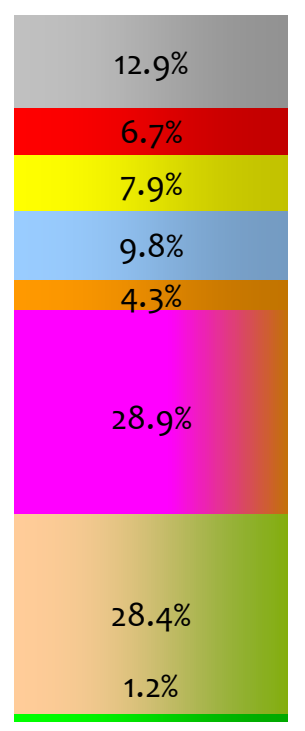

Other operating

range

Lighting

Fridge

Heating

Hot water

Other materials

Timber

In $\mathrm{CO}_{2}$ terms, hot water remains by far the largest category, while materials are larger than all categories except hot water, and in the 2020s house are larger than the combined two next largest categories - "Fridge" and "Other operating".

Hot water, construction and maintenance materials, and appliance operating energy are the biggest emitters, and thus the lowest hanging fruit when remedies are sought, across houses of all ages. The fridge, lighting and cooking categories all remain large enough to merit pursuing for reduced emissions. These same remedies are also applicable when seeking low-hanging fruit for existing houses, except that construction materials cannot be changed. From an analytical perspective, an older house would be likely to show a lower percentage of emissions from (maintenance) materials, and a correspondingly greater percentage from operating emissions, accentuating the importance of strategies to deal with these. 


\subsubsection{Sustainability Strategy Gains: $\mathrm{CO}_{2}$ Reduction}

Each design strategy was measured for its $\mathrm{CO}_{2}$ reduction contribution, separate from any other strategy. Table 9.8 shows the reduction in $\mathrm{CO}_{2}$ emissions for each applied strategy.

Table 9.8 $\mathrm{Net}_{\mathrm{CO}_{2}}$ Reductions for each Strategy (kg/yr)

\begin{tabular}{|c|c|c|}
\hline Introduced Strategy & Replaced Option & $\mathrm{CO}_{2}$ Reduction \\
\hline Wind generator & Grid electricity & 1,031 \\
\hline Strawbale floor, wall \& ceiling insulation & Polystyrene insulation & 491 \\
\hline Solar hot water ( $3.75 \mathrm{~m}^{2}$ panels) & Electric/gas hot water & 472 \\
\hline Photo voltaic panels $\left(10 \mathrm{~m}^{2}\right)$ & Grid electricity & 435 \\
\hline Strawbale insulation - walls and ceiling only & Polystyrene insulation & 348 \\
\hline Suspended straw-insulated floor & Slab floor & 197 \\
\hline Efficient refrigeration & Standard installed refrigeration & 171 \\
\hline Strawbale insulation - floor only & Polystyrene insulation & 143 \\
\hline Timber windows & Aluminium windows & 139 \\
\hline Timber shingle roof & Steel roof & 110 \\
\hline Efficient lighting & Standard lighting & 110 \\
\hline 2000s $R$ values & 1970s $R$ values & 90 \\
\hline Efficient appliances & Standard appliances & 90 \\
\hline 2010s $R$ values & 2000 s $R$ values & 82 \\
\hline Low $\mathrm{CO}_{2}$-emitting materials & Standard materials & 76 \\
\hline Suspended polystyrene-insulated floor & Slab floor & 50 \\
\hline Concrete tile roof & Steel roof & 40 \\
\hline Earth walls & Timber walls, polystyrene insulation & 40 \\
\hline 2020s $R$ values & 2000 s R value, polystyrene insulation & -54 \\
\hline 2020 s $R$ values & 2010s R value, polystyrene insulation & -136 \\
\hline Heavyweight (concrete masonry) walls & Timber walls, polystyrene insulation & -350 \\
\hline Average reduction of all strategies & & 182 \\
\hline $\begin{array}{l}\text { Average reduction, minus wind generator } \\
\text { outlier }\end{array}$ & & 168 \\
\hline Average reduction of all 2020 s strategies & & 205 \\
\hline
\end{tabular}

The ZALEH houses with conventional construction had total construction and operating $\mathrm{CO}_{2}$ emissions between 2,100 kg/yr (2010s house, concrete floor, timber walls, and steel roof) and 2,600 kg/yr (2020s house, concrete floor and walls, and steel roof). None of the adopted individual design strategies was alone capable of reducing emission from totals above 2000 down to the $\mathrm{CO}_{2}$ target of $19 \mathrm{~kg} / \mathrm{yr}$ perhouse, or even the easier "soft" target of $282 \mathrm{~kg} / \mathrm{yr}$. 
The largest individual design strategy change was introducing a (common, domestic size) wind generator, which reduced total $\mathrm{CO}_{2}$ emissions by $1,031 \mathrm{~kg} / \mathrm{yr}$. The smallest individual strategy change was from earth walls versus timber walls, for a net $\mathrm{CO}_{2}$ reduction of $40 \mathrm{~kg} / \mathrm{yr}$. A concrete tile roof, in place of a steel one, also showed a net $\mathrm{CO}_{2}$ improvement of $40 \mathrm{~kg} / \mathrm{yr}$. The average $\mathrm{CO}_{2}$ reduction from the individual design strategy changes was $182 \mathrm{~kg} / \mathrm{yr}$ for all houses, or $205 \mathrm{~kg} / \mathrm{yr}$ for just the 2020s houses. Given the modest improvement from each change, no single strategy was capable of reaching the target on its own, and not until all the strategies listed were included in one design was the target reached.

When the target emission level had been reached (and exceeded), the hypothesis that houses can be brought within a target emission limit that can be considered sustainable at current population and long-term global absorption levels - was proved. Modelling was not continued beyond this target.

\subsection{Conclusion}

A large number of other individual or combined design strategies could have been modelled. These include: different roofing materials, such as aluminium, bitumen or rubber; aluminium, brick, plastic or steel cladding; or steel framing. Other insulation strategies could have been modelled, such as fibreglass with more framing timber, or wool as another bio-based option. Other energy technology strategies could also been modelled, such as on-site energy storage, with batteries, for example. While these and other strategies might have helped reach the sustainability target, the target emission level was reached and the hypothesis was proved, even if some strategies such as urban wind generation did have caveats attached to them. Time and resources prevented a larger range of houses being modelled. Furthermore, it was apparent that strategies which reduced total (construction and operating) emissions, in order of effectiveness, were those where:

- $\quad$ electricity demand from the national grid was reduced

- materials showed a net absorption

- a material and its related systems had lower emissions.

No strategies were apparent that would meet these criteria better than the strategies already chosen. 
135 variables could be altered from the calculator's front page. This enabled assessment of the importance of different design changes, within the scope of the calculator. With more time and effort the scope of the calculator could be expanded to include, for example, other materials, major plan changes, or fit-out and furniture. These inclusions may indicate fruitful design directions in the pursuit of lower total emissions. It is likely that other combinations of design strategies would achieve the sustainability target, but also likely they would show similarities to the successful strategies already identified.

Since all the houses were based on a single architectural design, the omitted materials: plumbing, wiring, carpet, and fit-out would have been the same for all the houses. Built-in furniture and fittings, as generally occurs in kitchens and bathrooms, may be renewed at relatively frequent intervals. Loose furniture and furnishings may also have short lifetimes, compared to the building shell. These inputs to housing are potentially important and deserve analysis, but were beyond the scope of this thesis.

Once the sustainability target had been reached, and exceeded, there was sufficient margin to, very likely, allow for all missing materials, and still be within the sustainability limit if they were included. Conversely, the houses that failed to reach the sustainability target would have been even further away from it if these items were included. The missing materials contribution would thus not have altered the outcomes of searching for, and reaching, a sustainable design strategy.

The 1970s, 2000s and 2010s houses needed greater than $99 \% \mathrm{CO}_{2}$ reductions to reach the sustainability target: a daunting goal. The housing sector is fortunate in having available technologies that can be used to achieve the sustainability target, as this chapter has shown. Even so, several unfamiliar strategies for house design need to be incorporated simultaneously. Hot water emissions are most easily addressed. But with such a challenging sustainability requirement it is necessary to reduce emissions from all sources. The debate which has pitted operating emissions against construction emissions as avenues for $\mathrm{CO}_{2}$ reductions needs to be broadened. While, after hot water, construction emissions are higher than any other operating 
category emissions and up to $1 / 3$ of total emissions, all categories need to be addressed simultaneously, and aggressively, if warnings such as those from Hansen (2008; 2007) are to be heeded and actioned. This chapter has focused on new-build strategies. Although not part of the aim of this thesis, existing housing stock could also benefit from many of the strategies identified in this chapter. Solar hot water, electricity generating technologies, efficient appliances, and low-emission or $\mathrm{CO}_{2-}$ absorbing maintenance or retrofitting materials are all options for existing houses.

This chapter has brought together from earlier chapters the results of $\mathrm{EE}$ and $\mathrm{ECO}_{2}$ analyses, and calculated sustainability limits, and applied them to specific house designs in the New Zealand context. It has shown that a sustainable house can be built in the context of global environmental realities and New Zealand construction practicalities. To achieve the sustainability target established in Chapter 5, however, requires a combination of several construction and operation strategies. Chapter 10 summarises the outcomes of this and earlier chapters, in relation to the research question and hypothesis of this thesis. 


\section{Conclusions}

This is the first age that's paid much attention to the future, which is a little ironic since we may not have one.

It is a rare mind indeed that can render the hitherto non-existent blindingly obvious. The cry 'I could have thought of that' is a very popular and misleading one, for the fact is that they didn't, and a very significant and revealing fact it is too.

- Douglas Adams, 1984

\subsection{A Sustainability Definition and the Steps To It}

"How do you build a sustainable house in New Zealand?" This question began the thesis; to answer it, a number of milestones had to be achieved. The question could not be answered without first knowing what sustainability meant. The first of the three parts of the thesis dealt with what sustainability means, and how to measure it.

It was essential to begin by knowing something of the history of the sustainability effort over the last decades and centuries. It was not enough to pluck a definition of sustainability from the ongoing debate and put it on the page; the sustainability definition needed to be workable, robust, readily understood and applied, and pertinent to current and future environmental concerns. To be workable it needed to acknowledge and incorporate the conflicting concerns of both the 'sustainable' and 'development' sides of the 'sustainable development' debate. Only after a clear meaning of sustainability was defined could measurements be made to discover whether actions, in this case house construction and operation, were meeting the definition.

Secondly, without any chance of canvassing all participants and interested parties in the debate, a way of assessing the definition was needed. This was provided by a checklist of requirements for a definition. Using the checklist, climate change was 
flagged as the central environmental challenge, and therefore as the key parameter in a sustainability definition. The requirements checklist was a key outcome of this thesis.

Two requirements in the checklist were: 1) a way of measuring sustainability; and 2) a limit for sustainability, beyond which individuals, organisations, countries, or the whole human population are unsustainable. This required comparing different environmental impacts and knowing how to weight them. The problem of weighting still bedevils many assessment methods, including currently popular LCA. The method for comparing environmental impacts was thus a key outcome. It compares the time taken, presently or potentially, for the environment to recover after cessation of a particular impact. Using this method, GHGs, particularly $\mathrm{CO}_{2}$, were confirmed as the key environmental impact, in Chapter 4. Chapter 4 also identified why energy is closely linked to $\mathrm{CO}_{2}$ emissions, and why it is central to environmental impacts and their measurement.

A sustainability limit was needed along with a sustainability measurement method so the measured value for an action - building and operating a house - could be known to be within, or beyond, that limit. Hitherto, no such limit has been in circulation.

To define the sustainability limit clearly, it was essential to know what the units were, and that they fitted the requirements checklist for the sustainability definition. Being able to compare environmental impacts, and identifying $\mathrm{CO}_{2}$ as the key impact and thus the basis for a measurement method, enabled a sustainability limit to be identified. Even though the sustainability limit defined in this thesis is simple to calculate, it has not been applied in this way before. The sustainability measurement method and limit were key outcomes of this thesis.

With: a checklist of requirements; a limit for sustainability; and a measurement method, a functional definition was possible:

\section{Sustainability means meeting the needs of the present without annual $\mathrm{CO}_{2}$ emissions exceeding what the planet can absorb.}


Chapter 2 contained the steps to: delineate the requirements of a sustainability definition; reach that definition; and define a limit for sustainability.

\subsection{Discarding Unsuitable Sustainability Indicators}

Chapter 3 identified the requirements for sustainability indicators, tested common indicators against those requirements, and identified indicators which were deficient, and therefore inadequate for the purposes of answering the research question.

The lack of effective sustainability indicators in common use is one reason the sustainability debate is still so active. Climate change is recognised as the primary environmental threat but without a clearly and widely conveyed limit for GHG emissions, the scope for arguing, about how much GHG emissions need to be reduced, is greater than if there were a clear limit. The failure at Copenhagen in 2009 (Klein, 2009) is a demonstration of such argument. Even the Ecological Footprint method fails to say what a sustainable limit is; it cannot determine if a house design is sustainable or not. Similarly, LCA would have been convenient for analysing house performance, but it would not have been able to say when a house was, or was not, sustainable.

\subsection{Effectively Comparing and Measuring Environmental Impacts}

Chapter 4 explored energy analysis and $\mathrm{CO}_{2}$ analysis as effective methods that met the listed requirements for sustainability indicators. In particular, they were assessed for their relevance to a range of environmental impacts. Embodied energy (EE) and embodied $\mathrm{CO}_{2}\left(\mathrm{ECO}_{2}\right)$ analysis have been used for assessing environmental impacts for many years. A key outcome from Chapter 4, however, was that it identified clearly why $\mathrm{EE}$ and $\mathrm{ECO}_{2}$ are effective for measuring sustainability, and superior to other sustainability indicators.

\section{4 $\mathrm{CO}_{2}$ Limits}

Having established a sustainability definition, a way of measuring sustainability, and a sustainability limit, a method was needed to accurately apply the limit to houses in 
New Zealand. Chapter 5 sharpened the focus on global $\mathrm{CO}_{2}$ emissions, and related them to the global human population. Current and projected populations were presented along with current and long-term global $\mathrm{CO}_{2}$ absorption abilities, to define a range of sustainability limits under different scenarios.

The resulting key outcome of the thesis is a per-capita sustainability limit for annual carbon emissions, of just $29 \mathrm{~kg}$, or $108 \mathrm{~kg}$ of $\mathrm{CO}_{2}$. This can be applied to a wide range of activities at different scales: individual, local, regional, national, and global.

Chapter 5 applied the per-capita limit firstly to New Zealand and its housing industry, which accounts for $6.4 \%$ of national emissions, and then to the level of the individual house. This provided the sustainable annual $\mathrm{CO}_{2}$ target for the analysis of houses in Chapter 9, which was found to be 19kg. This is a very low and challenging target in comparison with current emissions levels. The gap between the sustainable per-capita $\mathrm{CO}_{2}$ emissions limit and current emissions in developed countries was found to be approximately two orders of magnitude. That is, using the definition from this thesis, per-capita emissions in developed countries need to fall by about $99 \%$ to be sustainable. No countries currently meet the sustainability limit.

\subsection{Detailed Analysis Methods}

Having identified ways of defining and measuring sustainability, a robust measurement methodology was required. The second part of the thesis, in Chapters 6-8, dealt with EE and $\mathrm{ECO}_{2}$ analysis, and how to do it. Chapters 6 and 7 described $\mathrm{EE}$ and $\mathrm{ECO}_{2}$ analysis methods in detail. To be able to analyse different house design strategies, $\mathrm{EE}$ and $\mathrm{ECO}_{2}$ coefficients for relevant materials and systems were needed. These were available from earlier publications by the author, but were updated and enhanced for this thesis.

The process-based hybrid analysis methodology was first developed by the author in 1995 (Alcorn, 1995). This is the first time this methodology and the resulting energy and $\mathrm{CO}_{2}$ coefficients have been applied to specific house designs and corresponding operating energy values. For the first time a comprehensive view of energy and $\mathrm{CO}_{2}$ profiles for New Zealand houses has been gained. This is a key outcome of this thesis. 
Chapter 8 gave detailed examples for materials and processes specific to the construction of New Zealand houses. The EE and $\mathrm{ECO}_{2}$ coefficients derived for analysing New Zealand houses in this thesis are applicable to a wide range of analyses, and form a key outcome of this thesis.

\subsection{Testing the Hypothesis: Sustainability Analysis of New Zealand Houses}

Finally, the third part of the thesis applied the arguments and knowledge from the earlier chapters to test the hypothesis that:

by making strategic design and construction decisions, materials choices, and technology selections, the $\mathrm{CO}_{2}$ profile of houses can be brought within a target limit that can be considered sustainable.

Chapter 9 assembled all the necessary steps made available by the earlier chapters:

- The requirements that a functional definition of sustainability needed to meet

- A functional definition of sustainability

- $\quad$ The requirements a sustainability measurement method needed to meet

- A robust way of comparing environmental impacts

- A robust analysis methodology for measuring sustainability

- A robust measurement unit for sustainability

- A (per-capita) sustainability limit

- A way to apply the sustainability limit to New Zealand houses

- $\quad$ Impact coefficients (EE and $\mathrm{ECO}_{2}$ ) for building materials.

These features were assembled into a calculator tool that could answer the question, "How do you build a sustainable house in New Zealand?", and test the hypothesis.

The calculator has potential application beyond this thesis, in answering many other questions about the performance of houses and their parts. The calculator tool is a key outcome of this thesis. 
Existing house designs were adopted and their components and operating energy analysed. Each construction design was analysed according to current building codes and practices, along with the life expectancies of the materials and components. A key outcome of the detailed analyses of the houses and materials was a method to annualise energy and $\mathrm{CO}_{2}$ emissions of components and materials, and so harmonise them with operating energy and global emissions data.

\subsection{Conclusion: Proving the Hypothesis}

The final house analysed at the end of this thesis, House 14 in Chapter 9, proved the hypothesis.

\section{A sustainable house is indeed possible.}

The hypothesis was phrased positively, but it could just as well have been couched in the negative. At the opening of Chapter 1, Douglas Adams' (1984) injunction to "See first, think later, then test" was quoted. Until the results from Chapter 9 emerged, there was no way of knowing if a sustainable house was achievable. In earlier chapters, when it became clear that developed countries were about two orders of magnitude above a sustainable emissions limit, achieving a sustainable house seemed unlikely, and the hypothesis looked like it would be disproved. Finding that a sustainable house $i s$ possible was thus a surprise result.

Can sustainability be achieved by the design strategies described in this thesis being adopted as the housing portion of a general move towards sustainability? Will Gaia (Lovelock, 2009) feel an overall move to sustainability from house designs like these? Not unless the entire world, in its housing, and all other activities, also adopts and adheres to the same per-capita sustainability limit described here. Without that coordinated move to adhere to the sustainability limit, Jevons' Paradox, as discussed in Chapter 4, dictates that the effect of the local building of houses in the 'sustainable' manner described in this thesis would be to reduce resource use for local construction, only to facilitate even greater resource use elsewhere. The effect would be an overall move away from sustainability, not towards it. Building houses that emit little $\mathrm{CO}_{2}$ would merely allow other uses to (more than) take up the reduced demand for $\mathrm{CO}_{2}$-generating energy. Jevons' Paradox applies not only to 
$\mathrm{CO}_{2}$ emissions and fossil fuels, but other resource use as well, such as water, minerals, and all the sources for products and consumables that form part of the daily running of a household, including the pet $\operatorname{dog}$ (Vale and Vale, 2009).

Nonetheless, if global sustainability is to be realised, and a coordinated move to adhere to the sustainability limit is adopted as an essential way to achieve it, this thesis has used the New Zealand context to show how houses can be designed, built, maintained, and operated, to be sustainable. The general and specific aims of the thesis stated in Chapter 1 are therefore met:

to reduce the environmental impact of housing to a sustainable level, and:

to provide a reliable, accurate, and specific guide to building a sustainable house in the New Zealand context.

\subsection{Specific Results}

As well as proving the hypothesis, this thesis, especially Chapter 9, produced some significant results which provide further specific New Zealand house building guidance, as called for in the thesis aims.

\subsubsection{Heating Emissions Insignificance}

Heating has been pursued for many years as an important energy use that needed minimising to reduce $\mathrm{CO}_{2}$ emissions. A likely reason for the focus on heating is its large energy use, which for New Zealand's average housing stock is over 25\%, almost as much as hot water. Because about half of heating energy for New Zealand houses comes from firewood, however, the net emissions from heating are a much smaller percentage. This thesis has shown that, even in average New Zealand housing stock, on an annualised basis, heating is in fact a smaller emitter than hot water, appliances, construction materials, or refrigeration. For New Zealand's average housing stock it represents only about $11 \%$ of emissions. For currently constructed houses it represents the smallest annual $\mathrm{CO}_{2}$ flux, at $143 \mathrm{~kg}$, or $6 \%$, smaller even than cooking or lighting, at 179 and $221 \mathrm{~kg}$, respectively, out of a total of 2,197kg. For equivalent but highly insulated houses, heating is less than $2 \%$ of annual emissions. 


\subsubsection{Hot Water Emissions}

Hot water is the single biggest emitter of $\mathrm{CO}_{2}$ in current $\mathrm{New}$ Zealand houses. At over $30 \%$ of annual emissions it is more than double any other category, and over five times the emissions from heating for currently constructed houses. All houses, from average through to 2020s houses, showed similar hot water emissions of $\sim 30 \%$. When solar hot water was introduced, however, hot water emissions reduced to less than $13 \%$. Other than the addition of a wind generator, solar hot water systems offered the single greatest reduction in net emissions available.

Water heating has a high energy demand, and the main energy source is grid electricity. The high associated emissions are the underlying cause of hot water's prominence in the annual $\mathrm{CO}_{2}$ totals. Hot water should be pursued most vigorously as the leading candidate for emissions reductions.

\subsubsection{Construction Emissions}

The $\mathrm{EE}$ and $\mathrm{ECO}_{2}$ of construction materials has for many years been regarded as of minor significance. This thesis has shown that the ratio of construction $\mathrm{CO}_{2}$ emissions and absorptions to total emissions for average and currently constructed New Zealand housing is significant, at approximately 1:4. The opportunity for gains is thus significant also, and second only to hot water. As operating emissions reduced from using optimum levels of insulation, about $\mathrm{R} 5$, the construction emissions and absorptions to operating emissions ratio became 1:3. For even more highly insulated houses (R10) the ratio became 1:2. For House 14, the ratio was 2:1 (emissions and absorptions for materials were twice as large as emissions from operating energy).

Maximising carbon-sequestering materials, such as timber and strawbale, is more effective at reducing net annual emissions than minimising emissions from other materials, although that is also a worthwhile strategy. In percentage terms, $\mathrm{CO}_{2}$ flux for construction is currently over 18\% in New Zealand's average housing stock. This rises to over $20 \%$ for currently constructed houses, and nearly $28 \%$ for an equivalent but highly insulated 2020s house. For House 14, the sustainable house, the annual construction $\mathrm{CO}_{2}$ flux is $73 \%$ of the total. 
Construction materials, as the second biggest emitting category after hot water, should be pursued vigorously as a means of reducing total emissions.

\subsubsection{Other Emissions}

Appliance emissions, at $\sim 15 \%$ of annual emissions, are third behind hot water and construction emissions. Refrigeration and lighting, at $\sim 11.5 \%$ and $\sim 9 \%$ are also worthy of attention in the effort to reduce net annual emissions.

\subsubsection{Grid Electricity Emissions}

New Zealand's high proportion of hydro generated electricity (about 2/3) reduces average grid electricity emissions, since the $\mathrm{CO}_{2}$ emission factor for delivered hydro electricity is only $\sim 5 \mathrm{~g} / \mathrm{MJ}$. However, while average emissions are lower in New Zealand than countries that rely on more fossil-fuel generation, the average emission factor for grid electricity is close to the emission factor for the fossil fuels themselves. The average grid electricity $\mathrm{CO}_{2}$ emission factor is around $60-65 \mathrm{~g} / \mathrm{MJ}$, depending on hydro inflow variations. $\mathrm{CO}_{2}$ emission factors for coal and gas combustion are 93 and 52g/MJ, respectively. Once generation (in)efficiencies and transmission losses are accounted for, however, the weighted average $\mathrm{CO}_{2}$ emission factor for fossil fuel generated delivered electricity is $170-200 \mathrm{~g} / \mathrm{MJ}$, depending on varying proportions of coal and gas. The emissions from fossil fuel generated grid electricity are thus $\sim 90 \%$ of total grid electricity emissions, or about 3 times greater than the $\sim 30 \%$ of grid electricity thermal generation represents. Technologies that reduce or eliminate use of grid electricity, and thus the associated $\mathrm{CO}_{2}$ emissions, are therefore a vital part of a sustainable house.

Chapter 9 shows that while a house does not have to be fully autonomous in its electricity provision, this is close to the situation that emerges when grid electricity use is lowered sufficiently to reduce total emissions to a sustainable level. The technologies that contribute most (with respective annual $\mathrm{CO}_{2}$ reduction contribution in brackets) are: a wind generator $(1,031 \mathrm{~kg})$; solar hot water $(472 \mathrm{~kg})$; PV panels (435kg); efficient refrigeration $(171 \mathrm{~kg})$; efficient lighting $(110 \mathrm{~kg})$; and efficient appliances $(90 \mathrm{~kg}) \cdot \mathrm{CO}_{2}$ reductions from avoided grid electricity emissions are also 
available if construction materials that use less grid electricity replace those that use large amounts, such as timber window frames replacing aluminium (139kg), or timber shingles $(110 \mathrm{~kg})$ or concrete tiles $(40 \mathrm{~kg})$ replacing steel roofing.

\subsubsection{Policy Directions}

To date New Zealand environmental policy effort for houses has focused on heating and lighting emissions. If it is to be effective, however, emissions reduction attention should be focused first on reducing emissions associated with grid electricity, on the supply side. On the demand side, in the housing context, the three big categories should be addressed as priorities: hot water; construction and maintenance; and appliances, in that order. Other categories should be given the attention their emissions percentage warrants. Refrigeration, lighting and cooking, are all worthy of second-order policy attention, after the three big categories are addressed. All the above categories need attention if sustainable houses are to be achieved.

\subsection{Key Outcomes}

The key outcomes relating to the three parts of this thesis are listed below.

Part 1, dealing with what sustainability means, and how to measure it, produced 6 key outcomes, nos. 1 to 6.

Part 2, dealing with $\mathrm{EE}$ and $\mathrm{ECO}_{2}$ analysis, and how to do it, produced 2 key outcomes, nos. 7 and 8 .

Part 3, applying the arguments and knowledge from the earlier chapters and testing the hypothesis, produced: 3 key outcomes, nos. 9, 10 and 11; and 8 key results, nos. 12 to $19:$

1. A requirements checklist for a functional definition of sustainability

2. A scientific method for comparing environmental impacts

3. A method for measuring sustainability that meets the checklist requirements

4. A functional definition of sustainability

5. The definition of a sustainability boundary or limit

6. A per-capita sustainability limit applicable to many activities at many scales 
7. A process-based hybrid energy and $\mathrm{CO}_{2}$ analysis method that enables fast, accurate, and reliable results

8. Updated $\mathrm{EE}$ and $\mathrm{ECO}_{2}$ coefficients for New Zealand building materials

9. A method to annualise $\mathrm{EE}$ and $\mathrm{ECO}_{2}$ of materials, components, and houses

10. A calculator to analyse houses' environmental performance, especially EE and $\mathrm{ECO}_{2}$

11. A full life cycle analysis of New Zealand house construction and operation

12. Reducing houses' grid electricity use is the most effective way to reduce $\mathrm{CO}_{2}$ emissions

13. Hot water is the single biggest $\mathrm{CO}_{2}$ emitting category

14. Maximising bio-based materials is the second most effective way to reduce net $\mathrm{CO}_{2}$

15. Bio-based insulation to very high $\mathrm{R}$ values helps reduce net $\mathrm{CO}_{2}$ emissions

16. Optimal conventional insulation to minimise $\mathrm{CO}_{2}$ emissions is about $\mathrm{R} 5$

17. Construction $\mathrm{CO}_{2}$ flux is significant: $1 / 5$ for current houses, and $2 / 3$ for sustainable houses

18. Heating is the least cause of net annual $\mathrm{CO}_{2}$ emissions from $\mathrm{New}$ Zealand houses

19. Sustainable houses can be built, maintained, and operated in the New Zealand context.

\subsection{Further Research}

This thesis has produced an accurate and reliable sustainability analysis of different house designs. It was only possible because good data existed on which it could be based. All such data however, loses accuracy progressively after it is collected. It is essential for future research in this field to be based on good data. This requires ongoing updating of all the various pieces of input data, be they from I-O analyses of the economy, to annual and seasonal changes in energy use and emissions. This is the prime requirement for future work: that the data is updated in a timely manner.

Some avenues for further research are direct outcomes from the analyses in this thesis. Others are more general, and more in the philosophical realm, prompted by the insights from certain parts of the research. 


\subsubsection{Comparing Environmental Impacts: Recovery Times}

The time taken for environmental damage to repair, or be repaired, provides an objective means of comparing hitherto conceptually disparate environmental impact categories and specific impacts. Recovery times as a means of weighting impact categories, however, is not simple. Further research to reliably and specifically allocate recovery times to individual impacts would make this a highly valuable tool that would considerably advance environmental impact assessment methodology.

\subsubsection{Life Expectancy}

The life expectancy of materials has a significant bearing on the annualised, and lifetime, $\mathrm{EE}$ and $\mathrm{ECO}_{2}$ of buildings. For many materials, accurate data is unavailable. Assumptions must therefore be made for them about typical life expectancies. Where data does exist it is often based on a small number of examples, or on theoretical or assumed durability. Careful research into how long specific materials have lasted in certain cases, how long they last in adverse conditions, how long they may last in good practice installations, and what a typical life expectancy is, would be valuable.

More accurate lifetime assessment is important for all materials, but particularly for high $\mathrm{CO}_{2}$ emitting and absorbing materials. The examples of timber framing and strawbale illustrate the importance of correctly assessing the life expectancy of materials in use when evaluating emissions. Further research could investigate what proportion of each material required replacement over the life of the building, and at what intervals. Minimum, maximum, weighted-average, and specific-use life expectancies thus derived for materials would have valuable and significant effects on sustainability assessments of buildings.

\subsubsection{End of Life}

Assessment of the destinies of materials after they have been removed from a building, or after the building is demolished, requires careful consideration. Overseas practice is often significantly different from New Zealand practice. In Switzerland, for example, wood products are typically burnt for electricity generation. In New 
Zealand the most common practice is landfilling. The proportion of materials that are landfilled, burnt, re-used, or recycled needs to be established so that accurate end-of-life scenarios can be factored in to $\mathrm{EE}$ and $\mathrm{ECO}_{2}$ calculations.

The decomposition of materials in New Zealand landfills also needs careful analysis. Overseas studies (Ximenes, 2008; Micales and Skog, 1997) indicate low levels of carbon loss from buried timber products, which is contrary to IPCC assumptions that all carbon from timber products is released in a short time. Conditions in landfills, especially moisture content, affect decomposition rates. These conditions may vary significantly from the examples in the cited works from countries with different climates and landfill practices. Actual carbon release rates from New Zealand landfills need to be understood so these can be factored in to EE and $\mathrm{ECO}_{2}$ calculations, and so New Zealand policy makers can have accurate figures for overall carbon balances. If it was found, for example, that New Zealand practices in some landfills, where burial takes place almost immediately with earth material, are effective at keeping a high percentage of carbon below ground, while less carefully managed landfills allowed greater decomposition and carbon loss, the national balance of carbon emissions might be significantly reduced by relatively simple and cheap changes to landfill management practices. Such an outcome would also have a major bearing on policy strategies for the end-of-life treatment of materials. This is an area where relatively simple research and practices could have a major benefit for the national $\mathrm{CO}_{2}$ emissions bottom line.

\subsubsection{Extending the Calculator Model}

The model developed in this thesis incorporates:

- Construction and maintenance inputs

- $\quad$ Operating energy inputs

- Environmental impact of inputs

- $\quad \mathrm{EE}$ and $\mathrm{ECO}_{2}$ coefficients

- National energy industries data

- Manufacturing process data. 
The items in this list all need continual updating. Many need further data improvement, or missing components added. As well as the current inputs, however, the model developed for this thesis could be made even more powerful by adding further aspects that refine and extend the ability to determine the sustainability of particular house designs and the full operation of households. These aspects include:

- $\quad$ Plumbing and drainage

- Wiring

- $\quad$ Non-plumbing services (data, energy delivery, water, waste)

- Floor coverings

- $\quad$ Site preparation and development

- Appliances

- Furniture and furnishings

- House-ware (crockery, kitchenware, artwork)

- $\quad$ Existing houses

- $\quad$ Transport

- Personal clothing

- $\quad$ Food.

\subsubsection{Other Sustainability Strategies}

What is the relative contribution towards $\mathrm{CO}_{2}$ emissions reduction available from other 'sustainable' building technologies? Analyses of these technologies could make useful contributions towards the sustainability target. These technologies include:

- Composting toilets

- Rainwater collection

- $\quad$ On-site grey water treatment

- $\quad$ Food production

- $\quad$ Aspirated air collector heating.

\subsubsection{Global Actions towards Sustainability}

Jevons' Paradox is still a difficult effect to quantify. This does not mean it should be ignored in sustainability research, however. Further work on its relation to buildings could show highly significant effects in the outcomes of sustainability analyses. At a higher level, the implications of Jevons' Paradox become philosophical questions. 
- How does Jevons' Paradox work in practice in the housing sector?

- What are the philosophical implications of Jevons' Paradox and sustainability?

- If 'efficiency' or doing things with less environmental impact means a greater net level of activity, and therefore greater total resource use, rather than a reduction in activity and a reduction in total resource use, (how) is it possible to progress towards sustainability?

- If there is a trade-off between continued consumption and population at current levels, and continued human existence, which path offers the better long-term prospects - an early decline in population/environmental impacts, or a delayed one?

- Are any such trade-offs affected by improvements in 'efficiency' or other 'sustainable' ways of using resources?

- Can development continue to co-exist with a satisfying human existence, and if so, at what level of lifestyle?

\subsubsection{Average versus Marginal Energy: Implications}

Average and marginal energy and $\mathrm{CO}_{2}$ emissions were discussed as they applied to this thesis. The implications of using one or the other however, are extensive. If marginal energy and emissions are used to calculate the sustainability target, that target becomes more stringent and difficult to reach. Should this be the basis for decision making, nonetheless? More research would reveal just how significant these implications are, and to what extent policy decisions need to take account of them.

\subsubsection{Labour, Profits, Taxes, and Money in Sustainability Measures}

The research undertaken for this thesis indicates the scale of (conventionally ignored) labour, profits and taxes, to be of a similar magnitude to the energy and $\mathrm{CO}_{2}$ that is currently counted in process analyses. Treloar (1998) left a legacy of research in this field, but more work is required to accurately reveal the magnitude of these omitted inputs. Under current analysis conventions some industries that have high labour but low material inputs, such as legal, engineering, or other service industries, appear insignificant. Conversely, high material, low labour, low profit industries, such as concrete manufacture, appear to be more significant than they 
otherwise would be if labour, profits, and taxes were counted. This has large implications, both in New Zealand and internationally. Further research would reveal the scale and prevalence of these omissions. Such research may also shed valuable light on the use of dollars or other currencies as viable and useful indicators of sustainability.

\subsubsection{Comparison with Other Methods}

This thesis has argued for the use of $\mathrm{EE}$ and $\mathrm{ECO}_{2}$ as appropriate sustainability measurement methods. How different are the results obtained by these methods from other currently used sustainability indicators? If the differences are significant, what are the key factors that account for those differences? The sustainability debate seems likely to continue for many years. This thesis has attempted to provide useful results for sustainable building practices. Further research in the directions taken in this thesis is likely to contribute more valuable and practical sustainability insights. 


\section{Appendix A: Lifetimes of Building Materials, Components, Houses}

\begin{tabular}{|c|c|c|}
\hline Material & Life & Source \\
\hline Aluminium windows & 35 & Bennet (2008) \\
\hline Concrete block masonry, painted & 80 & Bennet \\
\hline Concrete in floors & 150 & This thesis \\
\hline Concrete in walls & 100 & Bennet \\
\hline DPM & 150 & This thesis \\
\hline Earth & 150 & This thesis \\
\hline Floor boards & 150 & This thesis \\
\hline Glass & 100 & Bennet \\
\hline Gypsum plaster board & 50 & Bennet \\
\hline Hardfill & 150 & This thesis \\
\hline Insulation & 50 & Bennet \\
\hline Insulation EPS & 50 & Bennet \\
\hline Insulation XPS & 150 & This thesis \\
\hline Nails, framing & 90 & This thesis \\
\hline Nails, galvanised, cladding & 40 & Page (2005) \\
\hline Nails, lining fixing & 50 & This thesis \\
\hline Paint, factory applied & 15 & Page \\
\hline Paint, normal & 8 & Page \\
\hline PV panels & 25 & Alsema (2000) \\
\hline Solar hot water system & 20 & $\operatorname{EECA}(2001)$ \\
\hline Steel reinforcing & 150 & This thesis \\
\hline Steel sheet, factory painted \& repainted & 50 & Page \\
\hline Strawbale & 100 & This thesis \\
\hline Timber, roof framing & 90 & Page \\
\hline Timber, sub-floor framing & 90 & Page \\
\hline Timber, external windows and doors & 90 & This thesis \\
\hline Timber, internal doors & 150 & This thesis \\
\hline Timber, exterior wall framing & 90 & Page \\
\hline Timber, H1.2 treated & 90 & Page \\
\hline Timber, interior wall framing & 150 & This thesis \\
\hline Timber, shingles & 40 & Greenspec (2009) \\
\hline Underfloor foil & 50 & This thesis \\
\hline Weatherboard, radiata & 70 & Page \\
\hline Wind generator & 10 & Dunford \\
\hline Houses, $1860-1980$ & 90 & Johnstone (2004) \\
\hline Houses, 2000 - & 130 & Johnstone \\
\hline Houses, service life span & 140 & Johnstone \\
\hline House, average residence at an address & 8 & Page \\
\hline
\end{tabular}




\section{Appendix B: Embodied Energy and Embodied $\mathrm{CO}_{2}$ Coefficients}

The data in this Appendix is as correct as possible at the publication date. Some data inputs are subject to constant change. Care should be exercised in using the data, since it will gradually lose accuracy with time, to varying degrees of significance.

Under the terms of the Creative Commons Non Commercial 3.0 License at

$<$ http://creativecommons.org/licenses/by-nc-sa/3.0/>, and

$<$ http://creativecommons.org/licenses/by-nc-sa/3.0/legalcode $>$,

the information in this Appendix and the whole thesis may be used under the following conditions:

You are free to share, copy, distribute, and transmit the work under the following conditions:

- Attribution - You must attribute the work with full publication details (but not in any way that suggests that the author endorses you or your use of the work)

- Non-commercial - You may not use this work for commercial purposes

- Share Alike - If you alter, transform, or build upon this work, you may distribute the resulting work only under the same or similar license to this one

With the understanding that:

- Waiver - Any of the above conditions can be waived if you get permission from the author

- Public Domain - Where the work or any of its elements is in the public domain under applicable law, that status is in no way affected by the license.

Other Rights - In no way are any of the following rights affected by the license:

- Your fair dealing or fair use rights, or other applicable copyright exceptions and limitations

- The author's moral rights

- Rights other persons may have either in the work itself or in how the work is used, such as publicity or privacy rights.

(C) J. Andrew Alcorn, 2010. 
Embodied Energy and Embodied $\mathrm{CO}_{2}$ Coefficients

\begin{tabular}{|c|c|c|c|c|}
\hline \multirow[t]{2}{*}{ Material } & \multicolumn{2}{|c|}{ Embodied energy } & \multicolumn{2}{|c|}{ Embodied $\mathrm{CO}_{2}$} \\
\hline & $\begin{array}{c}\mathrm{MJ} / \mathrm{kg} \\
\text { (or other) }\end{array}$ & $\begin{array}{c}\mathrm{MJ} / \mathrm{m}^{3} \\
\text { (or other) }\end{array}$ & $\begin{array}{c}\text { g/kg } \\
\text { (or other) }\end{array}$ & $\begin{array}{c}\mathrm{kg} / \mathrm{m}^{3} \\
\text { (or other) }\end{array}$ \\
\hline Aggregate & 0.04 & 65 & 3 & 4.5 \\
\hline Aluminium, virgin & 194 & 524,050 & 14,200 & 38,340 \\
\hline Aluminium, extruded & 204 & 551,700 & 14,830 & 40,040 \\
\hline Aluminium, extruded, anodised & 230 & 621,240 & 16,350 & 44,140 \\
\hline Aluminium, extruded, factory painted & 220 & 597,700 & 15,770 & 42,570 \\
\hline Aluminium, recycled & 9 & 24,410 & 645 & 1,750 \\
\hline Aluminium, recycled, extruded & 14.6 & 39,490 & 1,020 & 2,760 \\
\hline Aluminium, recycled, factory painted & 22 & 58,890 & 1,080 & 2,920 \\
\hline Bitumen fibre board & 1.8 & $11.7\left(\mathrm{MJ} / \mathrm{m}^{2}\right)$ & -460 & $-1.6\left(\mathrm{~kg} / \mathrm{m}^{2}\right)$ \\
\hline Building wrap & 51 & $2.2\left(\mathrm{MJ} / \mathrm{m}^{2}\right)$ & $148\left(\mathrm{~g} / \mathrm{m}^{2}\right)$ & \\
\hline Cement, average NZ & 6.2 & 12,000 & 1,025 & 2,000 \\
\hline Cement fibre board & $9 \cdot 3$ & 13,180 & 725 & 1,030 \\
\hline Ceramic brick, NZ average & 3 & 5,940 & 190 & 375 \\
\hline Ceramic pipe & 6.6 & 13,070 & 600 & 1,190 \\
\hline Concrete block & 0.9 & & 112 & \\
\hline Concrete $17.5 \mathrm{MPa}$ & 0.9 & 2,020 & 118 & 280 \\
\hline Concrete $30 \mathrm{MPa}$ & 1.2 & 2,760 & 164 & 390 \\
\hline Copper tube $^{1}$ & 2.4 & 21,290 & 150 & 1,340 \\
\hline DPM & 64 & & $172\left(\mathrm{~g} / \mathrm{m}^{2}\right)$ & \\
\hline Earth (straw stabilised adobe) & 0.15 & 250 & -12 & -20 \\
\hline Electricity, average, $\mathrm{NZ}^{2}$ & $1.54(\mathrm{MJ} / \mathrm{MJ})$ & & $67(g / M J)$ & \\
\hline Electricity, marginal, $\mathrm{NZ}^{2}$ & $18.7(\mathrm{MJ} / \mathrm{MJ})$ & & 199 (g/MJ) & \\
\hline Firewood & 0.06 & 27 & $-1,690^{3}$ & $-150(\mathrm{~g} / \mathrm{kg})^{4}$ \\
\hline Glass, float & $15 \cdot 9$ & 40,040 & 1,740 & 4,370 \\
\hline Glass, toughened & 27 & 66,880 & 2,450 & 6,180 \\
\hline Gypsum plaster board & 7.4 & 7,080 & 470 & 450 \\
\hline Hard-fill & 0.04 & 65 & 3 & $4 \cdot 5$ \\
\hline Insulation, fibreglass & 32 & 1,540 & 770 & 37 \\
\hline Insulation EPS & 58 & 1,400 & 2,500 & 60 \\
\hline Insulation XPS & 58 & 2,450 & 2,500 & 105 \\
\hline MDF & 12 & 8,280 & -320 & -220 \\
\hline
\end{tabular}




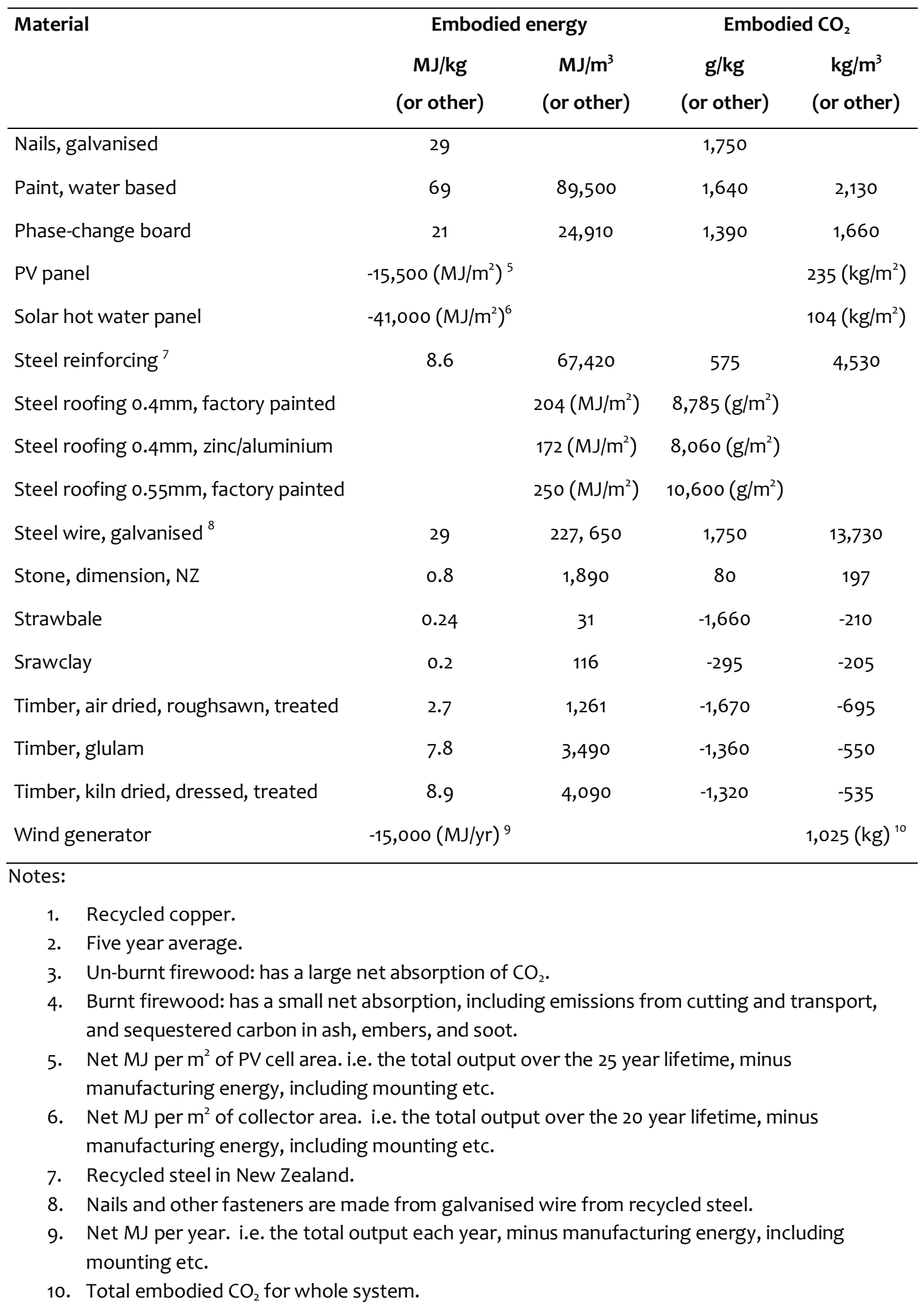




\section{References}

Abernethy, Virginia (1991), 'How Julian Simon could win the bet and still be wrong', Population \& Environment, 13 (1), 3-7.

Adam, David (2008), 'I underestimated the threat, says Stern', The Guardian, Friday 18 April, 2008, sec. Environment.

Adams, Douglas (1984), So Long, and Thanks for All the Fish (Hitchhiker's Guide to the Galaxy; London: Pan Books, UK).

Albritton, D.L. and Meira Filho, L.G. (2001), 'Technical Summary of the Working Group I', in J.T. Houghton, et al. (eds.), Climate Change 2001: The Scientific Basis: Contribution of working Group I to the Third Assessment Report of the Intergovernmental Panel on Climate Change (Cambridge: Cambridge University Press), 21-83.

Alcorn, Andrew (1995), 'Embodied Energy Coefficients of Building Materials', (Wellington: Centre for Building Performance Research, Victoria University of Wellington).

Alcorn, Andrew (1996a), 'Embodied Energy Coefficients of Building Materials', (Wellington: Centre for Building Performance Research, Victoria University of Wellington).

Alcorn, J. A. and Baird, G. (1996b), 'Embodied Energy Analysis of New Zealand Building Materials - Methods and Results', in Graham Treloar, Roger Fay, and Selwyn Tucker (eds.), Embodied Energy: The Current State of Play (Deakin University, Geelong: School of Architecture and Building, Deakin University) $61-71$

Alcorn, J. A. and Haslam, P. J. (1996c), 'The Embodied Energy of a Standard House - Then and Now', in Graham Treloar, Roger Fay, and Selwyn Tucker (eds.), Embodied Energy: The Current State of Play (Deakin University, Geelong: The School of Architecture and Building, Deakin University), 133-140.

Alcorn, Andrew (1998a), 'Embodied Energy Coefficients of Building Materials', (Wellington: Centre for Building Performance Research, Victoria University of Wellington).

Alcorn, Andrew and Wood, Peter (1998b), 'New Zealand Building Materials Embodied Energy Coefficients Database: Volume 1 - Database', (Wellington: Centre for Building Performance Research, Victoria University of Wellington).

Alcorn, Andrew, et al. (1999), 'Water Penetration of Straw Bale Walls', Solar99, Conference of the International Solar Energy Society (Geelong, Australia: International Solar Energy Society). 
Alcorn, Andrew (2001), 'Embodied Energy and $\mathrm{CO}_{2}$ Coefficients for NZ Building Materials', (Wellington: Centre for Building Performance Research, Victoria University of Wellington).

Alcorn, Andrew (2003), 'Embodied Energy and $\mathrm{CO}_{2}$ Coefficients for NZ Building Materials', (Wellington: Centre for Building Performance Research, Victoria University of Wellington,).

Alcott, Blake (2005), 'Jevons’ paradox', Ecological Economics, 54 (1), 9-21.

Alsema, E.A. (1998), 'Energy requirements and $\mathrm{CO}_{2}$ Mitigation Potential of PV Systems', BNL/NREL Workshop "PV and the Environment 19987" (Keystone, Colorado: Dept. of Science and Technology and Society, Utrecht University).

Alsema, E. A. (2000), 'Energy Pay-back Time and $\mathrm{CO}_{2}$ Emissions of PV Systems', Progress in Photovoltaics: Research and Applications, 8 (1), 17-25.

Anderson, Victor (2006), 'Turning economics inside out', International Journal of Green Economics, 1 (1/2), 11-22.

Ayres, Robert U. (2000), 'Commentary on the utility of the ecological footprint concept', Ecological Economics, 32 (3), 347-49.

Baines, J.T (1993), New Zealand Energy Information Handbook: Energy Data, Conversion Factors, Definitions, (Christchurch: Taylor Baines and Associates).

Baines, J.T. and Peet, N.J. (1995), '1991 Input-Output Energy Analysis Coefficients', (Taylor Baines and Associates).

Baird, George and Chan Seong Aun, (1983), 'Energy Cost of Houses and Light Construction Buildings', (Auckland: New Zealand Energy Research and Development Committee, University of Auckland).

Baird, G., Alcorn, A., Haslam, P. (1997), 'The Energy Embodied in Building Materials - Updated New Zealand Coefficients and Their Significance', IPENZ Transactions: Civil Engineering Section, 24 (1/CE), 46-54.

Barnes, Alysia (2006), 'Residential Buildings', 'Personal communication', with Andrew Alcorn (ed.), (Wellington: Statistics New Zealand), email.

Barney, Gerald O., Ed. (1980), 'The Global 2000 Report to the President of the U.S., Entering the 21st Century', (1; Washington: United States Council on Environmental Quality and the Department of State).

Bartlett, Albert A. (2000), 'Reflections in 1998 on the Twentieth Anniversary of the Paper "Forgotten Fundamentals of the Energy Crisis", Proceedings of the Energy Efficiency Policy Symposium (Honolulu, Hawaii).

Bartley, David (2004), Soma 1000 (Copacabana, NSW: Soma Power Pty Ltd). 
Battles, Stephanie J. and Hojjati, Behjat (2005), 'Two Decades of U.S. Household Trends in Energy-Intensity Indicators: A Look at the Underlying Factors', (Washington, D.C: Energy Information Administration).

Beacon (2005), 'Monitoring Construction Waste for the Rotorua NOW Home', (Auckland: Beacon Pathway Ltd).

Bennet, Mary (ed.), (2008), Materials: Level Sustainable Building Series, ed. Trevor Pringle (June 2008 edn., Level Sustainable Building Series, Porirua: BRANZ Ltd).

Benton, Michael J. (2003), When Life Nearly Died (New York: Thames and Hudson).

Berry, R. Stephen and Fels, Margaret F. (1973), 'The Energy Cost of Automobiles', Bulletin of the Atomic Scientists, 29 (10), 11-17, 58-60.

Binswanger, Mathias (2001), 'Technological progress and sustainable development: what about the rebound effect?' Ecological Economics, 36 (1), 119-32.

Birdsong, Bret (1998), 'Adjudicating Sustainability: New Zealand's Environment Court And The Resource Management Act', Ian Axford (New Zealand) Fellowship in Public Policy, <http://www.fulbright.org.nz/voices/axford/ $\sim$ docs/birdsongb.pdf $>$, accessed 17 November 2010 .

Black, Stuart (2006), 'Personal communication', with Andrew Alcorn (ed.), (Wellington: Ministry of Economic Development), email.

Bonner, William and Wiggin, Addison (2006), Empire of Debt: The Rise of an Epic Financial Crisis (Hoboken, New Jersey: John Wiley and Sons).

Boston, Jonathan (2006), 'The Public Interest, Climate Change and the Future of the Planet: Reducing the Sins of Emission', paper given at In The Public Interest Conference: A Tribute to Professor Keith Jackson, University of Canterbury, Christchurch, 25-26 August 2006.

Boulding, K. E. (1958), Principles of Economic Policy (Englewood Cliffs, New Jersey: Prentice-Hall).

Boulding, Kenneth E. (1966), 'The Economics of the Coming Spaceship Earth', in H. Jarret (ed.), Environmental Quality in a Growing Economy (Washington D.C.: Johns Hopkins Press).

Boulding, K. E. (1971), 'Foreword to T. R. Malthus, Population: The First Essay', Boulding, K. E. Collected Papers (2; Boulder: Colorado Associated University Press), 137-142.

Boulding, K. E. (1971), Toward a modest society: the end of growth and grandeur (Durham, New Hampshire: Whittemore School of Business and Economics, University of New Hampshire). 
Boulding, Kenneth E. (1986), 'The Science of Synthesis', Proceedings of the 7th Friends Association for Higher Education Conference, (Canton, Ohio: Malone College).

Boustead, I. and Hancock, G. F. (1979), Handbook of Industrial Energy Analysis (1 edn.; Chichester: Ellis Horwood Ltd; Halsted Press/Wiley).

Boustead, I. (1999), 'Eco-labels and eco-indices. Do they make sense?' Fourth International Ryder Transpac Conference (Brussels: Ryder Transpac).

Boustead, I, et al. (2000), 'Eco-Indices: What Can They Tell Us?' (Horsham, UK: Boustead Consulting/ ICME).

Bows, Alice, et al. (2006), 'Living within a carbon budget', (Manchester: Tyndall Centre for Climate Change Research, University of Manchester).

BP (2009), 'BP Statistical Review of World Energy June 2009', (http://www.bp.com/statisticalreview).

Bringezu, Stefan (2000), 'History and Overview of Material Flow Analysis', Special Session on Material Flow Accounting (Paris: OECD Working Group on Environmental Information and Outlooks).

Brown, Lester R. (2004), Outgrowing the Earth (New York: W.W. Norton \& Co.).

Brown, M.T. and Herendeen, R.A. (1996), 'Embodied energy analysis and EMERGY analysis: a comparative view', Ecological Economics, 19 (3), 219-235.

Brown, M.T. and Ulgiati, S. (1997), 'Emergy-based indices and ratios to evaluate sustainability: monitoring economies and technology toward environmentally sound innovation', Ecological Engineering, 9, 51-69.

Brundtland, Gro Harlem (1987), Our common future/World Commission on Environment and Development, ed. Gro Harlem Brundtland (Oxford: Oxford University Press).

Bullard, C.W. and Herendeen, R.A. (1975), 'The energy costs of goods and services', Energy Policy, 3 (4), 268-278.

Bullard, Clark W., Penner, Peter S., and Pilati, David A. (1978), 'Net Energy Analysis: Handbook for Combining Process and Input-Output Analysis', Resources and Energy, 1 (3), 267-313.

Burke, Eleanor J., Brown, Simon J., and Christidis, Nikolaos (2006), 'Modelling the Recent Evolution of Global Drought and Projections for the Twenty-First Century with the Hadley Centre Climate Model', Journal of Hydrometeorology, 7 (5), 1113-1125.

Carson, Rachel (1962), Silent Spring (New York: Houghton Mifflin). 
Carter, A.J., Peet, N.J, and Baines, J.T (1981), 'Direct \& Indirect Energy Requirements of the New Zealand Economy; An Energy Analysis of the 1971-72 Inter-Industry Survey', New Zealand Energy Research and Development Committee Report (Auckland: University of Auckland).

Castaneda, Beatriz E. (1999), 'An index of sustainable economic welfare (ISEW) for Chile', Ecological Economics, 28 (2), 231-244.

Census Bureau, U.S. (2006), 'Total Midyear Population for the World: 1950-2050', <http://www.census.gov/ipc/www/worldpop.html>, accessed 30 August 2006.

Census Bureau, U.S. (2009), 'U.S. \& World Population Clocks', (Washington: U.S. Census Bureau, Population Division).

Chapman, P.F. (1974), 'The Energy Costs of Producing Copper and Aluminium From Primary Sources', Met Mater, 8 (2), 107-111.

Chapman, P. F., Leach, G., and Slesser, M. (1974), 'The energy cost of fuels', Energy Policy, 2 (3), 231-243.

Chesworth, Ward (Ed.) (2008), Encyclopedia of Soil Science, (Dordrecht, The Netherlands: Springer).

Churchill, Winston (1943), 'Speech to the House of Commons', (London: Hansard).

Clarke, Arthur C. (1976), in 'The Peter Plan : A Proposal for Survival' (Ealing: Bantam)

Cleveland, Cutler J., Kaufmann, Robert K., and Stern, David I. (2000), 'Aggregation and the role of energy in the economy', Ecological Economics, (32), 301-317.

Cohen, Joel E. (2003), 'Human Population: The Next Half Century', Science, (Vol 302), 1172-1175.

Cole, Raymond (2006a), 'Moving from green to sustainable buildings', Build, June/July 2006.

Cole, Raymond J. (2006b), 'Editorial: Building Environmental Assessment: Changing the culture of practice', Building Research \& Information, 34 (4), 303-307.

Cole, Raymond (2006c), 'Shared markets: coexisting building environmental assessment methods', Building Research and Information, 34 (4), 357-371.

Collins, Chris (1993), Transport Energy Management Policies: Potential in New Zealand (Wellington: Energy Efficiency and Conservation Authority). 
Concept Consulting Group (2003), 'An Electricity Emission Factor', (Wellington: Wellington Climate Change Office, Ministry for the Environment).

Concept Consulting Group (2004), 'Electricity Emission Factor Review', (Wellington: Wellington Climate Change Office, Ministry for the Environment).

Costanza, Robert (2000), 'The dynamics of the ecological footprint concept', Ecological Economics, 32 (3), 341-345.

Cox, Peter M, et al. (2000), 'Acceleration of global warming due to carbon-cycle feedbacks in a coupled climate model', Nature, 408 (9), 184-187.

Coxall, Helen K., et al. (2005), 'Rapid stepwise onset of Antarctic glaciation and deeper calcite compensation in the Pacific Ocean', Nature, 433 (7021), 53-57.

CSR (2009), 'Architectural Roofing Manual', (Auckland: CSR Roofing).

Dahmus, Jeffrey B. and Gutowski, Timothy G. (2005), 'Efficiency and Production: Historical Trends for Seven Industrial Sectors', 3rd Biennial Conference of the US Society for Ecological Economics (Tacoma, WA: US Society for Ecological Economics).

Daly, Herman E. (1977), Steady-state economics: The economics of biophysical equilibrium and moral growth (San Francisco: W. H. Freeman).

Daly, Herman E. (1992), 'Elements of Environmental Macroeconomics', in Robert Costanza (ed.), Ecological Economics: The Science and Management of Sustainability (New York: Columbia University Press).

Dang, Hien, et al. (2009), 'New Zealand Energy Data File 2009', in Ministry of Economic Development (ed.), (Wellington: Ministry of Economic Development).

Darley, Julian (2004), High Noon for Natural Gas: The New Energy Crisis (White River Junction, Vermont: Chelsea Green).

Darwin, Charles Galton (1953), The Next Million Years (New York: Doubleday)

Davidson, Kelvin (2007), 'Residential: Us and them - a Trans-Tasman comparison of residential building statistics', Online Index <http://www.infometrics.co.nz/ top10/art1719.htm>, accessed 1-11-2007.

Davison, Aidan (2001), Technology and the Contested Meanings of Sustainability (New York: State University of New York Press).

Dawkins, Richard (1976), The Selfish Gene (Oxford: Oxford University Press). 
Dawson, S.M. (1978), 'Energy Requirements of Inputs to Agriculture in New Zealand', (Auckland: New Zealand Energy Research and Development Committee, University of Auckland).

DBH (2006c), 'Building and Housing Trends: January - March 2006', in DBH (ed.), (Wellington: Department of Building and Housing).

DESA, United Nations (1998), 'World Population Projections to 2150', (New York: Population Division, Department of Economic and Social Affairs, United Nations Secretariat).

Desai, Nitin (2002), 'Sustainable development', (ed.), Interview by Simon Dresner, in Simon Dresner, The Principles of Sustainability, (London: Earthscan).

Diamond, Jared (2005), Collapse: How Societies Choose to Fail or Survive (Camberwell, Victoria, Australia: Penguin Group).

Dove, William (2005), 'Life Cycle Assessment: An Argument for a Detailed Approach', LCM 2005 Innovation by Life Cycle Management International Conference (Barcelona: Boustead Consulting Limited).

Dresner, Simon (2002), The Principles of Sustainability (London: Earthscan Publications).

DTI (2006), 'Our energy challenge: securing clean, affordable energy for the longterm', (London: Department of Trade and Industry).

Dunford, Grant (2004), 'Wind Generators', 'Personal communication', with Andrew Alcorn (ed.), (Wellington: Negawatt Resources).

Edison, Thomas (1931) 'I'd put my money on solar energy', in Newton, James, Uncommon Friends: Life with Thomas Edison, Henry Ford, Harvey Firestone, Alexis Carrel \& Charles Lindbergh, (San Diego: Harcourt).

EECA (1995), Guidelines for Renewable Energy Developments, Wind Energy (Wellington: Energy Efficiency and Conservation Authority).

EECA (2001), 'Solar Energy Use and Potential in New Zealand', (Wellington: Energy Efficiency and Conservation Authority).

EECA and Consumer (2007), Solar W ater Heating Guide (Wellington: Consumers' Institute).

Ehrlich, Paul and Ehrlich, Anne (1968), The Population Bomb (New York: Ballantine).

Ehrlich, P.R. and Holdren, J. P (1971), 'Impact of Population Growth', Science, 171 (3977), 1212-1217. 
EIA (2008) 'Table H.1c World Per Capita Carbon Dioxide Emissions from the Consumption and Flaring of Fossil Fuels, 1980-2006' International Energy Annual, June-December 2008.

Ekvall, Tomas (2002), 'Limitations of Consequential LCA', InLCA/LCM 2002 (American Center for Life Cycle Assessment).

Elkington, John (1997), Cannibals with Forks: Triple Bottom Line of 21st Century Business (Oxford: Capstone).

Elmer-DeWitt, Philip, et al. (1992), 'Summit to Save the Earth: Rich Vs. Poor', Time, 139 (2), 42-58.

Emanuel, Kerry (2005), 'Increasing destructiveness of tropical cyclones over the past 30 years', Nature, 436/4, 686-688.

ENS (2010), 'Unmoved by Heating Planet, Climate, Talks in China Stumble', Environmental News Service, <http://www.ens-newswire.com/ens/ ح oct2010/2010-10-08-01.html> , accessed 7 November 2010.

Fay, Roger, Treloar, Graham and Iyer-Raniga, Usha (2000), 'Life-cycle energy analysis of buildings: A case study', Building Research \& Information, 29 (1), 31-41.

Fischlin, A. et al. (2007), 'Ecosystems, their properties, goods, and services. Climate Change 2007: Impacts, Adaptation and Vulnerability. Contribution of Working Group II to the Fourth Assessment Report of the Intergovernmental Panel on Climate Change', in O.F. Canziani et al. (eds.), Fourth Assessment Report of the Intergovernmental Panel on Climate Change (Cambridge,: Cambridge University Press), 211-272.

Forintek (1993), Raw Material Balances, Energy Profiles and Environmental Unit Factor Estimates for Cement and Structural Concrete Products (Building Materials in the Context of Sustainable Development; Toronto: Canada Centre for Mineral and Energy Technology and Radian Canada Inc.).

Gagnon, Luc and van de Vate, Joop F. (1997), 'Greenhouse gas emissions from hydropower: The state of research in 1996’, Energy Policy, 25 (1), 7-13.

GCI (2009), 'Contraction and Convergence', (Global Commons Institute) <http://www.gci.org.uk/contconv/cc.html>, accessed 1-9-2009.

GCP (2009), Global Carbon Project, <http:/ /www.globalcarbonproject.org/ index.htm>, accessed 29 November 2009.

Georgescu-Roegen, N. (1977), 'Inequality, Limits and Growth from a Bioeconomic Viewpoint', Review of Social Economy 35, 361-375. 
Giampietro, Mario and Mayumi., Kozo (1998), 'Another view of development, ecological degradation, and north-south trade.' Review of Social Economy, $56(1), 20$.

Gifford, J.S., et al. (1997), Energy Use in the New Zealand Forest Processing Industry (Rotorua: New Zealand Forest Research Institute Limited).

Gifford, Roger M. (2000a), 'Carbon Contents of Above-Ground Tissues of Forest and Woodland Trees', National Carbon Accounting System Technical Report No. 22 (Canberra: Australian Greenhouse Office).

Gifford, Roger M. (2000b), 'Carbon Content of Woody Roots: National Carbon Accounting System Technical Report No. 7 (Revision 1)', (Canberra: Australian Greenhouse Office).

Goedkoop, Mark and Oele, Michiel (2002), 'User Manual: Introduction into LCA methodology and practice with SimaPro 5', (Amersfoort, the Netherlands: Pre Consultants).

Goldsmith, Edward (1975), 'Strategy for tomorrow', The Ecologist, 5 (2), Editorial.

Goldsmith, Edward and Ferry, Steven (1999), 'Profits of doom', Government Technology, May 1999.

Grant, Tim. (2003), Australian Data Inventories, (Melbourne: RMIT Centre for Design).

Greening, Lorna A., Greene, David L. and Difiglio, Carmen (2000), 'Energy Efficiency and consumption - the rebound effect - a survey', Energy Policy, 28 (6-7), 389-401.

Greenspec (2009), 'Pitched roofing materials compared', (Greenspec) <http://www.greenspec.co.uk/html/materials/pitchedroofs.html>, accessed 2-5-2009.

Grönkvist, Stefan (2005), 'All $\mathrm{CO}_{2}$ molecules are equal, but some $\mathrm{CO}_{2}$ molecules are more equal than others', (Stockholm: KTH - Royal Institute of Technology).

Hallman, David G. (2002), 'Report on the World Summit on Sustainable Development' (World Council of Churches).

Hannon, B. (1973), 'The Structure of Ecosystems', Journal of Theoretical Biology, 41 (3), 535-46.

Hansen, James E (2006), 'Global Land-Ocean Surface Temperature Anomaly, 0.01C, Base: 1951-1980’, (Goddard Institute for Space Studies).

Hansen, James, et al. (2007), 'Climate change and trace gases', Philosophical Transactions of the Royal Society A 365 (1856), 1925-54. 
Hansen, J., et al. (2008), 'Target atmospheric $\mathrm{CO}_{2}$ : Where should humanity aim?' Open Atmospheric Science Journal, 2, 217-31.

Hansen Products, NZ Ltd (1996), PVC and the Environment (Hansen Products NZ Ltd).

Hartenstein, Hans-Ulrich, and Horvay, Marc (1996), 'Overview of municipal waste incineration industry in West Europe (based on the German experience)', Journal of Hazardous Materials, 47(1-3), 19-30.

Hasselmann, K., et al. (2003), 'The Challenge of Long-Term Climate Change', Science 302 (5652), 1923-25.

Haub, Carl (1995), 'Global and U.S. National Population Trends', Consequences, U.S. Global Change Research Information Office, 1 (2).

Hecht, Joy E. (2005), 'Tracking Sustainability: A Review of Strategies', US EPA Workshop on Sustainability (Washington: US EPA).

Heijungs, Reinout, et al. (1996), Life Cycle Assessment: What it is and how to do it, eds Jacqueline Aloisi de Larderel, Sybren de Hoo, and John Kryger (Paris: United Nations Environment Programme/Industry and Environment).

Heinberg, Richard (2003), The Party's Over (Gabriola Island, Canada: New Society Publishers).

Heinberg, Richard (2007), Peak Everything: Waking Up to the Century of Declines (Gabriola Island, Canada: New Society Publishers).

Herendeen, R (1972), 'The Energy Costs of Goods and Services', (Urbana, Illinois: Center for Advance Computation, University of Illinois).

Herendeen, R. and Tanaka, J. (1976), 'Energy Cost of Living', Energy, 1, 165-78.

Herendeen, Robert A. (2000), 'Ecological footprint is a vivid indicator of indirect effects', Ecological Economics, 32 (3), 357-58.

Herring, E Horace (1998), 'Does Energy Efficiency Save Energy: The Implications of accepting the Khazzoom-Brookes Postulate', Energy Journal, 1 (4), 21-39.

Herring, H. (2000), 'Is Energy Efficiency Environmentally Friendly?' Energy and Environment, 11 (3), 313-25.

Hobbs, Marion (2005), 'Speech to Sustainable Architecture Awards Ceremony', in Victoria University of Wellington School of Architecture, Wellington, 30 August, 2005.

Holmberg, J. and Karlsson, S. (1992), 'Society and The Environment: a Swedish 
Research Perspective, quoted in Upham, P., 'An assessment of The Natural Step theory of sustainability', Journal of Cleaner Production, 8 (6), 445-54.

Hondo, Hiroki (2000), 'Finding Life Cycle CO2 Emissions by Power Generation Type: Calculated and Reassessed Using the Latest Data', CRIEPI News, (338).

Houben, Hugo and Guillard, Hubert (1994), Earth Construction: A Comprehensive Guide (London: Intermediate Technology Publications).

Houghton, J.T., et al. (2001), Climate Change 2001: The Scientific Basis; Contribution of Working Group I to the Third Assessment Report of the Intergovernmental Panel on Climate Change (Cambridge: Cambridge University Press).

Houghton, R.A., (1999), 'The annual net flux of carbon to the atmosphere from land use 1850-1990'. Tellus, 51B, 298-313.

Isaacs, Nigel, et al. (2006), 'Energy Use in New Zealand Households: Report on the Year 10 Analysis for the Household Energy End-use Project (HEEP)', (Judgeford, New Zealand: BRANZ).

Isaacs, Nigel (2010), 'Keeping warm with rainbows of colour', Build, 118, June/July 2010, 94-95.

ISO:14040:1997 (1997), 'Environmental management - Life cycle assessment Principles and framework', (TC 207/SC 5: International Organization for Standardization).

IUCN (1980), World Conservation Strategy: Living Resources Conservation for Sustainable Development (Gland, Switzerland: International Union for Conservation of Nature and Natural Resources).

Jaques, Roman (2001), 'Environmental Impacts Associated with New Zealand Concrete Manufacture', (Porirua: Building Research Association of New Zealand).

Jevons, William Stanley (1865), The Coal Question: An Inquiry Concerning the Progress of the Nation, and the Probable Exhaustion of Our Coal-mines (New York: Augustus M. Kelley).

Johnstone, Ivan M. (2001), 'Energy and mass flows of housing: estimating mortality', Building and Environment Volume 36 (Issue 1), 43-51.

Johnstone, Ivan M. (2004), 'Stock and Flow Models of Housing', The New Zealand Society for Sustainability Engineering and Science International Conference on Sustainability Engineering and Science (Auckland: The New Zealand Society for Sustainability Engineering and Science).

Jollands, Nigel (2003), 'An Ecological Economics of Eco-Efficiency: Theory, Interpretations and Applications to New Zealand', (Palmerston North: 
Massey University).

Joint Research Centre, European Commission (2009), 'Life Cycle Thinking', <http://lct.jrc.ec.europa.eu/about-lca-lct>, accessed 2 October, 2009.

Keeling, C.D. and Whorf, T.P. (2005), 'Atmospheric CO2 records from sites in the SIO air sampling network.' Trends: A Compendium of Data on Global Change, Carbon Dioxide Information Analysis Center, Oak Ridge National Laboratory US Department of Energy <http://cdiac.esd.ornl.gov/ $\sim \mathrm{ftp} /$ trends/co2/maunaloa.co2>, accessed September 2005.

Khazzoom, J. Daniel (1980), 'Economic implications of mandated efficiency in standards of household appliances.' Energy Journal, 1 (4), 21-40.

Kitzes, Justin, et al. (2007), 'Shrink and share: humanity's present and future Ecological Footprint', Philosophical Transactions of the Royal Society B, 363, 46775.

Klein, Naomi (2009), 'Copenhagen's failure belongs to Obama', Guardian, Monday 21 December 2009.

Knutson, Thomas R. and Tuleya, Robert E. (2004), 'Impact of $\mathrm{CO}_{2}$-Induced Warming on Simulated Hurricane Intensity and Precipitation: Sensitivity to the Choice of Climate Model and Convective Parameterization', Journal of Climate, 17 (18), 3477 - 95.

Kuroda, Toshio (1999), 'A Compass to Lead us to the Future', Asian Urban Information Center of Kobe Newsletter, (35).

Lawn, Philip A. (2003), 'A theoretical foundation to support the Index of Sustainable Economic Welfare (ISEW), Genuine Progress Indicator (GPI), and other related indexes', Ecological Economics, 44 (1), 105-18.

Le Quéré, Corinne, et al. (2007), 'Saturation of the Southern Ocean $\mathrm{CO}_{2}$ Sink Due to Recent Climate Change - Le Quéré et al.' Science, 316 (5832), 1735 - 38.

Le Quéré, Corinne, et al. (2009), 'Trends in the sources and sinks of carbon dioxide', Nature Geoscience 2(11).

Leach, G. (1975), 'Energy and food production', Food Policy 1(1), 62-73.

Leontief, Wassily (1986), Input-Output Economics (New York: Oxford University Press).

Leopold, Aldo (1949), A Sand County Almanac (Oxford: Oxford University Press).

Liu, Yingling (2005), 'China Calls on the U.S. to Join Kyoto Protocol', Worldwatch, <http://www.worldwatch.org/node/144>, accessed 7 November 2010. 
Long, Thomas Veach (ed.), (1975), Workshop on Energy Analysis and Economics (Stockholm: International Federation of Institutes for Advanced Study (IFIAS)).

Lotka, Alfred J. (1922), 'Contribution to the Energetics of Evolution', Proceedings of the National Academy of Sciences of the United States of America, 8 (6), 147-51.

Lovelock, James (2006), The Revenge of Gaia (London: Allen Lane: Penguin).

Lovelock, James (2009), The Vanishing Face of Gaia: A Final Warning (London: Allen Lane: Penguin).

Lowe, Robert (2000), 'Defining and meeting the carbon constraints of the 21st century', Building Research \& Information, 28 (3), 159-75.

Lowe, Ian (2005), 'Sustainability in Practice: An Integrated Approach', Working On The Frontier: Environmental Sustainability In Practice (Christchurch: Environment Institute of Australia and New Zealand).

Machlup, Fritz (1939), 'Period Analysis and Multiplier Theory', The Quarterly Journal of Economics, 54 (1), 1-27.

Malthus, Thomas (1798), An Essay on the Principle of Population (London: J. Johnson).

Marland, G., Boden, T.A., and Andres, R. J (2005), 'Global, Regional, and National fossil fuel CO2 emissions', Trends: A Compendium of data on global change. Carbon Dioxide Information Analysis Center, Oak Ridge National Laboratory (Oak Ridge, Tennessee: U.S. Department of Energy).

Mawhinney, Mark (2002), Sustainable Development: Understanding the green debates (Oxford: Blackwell Science Ltd).

McDonough, William and Braungart, Michael (1998), 'The Next Industrial Revolution', The Atlantic Monthly, 282 (4), 82-92.

McLaren, P. (2001), 'Carbon in radiata pine', in Andrew Alcorn, (Rotorua: Forest Research Institute).

Meadows, Donella H. et al. (1972), The Limits to Growth (New York: Universe Books).

Meadows, Donella, Jorgen Randers and Dennis Meadows (2004), Limits to Growth: The 30-Year Update (Chelsea Green Publishing).

MED (1997a), 'New Zealand Energy Data File January 1997', (Wellington: Ministry of Economic Development).

MED (1997b), 'New Zealand Energy Data File July 1997', (Wellington: Ministry of Economic Development). 
MED (1998a), 'New Zealand Energy Data File January 1998', (Wellington: Ministry of Economic Development).

MED (1998b), 'New Zealand Energy Data File July 1998', (Wellington: Ministry of Economic Development).

MED (1999a), 'New Zealand Energy Data File January 1999', (Wellington: Ministry of Economic Development).

MED (1999b), 'New Zealand Energy Data File July 1999', (Wellington: Ministry of Economic Development).

MED (2000a), 'New Zealand Energy Data File January 2000', (Wellington: Ministry of Economic Development).

MED (2000b), 'New Zealand Energy Greenhouse Gas Emissions 1990-1999', in Ministry of Economic Development, (Wellington: Energy Markets Information and Services, Networks Directorate, Resources and Networks Branch, Ministry of Economic Development).

MED (2000c), 'New Zealand Energy Data File July 2000', (Wellington: Ministry of Economic Development).

MED (2001a), 'New Zealand Energy Data File January 2001', (Wellington: Ministry of Economic Development).

MED (2001b), 'New Zealand Energy Greenhouse Gas Emissions 1990-2000', in Ministry of Economic Development, (Wellington: Energy Markets Information and Services, Networks Directorate, Resources and Networks Branch, Ministry of Economic Development).

MED (2001c), 'New Zealand Energy Data File July 2001', (Wellington: Ministry of Economic Development).

MED (2002a), 'New Zealand Energy Data File January 2002', (Wellington: Ministry of Economic Development).

MED (2002b), 'New Zealand Energy Greenhouse Gas Emissions 1990-2001', in Ministry of Economic Development, (Wellington: Energy Markets Information and Services, Networks Directorate, Resources and Networks Branch, Ministry of Economic Development).

MED (2002c), 'New Zealand Energy Data File July 2002', (Wellington: Ministry of Economic Development).

MED (2003a), 'New Zealand Energy Data File January 2003', (Wellington: Ministry of Economic Development). 
MED (2003b), 'New Zealand Energy Greenhouse Gas Emissions 1990-2002', in Ministry of Economic Development, (Wellington: Energy Markets Information and Services, Networks Directorate, Resources and Networks Branch, Ministry of Economic Development).

MED (2003c), 'New Zealand Energy Data File July 2003', (Wellington: Ministry of Economic Development).

MED (2004a), 'New Zealand Energy Data File January 2004', (Wellington: Ministry of Economic Development).

MED (2004b), 'New Zealand Energy Greenhouse Gas Emissions 1990-2003', in Ministry of Economic Development, (Wellington: Energy Markets Information and Services, Networks Directorate, Resources and Networks Branch, Ministry of Economic Development).

MED (2004c), 'New Zealand Energy Data File July 2004', (Wellington: Ministry of Economic Development).

MED (2005a), 'New Zealand Energy Data File January 2005', (Wellington: Ministry of Economic Development).

MED (2005b), 'New Zealand Energy Greenhouse Gas Emissions 1990-2004', in Ministry of Economic Development, (Wellington: Energy Information \& Modelling Group, Resources and Networks Branch, Ministry of Economic Development).

MED (2005c), 'New Zealand Energy Data File July 2005', (Wellington: Ministry of Economic Development).

MED (2006a), 'New Zealand Energy Data File January 2006', (Wellington: January 2006 edn.: Ministry of Economic Development).

MED (2006b), 'New Zealand Energy Greenhouse Gas Emissions 1990-2005', in Ministry of Economic Development, (Wellington: Energy Information \& Modelling Group, Resources and Networks Branch, Ministry of Economic Development).

MED (2006c), 'New Zealand Energy Data File September 2006', (Wellington: September 2006 edn.: Ministry of Economic Development).

MED (2006d), 'Revised New Zealand Energy Greenhouse Gas Emissions 1990-2005', in Ministry of Economic Development, (Wellington: Energy Information \& Modelling Group, Resources and Networks Branch, Ministry of Economic Development).

MED, Energy Information and Modelling Group (2007), 'New Zealand Energy Greenhouse Gas Report 1990-2006', (Wellington: Energy Information and 
Modelling Group, Energy and Communications Branch, Ministry of Economic Development, New Zealand).

MED (2008a), 'New Zealand Energy Data File June 2008', (Wellington: Ministry of Economic Development).

MED, Gabriels, Micah, Kent Hammond, Simon Lawrence, and Kennie Tsui, Mark Walkington and David Wilkinson (2008b), New Zealand Energy Greenhouse Gas Report 1990-2007', (Wellington: Energy Information and Modelling Group, Energy and Communications Branch, Ministry of Economic Development, New Zealand).

MED, et al. (2009b), 'New Zealand Energy Greenhouse Gas Emissions 2009', (Wellington: Energy Information and Modelling Group, Energy and Communications Branch, Ministry of Economic Development, New Zealand).

Meehl, G.A. et al. (2007), 'Global Climate Projections.' in Solomon, S. et al. (eds.), Climate Change 2007: The Physical Science Basis. Contribution of Working Group I to the Fourth Assessment Report of the Intergovernmental Panel on Climate Change (Cambridge: Cambridge University Press).

Meinshausen, Malte (2006), What does a 20C Target Mean for Greenhouse Gas Concentrations? A Brief Analysis Based on Multi-Gas Emission Pathways and Several Climate Sensitivity Uncertainty Estimates', in H.J. Schellnhuber, et al. (eds.), Avoiding Dangerous Climate Change (Cambridge: Cambridge University Press).

Meinshausen, Malte et al. (2009), 'Greenhouse-gas emission targets for limiting global warming to $2{ }^{\circ} \mathrm{C}$ ', Nature, 458 (7242), 1158-62.

Metz, B and vanVuuren, D (2006), 'How, and at What Costs, can Low-Level Stabilization be Achieved? - An Overview', in Hans Joachim Schellnhuber, et al. (eds.), Avoiding Dangerous Climate Change (Cambridge: Cambridge University Press).

Meyer, Aubrey (2000), Schumacher Briefing 5: Contraction and Convergence: A Global Framework to Cope with Climate Change (Totnes: Green Books).

MfE (1991), 'Resource Management Act 1991', in Ministry for the Environment, (Wellington: Ministry for the Environment).

Micales, J. A. and Skog, K. E. (1997), 'The Decomposition of Forest Products in Landfills', International Biodeterioration \& Biodegradation, 39 (2-3), 145-58.

Miller, G Tyler (1992), Living in the Environment (7th edn.; Belmont, California: Wadsworth). 
Milne, Markus J. and Ball, Amanda (2005), 'Examining the Triple Bottom Line: From soothing palliatives and towards ecological literacy', 16th International Conference on Social and Environmental Accounting Research, (Geelong, Victoria, Australia: Deakin University).

Moffatt, Ian (2000), 'Ecological footprints and sustainable development', Ecological Economics, 32 (3), 359-62.

Mortished, Carl (2007), 'Energy crisis cannot be solved by renewables, oil chiefs say', The Times, June 25, 2007.

Muir, John (1911), My First Summer in the Sierra (Boston: Houghton Mifflin).

Mycio, Mary (2005), Wormwood Forest - A Natural History of Chernobyl (Washington: Joseph Henry Press).

Myers, Ransom A; Hutchings, Jeffrey A; Barrowman, Nicholas J. (1997), 'Why do Fish Stocks Collapse?’ Ecological Applications, Vol. 7 (No. 1), 91-106.

Myerson, George and Rydin, Yvonne (1996), The Language of Environment (London: Routledge).

Najam, Adil, Huq, Saleemul, and Sokona, Youba (2003), 'Climate negotiations beyond Kyoto: developing countries concerns and interests', Climate Policy, 3, 221-31.

Nakicenovic, Nebojsa, et al. (2000), 'IPCC Special Report Emissions Scenarios', (Nairobi: Intergovernmental Panel on Climate Change).

Nebel, B. and Szalay, Z. (2007), 'Life Cycle Assessment of a New Zealand house', New Zealand Society for Sustainability Engineering and Science Conference, (Auckland: New Zealand Society for Sustainability Engineering and Science).

Nebel, Barbara, Alcorn, Andrew and Wittstock, Bastian (2008), 'Life Cycle Assessment: Adopting and adapting overseas LCA data and methodologies for building materials in New Zealand', (Wellington, Ministry of Agriculture and Forestry).

Nebel, Barbara, et al. (2009), 'Life Cycle Inventory - Review of data collection protocols', (Wellington: New Zealand Ministry of Economic Development), 90.

Nielsen, Ole (2009), 'From Palaeozoic via Mass Extinctions to Quaternary', http://images.google.co.nz/imgres?imgurl=http:// files.myopera.com/nielsol /blog/Phanerozoic_Biodiversity.jpg\&imgrefurl=http://my.opera.com/nielsol /archive/monthly/\%3Fmonth\%3D200911\&usg=_a1bO4ylacZDlzt3GnnSlJ $\mathrm{FJXwiQ}=\& \mathrm{~h}=379 \& \mathrm{w}=640 \& \mathrm{sz}=62 \& \mathrm{hl}=$ en $\&$ start $=16 \& \operatorname{sig} 2=$ jcykDe6brXWfq $2 \mathrm{mLqcfMnQ} \& u m=1 \&$ itbs $=1 \&$ tbnid $=\mathrm{jMl} 3 \mathrm{VKaeNL}$ ovM:\&tbnh=81\&tbnw $=$ 137\&prev $=/$ images $\% 3 \mathrm{Fq} \% 3 \mathrm{Dmass} \% 2 \mathrm{Bextinction} \% 2 \mathrm{Btime} \% 2 \mathrm{Bchart} \% 26 \mathrm{um}$ 
$\% 3 \mathrm{D} 1 \% 26 \mathrm{hl} \% 3 \mathrm{Den} \% 26 \mathrm{client} \% 3 \mathrm{Dfirefox}-$

$\mathrm{a} \% 26 \mathrm{sa} \% 3 \mathrm{DN} \% 26 \mathrm{rlz} \% 3 \mathrm{D} 1 \mathrm{R} 1 \mathrm{GGGL}$ en-

GB___NZ369\%26tbs\%3Disch:1\&ei=sN-6S4WTJ82HkAWGIKyvCA, accessed December 2009.

Noble, J., Clarke, R.B. and Naylor, T. (1976), 'Energy Use in the Kilning Drying and Heat Curing Industries, Report No. 11.' New Zealand Energy Research Development Committee Reports (Auckland: University of Auckland).

Norberg-Hodge, Helena (2010), North-South Divide And Tackling Global Warning, Counter Currents, < $\underline{\text { http://www.countercurrents.org/ }}$ ح hodge280210.htm >, accessed 5 March 2010.

Odum, Howard T. (1971), Environment, power, and society (New York: WileyInterscience).

Odum, Howard, T. and Odum, Elisabeth C. (1976), Energy Basis for Man and Nature (New York: McGraw-Hill).

Odum, Howard T. (1996), Environmental Accounting, Emergy and Decision Making (New York: John Wiley).

OECD (2004), 'OECD Key Environmental Indicators', (Paris: Working Group on Environment Information and Outlooks, Organisation for Economic Cooperation and Development).

OED ‘The Oxford English Dictionary’, <http://www.oed.com/>.

Oka, Tatsuo, Suzuki, Michiya, and Konnya, Tetsuo (1993), 'The estimation of energy consumption and amount of pollutants due to the construction of buildings.' Energy and Buildings, 19 (4), 303-311.

O’Neill, Brian C and Oppenheimer, Michael (2002), 'Dangerous Climate Impacts and the Kyoto Protocol', Science, 296 (5575), 1971-1972.

Onigkeit, Janina and Alcamo, Joseph (1999), 'A Different Perspective for Global Climate Policy: Combining Burden Sharing and Climate Protection', in Carlo Carraro (ed.), FEEM Fondazione Eni Enrico Mattei Research Working Paper (Milano: Fondazione Eni Enrico Mattei).

O'Riordan, Timothy (1988), 'The Politics of Sustainability', in R. Kerry Turner (ed.), Sustainable Environmental Management: Principles and Practice (London: Belhaven Press), 29-50.

Osborn, Fairfield (1948), Our Plundered Planet (Boston: Little, Brown and Co.).

Pachauri, Rajendra (2005), 'Global warming approaching point of no return', Small Island Developing States Conference, (Mauritius). 
Page, Ian (2005), 'Building material life expectancy: Life Cycle Costs', 'Personal communication', with Andrew Alcorn (ed.), (Porirua: Building Research Association of New Zealand), email.

Park, Julian, Finn, John and Cooke, Richard (2005), 'Environmental Challenges in Farm Management', <http://www.ecifm.rdg.ac.uk/\#Intro; http://www. ecifm.rdg.ac.uk/inofsd.htm>, accessed 9-May-2006.

Parris, Thomas M. and Kates, Robert W. (2003), 'Characterizing And Measuring Sustainable Development', Annual Review of Environment and Resources, 28 (1), 559-586.

Parry, M.L. et al. (2007), 'Technical Summary. Climate Change 2007: Impacts, Adaptation and Vulnerability. Contribution of Working Group II to the Fourth Assessment Report of the Intergovernmental Panel on Climate Change', in O.F. Canziani et al. (eds.), Fourth Assessment Report of the Intergovernmental Panel on Climate Change (Cambridge, Cambridge University Press).

Peet, N.J and Baines, J.T. (1986), 'Energy Analysis: A Review of Theory and Applications', New Zealand Energy and Development Committee Reports (Auckland: University of Auckland).

Peet, John (1993), 'Input-output methods of energy analysis', International Journal of Energy Issues, Special Issue on Energy Analysis, 5 (1), 10-18.

Peet, John (2004), 'Technology for Sustainability - Some Facts and Some Fallacies', International Conference on Sustainability Engineering and Science (Auckland: The New Zealand Society for Sustainability Engineering and Science).

Pinchot, Gifford (1998), Breaking new ground (Washington, D.C: Island Press).

Pink, Brian (2002), '2001 Census Of Population And Dwellings: Population and Dwelling Statistics', (Wellington: Statistics New Zealand).

Pollard, William C (1969), 'Man on a Spaceship', Journal of the American Scientific Affiliation, (21), 34-39.

Prentice, I.C., et al. (2001a), 'Climate Change 2001: Working Group I: The Scientific Basis, 3. The Carbon Cycle and Atmospheric Carbon Dioxide', (Cambridge: Cambridge University Press).

Prentice, I.C., et al. (2001b), 'The Carbon Cycle and Atmospheric Carbon Dioxide', Climate Change 2001: The Scientific Basis, Contribution of Working Group I to the Third Assessment Report of the Intergovernmental Panel on Climate Change (Cambridge: Cambridge University Press).

Price, David (1995), 'Energy and Human Evolution', Population and Environment: $A$ Journal of Interdisciplinary Studies, 16 (4), 301-19. 
Raupach, M and Fraser, Paul (2006), 'Increase in carbon dioxide emissions accelerating, CSIRO Media Release, (06/243).

Rees, William E. (2000), 'Eco-footprint analysis: merits and brickbats', Ecological Economics, 32 (3), 371-74.

Resene (2007), 'Resene expected paint system life', (Resene Paints Ltd).

RioTinto (2007), 'Aluminium Production', (Rio Tinto Aluminium).

Robert, Karl-Henrik (2002), The Natural Step Story: Seeding a Quiet Revolution (Gabriola Island, British Columbia: New Society Publishers).

Romm, Joseph J. (2004), The Hype About Hydrogen: Fact and Fiction in the Race to Save the Climate (Washington: Island Press).

Roose, S.A. and S.H. Gowland (2005), 'Zero and Low Energy Houses Summary Report', in A. Stoecklein, et al. (eds.), (Porirua: Building Research Association of New Zealand).

Saunders, Harry D. (1992), 'The Khazzoom-Brookes Postulate and Neoclassical Growth', Energy Journal, 13 (4), 131-48.

Saunders, Caroline, Barber, Andrew, and Taylor, Greg (2006), 'Food Miles Comparative Energy/Emissions Performance of New Zealand's Agriculture Industry', (Christchurch: Agribusiness \& Economics Research Unit, Lincoln University).

Savinar, Matt (2004), The Oil Age Is Over: What to Expect as the World Runs Out of Cheap Oil, 2005-2050 (Santa Rosa: Savinar).

Schmidt, Gavin (2005), 'Planetary energy imbalance?' RealClimate: Climate science from climate scientists, 3 May 2005, <http://www.realclimate.org/ index.php/archives/2005/05/planetary-energy-imbalance/\#more-148>, accessed 20 October 2006.

Sitch, S. et al. (2008), 'Evaluation of the terrestrial carbon cycle, future plant geography and climate-carbon cycle feedbacks using five dynamic global vegetation models (DGVMs)', Global Change Biology, 14, 2015-2039.

Slesser, Malcolm (ed.), (1974), Energy Analysis Workshop on Methodology and Conventions (Stockholm: International Federation of Institutes for Advanced Study).

Smith, J.B.; Schellnhuber, H.J.; Monirul Qader Mirza, M.; Fankhauser, S.; Leemans, R.; Erda, L.; Ogallo, L.; Pittock, B.; Richels, R.; Rosenzweig, C.; Safriel, U.; Tol, R.S.J.; Weyant, J.; Yohe, G. (2001), 'Vulnerability to Climate Change and Reasons for Concern: A Synthesis', Climate Change 2001: Impacts, Adaptation, 
and Vulnerability. Contribution of Working Group II to the Third Assessment Report of the IPCC, eds McCarthy J., Canziana O., Leary N., Dokken D., and White K. (Cambridge: Cambridge University Press).

Soddy, Frederick (1926), Wealth, Virtual Wealth and Debt: The Solution of the Economic Paradox (London: George Allen \& Unwin).

Solomon, S., et al. (2007), 'Technical Summary. In: Climate Change 2007: The Physical Science Basis. Contribution of Working Group I to the Fourth Assessment Report of the Intergovernmental Panel on Climate Change', in S. Solomon, et al. (eds.), Climate Change 2007: The Physical Science Basis. Contribution of Working Group I to the Fourth Assessment Report of the Intergovernmental Panel on Climate Change (Cambridge: Cambridge University Press).

SOMA (2004), 'SOMA 1000', http://www.somapower.com.au/wind/soma1000. htm, accessed 1 November 2009.

Standards, New Zealand (1998), 'NZS 4299:1998 Earth Buildings Not Requiring Specific Design', (NZS 4299:1998: Standards New Zealand).

Standards, New Zealand and Committee, Timber Framing (1999a), 'NZS 3604:1999 Timber Framed Buildings', (NZS 3604:1999: Standards New Zealand).

Standards, New Zealand (1999b), 'NZS 4229:1999 Concrete Masonry Buildings Not Requiring Specific Engineering Design', (NZS 4229:1999: Standards New Zealand).

Statistics New Zealand (1995), 'Inter-Industry Transaction Study at the 80 Industry Level for 1991', (Wellington: Statistics New Zealand).

Statistics New Zealand (2001), 'Inter-Industry Transaction Study at the 126 Industry Level for 1995/96', (Wellington: Statistics New Zealand).

Statistics New Zealand (2003), 'Building Consents Issued: November 2003', (Wellington: Statistics New Zealand).

Statistics New Zealand (2006b), Energy, Economy and Emissions 1997 to 2003 (Wellington: Environmental Accounts, Product Development and Publishing, Statistics New Zealand).

Statistics New Zealand (2007), 'Information about the Inter Industry Study'. (Wellington: Statistics New Zealand).

Statistics New Zealand (2008b), 'Building Consents Issued: October 2008', (Wellington: Statistics New Zealand).

Statistics New Zealand (2008c), 'National Population Estimates: September 2008 quarter', (Wellington: Statistics New Zealand). 
Statistics New Zealand (2008d), 'Demographic Trends: 2007', (Wellington: Statistics New Zealand).

Statistics New Zealand (2008e), 'Private dwelling estimates by tenure, March 1991 September 2008, (Wellington: Statistics New Zealand).

Steen, Athena Swentzell, et al. (1994), The Straw Bale House (White River Junction, Vermont: Chelsea Green Publishing).

Stein, R.G. (1976), Energy Use for Building Construction (New York: CAC, University of Illinois and R.G. Stein \& Associates).

Stern, Sir Nicholas (2006), 'Stern Review Report', (Cambridge: Cambridge University Press).

Stoecklein, Albrecht, et al. (2005a), '100\$ Worth of Comfort: The Real Value of Energy Technologies', 39th Annual Australia and New Zealand Architectural Science Conference (Porirua: Building Research Association of New Zealand).

Stoecklein, Albrecht, et al. (2005b), "The Value of Low Energy technologies for Occupant and Landlord', ANZSEE 2005 "Ecological Economics in Action" (Massey University, Palmerston North, New Zealand: Building Research Association of New Zealand).

Tainter, Joseph A. (1988), The Collapse of Complex Societies (Cambridge: Cambridge University Press).

Tans, Pieter (2008), 'Trends in Atmospheric Carbon Dioxide - Mauna Loa', National Oceanic and Atmospheric Administration, U.S. Department of Commerce, <www.esrl.noaa.gov/gmd/ccgg/trends/>, accessed 19 November 2010.

Treloar, Graham (1996), Environmental Impact of Construction - A Case Study (Master of Architecture; Sydney: Australia and New Zealand Architectural Science Association).

Treloar, Graham John (1998), 'A Comprehensive Embodied Energy Analysis Framework', (PhD Thesis, Deakin, Australia: Deakin University).

Treloar, G.J., Love, Peter E. D., and Holt, Gary D. (2001), 'Using National InputOutput Data for Embodied Energy Analysis of Individual Residential Buildings', Construction Management and Economics, (19), 49-61.

UNFCCC (1992), 'United Nations Framework Convention on Climate Change', (FCCC/INFORMAL/84 GE.05-62220 (E) 200705: Climate Change Secretariat (UNFCCC)).

Upham, Paul (2000), 'An assessment of The Natural Step theory of sustainability', Journal of Cleaner Production, 8 (6), 445-54. 
Vale, Robert and Vale, Brenda (2009), Time to Eat the Dog?: The Real Guide to Sustainable Living (London, Thames and Hudson).

van den Bergh, Jeroen C. J. M. and Verbruggen, Harmen (1999), 'Spatial sustainability, trade and indicators: an evaluation of the "ecological footprint", Ecological Economics, 29 (1), 61-72.

van der Werf, G. R. et al., (2009) 'Estimates of fire emissions from an active deforestation region in the southern Amazon based on satellite data and biogeochemical modelling'. Biogeosciences 6, 235-249 (2009).

van Engelenburg, B. C. W, et al. (1994), 'Calculating the Energy Requirements of Household Purchases: A practical step by step method', Energy Policy, 22 (8), 648-56.

van Kooten, G. Cornelis and Bulte, Erwin H. (2000), 'The ecological footprint: useful science or politics?' Ecological Economics, 32 (3), 385-89.

Vogt, William (1948), Road to Survival (New York: William Sloane Associates).

Wackernagel, Mathis and Rees, William (1996), Our Ecological Footprint: Reducing Human Impact on the Earth (Gabriola Island, Canada: New Society Publishers).

Wackernagel, Mathis (2005), 'The Ecological Footprint: What's in it for you?', $<$ http://www.sustainable-scotland.net/documents/conf/pres_mw.pdf>, accessed 25 May 2006.

Ward, Peter D. (2008), Under a Green Sky: Global Warming, the Mass Extinctions of the Past, and What They Can Tell Us About Our Future (New York: Smithsonian Books/Harper Collins).

Watson, Traci (2009), 'Deal on climate change is elusive', USA TODAY, http://www.usatoday.com/weather/climate/2009-09-22-climatechange_N.htm23, accessed 23 September, 2009.

Wei, Yi-Ming , et al. (2006), 'A scenario analysis of energy requirements and energy intensity for China's rapidly developing society in the year 2020', Technological Forecasting and Social Change, 73 (4), 405-21.

Weidema, Bo Pedersen (1997), Environmental Assessment of Products (Helsinki: Finnish Association of Graduate Engineers).

Weir, G. and Muneer, T. (1998), 'Energy and Environmental Impact Analysis of Double-Glazed Windows', Energy Conversion and Management, 39 (3/4), 243-56.

White, Leslie A. (1959), The Evolution of Culture; The Development of Civilization to the Fall of Rome (Toronto: Mcgraw-Hill). 
Wilson, Edward. O. (2002), The Evolution of Life (New York: Vintage Books, Random House)

Wilson, R.J. (2002), The Exemplar House: A Specific Example of Residential Costing (Auckland: Plans and Specifications Ltd).

Wilting, Harm Christiaan (1996), 'An energy perspective on economic activities', (Groningen, The Netherlands: Rijksuniversiteit Groningen University).

Wright, Ronald (2006), 'Flashpoints: A Short History of Progress', New Zealand Post Writers and Readers Week, (Wellington: New Zealand Post.)

Ximenes, F.A., Gardner, W.D., and Cowie, A.L. (2008), 'The decomposition of wood products in landfills in Sydney, Australia', Waste Management, (10.1016/j.wasman.2007.11.006).

Zhang, David D., Brecke, Peter, Lee, Harry, F., He, Yuan-Qing and Zhang, Jane (2007), 'Global climate change, war, and population decline in recent human history', Proceedings of the National Academy of Sciences of the United States of America, 104 (49) 19214-19219. 